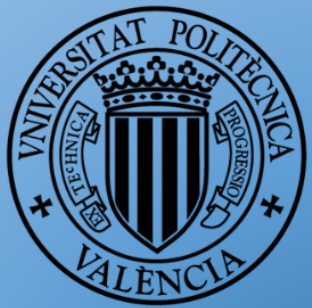

UNIVERSITAT POLITĖCNICA $\underline{\text { PhD Thesis }}$ DE VALĖNCIA

Author

Yousaf Hameed Khattak

Supervisor

Prof. Dr. Bernabé Marí Soucase

\title{
Thin Film Solar Cells
}





\title{
Modeling of High Power Conversion Efficiency Thin Film Solar Cells
}

\author{
Dissertation submitted \\ in partial fulfillment of the requirements \\ for the degree of
}

Doctor of Philosophy

Author:

Yousaf Hameed Khattak

\author{
Supervisor: \\ Prof. Dr. Bernabé Marí Soucase \\ Instituto de Diseño para la Fabricación y Producción Automatizada \\ Escuela Técnica Superior de Ingeniería del Diseño \\ Universitat Politècnica de València
}

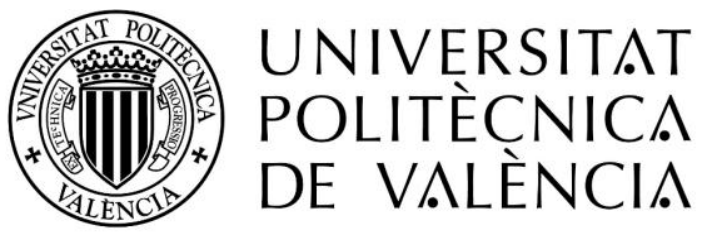

Universitat Politècnica de València

February, 2019 
This page intentionally left blank 


\begin{abstract}
The solar cell has emerged as a newer and a relatively sustainable energy source, that is eco-friendly and cost-effective if the production is on a larger scale. In the current scenario, the economic and high-power conversion efficiency photovoltaic devices without degradation of materials are designed for the generation of electricity. The silicon-based solar cells dominated the market for many years. For the manufacturing and production of silicon-based solar cells, sophisticated fabrication techniques are required that make the solar panel costly. Due to intensification in manufacturing capabilities, thin film solar cells are gaining significance. Thin film technology is one of the most cost-effective and efficient technologies for the manufacturing of solar cells, and it is an excellent subject of intense research in the photovoltaic industry. Thin film technology is economical than other technologies because devices have relatively less material and are based on various types of light absorbing semiconductor materials. Among these materials, kesterite solar cells utilizing CZTS, CZTSe and their alloys CZTSSe are emerging as the most auspicious replacement for the chalcopyrite absorbers. The outstanding electrical and optical features having direct optical band gap ranges among $1.4 \mathrm{eV}$ to $1.5 \mathrm{eV}$ and large absorption coefficient $\alpha>10^{4} \mathrm{~cm}^{-1}$ of CZTS have made it very interesting in the thin film community. According to the Shockley-Queisser limit, the optimum conversion efficiency of around $28 \%$ is theoretically possible from a CZTS based solar cell by tuning the band gap, but still, it is not experimentally possible to achieve $28 \%$ conversion efficiency from a solar cell due to lack of understanding of device characteristics. For a better understanding of device characteristics, numerical modeling can play a significant role by modeling different device structures that can save time and cost of the research community. In this work, numerical modeling was carried out for estimating and analyzing the effect of physical parameters such as thickness and doping concentration of absorber, buffer and window layers, temperature effect and effect of illumination power of the sun on device performance. Device modeling had performed on the dedicated simulation software "Solar Cell Capacitance Simulator" (SCAPS $-1 D)$. To achieve this task first, a simple $p-n-n^{+}$structure for Mo/CZTS/CdS/ZnO/FTO had been analyzed with molybdenum as back contact and FTO as a front contact. Through analysis, it had been found that solar cell performance was affected by variation in absorber thickness, doping concentration, and metal work function. After visualization of a basic device structure in SCAPS $-1 D, C Z T S$ based experimental solar cell had been modeled. Experimentally
\end{abstract}


designed CZTS solar cell results were first simulated in SCAPS - $1 D$ environment. The $S C A P S-1 D$ simulated results were then compared with experimental results. After optimization of cell parameters, the conversion efficiency of an optimized device was increased and from modeling, it had been found that device performance was improved by improving minority carrier lifetime and integration of back surface field at the back contact. Based on the results presented, it was found that recombination in a solar cell can greatly affect the performance of a solar cell. Therefore, a new structure (Back contact/ CFTS/ZnS/Zn $(O, S) / F T O)$ was modeled and analyzed in which interface recombination is reduced by optimizing the band gap of $\operatorname{Zn}(O, S)$ layer. Based on different device structure modeling, it was found that solar cell with structure $\operatorname{CFTS} / \operatorname{ZnS} / \operatorname{Zn}(O, S) / F T O$ can exhibit an efficiency of $26.11 \%$ with optimized physical parameters like absorber thickness layer of $4 \mu \mathrm{m}$ and acceptor concentration density of $2 \times 10^{18} \mathrm{~cm}^{-3}$. The proposed results will give a valuable guideline for the feasible fabrication and designing of high-power conversion efficiency solar cells. 


\section{Resumen}

Las energía solar fotovoltaica ha emergido como una fuente de energía nueva y sostenible, que es ecológica y rentable si la producción es a gran escala. En el escenario actual, los dispositivos fotovoltaicos económicos y de alta eficiencia de conversión sin que se degraden sus componentes están bien posicionados para la generación de electricidad. Las células solares basadas en silicio dominan este mercado desde hace muchos años. Para la fabricación y producción de células solares basadas en silicio, se requieren sofisticadas técnicas de fabricación que hacen que el panel solar sea costoso. Por otra parte estan las células solares de película delgada, las cuales, debido a la intensificación de las capacidades de fabricación están ganando importancia. La tecnología de película delgada es una de las tecnologías más rentables y eficientes para la fabricación de células solares, y es un tema de intensa investigación en la industria fotovoltaica. La tecnología de película delgada es más económica que otras tecnologías porque los dispositivos utilizan menos material y están basados en varios tipos de materiales semiconductores que absorben la luz. Entre estos materiales, las células solares de kesterita que utilizan CZTS, CZTSe y sus aleaciones CZTSSe pueden convertirse en el reemplazo óptimo a los absorbentes de calcopirita. Estos materiales presentan unas características ópticas y eléctricas sobresalientes y tienen un gap óptico directo con una banda prohibida que oscila entre $1,4 \mathrm{eV}$ y $1,5 \mathrm{eV}$ y un coeficiente de absorción, $\alpha>10^{4} \mathrm{~cm}^{-1}$. Estas características han propiciado que las kesteritas esten siendo muy investigadas por la comunidad fotovoltaica de películas delgadas. De acuerdo con el límite de Shockley-Queisser, la eficiencia de conversión para una célula solar basada en CZTS es alrededor del 28\%. Esta eficiencia es teóricamente posible mediante el ajuste de la banda prohibida, pero aún así, todavia no se ha podido alcanzar experimentalmente, probablemente debido a la falta de comprensión de las características de los dispositivos.Para una mejor comprensión de las características de los dispositivos, la modelación numérica puede jugar un papel importante al perimitir estudiar diferentes estructuras de dispositivos que pueden ahorrar tiempo y costos a la comunidad científico-técnica. En este trabajo, se ha llevado a cabo una modelazación numérica para estimar y analizar el efecto de parámetros físicos como el espesor y la concentración de dopado de la capa absorbente, la capa tampón y las capas ventana, además de estudiar el efecto de la temperatura y el efecto de la potencia de iluminación del sol en el rendimiento del dispositivo. El análisis numérico de los dispositivos se realizó con el software de simulación denominado "Solar Cell Capacitance Simulator" (SCAPS - 1D). 
Para ello se analizó una estructura simple $p-n-n^{+}$usando molibdeno como contacto posterior y FTO como ventana óptica y contacto frontal y siguiendo la secuencia de materiales $M o / C Z T S / C d S / Z n O / F T O$. A través del análisis, se estudió el rendimiento de las células solares con la variación en el espesor del absorbente para encontrar el espesor óptimo de la capa absorbente. También se estudió el efecto de la concentración del dopado y de la función de trabajo del metal. Después de la visualización de una estructura de dispositivo básica en $S C A P S-1 D$, se modelo una célula solar experimental basada en CZTS. Los resultados de las células solares CZTS diseñados experimentalmente se simularon por primera vez en el entorno SCAPS $-1 D$. Los resultados simulados de $S C A P S-1 D$ se compararon con los resultados experimentales. Después de la optimización de los parámetros de la celda, se incrementó la eficiencia de conversión de un dispositivo optimizado y, a partir del modelado, se descubrió que el rendimiento del dispositivo mejora al aumentar el tiempo de vida de los portadores minoritarios, cosa que se consigue con la incorporación de un campo eléctrico en la superficie del contacto posterior. Sobre la base de los resultados obtrenidos, se encontró que la recombinación en una célula solar puede afectar en gran medida el rendimiento de una célula solar. Por lo tanto, se modeló y analizó una nueva estructura (contacto posterior/CFTS/ZnS/Zn $(O, S) / F T O$ ) en la que se reduce la recombinación de la interfase optimizando la anchura de la banda prohibida de la capa $\operatorname{Zn}(O, S)$. Sobre la base de diferentes modelos de estructuras de dispositivos, se encontró que la célula solar con estructura $\operatorname{CFTS} / \operatorname{ZnS} / \operatorname{Zn}(O, S) / F T O$ puede alcanzar una eficiencia del 26,11\%, después de óptimizar algunos parámetros físicos como son el espesor de la capa absorbente de $4 \mu \mathrm{m}$ y la densidad de aceptores de $2 \times 10^{18} \mathrm{~cm}^{-3}$. Los resultados obtenidos aportarán una valiosa guía para la fabricación y el diseño de células solares de alta eficiencia de conversión. 


\section{Resum}

L'energia solar fotovoltaica ha emergit com una font d'energia nova i sostenible, que és ecològica i rendible si la producció és a gran escala. En l'escenari actual, els dispositius fotovoltaics econòmics i de gran eficiència de conversió estan ben posicionats per a la generació d'electricitat neta i sostenible. Les cèl-lules solars basades en silici dominen aquest mercat des de fa molts anys. Per a la fabricació i producció de cèl-lules solars basades en silici, es requereixen tècniques de fabricació sofisticades que fan que el panell solar sigui costós. Per altra banda estan les cel-les solars de capa fina, que estan guanyant importància a causa de l'intensificació de les capacitats de fabricació. La tecnologia de capa fina és una de les tecnologies més rentables i eficients per a la fabricació de cel solars, i és un tema d'intensa investigació en la fotovoltaica industrial. La tecnologia de capa fina és més econòmica que altres tecnologies perquè els dispositius utilitzen menys material $\mathrm{i}$ estan basats en diversos tipus de materials semiconductors que absorbeixen la llum. Entre aquests materials, les cèl-lules solars de kesterita que utilitzen CZTS, CZTSe i les seves aleacions CZTSSe poden convertir-se en el reemplaçament òptim als absorbents de calcopirita. Aquests materials presenten unes característiques òptiques i elèctriques sobresalientes i tenen un gap òptic directe amb una banda prohibida que oscil-la entre $1,4 \mathrm{eV}$ i $1,5 \mathrm{eV}$ i un coeficient d'absorció, $\alpha>10^{4} \mathrm{~cm}^{-1}$. Aquestes característiques han propiciat que les Les kesteritas estan sent molt investigades per la comunitat fotovoltaica de capes primes. D'acord amb el límit de Shockley-Queisser, l'eficiència de conversió per a una cel-la solar basada en CZTS és d'aproximadament 28\%. Aquesta eficiència és teòricament possible a través de l'ajust de la banda prohibida, però tot i així, encara no s'ha pogut assolir experimentalment, probablement a causa de la incomprensió del funcionament dels dispositius. Per a una millor comprensió de les característiques i funcionament dels dispositius, la modelització numèrica pot jugar un paper important al permetre estudiar diferents estructures de sistemes que poden estalviar temps i costos a la comunitat científica-tècnica. En aquest treball, s'ha dut a terme una modelització numèrica per estimar i analitzar l'efecte de paràmetres físics com l'espessor i la concentració de dopatge de la capa absorbent, la capa tampó i la capa finestra, a més d'estudiar l'efecte de la temperatura i l'efecte de la potència d'il-luminació del sol en el rendiment del dispositiu. L'anàlisi numèrica dels dispositius es va realitzar amb el programari de simulació denominat "Solar Cell Capacitance Simulator" (SCAPS - 1D). Per això es va analitzar una estructura senzilla $p-n-n^{+}$utilitzant molibdé com contacte posterior i FTO com a 
finestra òptica i contacte frontal i seguint la sequiència de materials $M o / C Z T S / C d S / Z n O / F T O$. A través de l'anàlisi, es va estudiar el rendiment de les cel·les solars amb la variació en l'espessor de l'absorbent per trobar l'espessor òptim de la capa absorbent. També es va estudiar l'efecte de la concentració del dopatge i de la funció de treball del metall. Després de la visualització d'una estructura de dispositiu bàsic en $S C A P S-1 D$, es model una cel·la solar experimental basada en CZTS. Els resultats de les cel-les solars CZTS dissenyats experimentalment es simularen per primera vegada en l'entorn $S C A P S-1 D$. Els resultats simulats de $S C A P S-1 D$ es van comparar amb els resultats experimentals. Després de l'optimització dels paràmetres de la celda, es va incrementar l'eficiència de conversió d'un dispositiu optimitzat i, a partir del modelatge, es va descobrir que el rendiment del dispositiu es millora a l'augmentar la vida útil dels minoritaris, cosa que es aconsegueix amb la incorporació d'un camp elèctric a la superfície del contacte posterior. Sobre la base dels resultats obtinguts, es va trobar que la recombinació en una cel·la solar pot afectar en gran mesura el rendiment d'una cel·la solar. Per tant, es va modelar i analitzar una nova estructura (contacte posterior/CFTS/ZnS/Zn(O,S)/FTO) en què es redueix la recombinació de la interfície optimitzant l'amplada de la banda prohibida de la capa $\operatorname{Zn}(O, S)$. Sobre la base de diferents models d'estructures d'equips, es va trobar que la cel.la solar amb estructura CFTS/ZnS $/ \operatorname{Zn}(O, S) / F T O$ pot aconseguir una eficiència del $26,11 \%$, després d'optimitzar alguns paràmetres físics com són l'espessor de la capa absorbent de $4 \mu \mathrm{m}$ i la densitat d'acceptors de $2 \times 10^{18} \mathrm{~cm}^{-3}$. Els resultats obtinguts aportaran una valiosa guia per a la fabricació i el disseny de solars cel·lulars de gran conversió d'eficiència. 


\section{Acknowledgements}

First and the foremost, I am thankful to ALLAH, the most Beneficent and the most Merciful, who helped me by gracing his blessings on me and without his guidance I could not achieve my goal.

I would like to thank Almighty ALLAH for giving me an opportunity, determination, and strength to complete this research work. His continuous grace and mercy were with me throughout my life.

I would like to thank my supervisor Professor Dr. Bernabé Marí Soucase for supervising me and providing the inspiration and for his efforts in assisting me with this work. The thesis could not complete without his genuine support and assistance.

I would like to dedicate this thesis to my sincere and generous father and my loving mother, who encouraged and helped me at every stage of my life and longed to see this achievement come true. I am indebted to my parents for their moral support throughout my Ph.D. tenure. I am grateful to my family and my kids for supporting me during this period of research. I would not have achieved the goals without their sincere cooperation and love.

I am obliged all those who helped me to write this thesis successfully. Special thanks to Dr. Shafi Ullah, Mr. Faisal Hameed Butt, and Dr. Hanif Ullah

FUUAST Islamabad thank you for being so perfect. For being exactly what I needed. For teaching me so much both about the world and about myself. I will forever hold you near and dear to my heart.

Mr. Faisal Baig thank you. I find myself thinking about a lot of the amazing experiences you've provided me. I appreciate your love, kindness, support, and generosity.

I shall always remember these wonderful people in my prayers.

Yousaf Hameed Khattak

February 2019 
This page intentionally left blank 


\section{Dedication}

This dissertation is dedicated to

My mother, who taught me to trust in ALLAH, believe in hard work and that so much could be done with little.

My father, who always picked me up on time, supporting and encouraging me to believe in myself.

My beloved spouse, who has been a constant source of support and encouragement during the challenges of my doctorate. I am truly thankful for having you in my life.

I wish to express my heartfelt love to my kids Minsa Yousaf and Muhammad Unais Yousaf for coping with the undue paternal deprivation during the time of my studies. 
This page intentionally left blank 


\section{Motivation}

The last century has been the period of great advancement in technology due to science. Moreover, some specific events in that time also increased the need of modern technology, which helped this world to achieve today's status as modern technology played a vital role in mass production of required necessities efficiently. Consequently, the need of energy increased throughout the world during this period, causing countries to find economical and efficient sources of energy production. The sources like gasoline, coal, and oil, which are generally known as fossil fuel energy sources, have been used for the production of energy, but these sources of energy deplete with the passage of time. Similarly, nuclear energy has also been used for producing electrical energy, but only some countries can afford using this source for the above-mentioned purpose. Another reason for the increase in energy demand is population growth in the world. Similarly, an increase in living standards of people has also aggravated the need of electrical energy as it is the part and parcel of providing day to day amenities. As it has been mentioned above that the fossil fuel energy sources deplete with the passage of time, another disadvantage of using fossil fuel energy sources is that it causes huge damage to climate due to $\mathrm{CO}_{2}$ emissions. Adding to this, these $\mathrm{CO}_{2}$ emissions also contribute a lot to global warming, which has destroyed the balance of nature in this beautiful world. Therefore, urge for exploring renewable sources of energy, which are efficient, long-lasting, clean as well as economical, has got strength. These renewable energy resources comprise hydrogen, geothermal, hydropower, solar, wind and biomass. As it is envisaged that in next two decades the demand of electricity will be doubled as compared to today's demand, filling the gap between the demand and supply of energy has become the foremost challenge of the time. To accomplish this challenge, reliance on renewable energy resources will increase because of the above-mentioned advantages of renewable energy resources.

Solar energy is one of the best renewable energy sources to full fill the energy demands because it's a nature free gift for human mankind. Solar energy provides low-cost, abundant and clean electricity without emitting harmful waste and fumes. Photovoltaic cells are immensely used for the generation of electricity from solar energy. The solidstate semiconductor photovoltaic devices have emerged as a newer and a relatively sustainable energy source. Which is eco-friendly and cost-effective if the production is on large scale. Semiconductor devices play a significant role in commercial applications and 
can be widely used in power generation in the form of photovoltaics. Thin film technology is one of the most cost-effective and efficient technology for the manufacturing of semiconductor-based photovoltaic cells and it is an excellent subject of intense research in photovoltaic industry. Thin films are very suitable for low and large-scale photovoltaic cell applications. Thin film photovoltaic solar cells belong from second and third generation solar cell technology. These types of solar cells are manufactured by depositing one or more layers of photovoltaic materials on a metal, plastic or glass substrate. The film thickness of these types of solar cells varies from few $n m$ to tens of $\mu \mathrm{m}$, so these types of solar cells are flexible and lower in weight. Thin film technology is cheaper than other technologies because of devices have relatively less material. Thin film photovoltaic technologies are based on various types of light absorbers semiconductor materials. The absorption coefficient of these types of materials is higher than crystalline materials. Therefore, a very thin layer of the absorber layer is sufficient for the effective absorption of sunlight. Historically in the thin film technology, amorphous silicon-based solar cells played a momentous role. Now a day's researchers move towards cadmium telluride (CdTe) and copper indium gallium selenide (CIGS) based thin film devices because of their high efficiency and good performance and reached in commercial stages. In research and development scale these technologies have power conversion efficiency up to $18 \%$ while commercially they have a conversion efficiency of $14-16 \%$. For the fabrication and development of low cost and sustainable thin film photovoltaic cells, currently kesterite based absorber materials are intensively studies such as copper zinc tin sulfide $\mathrm{Cu}_{2} \mathrm{ZnSnS}_{4}(\mathrm{CZTS})$, copper zinc tin selenide $\mathrm{Cu}_{2} \mathrm{ZnSnSe}_{4}(\mathrm{CZTSe})$ and sulfur-selenium alloy $\mathrm{Cu}_{2} \mathrm{ZnSn}\left(\mathrm{S}_{x} \mathrm{Se}_{1-x}\right)_{4}$ (CZTSSe). These materials drawing attention because of their good optical properties for photovoltaic applications. These absorber materials are copper based nontoxic semiconductor materials. They are the good replacement for the chalcopyrite absorbers by replacing indium (In) with comparatively inexpensive zinc $(\mathrm{Zn})$ and gallium (Ga) with tin $(S n)$ in the CIGS absorbers. The outstanding features and efficient performance of these kesterite based materials made them very fascinating in the thin film's community. 


\section{Motivación}

Las centrales térmicas han sido la principal fuente de energía en el mundo durante siglos. En las centrales térmicas, el agua se calienta y se convierte en vapor que hace girar las turbinas e impulsa un generador eléctrico, pero el costo de la electricidad aumenta debido a esta disposición. Este sistema tampoco es ecológico debido a la gran cantidad de humos emitidos en la atmósfera. La solución más rentable es utilizar recursos de energías renovables junto con otras fuentes que sean respeten el medio ambiente. Actualmente, semiconductores y dispositivos comerciales son ampliamente usados en diversas aplicaciones y son la base de las modernas tecnologías. Una célula fotovoltaica convierte la energía de la luz solar en energía eléctrica a través de la absorción de fotones por los materiales semiconductores. Una variedad de aplicaciones fotovoltaicas está hechas de materiales cristalinos y no cristalinos de materiales elementales y/o compuestos. Los materiales que exhiben mayores eficiencias de conversión son monocristalinos y su costo de producción es mayor que los polis y microcristalinos. No obstante, debido a su buen rendimiento, al bajo costo de fabricación y la fiabilidad y estabilidad de los materiales poli y microcristalinos los investigadores les han dedicado su atención en las últimas décadas. Una de las aplicaciones importantes de los dispositivos de semiconductores compuestos es la industria de las células fotovoltaicas.

Con el paso del tiempo aumenta la demanda de fuentes de energía renovables. Uno de los regalos que nos ofrece la naturaleza como fuente de energía alternativa es la energía solar. Debido a la crisis energética y las demandas de energía, los dispositivos fotovoltaicos se utilizan ampliamente para satisfacer las crecientes demandas de energía eléctrica. La importancia de los dispositivos fotovoltaicos surge debido a la limitación de los recursos naturales de combustibles fósiles y al efecto invernadero asociado causado por las emisiones de carbono. La creciente demanda de dispositivos fotovoltaicos a bajo costo con una mayor eficiencia de conversión de energía ha llevado a los investigadores del mundo a explorar el uso de capas mas finas materiales, de bajo costo, y de estructuras de dispositivos más eficientes. Diferentes materiales se utilizan en la fabricación de células solares fotovoltaicas para convertir esta energía solar en electricidad. Por ejemplo CdTe, $\mathrm{Si}, \mathrm{CuInSe} 2, \mathrm{CuGaSe} 2, \mathrm{Cu}$ (In, Ga) Se2 (CIGS) se utilizan como material tipo p en estas células fotovoltaicas de heterounión. 
En este trabajo se ha modelizado numéricamente y se han analizado los parámetros de rendimiento de las células solares fotovoltaicas de película delgada. La simulación y el análisis de las células solares fotovoltaicas de película delgada se ha realizado con los softwares de simulación específicos disponibles. Se han analizado los siguientes parámetros: el espesor de la capa absorbente, el efecto de las variaciones de temperatura en el rendimiento de la célula solar de película delgada, la concentración de dopantes en la capa absorbente, la concentración de dopantes en la capa tampón, la relación de compensación y el efecto de la potencia de la iluminación. Este análisis ayuda a lograr una célula solar de película delgada con alta eficiencia de conversión. 


\section{Summary}

Numerical modeling or analysis is a computer simulation program which uses the mathematical model for the implementation of a physical system. Numerical modeling is the tool to study the system behavior having complex mathematical models and helps provide analytical solutions. It is an essential tool for better understanding of the working parameters of any device. Numerical analysis can play a significant role in the manufacturing and fabrication of efficiently working semiconductors based photovoltaic devices. For design engineers and researchers, the highest priority job of numerical modeling techniques implementation is the integration of real-life problem with virtual machine environment because of finding the optimum and efficient ways for solving a complex problem. The precious time is saved due to performing the real design problem in computer-based tests environments without physical or practical implementation, therefore research institutions and universities emphasize on computer-based learnings techniques. The modeling techniques are used to compute the fundamental physical properties such as holes and electrons concentration and electrical potential. It also provides more information regarding the influence of material physical parameters on device functional parameters or characteristics. For the numerical modeling of solar cells, physical parameters of material are taken as input for the simulation software. To translate the practical or real device $J-V$ characteristics and functional parameters such as power conversion efficiency, fill factor, open circuit voltage and short circuit current in device modeling, it is mandatory to take experimental data. Numerical simulation provides a better and easier way to understand the device behavior. For the better understanding of the performance of a device, the simulation software that can be used for device modeling must be able to solve semiconductor basic equations like continuity equation for holes and electrons and the Poisson equation relating the charge to electrostatic potential.

In this work, numerical modeling is carried out to estimate and analyze the parameters of different photovoltaic thin-film solar cells. Device modeling can be performed on the dedicated simulation software "Solar Cell Capacitance Simulator" (SCAPS). To analyze the performance of a photovoltaic device, the analysis was performed on different physical parameters such as thickness and doping concentration of absorber, buffer and window layers, temperature effect and effect of illumination power of the sun on a solar cell. This analysis can help to achieve the high conversion efficiency from thin film solar cells. 
Numerical modeling of CZTS based kesterite solar cell is explained in this work is carried out in detail. We simulate kesterite based $\mathrm{ZnO} / \mathrm{CdS} / \mathrm{CZTS} / \mathrm{Mo}$ structured solar cell on SCAPS-1D software. Different parameters which affected the performance of a photovoltaic cell and the conversion efficiency is explained. For the In-depth understanding of a solar cell, $J-V$ characteristic measures are not enough to describe the behavior of a device because the response of the solar cell also depends on its internal physical mechanism. Forgetting the confidence in the modeling of a solar cell, different characteristics, as well as different possible conditions, are to be considered for simulation. Promising optimized results had been achieved with the power conversion efficiency of $23.72 \%$, fill factor of $82.54 \%$, short-circuit current $44.87 \mathrm{~mA} / \mathrm{cm}^{2}$ and open circuit voltage $0.64 \mathrm{~V}$. The results will give important guidance for the feasible fabrication of high efficiency CZTS based photovoltaic cells.

Efficiency enhancement of CZTS based experimental solar cell is also presented. The work presents numerical modeling of experimentally designed CZTS solar cell by applying CZTSe as back surface field layer. Experimentally designed CZTS solar cell results are first simulated in SCAPS $-1 D$ environment. The SCAPS $-1 D$ simulated results are then compared with experimental results. After optimization of cell parameters, the conversion efficiency of an optimized device is increased. With further optimization and by applying a back-surface layer, conversion efficiency further increases. All the simulations are conducted under 1.5AM solar radiation spectrum. The technique to boosts the photovoltaic cell conversion efficiency is the use of a back-surface field layer. In the comparison of a conventional device, the device with a back surface filed layer gives much greater output voltage. Our approach for the improvement of CZTS solar cell performance is by means of comparing and validating SCAPS $-1 D$ simulation with an experimental cell, optimization of the validated simulation, analyzing the minority carrier lifetime and proposing a back-surface field layer for further enhancing the conversion efficiency of a solar cell.

Baseline study for the modeling of $\operatorname{CFTS}\left(\mathrm{Cu}_{2} \mathrm{FeSnS}_{4}\right)$ solar cell is also deliberated. FTO/TiO 2 / CFTS / Mo structured photovoltaic device modeling was performed and analyzed. CFTS is auspicious nontoxic and earth-abundant semiconductor compound. It is an attractive and suitable material for the fabrication of low cost, high efficiency, and sustainable thin film photovoltaic cell. The influence of device parameters such as the thickness, acceptor and donor carrier concentration densities of absorber and electron 
transport layers, the effect of back contact metal work function and the temperature effect on the performance of CFTS based photovoltaic cell are analyzed by using onedimensional SCAPS software. Promising optimized results have been achieved with the conversion efficiency of $19.97 \%$, fill factor of $85.94 \%$, short-circuit current of 23.37 $\mathrm{mA} / \mathrm{cm}^{2}$ and open circuit voltage of $0.995 \mathrm{~V}$. The results will give imperative guidance for the feasible fabrication of higher efficiency CFTS based photovoltaic cells.

A novel structure for CFTS quaternary semiconductor compound based thin film solar cell device is also proposed and having the structure $C F T S / Z n S / Z n(O, S) / F T O$. Performance of a proposed device is analyzed by means of numerical modeling. $\operatorname{Zn}(O, S)$ as buffer layer up till now has not been used for CFTS based solar cells. The significance of this work increases because we propose for the first time $\operatorname{Zn}(O, S)$ as a buffer layer for highefficiency CFTS solar cell. In this work auspicious optimized results had been achieved with the conversion efficiency of $26.11 \%$, fill factor of $87.90 \%$, short-circuit current of $29.22 \mathrm{~mA} / \mathrm{cm}^{2}$ and open circuit voltage of $1016.5 \mathrm{mV}$. The proposed results will greatly help the engineers and researches to find an optimum way to optimize the solar cell performance and will also help in the design of efficient CFTS based solar cell. 
This page intentionally left blank 


\section{Acronyms}

\begin{tabular}{|c|c|}
\hline Symbol & Explanation \\
\hline$P V$ & Photovoltaic \\
\hline$Q E$ & Quantum efficiency \\
\hline$B S F$ & Back surface field \\
\hline HTL & Hole transport layer \\
\hline ETL & Electron transport layer \\
\hline$J-V$ & Current-density vs. voltage \\
\hline$S R H$ & Shockley-Read-Hall \\
\hline$A M 1.5$ & Standard terrestrial solar spectrum 'Air Mass 1.5' \\
\hline TCO & Transparent conduction oxide \\
\hline$S i$ & Silicon \\
\hline Ge & Germanium \\
\hline$C d$ & Cadmium \\
\hline$T e$ & Tellurium \\
\hline In & Indium \\
\hline Ga & Gallium \\
\hline $\mathrm{Fe}$ & Iron \\
\hline$Z n$ & Zinc \\
\hline Sn & Tin \\
\hline Se & Selenium \\
\hline$S$ & Sulfide \\
\hline$a-S i$ & Amorphous silicon \\
\hline CGS & Copper gallium selenide, $\mathrm{CuGaSe}_{2}$ \\
\hline CIGS & Copper indium gallium selenide, $\mathrm{Cu}(\mathrm{In}, \mathrm{Ga}) \mathrm{Se}_{2}$ \\
\hline CZTS & Copper zinc tin sulfide, $\mathrm{Cu}_{2} \mathrm{ZnSnS}_{4}$ \\
\hline CZTSe & Copper zinc tin selenide, $\mathrm{Cu}_{2} \mathrm{ZnSnSe}_{4}$ \\
\hline CFTS & Copper iron tin sulfide, $\mathrm{Cu}_{2} \mathrm{FeSnS}_{4}$ \\
\hline CFTSe & Copper iron tin selenide, $\mathrm{Cu}_{2} \mathrm{FeSnSe}_{4}$ \\
\hline 1 Sun & Used as a synonym for AM1.5 illumination \\
\hline Zno & Zinc Oxide \\
\hline$C d S$ & Cadmium sulfide \\
\hline$E P H$ & Electron hole pair \\
\hline$C-S i$ & Crystalline silicon \\
\hline NREL & National Renewable Energy Laboratory \\
\hline
\end{tabular}




\begin{tabular}{|c|c|}
\hline$R 2 R$ & Roll to roll technology \\
\hline $1 G$ & First generation \\
\hline $2 G$ & Second generation \\
\hline $3 G$ & Third generation \\
\hline$L_{\text {diff }}$ & Diffusion length \\
\hline $\boldsymbol{k}$ & Boltzmann's constant \\
\hline$T$ & Environment temperature \\
\hline $\boldsymbol{D}$ & Diffusion coefficient \\
\hline Сво & Conduction band offset \\
\hline$G$ & Recombination rate \\
\hline$R_{s h}$ & Shunt resistance \\
\hline$R_{s}$ & Series resistance \\
\hline EHP & Electron-hole pair \\
\hline$I_{e}$ & Electron current \\
\hline$I_{h}$ & Hole current \\
\hline$l$ & Length of the intrinsic semiconductor \\
\hline SCAPS & Solar Cell Capacitance Simulator \\
\hline AMPS & Analysis of Microelectronics and Photonics Structures \\
\hline AFORS - HET & Automat FOR Simulation of HETero structures \\
\hline$A S A$ & Amorphous Semiconductor Analysis \\
\hline$E B$ & Energy band \\
\hline$E_{f}$ & Fermi energy \\
\hline$V_{t h}$ & Threshold voltage \\
\hline$I_{L}$ & Photocurrent \\
\hline$I_{0}$ & Reverse saturation current of solar cell/ Diode leakage current \\
\hline$I_{D}$ & Diode current \\
\hline$A M$ & Air-mass \\
\hline
\end{tabular}




\section{Symbols}

\begin{tabular}{|c|c|c|}
\hline Symbol & Explanation & Unit \\
\hline PCE & Power conversion efficiency & $\%$ \\
\hline $\mathbf{F F}$ & Fill factor & $\%$ \\
\hline $\mathbf{V}_{\text {oc }}$ & Open circuit voltage & $V$ \\
\hline $\mathbf{J}_{\text {sc }}$ & Short circuit current density & $\mathrm{mA} / \mathrm{cm}^{2}$ \\
\hline $\mathbf{J}_{\mathbf{0}}$ & Diode saturation current density & $\mathrm{mA} / \mathrm{cm}^{2}$ \\
\hline$\alpha$ & Absorption coefficient & $\mathrm{cm}^{-1}$ \\
\hline $\mathbf{E}_{\mathrm{g}}$ & Bandgap energy & $\mathrm{eV}$ \\
\hline$\chi$ & Electron affinity & $\mathrm{eV}$ \\
\hline$\varepsilon_{\mathrm{r}}$ & Dielectric permittivity & - \\
\hline $\mathbf{N}_{\mathrm{c}}$ & Conduction band effective density of states & $\mathrm{cm}^{-3}$ \\
\hline $\mathbf{N}_{\mathbf{v}}$ & Valence band effective density of states & $\mathrm{cm}^{-3}$ \\
\hline$\mu_{\mathrm{e}}$ & Electron mobility & $\mathrm{cm}^{2} / \mathrm{Vs}$ \\
\hline$\mu_{\mathrm{p}}$ & Hole mobility & $\mathrm{cm}^{2} / \mathrm{Vs}$ \\
\hline $\mathbf{N}$ & Electron concentration & $\mathrm{cm}^{-3}$ \\
\hline $\mathbf{P}$ & Hole concentration & $\mathrm{cm}^{-3}$ \\
\hline $\mathbf{k}$ & Boltzmann constant & $\mathrm{J} / \mathrm{K}$ \\
\hline $\mathbf{N}_{\mathrm{T}}$ & Bulk defect concentration & $\mathrm{cm}^{-3}$ \\
\hline$\Sigma$ & Capture cross-section & $\mathrm{cm}^{2}$ \\
\hline $\mathbf{E}_{\mathbf{T}}$ & Defect energy level & $\mathrm{eV}$ \\
\hline$\Phi_{\mathrm{M}}$ & Metal work function & $\mathrm{eV}$ \\
\hline$\Phi$ & Photon flux density & $1 / \mathrm{cm}^{2} s$ \\
\hline G & Generation rate & $1 / \mathrm{cm}^{3} \mathrm{~s}$ \\
\hline $\mathbf{E}_{\mathbf{C}}$ & Conduction band minimum & $\mathrm{eV}$ \\
\hline $\mathbf{E}_{\mathrm{V}}$ & Valence band minimum & $\mathrm{eV}$ \\
\hline $\mathbf{E}_{\mathrm{fn}}$ & Electron quasi-Fermi level & $\mathrm{eV}$ \\
\hline$E_{f p}$ & Hole quasi-Fermi level & $\mathrm{eV}$ \\
\hline$\triangle \mathrm{E}_{\mathrm{C}} / C B O$ & Conduction band offset & $\mathrm{eV}$ \\
\hline$\Delta \mathbf{E}_{\mathrm{V}} / \mathrm{VBO}$ & Valence band offset & $\mathrm{eV}$ \\
\hline $\mathbf{N}_{\mathrm{A}}$ & Uniform acceptor density & $\mathrm{cm}^{-3}$ \\
\hline $\mathbf{N}_{\mathbf{D}}$ & Shallow uniform donor density & $\mathrm{cm}^{-3}$ \\
\hline$\tau_{h}$ & Hole lifetime & s \\
\hline$\tau_{\mathbf{e}}$ & Electron lifetime & s \\
\hline$c$ & Speed of light in a vacuum $\left(\mathrm{c}=3 \times 10^{8} \mathrm{~m} / \mathrm{s}\right)$ & $\mathrm{m} / \mathrm{s}$ \\
\hline
\end{tabular}




\begin{tabular}{clc}
\hline $\boldsymbol{h}$ & Planck's constant $\left(\mathrm{h}=6.626 \times 10^{-34} \mathrm{Js}\right.$ & $\mathrm{Js}$ \\
$\boldsymbol{L}_{\boldsymbol{n}}$ & Electron diffusion length & $\mathrm{m}$ \\
$\boldsymbol{L}_{\boldsymbol{p}}$ & Hole diffusion length & $\mathrm{m}$ \\
$\boldsymbol{S}_{\boldsymbol{i F}}$ & Interface recombination velocity & $\mathrm{cm} / \mathrm{s}$ \\
$\boldsymbol{\lambda}$ & Wavelength & $\mathrm{nm}$ \\
$\boldsymbol{V}$ & Applied potential & $\mathrm{V}$ \\
$\boldsymbol{I}_{\boldsymbol{L}}$ & Light generated photon current & $\mathrm{A}$ \\
\hline
\end{tabular}




\section{List of Contents}

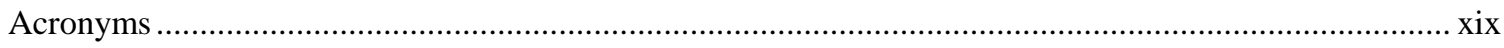

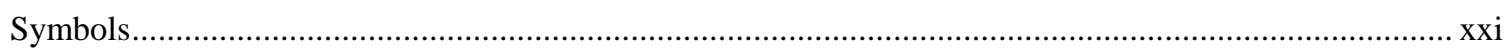

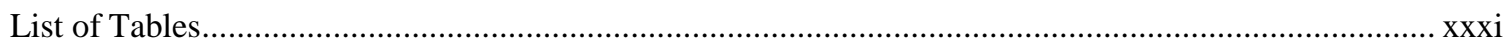

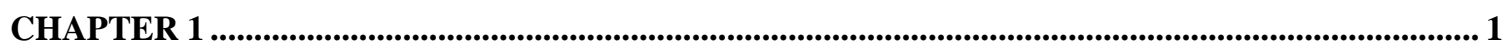

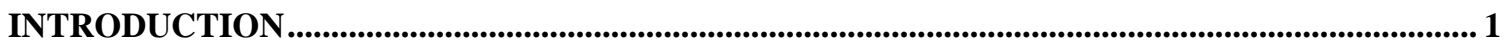

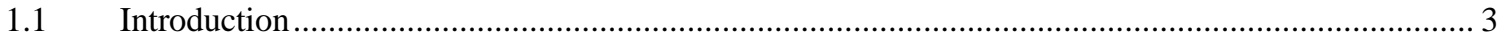

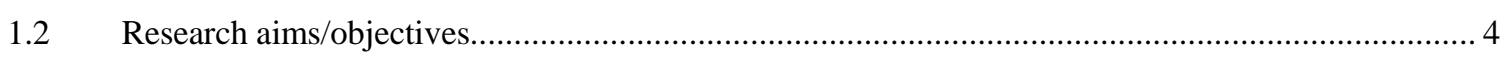

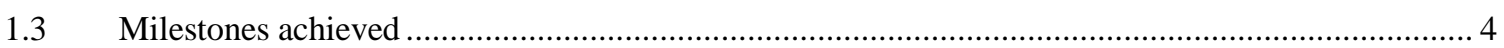

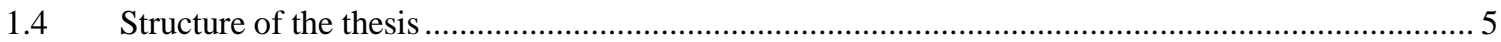

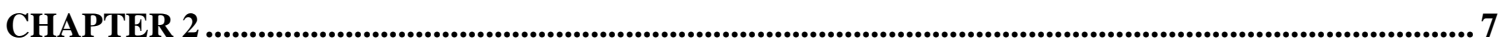

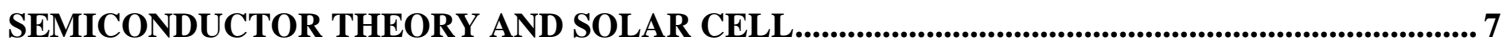

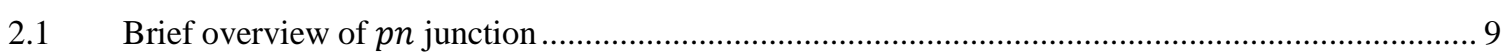

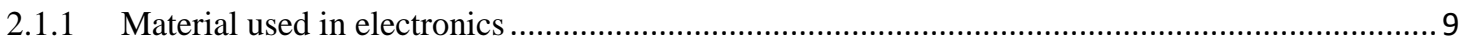

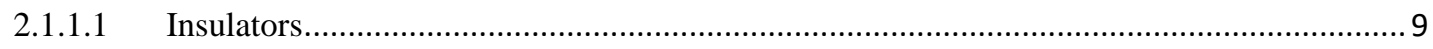

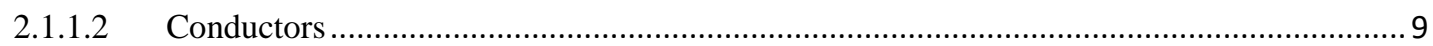

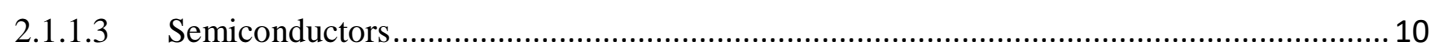

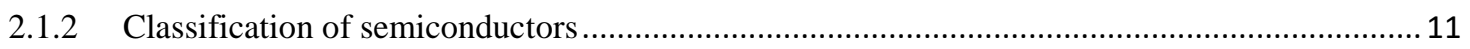

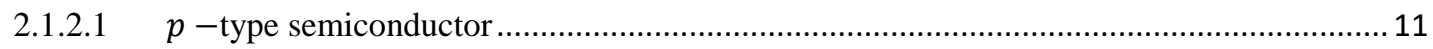

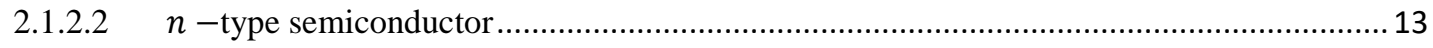

2.1.3 Conductivity of intrinsic semiconductors ................................................................... 14

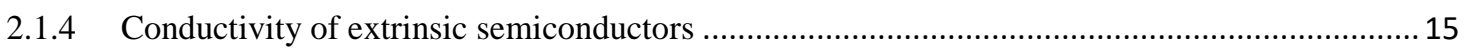

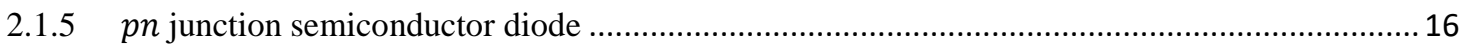

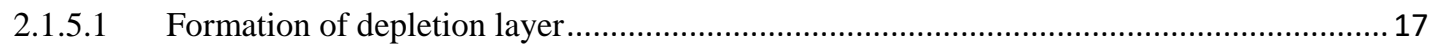

2.1.5.2 Energy band diagram of $p n$ junction ................................................................... 17

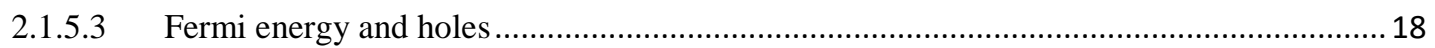

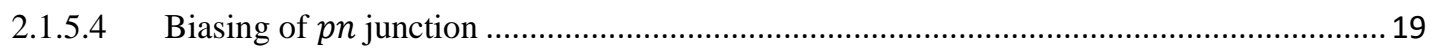

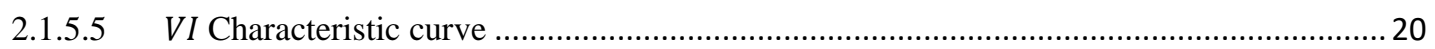

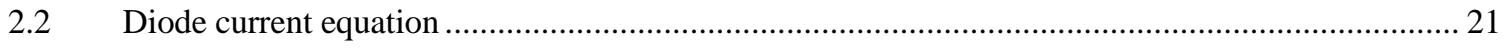

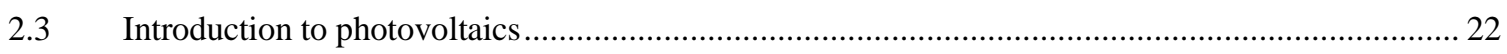

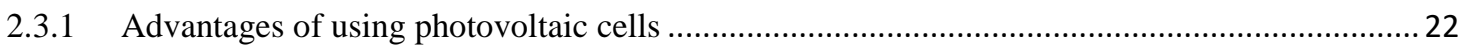

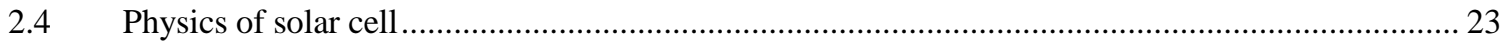

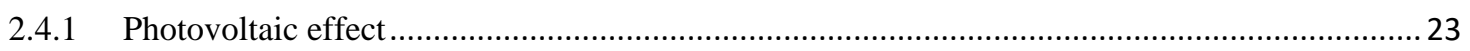

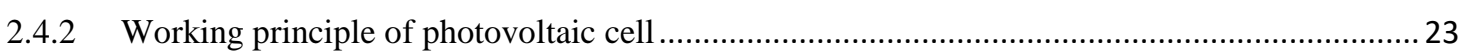

2.4.2.1 Generation of charge carriers due to photon absorption .............................................. 24

2.4.2.2 Separation of photogenerated charge carriers ........................................................ 24

2.4.2.3 Extraction of photogenerated charge carriers ..................................................... 25 


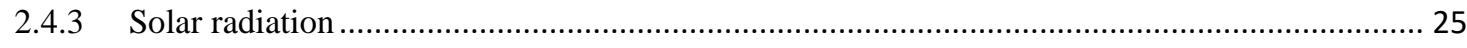

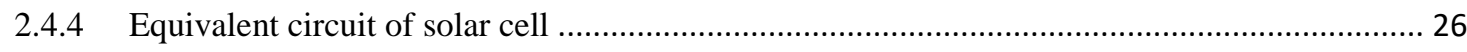

2.4.5 VI characteristic of a photovoltaic device ...................................................................... 28

2.5 Basic parameters and electrical characterization methods .........................................................29

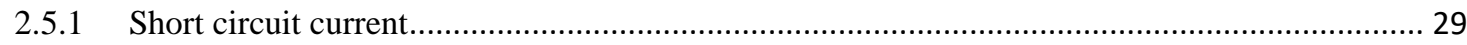

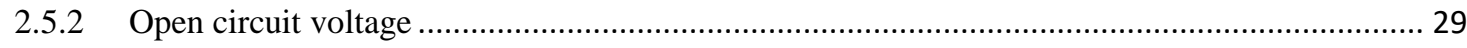

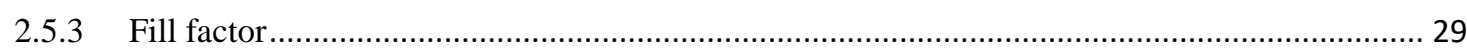

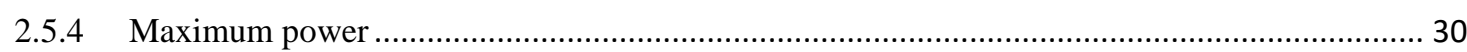

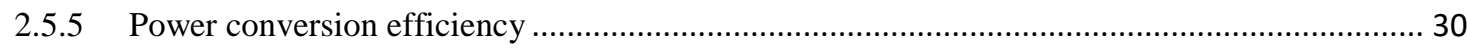

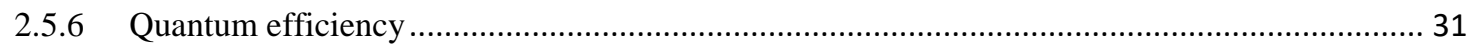

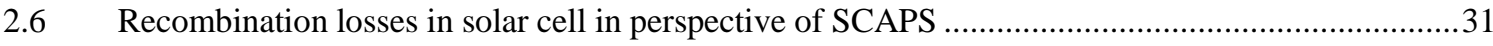

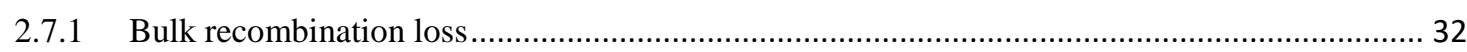

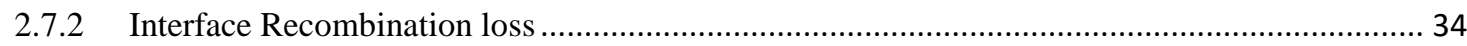

2.7.3 Recombination at semiconductor and metal contacts .................................................. 36

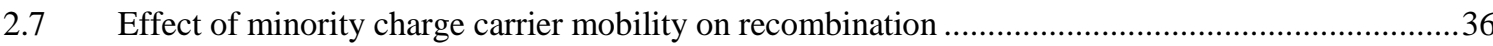

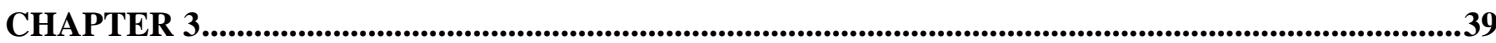

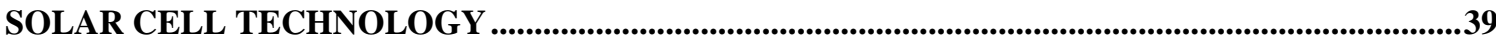

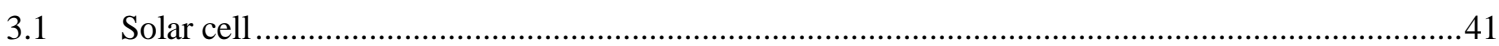

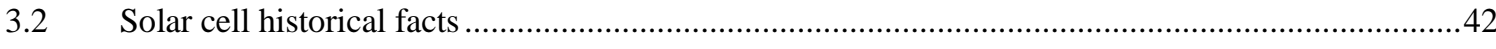

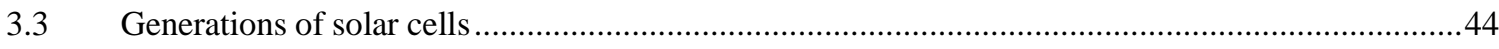

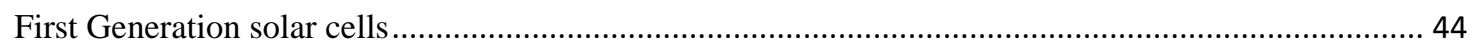

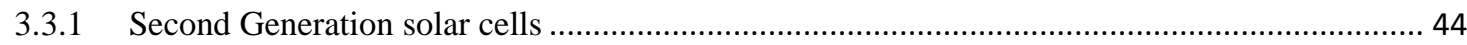

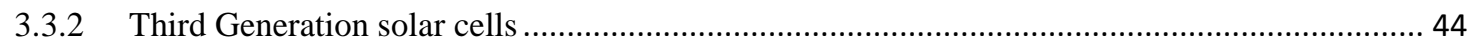

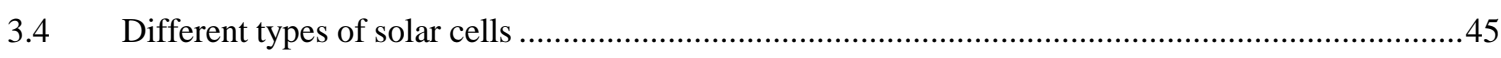

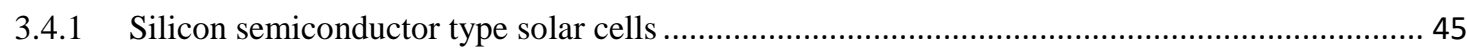

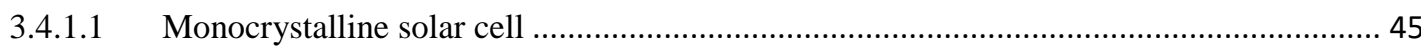

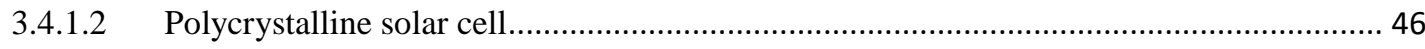

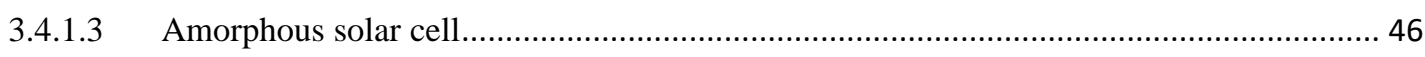

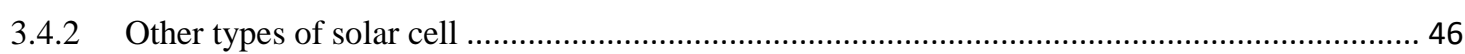

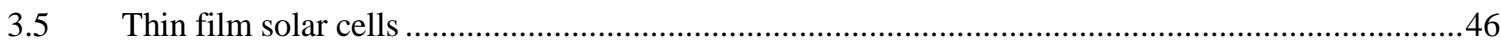

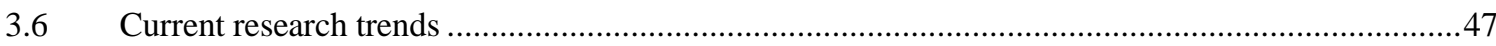

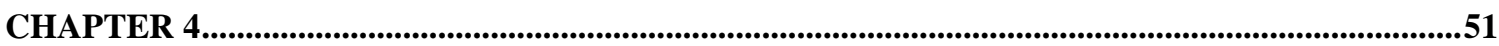

NUMERICAL MODELING ..............................................................................................................51

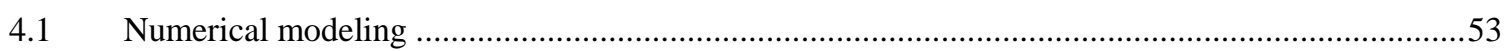

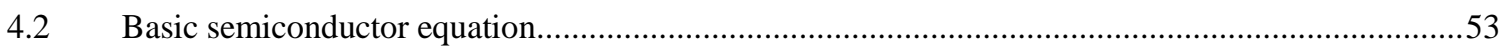

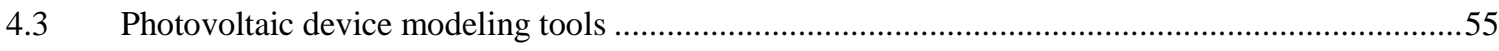

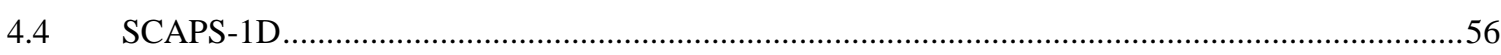

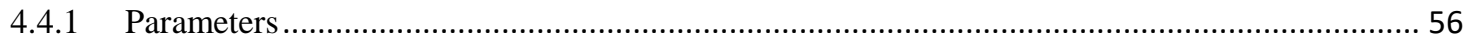


4.4.2 SCAPS startup panel interface.

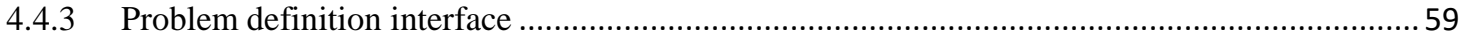

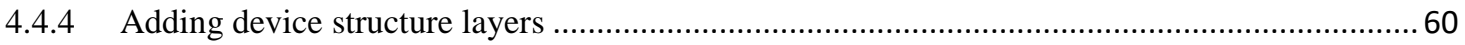

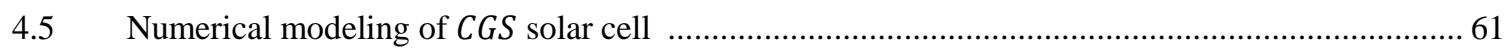

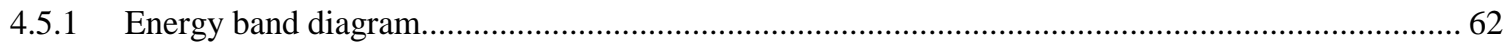

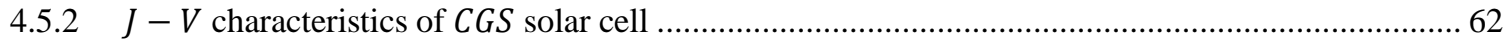

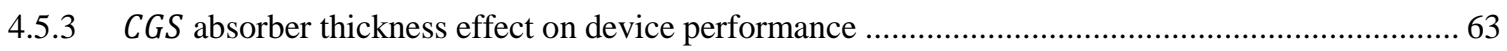

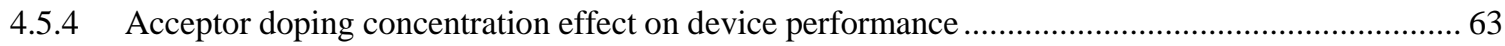

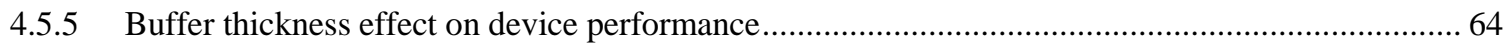

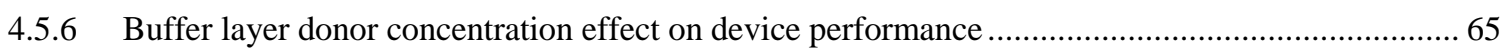

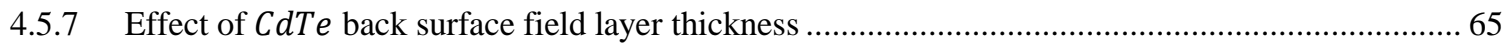

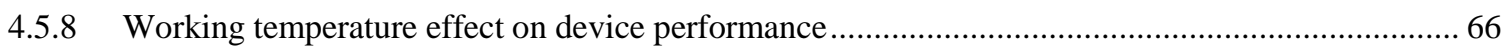

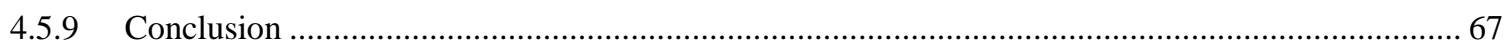

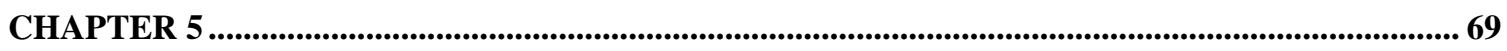

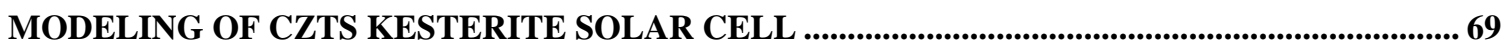

$5.1 \quad$ Numerical modeling of CZTS based kesterite solar cell .................................................... 72

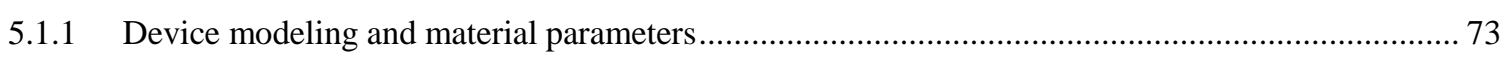

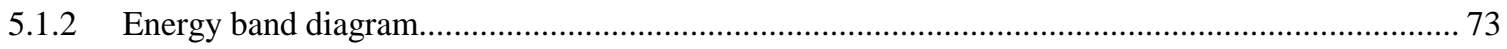

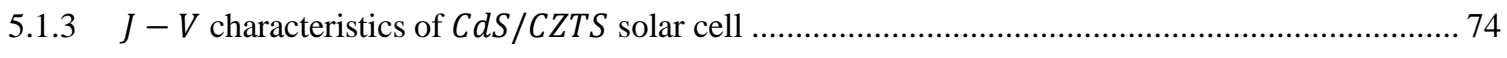

5.1.4 Absorber layer thickness effect on device performance.............................................................75

5.1.5 Acceptor doping concentration effect on device performance ................................................ 76

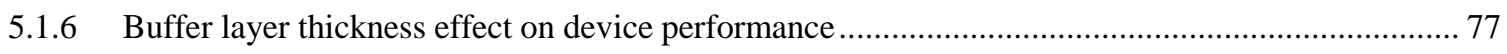

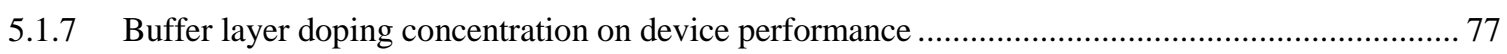

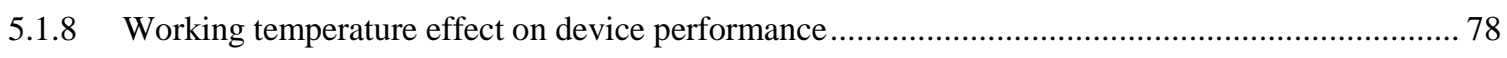

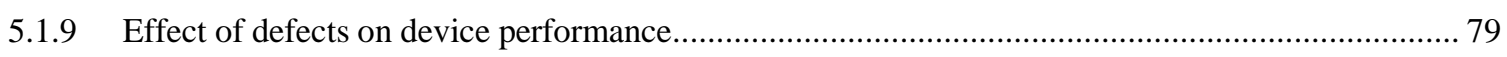

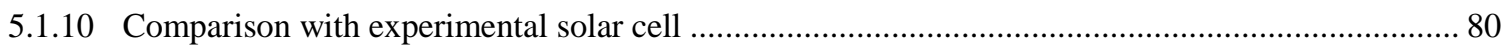

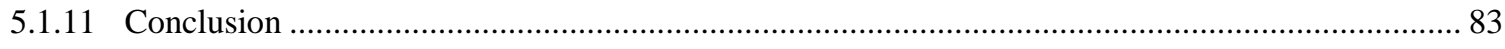

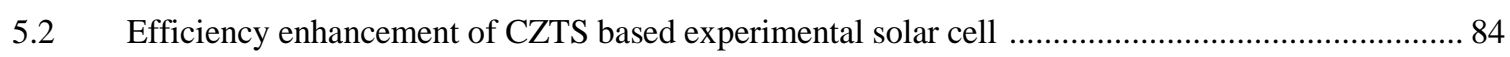

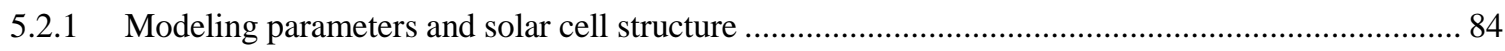

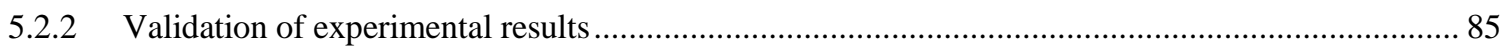

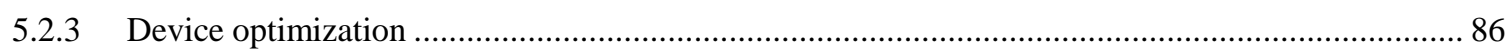

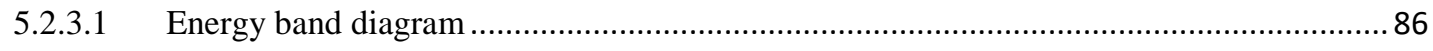

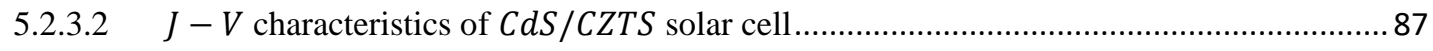

5.2.3.3 Acceptor doping concentration effect on device performance........................................ 87

5.2.3.4 Buffer layer doping concentration on device performance ............................................ 88

5.2.3.5 CZTS absorber thickness effect on device performance ..............................................89 89

5.2.3.6 Buffer layer thickness effect on device performance ................................................90

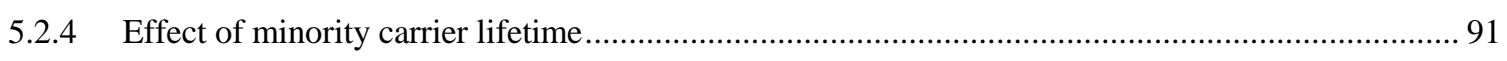

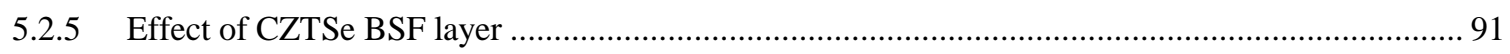




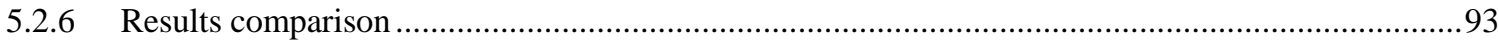

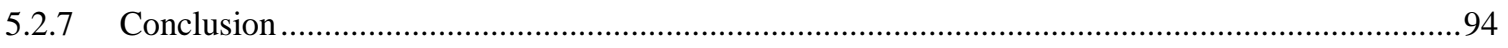

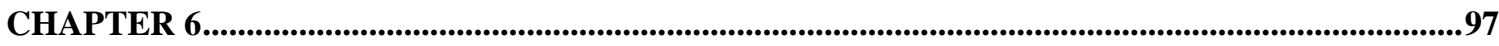

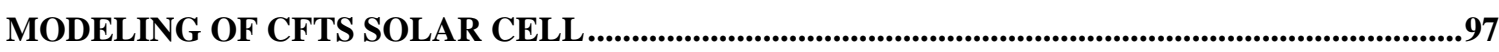

6.1 Baseline study for the modeling of CFTS based solar cell .........................................................99

6.1.1 Solar cell design and material parameters ................................................................... 99

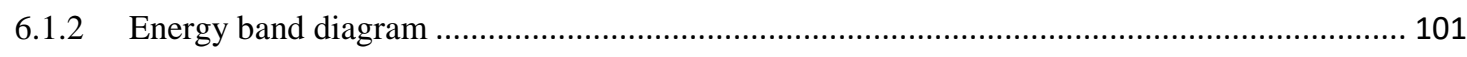

6.1.3 J - V characteristics of CFTS/TiO2 photovoltaic cell .................................................... 101

6.1.4 CFTS absorber thickness effect on device performance ................................................. 102

6.1.5 Acceptor doping concentration effect on device performance ........................................ 102

6.1.6 Electron transport layer effect on device performance ................................................. 103

6.1.7 Back contact metal work function effect on JV characteristic curve ................................... 105

6.1.8 Effect of working temperature on photovoltaic cell performance .......................................... 105

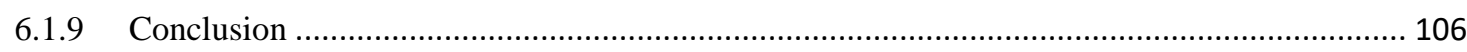

6.2 Proposing novel structure for CFTS based solar cell ….....................................................106

6.2.1 Numerical modeling and material parameters........................................................... 107

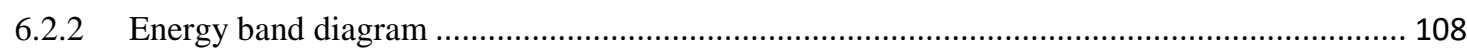

6.2.3 J - V characteristics of CFTS $/ \operatorname{ZnS} / \operatorname{Zn}(0, S)$ photovoltaic cell ......................................... 109

6.2.4 CFTS absorber thickness effect on device performance ................................................ 109

6.2.5 Acceptor doping concentration on device performance ................................................. 110

6.2.6 ZnS and $\mathrm{Zn}(\mathrm{O}, \mathrm{S})$ buffer layers parameters effect on device performance .......................... 111

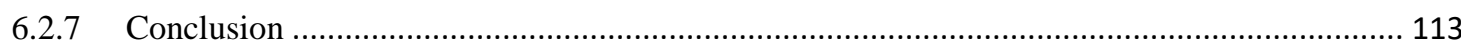

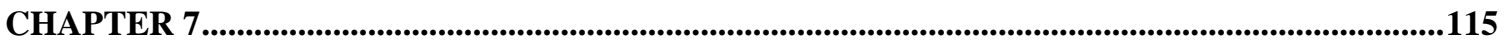

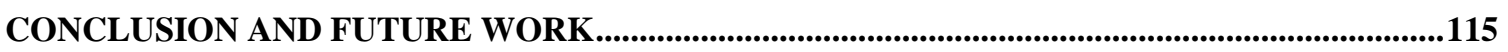

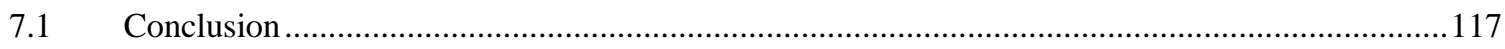

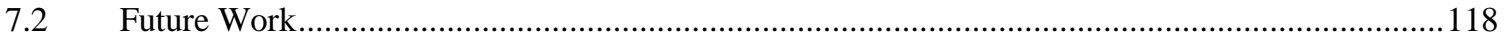

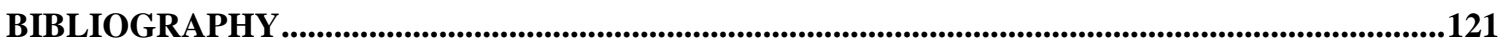

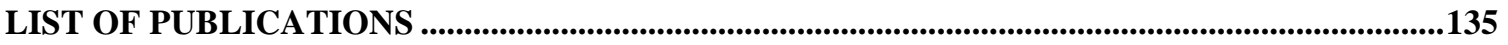




\section{List of Figures}

Figure 2.1: Energy diagrams of different type of materials. ........................................................... 9

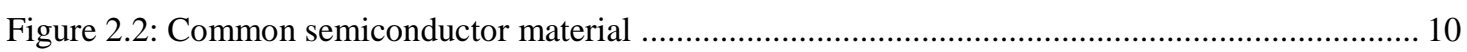

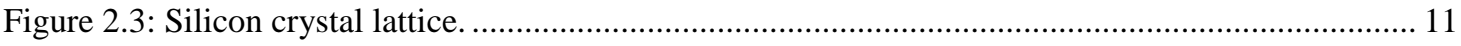

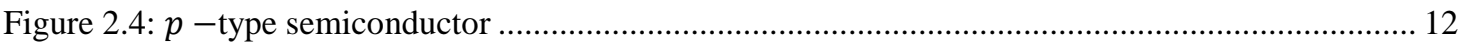

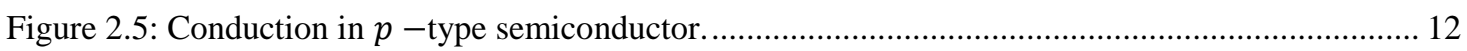

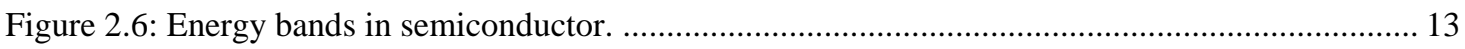

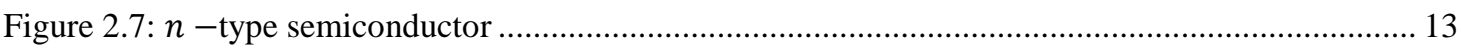

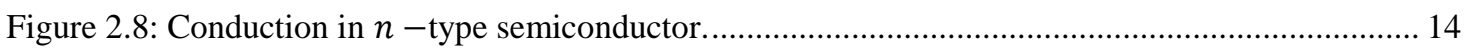

Figure 2.9: pn junction semiconductor diode........................................................................ 17

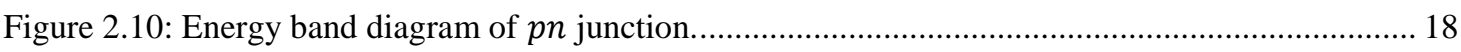

Figure 2.11: Semiconductor at room temperature showing fermi energy level. .................................. 19

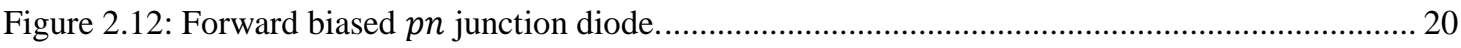

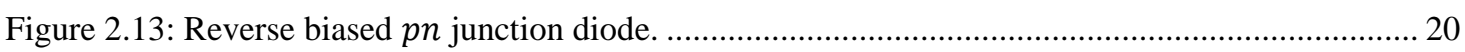

Figure 2.14: $p n$ junction semiconductor diode VI characteristics. .................................................... 21

Figure 2.15: Generation of charge carrier by photon absorption.................................................. 24

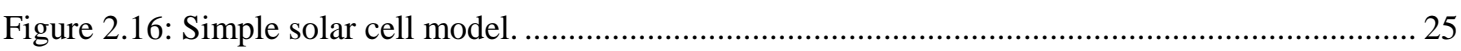

Figure 2.17: Solar irradiance spectrums versus wavelength. ...................................................... 26

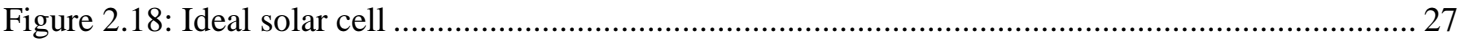

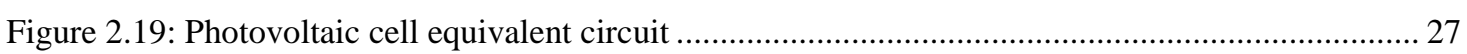

Figure 2.20: VI characteristic of photovoltaic cell under illuminated and dark .................................. 28

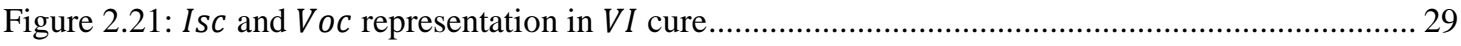

Figure 2.22: Attaining fill factor from VI characteristics cure ......................................................... 30

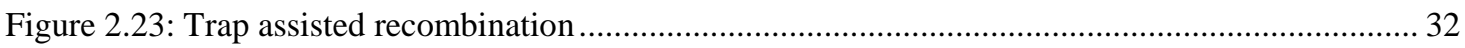

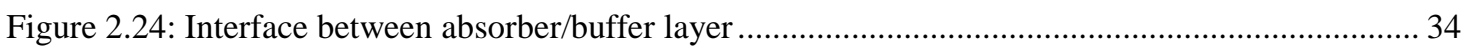

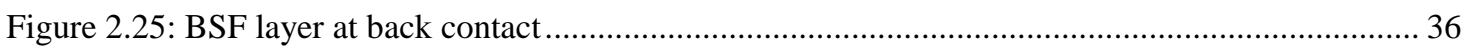

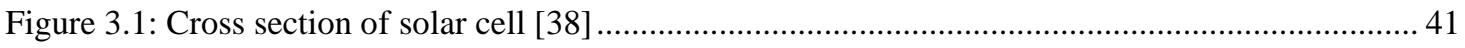

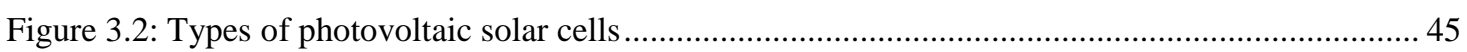

Figure 3.3: Conversion efficiencies of best research solar cells (NREL) [58] .................................. 49

Figure 4.1: SCAPS - 1D simulator startup panel interface …..................................................... 58

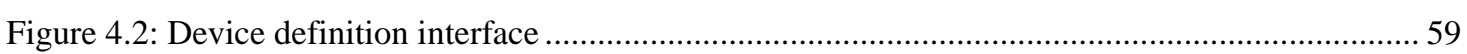

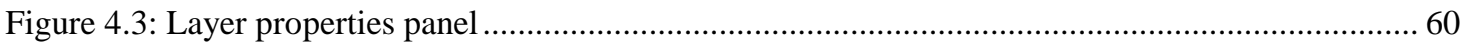

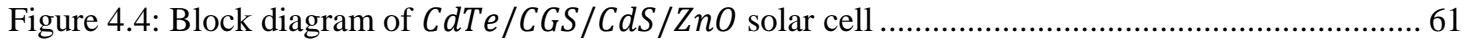

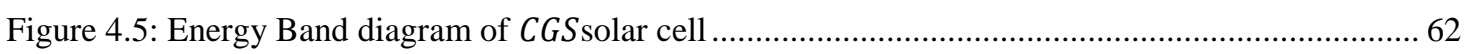

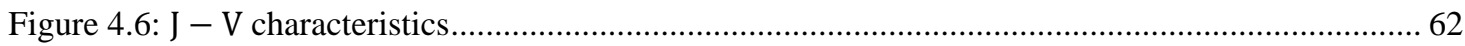

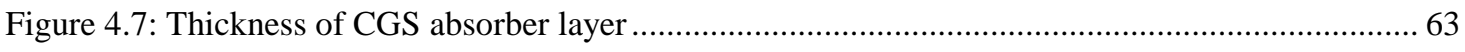

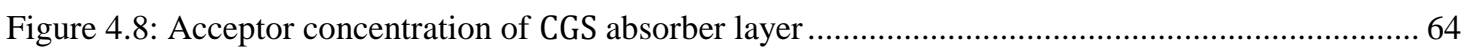

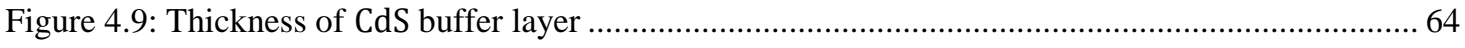

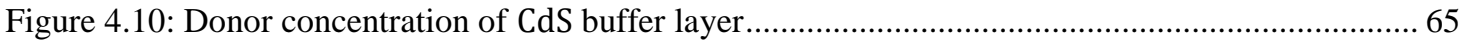


Figure 4.11: CdTe BSF layer thickness effect on functional parameters

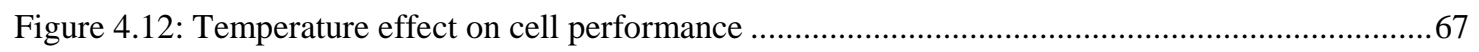

Figure 5.1: CZTS solar cell block diagram. ........................................................................................ 73

Figure 5.2: Energy band illustration of CZTS solar cell ...........................................................74

Figure 5.3: Dark vs light $J-V$ characteristics................................................................................ 75

Figure 5.4: Effect of the absorber layer thickness on CZTS photovoltaic cells. ....................................75

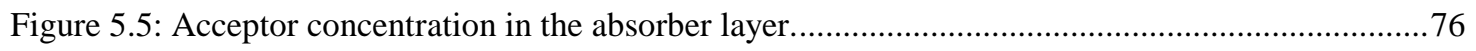

Figure 5.6: Effect of the buffer layer thickness on CZTS photovoltaic cells. .......................................77

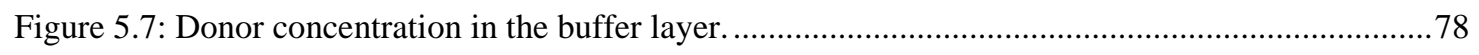

Figure 5.8: Effect of temperature on CZTS photovoltaic cell .......................................................79

Figure 5.9: Absorber layer defect effect on device performance ............................................................8

Figure 5.10: Effect of Interface defects on photovoltaic cell performance .........................................80

Figure 5.11: Comparison of SCAPS results with experimental data presented in [88].........................81

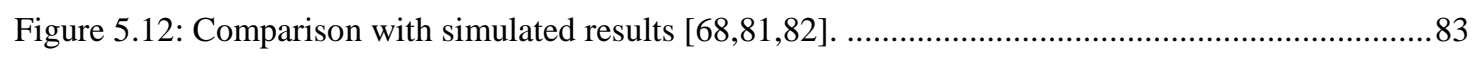

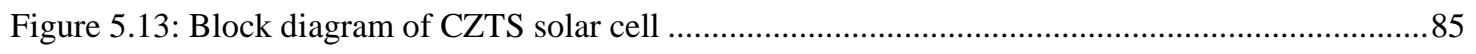

Figure 5.14: Comparison of SCAPS results with experimental data [88] .............................................86

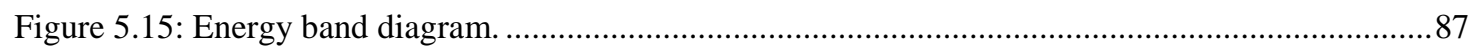

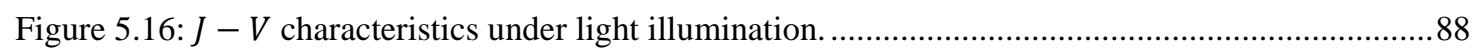

Figure 5.17: Acceptor concentration in the absorber layer..............................................................8 88

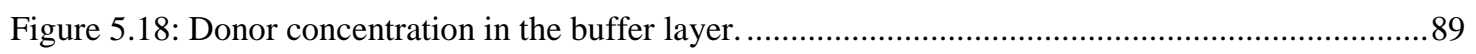

Figure 5.19: Effect of the absorber layer thickness on CZTS photovoltaic cells. ................................89

Figure 5.20: Effect of the buffer layer thickness on CZTS photovoltaic cells. .......................................90

Figure 5.21: $J-V$ characteristics of a proposed solar cell with different carrier lifetime. ....................91

Figure 5.22: Energy band diagram of the proposed solar cell with BSF layer......................................92

Figure 5.23: Effect of the BSF thickness on CZTS photovoltaic cells performance.............................992

Figure 5.24: $J-V$ characteristics curve of the proposed solar cell with BSF layer.............................93

Figure 5.25: $J-V$ characteristics curve of the proposed solar cell with BSF layer.............................94

Figure 6.1: Block diagram of CFTS solar cell ................................................................................... 100

Figure 6.2: Energy band illustration of CFTS solar cell............................................................. 101

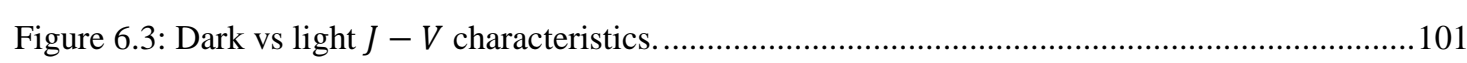

Figure 6.4: Effect of the absorber layer thickness on CFTS photovoltaic cells ...................................102

Figure 6.5: Acceptor concentration in the absorber layer............................................................. 103

Figure 6.6: Effect of the Electron Transport Layer thickness on CFTS photovoltaic cells....................104

Figure 6.7: Donor concentration in the Electron Transport Layer. ................................................... 104

Figure 6.8: Back contact metal work function affecting JV characteristic curve..................................105

Figure 6.9: Energy band diagram illustration of back contact metal work function effect ..................105

Figure 6.10: Effect of temperature on CFTS solar cell. ............................................................. 106

Figure 6.11: Block diagram of CFTS solar cell............................................................................. 107

Figure 6.12: Energy band illustration of CFTS solar cell .............................................................. 108

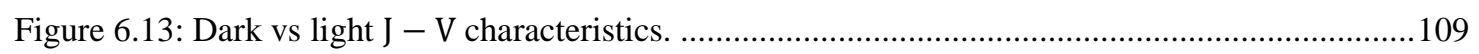


Figure 6.14: Effect of the absorber layer thickness on CFTS solar cell......................................... 110

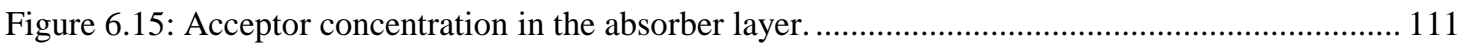

Figure 6.16: Effect of the ZnS buffer layer thickness. ...................................................................... 111

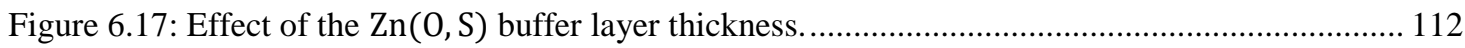

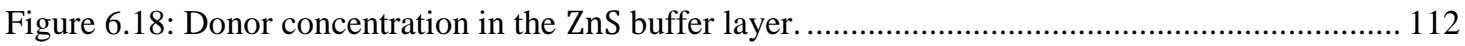

Figure 6.19: Donor concentration in the $\operatorname{Zn}(0, S)$ buffer layer........................................................ 113 
This page intentionally left blank 


\section{List of Tables}

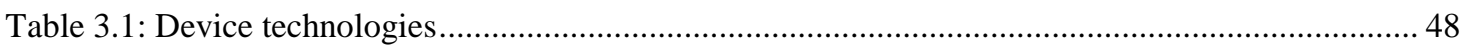

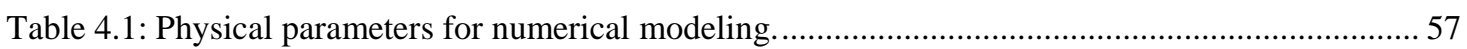

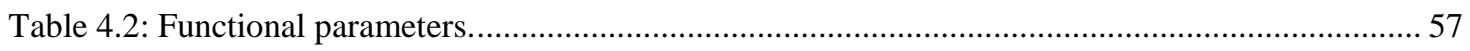

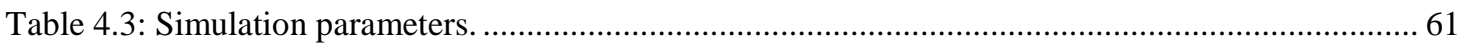

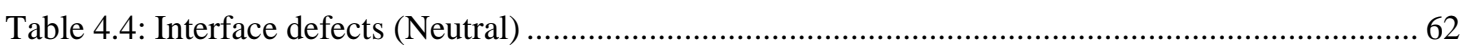

Table 5.1: Simulation parameters for modeling of CZTS based kesterite solar cell .......................... 74

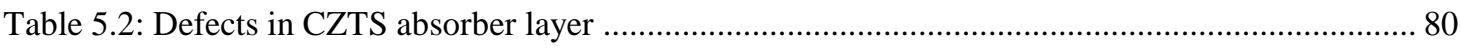

Table 5.3: Functional parameters of experimentally stated kesterite solar cell from literature. ..............81

Table 5.4: Functional parameters of simulation based kesterite solar cell from literature...................... 82

Table 5.5: Proposed results (with and without defects) of CZTS based kesterite solar cell................... 82

Table 5.6: Comparison of functional parameters with previous simulations....................................... 83

Table 5.7: Comparison of physical optimized parameters with previous simulations........................... 83

Table 5.8: Material parameters used in simulation for modeling CZTS based solar cells ..................... 85

Table 5.9: Added value of interface and absorber material defects .................................................... 86

Table 5.10: Simulation parameters of CZTSe as BSF layer. ............................................................... 93

Table 5.11: Comparison of functional parameters..................................................................... 94

Table 6.1: Baseline parameters for modeling CFTS based solar cells ................................................. 100

Table 6.2: Simulation parameters for modeling CFTS based solar cells ............................................ 108 
This page intentionally left blank 
CHAPTER 1 INTRODUCTION 
This page intentionally left blank 


\subsection{Introduction}

Semiconductor devices play a significant role in commercial applications and can be widely used in power generation in the form of photovoltaics. Photovoltaic cells absorb the radiation of sunlight and convert it into electrical energy [1]. Non-crystalline and crystalline photovoltaic cells are made from elemental and compound materials. Materials that exhibit higher conversion efficiencies are of a crystalline group; their cost of production is higher than polycrystalline and microcrystalline. The research about semiconductor devices has gained more attention due to satisfactory performance, lowcost manufacturing, reliability and stability of a polycrystalline, and microcrystalline family of materials [2]. Thin film technology is one of the most cost-effective and efficient technologies for manufacturing photovoltaic cells, and it is an excellent subject of intense research in photovoltaic industry. With the passage of time, the demand of renewable energy sources has increased. One of the free gifts of nature as an alternative energy source is solar energy. Due to an increase in the demand of energy, photovoltaic devices are used extensively [3]. Importance of photovoltaic devices has increased because the natural fossil fuel resources, which produce $\mathrm{CO}_{2}$ and affect climate negatively, are limited as they deplete gradually. To generate electricity fulfilling the demand of consumers, the highpower conversion efficiency solar cell without degradation of materials and economical photovoltaic cells are fabricated [4]. Silicon-based thin film photovoltaic cells are gaining significance due to intensification in manufacturing capabilities. For the manufacturing and production of silicon-based thin film solar cells, different major deposition techniques like sputtering, thermal evaporation, molecular beam epitaxy, e-beam evaporation, close space sublimation, and metal organic chemical vapor deposition techniques are used, so the cost of the material, technology, and energy consumption used by these sophisticated fabrication techniques makes the solar cell panel costly [5].

CdTe, CIGS and related alloy based thin-film chalcopyrite photovoltaic cell materials are commercially used for the fabrication of thin film photovoltaic devices because of high conversion efficiency, excellent electrical as well as optical properties, and these types of devices have high absorption coefficient. For many decades great effort has been done on the optimization of CIGS and CdTe-based devices. The scalability of technology is limited for commercial use because of the rising cost and toxic nature of content cadmium $(C d)$ in CdTe absorber and the scarcity of tellurium (Te), gallium ( $G a$ ) and indium (In). The toxic nature restricts the further development of these types of photovoltaic cells and the 
rare materials like indium (In) and gallium ( $G a$ ) used for the fabrication of photovoltaic cells also increase the fabrication cost, so the commercial production of CIGS-based photovoltaic cell is limited. Quaternary compounds are nontoxic earth abundant and promising semiconductor materials which have kesterite symmetrical structure like CZTS $\left(\mathrm{Cu}_{2} \mathrm{ZnSnS}_{4}\right), \quad$ CZTSe $\left(\mathrm{Cu}_{2} \mathrm{ZnSnSe} \mathrm{S}_{4}\right)$ and stannite structure like CFTS $\left(\mathrm{Cu}_{2} \mathrm{FeSnS}_{4}\right), \mathrm{CFTSe}\left(\mathrm{Cu}_{2} \mathrm{FeSnSe}_{4}\right)$, and their alloys are emerging as the most auspicious replacement for the chalcopyrite absorbers by replacing indium $(I n)$ and gallium ( $\mathrm{Ga}$ ) materials with iron $(\mathrm{Fe})$, zinc $(\mathrm{Zn})$ and tin $(\mathrm{Sn})$ in CIGS absorbers [6-8]. The growing attention towards these quaternary compounds for photovoltaic cells production is due to their potential. Their optimum direct band gaps make them suitable absorber materials for photovoltaic cell applications.

\subsection{Research aims/objectives}

The key aims and objectives of the research work presented in this thesis are:

i. Numerical modeling for the efficiency improvement of thin film solar cell.

ii. To propose new ways for the efficiency enhancement of experimental solar cells.

iii. To propose a new buffer and window layers to improve the efficiency of solar cells.

iv. To propose new absorber materials for getting high output voltage and high efficiency from thin film photovoltaic devices.

v. Discover alternate solutions for the cost reduction of thin film solar cells.

vi. To reduce the cost factor of photovoltaic devices.

vii. To propose new photovoltaic device structures based on new materials.

Device performances are described based on numerical modeling by using SCAPS $-1 D$ software. The analysis was performed on the following parameters such as the thickness and doping concentration of absorber, buffer and window layers and working temperature to analyze their effects on the cell performance. Different simulation software's like $S C A P S-1 D$ and Origin 8.0 is used for the analysis of photovoltaic solar cells.

\subsection{Milestones achieved}

The main result accomplished in this work were:

i. $\quad$ Efficiency enhancement of kesterite solar cell.

ii. Improve the efficiency of CZTS experimental solar cell by applying CZTSe back surface field layer. 
iii. $\quad$ Efficiency enhancement of CFTS solar cell.

iv. Proposing new stacked buffer layers for CFTS solar cells.

\subsection{Structure of the thesis}

The thesis is organized into seven chapters, whose contents are described below:

i. Chapter 1 includes the general introduction. Thesis organization is also described in it.

ii. Chapter 2 describes the semiconductor theory and presents a brief overview of pn-junction, diode current equation, solar cell physics and losses in a solar cell. Basic parameters and electrical characterization methods are also explained in this chapter.

iii. Chapter 3 presents the solar cell technology, generations of solar cells, solar cell types, thin film solar cells and the history of solar cells.

iv. Chapter 4 describes the basics of numerical simulation and use of SCAPS software for the modeling of a solar cell is presented here.

v. Chapter 5 covers the numerical modeling of copper zinc tin sulfide, $\mathrm{Cu}_{2} \mathrm{ZnSnS}_{4}$ (CZTS) based kesterite solar cells. Effect of different physical parameters of different layers is explained in detail in this chapter.

vi. Chapter 6 summarizes the results of copper iron tin sulfide, $\mathrm{Cu}_{2} \mathrm{FeSnS}$ (CFTS) thin film solar cells.

vii. Chapter 7 presents the concluding remarks. 
This page intentionally left blank 
CHAPTER 2

SEMICONDUCTOR THEORY AND SOLAR CELL 
This page intentionally left blank 


\subsection{Brief overview of $p n$ junction}

\subsubsection{Material used in electronics}

Different elements and compounds, electrical conduction properties can be explained in the relations of the conduction and valence band energies. In valence band, electrons having lower energies and not perform a part in the conduction process. The materials used in electronics are classified on the bases of their electrical properties into three major groups: insulators, conductors and semiconductors.

\subsubsection{Insulators}

Insulators are the type of materials, which are not conducting electrical current under normal conditions. Mostly good insulator materials are compound rather than a single element. They have a high resistivity. Electrons present in valence bands are very tightly bonded to their parent atoms. Therefore, a very large electric field is required to remove them from their nuclei attraction. It means that in normal conditions, insulators have no free charge carriers. In terms of energy band, insulators have a full valence and empty conduction band. The energy gap is very large between the valence and conduction bands. From Figure 2.1(a) it is illustrated that for conduction, valence electrons needed enough energy to jump from valence band to the conduction band [9].

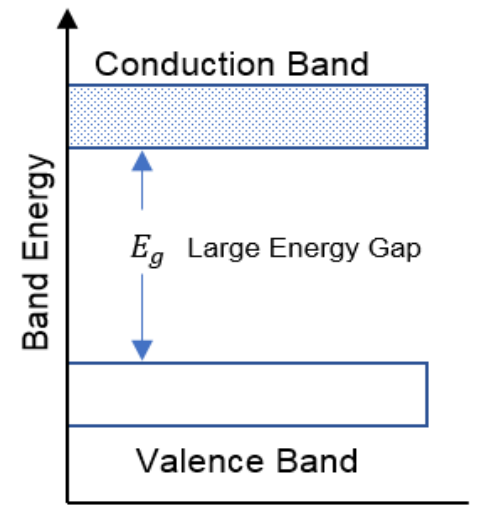

(a) Insulator

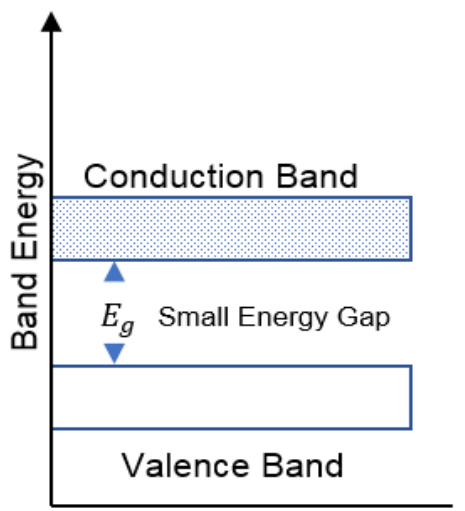

(b) Semiconductor

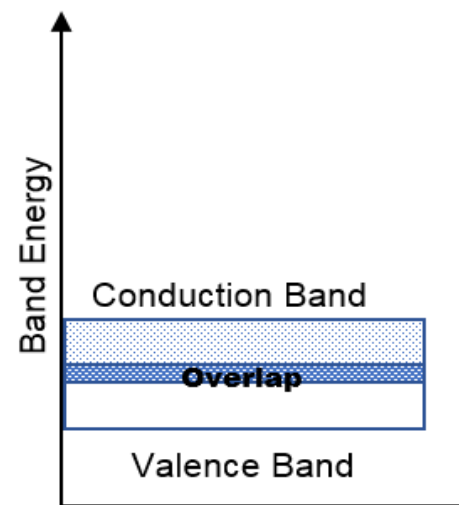

(c) Conductor

Figure 2.1: Energy diagrams of different type of materials.

\subsubsection{Conductors}

Conductors are the materials which are conducting electrons very easily. They have a large number of free electrons available for electrical conduction. In conductors, a large number of valence electrons are available in the valence band and they are loosely bonded with nuclei. When these valence electrons absorb energy, they excited and jumps from valence band to conduction band. Most metals are the good conductor. Normally single element materials are the best conductors, such as gold $(A u)$, silver $(A g)$ and copper $(C u)$ etc. 
In terms of energy band, conductors are the materials which have overlapped conduction and valence band as shown in Figure 2.1(c). In good conductors, there is no physical difference between two bands and the absence of forbidden energy gap in good conductors. Total current flows through a conductor is a flow of electrons [9].

\subsubsection{Semiconductors}

Semiconductors are the materials having electrical properties in between of conductor and a good insulator. Undoped or pure semiconductor is known as intrinsic semiconductor [10]. The semiconductor in its pure form is not a good insulator and nor a good conductor. In terms of energy bands, semiconductors have an empty conduction band and almost filled valence band having very small forbidden energy gap as shown in Figure. 2.1(b). At $0 \mathrm{~K}$ temperature conduction band have no electrons whereas valence band is completely filled. With the increase in temperature, the width of the forbidden gap is decreased. Therefore, some of the valence electrons jump into the conduction band. It means that the conductivity of a semiconductor is increased with temperature [11]. They can be a single element like $G e$ and $S i$, the compound like InP, GaAs, CdTe or alloys like $A l_{x} G a_{(1-x)} A s$ or $S i_{x} G e_{(1-x)}$. Semiconductors are characterized by atoms with four valence electrons. More common semiconductor materials are given in Figure 2.2.

\begin{tabular}{|c|c|c|c|c|c|}
\hline & & $\begin{array}{l}13 \\
\mathrm{Al} \\
\underset{\text { Aluminium }}{26.982}\end{array}$ & $\begin{array}{l}14 \\
\text { Si } \\
\text { Silicon } \\
\quad 28.085\end{array}$ & $\begin{array}{l}15 \\
\mathrm{P} \\
\text { Phosphorus } \\
\quad 30.974\end{array}$ & $\begin{array}{l}16 \\
\text { S } \\
\text { Sulfur } \\
\quad 32.065\end{array}$ \\
\hline $\begin{array}{l}29 \\
\mathrm{Cu} \\
\underset{\text { Copper }}{ } \\
\quad 63.546\end{array}$ & $\begin{array}{l}30 \\
\mathrm{Zn} \\
\text { Zinc }\end{array}$ & $\begin{array}{l}\text { Ga } \\
\text { Gallium } \\
69.723\end{array}$ & $\begin{array}{l}32 \\
\text { Germanium } \\
72.64\end{array}$ & $\begin{array}{l}33 \\
\text { As } \\
\text { Arsenic } \\
\quad 74.922\end{array}$ & $\begin{array}{l}34 \\
\text { Se } \\
\text { Selenium } \\
\quad 78.96\end{array}$ \\
\hline & $\begin{array}{l}48 \\
\mathrm{Cd} \\
\text { Cadmium } \\
\quad 112.441\end{array}$ & $\begin{array}{l}49 \\
\text { In } \\
\text { Indium } \\
114.818\end{array}$ & & $\begin{array}{l}51 \\
\mathrm{Sb} \\
\text { Antimony } \\
\quad 121.760\end{array}$ & $\begin{array}{l}52 \\
\text { Te } \\
\text { Tellurium } \\
127.60\end{array}$ \\
\hline
\end{tabular}

Figure 2.2: Common semiconductor material

Semiconductors like silicon and germanium have a crystalline structure. Their atoms are arranged in crystal lattice ordered array. In the crystal structure, valence electrons of all atoms are composed by forming covalent bonds. Silicon crystal lattice structure is shown in Figure 2.3. Semiconductors are tetravalent materials in their pure form. The presence of four valence electrons in their outermost shells makes their properties in between of conductors and insulators. They form covalent bonds with neighboring atoms by sharing 
four electrons with each other and completed their outer most shells. Two-dimensional view of the silicon crystal lattice is shown in Figure 2.3. Dots represent the valence electrons and circle represents the covalent bonds. From Figure 2.3 it is seen that each atom has 8 electrons under its influence.

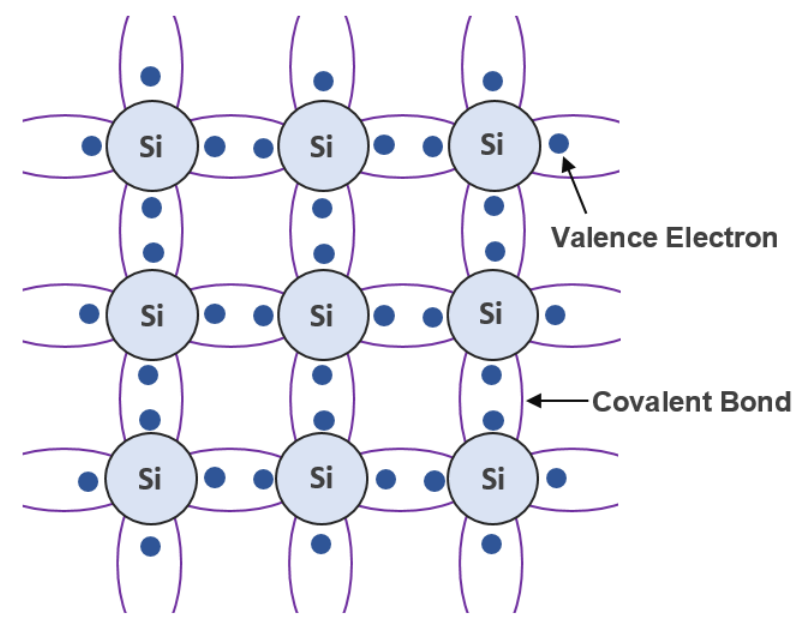

Figure 2.3: Silicon crystal lattice.

\subsubsection{Classification of semiconductors}

The semiconductor can be classified into intrinsic and extrinsic semiconductors. Intrinsic semiconductor allows a very small amount of current due to high resistance. Conducting ability can be considerably altered by adding certain impurities in intrinsic semiconductors. Semiconductors in which impurities are added are known as extrinsic semiconductor materials. The electrical conductivity of extrinsic semiconductors is higher than intrinsic semiconductors. Therefore, extrinsic semiconductors are used for the manufacturing of electronic devices such as diodes and transistors. Two types of impurities are added in intrinsic semiconductors to form extrinsic semiconductors. They are pentavalent and trivalent materials. Pentavalent materials have five valence electrons in their outermost orbit-like in antimony $(S b)$, phosphorus $(P)$ and arsenic $(A s)$. Whereas trivalent material has three valence electrons in their outermost orbit like indium (In), boron $(B)$, aluminum $(A l)$ and gallium $(G)$. Based on the addition of impurities, extrinsic semiconductors are further classified into two types [12].

\subsubsection{1 $p$-type semiconductor}

In intrinsic silicon, the number of holes can be increased by the addition of trivalent impurities. $p$-type semiconductors are formed by the doping of trivalent material in the intrinsic semiconductor material. These trivalent materials are known as acceptor impurities. When adding boron impurity in silicon, three boron's valence electrons forms covalent bonds with four adjacent silicon atoms. Due to the deficiency of electrons, the 
fourth covalent bond is incomplete [13]. This deficiency of electron is called a hole and shown in Figure 2.4. Figure 2.4 illustrates that boron atom accepts one electron to fill the hole. So, trivalent impurities are known as acceptors. Addition of small quantity of acceptor impurities provides a large number of holes. These holes are due to electrically neutral trivalent atoms.

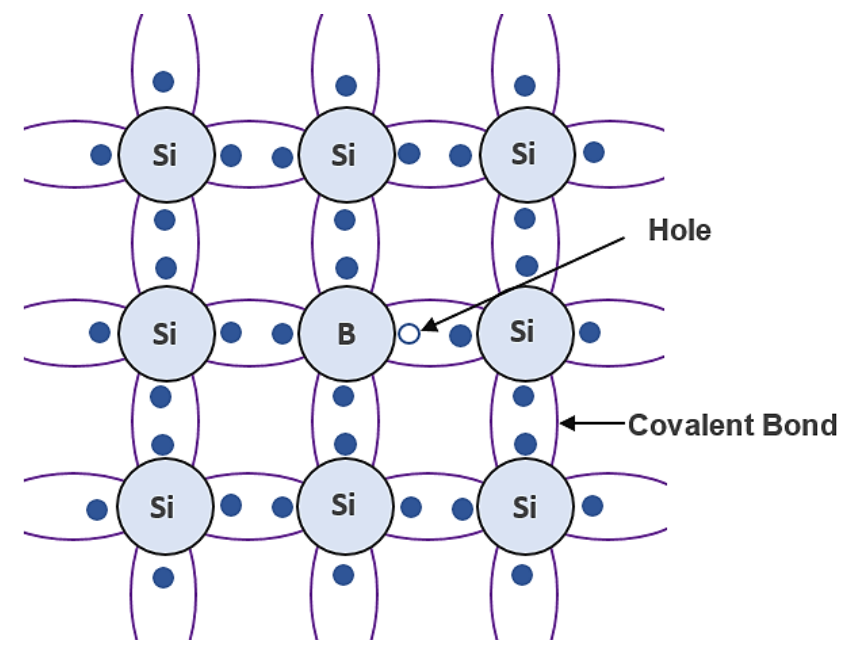

Figure 2.4: $p$-type semiconductor

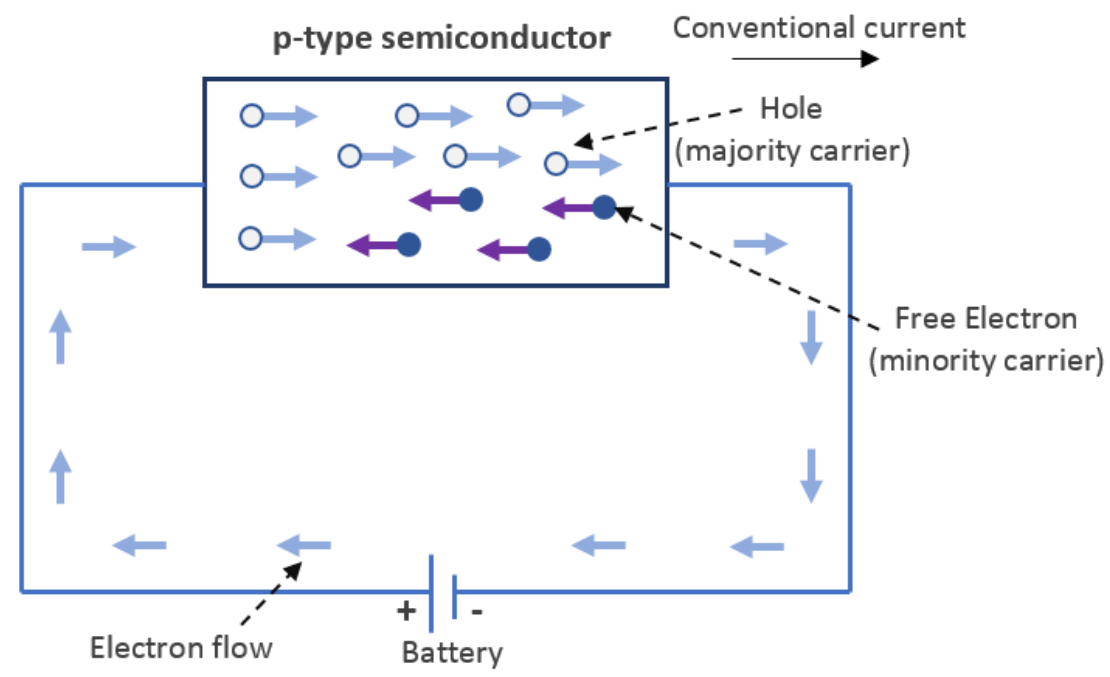

Figure 2.5: Conduction in $p$-type semiconductor.

When a $p$-type semiconductor is sourced by voltage supply; holes in valence band moves towards the negative terminal and free electrons towards the positive terminal of a voltage supply source. This phenomenon is well understood by Figure 2.5. In $p$-type semiconductor, holes population in the valence band is more than free electrons of the conduction band. Hence, in a $p$-type semiconductor, minority carriers are free electrons and majority carriers are holes.

Figure 2.6 illustrates the band theory of intrinsic and extrinsic semiconductors. The accepted electrons energy level is near to valence band and is also termed as acceptor level. 
Available electrons in the valence band can easily transfer to this level by leaving empty space known as a hole in valence band [14].
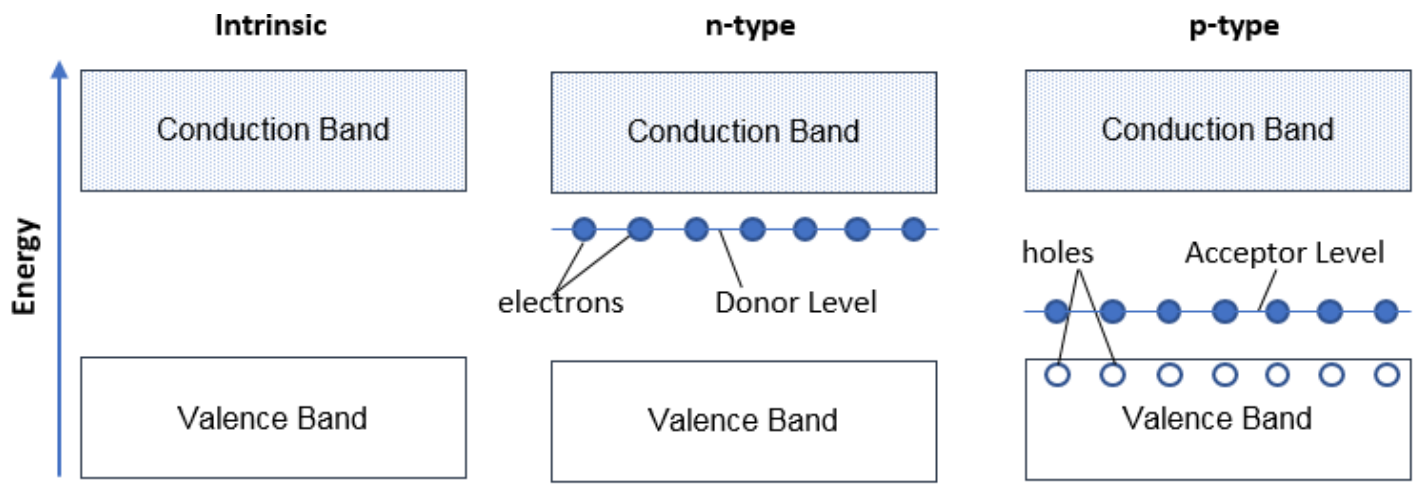

Figure 2.6: Energy bands in semiconductor.

\subsubsection{2 $n$-type semiconductor}

In intrinsic silicon, the number of conducting electrons available at conduction band can be increased by the addition of pentavalent impurities. $n$-type semiconductors are formed by the doping of pentavalent materials in the intrinsic semiconductor material. These pentavalent materials are termed as donor impurities. When pentavalent impurity such as phosphorus is doped in silicon, four valence electrons of phosphorus forms covalent bonds with adjacent silicon atoms and fifth valence electron is not involved in the formation of the covalent bond. Therefore, this fifth electron is free to move as shown in Figure 2.7. The number of free electrons depends on the amount of impurity added. Addition of small quantity of donor impurities provides a large number of free electrons.

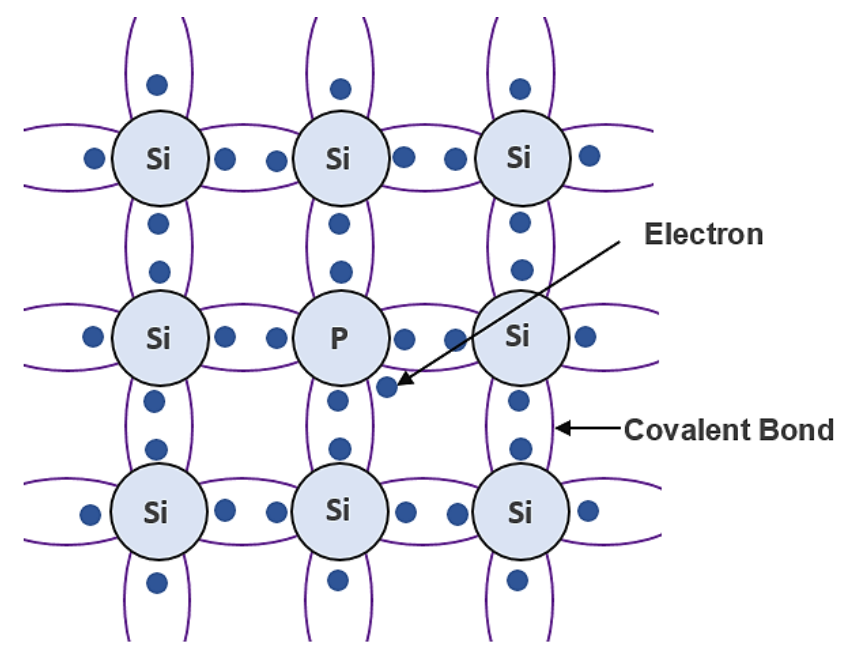

Figure 2.7: $n$-type semiconductor

When the $n$-type semiconductor is sourced by voltage supply; holes in valence band moves towards the negative terminal and free electrons towards the positive terminal of a voltage supply source. This phenomenon is well understood from Figure 2.8. In $n$-type semiconductor, free electrons population in the conduction band is more than holes of a 
valence band. Hence, in $n$-type materials, holes are minority carriers whereas free electrons are majority carriers. The band theory of $n$-type semiconductor is well comprehended from Figure 2.6. The free electrons energy level is very close to the conduction band. This free electron energy level is also termed as donor level. The energy gap between the donor level and conduction band is very small. Therefore, electrons available in donor level can easily transfer to the conduction band and conduction of current is started [14].

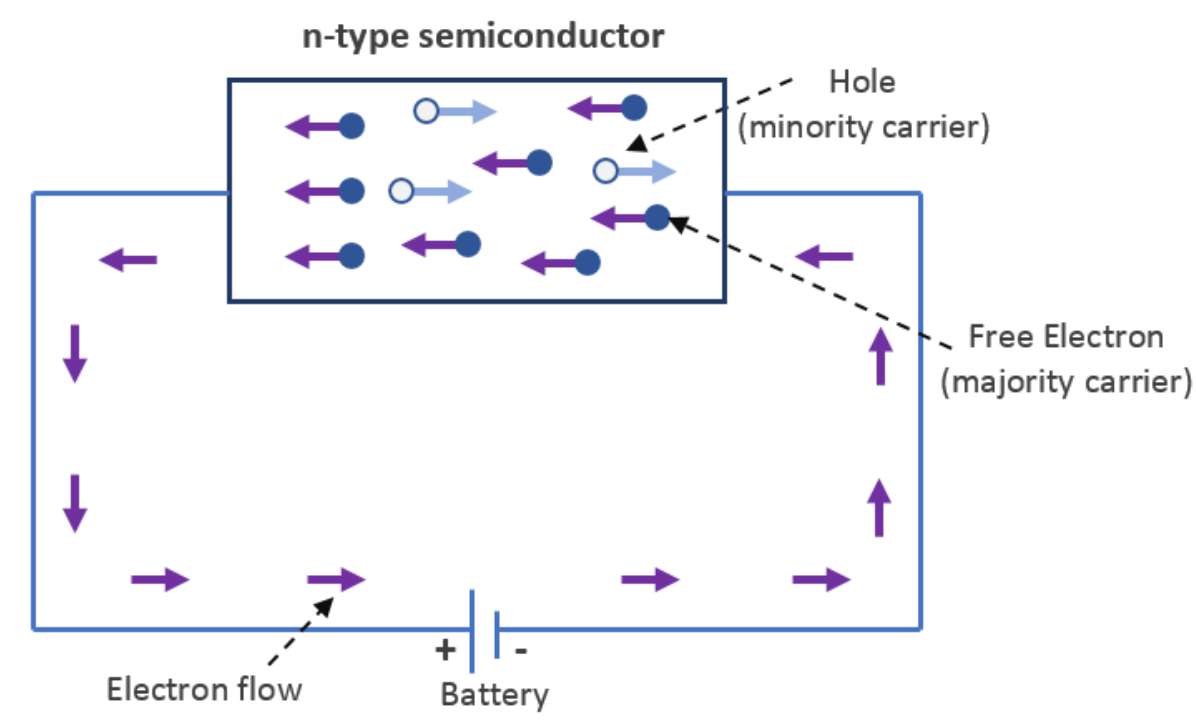

Figure 2.8: Conduction in $n$-type semiconductor.

\subsubsection{Conductivity of intrinsic semiconductors}

The electrons and holes movement in opposite directions is the main cause of current flow. The number of electrons and holes are equal. Hole mobility $\mu_{h}$ is practically half of the electron mobility $\mu_{e}$ [15]. The overall flow of current is due to electron and hole flow is given by $\mathrm{I}=\mathrm{I}_{e}+\mathrm{I}_{h}$

As current flowing through a semiconductor of cross-section $A$ in one second is

$$
\mathrm{I}=\operatorname{nev} A
$$

and in intrinsic semiconductor $n_{i}=p_{i}$

so

$$
\mathrm{I}=n_{i} e\left(v_{e}+v_{h}\right) A
$$

since $v=\mu E$

$$
\mathrm{I}=n_{i} e\left(\mu_{e}+\mu_{h}\right) E A
$$

since $E=V / l$

$$
\begin{aligned}
& \mathrm{I}=n_{i} e\left(\mu_{e}+\mu_{h}\right) A V / l \\
& \frac{V}{\mathrm{I}}=\frac{l}{A} \cdot \frac{1}{n_{i} e\left(\mu_{e}+\mu_{h}\right)}
\end{aligned}
$$


where

$\mu_{e}$ and $\mu_{h}$ are the electron and hole mobilities

$$
\mu_{e}=v_{e} / E \quad \text { and } \quad \mu_{h}=v_{h} / E
$$

$v_{h}$ and $v_{e}$ are the drift velocities of holes and electrons $(\mathrm{m} / \mathrm{s})$

$n_{i}$ and $p_{i}$ are free electrons and hole densities in an intrinsic semiconductor $\left(1 / \mathrm{m}^{3}\right)$

$e$ is electron charge (coulomb)

$A$ is cross-section of semiconductor $\left(\mathrm{m}^{2}\right)$

$E$ is applied electric field $(V / m)$

$l$ is length of the intrinsic semiconductor $(m)$

$V$ is the applied voltage

As $\rho$ is the resistivity of the semiconductor and is given by

$$
\rho_{i}=\frac{1}{n_{i} e\left(\mu_{e}+\mu_{h}\right)} \text { ohm }-\mathrm{m}
$$

By putting in equation $(i)$

$$
\frac{V}{\mathrm{I}}=\rho_{i} \frac{l}{A}
$$

The electrical conductivity which is the reciprocal of the resistivity is given by

$$
\sigma_{i}=n_{i} e\left(\mu_{e}+\mu_{h}\right) S / m
$$

As current density, $J=\mathrm{I} / A$ and $E=V / l$, by putting these values in equation $(i)$ we get

$$
\begin{aligned}
J & =n_{i} e\left(\mu_{e}+\mu_{h}\right) E \\
& =\sigma_{i} E
\end{aligned}
$$

Therefore, electrical conductivity becomes $\sigma_{i}=J / E$

The conductivity of semiconductor depends on current carriers and the number of current carriers presented per unit volume. From the above equation with an increase in temperature, $n_{i}$ and $p_{i}$ increases and the conductivity of intrinsic semiconductor increases, its means that resistivity decreases.

\subsubsection{Conductivity of extrinsic semiconductors}

The general expression for current density for extrinsic semiconductor is

as conductivity is $\sigma=J / E$

$$
J=\left(n e \mu_{e}+p e \mu_{h}\right) E
$$

$$
\sigma=n e \mu_{e}+p e \mu_{h}
$$

(a) For $n$-type semiconductor equations become 


$$
J_{n}=e\left(n_{n} \mu_{e}+p_{n} \mu_{h}\right) E
$$

and

$$
\sigma_{n}=e\left(n_{n} \mu_{e}+p_{n} \mu_{h}\right)
$$

Where $p_{n}$ and $n_{n}$ are after doping hole and electron densities.

(b) For $p$-type semiconductor equation becomes

$$
J_{p}=e\left(n_{p} \mu_{e}+p_{p} \mu_{h}\right) E
$$

and

$$
\sigma_{p}=e\left(n_{p} \mu_{e}+p_{p} \mu_{h}\right)
$$

Where $p_{p}$ are $n_{p}$ are after doping hole and electron densities.

In $n$-type semiconductor, electrons are majority carriers and holes are minority carriers [15]. Electron density in the extrinsic semiconductor is much more than hole density i.e. $n_{n} \gg p_{n}$. Therefore, the simplified expressions are

$$
\begin{aligned}
J_{n} & =n_{n} e \mu_{e} E \\
\text { and } \quad \sigma_{n} & =n_{n} e \mu_{e}
\end{aligned}
$$

In $p$-type semiconductors, conduction is due to holes of the valence band and hole density in an extrinsic semiconductor is much more than electron density i.e. $n_{p} \ll p_{p}$. Therefore, the simplified expressions are

$$
\begin{aligned}
J_{p} & =p_{p} e \mu_{h} E \\
\text { and } \quad \sigma_{p} & =p_{p} e \mu_{h}
\end{aligned}
$$

\subsection{5 pn junction semiconductor diode}

pn junction semiconductor diode is fabricated by doping $p$-type and $n$-type impurities on a wafer as shown in Figure 2.9. The boundary interface plane where two semiconductor regions are meeting is termed as a junction. Hypothetically, in junction plane the density of donors and acceptors are equal.

A grain boundary is introduced if constructed from two different pieces, so p-n junctions are created in the single crystal of semiconductor by a doping process. Following three phenomena take place at junction [13].

i. Space charge region or depletion region or transition region is established across the junction.

ii. Potential barrier is established across the $p n$ junction.

iii. The existence of depletion layer gives rise to junction and diffusion capacitances 


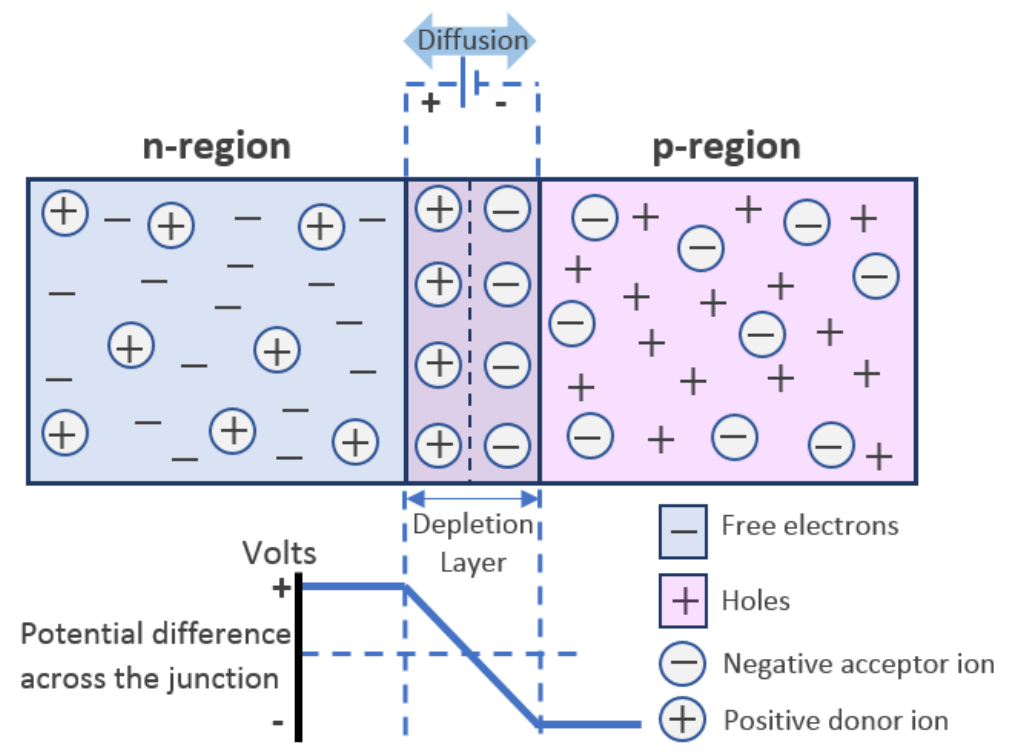

Figure 2.9: $p n$ junction semiconductor diode.

\subsubsection{Formation of depletion layer}

At the instant when $p n$ junction is formed, electrons are still in $n$-region and holes in $p$ region. The concentration of electrons is higher in $n$-region in comparison of $p$-region, means that electrons are the minority carriers in $p$-region. Similarly, the concentration of holes is higher in $p$-region in comparison of $n$-region, means that holes are the minority carriers in $n$-region. When $p n$ junction is formed, electron diffusion is from $n$-region to $p$ region and creates a positive charge near a junction whereas hole diffusion is from p-region to $n$-region and creates a negative charge near a junction. The creation of positive and negative charges across the junction makes a barrier potential $V_{B}$ (also termed depletion layer) as shown in Figure 2.9. Depletion layer forms very quickly across the junction and is very thin in comparison of $p$ and $n$ regions. Barrier potential stops the flow of carriers across the junction unless provides energy from an external voltage source. At room temperature $(300 \mathrm{~K})$ barrier potential of $S i$ is $0.7 \mathrm{~V}$ and $\mathrm{Ge}$ is $0.3 \mathrm{~V}$ [16].

\subsubsection{Energy band diagram of $p n$ junction}

Energy band diagram of $p n$ junction is shown below in Figure 2.10. The instant when pn junction is formed, the $p$-region side have trivalent added impurities at a slightly higher level than pentavalent added impurities in n-region. The reason behind this is the core attraction of trivalent material valence electrons are less than pentavalent material valence electrons. Therefore, valence electrons of trivalent material are at higher orbit, so energy level is high. There is overlap between bands of two regions. Due to this reason, the conduction band of n-region having high energy electrons in upper part diffuse in the lower 
part of the conduction band of $p$-region and they quickly recombine with holes in the valence band as shown in Figure 2.10 (a). Continuous diffusion forms a depletion layer. Loss of high energy electrons due to electron diffusion shifted down the energy bands of n-region. Further diffusion stops when the upper level of n-region conduction band reaches equal as the level of the lower level of a p-region conduction band and at this stage equilibrium condition is reached as shown in Figure 2.10 (b). Further diffusion of electrons across the junction is stopped due to the steep energy hill path. The electron can only cross this energy hill if an external energy source is applied [11,17].

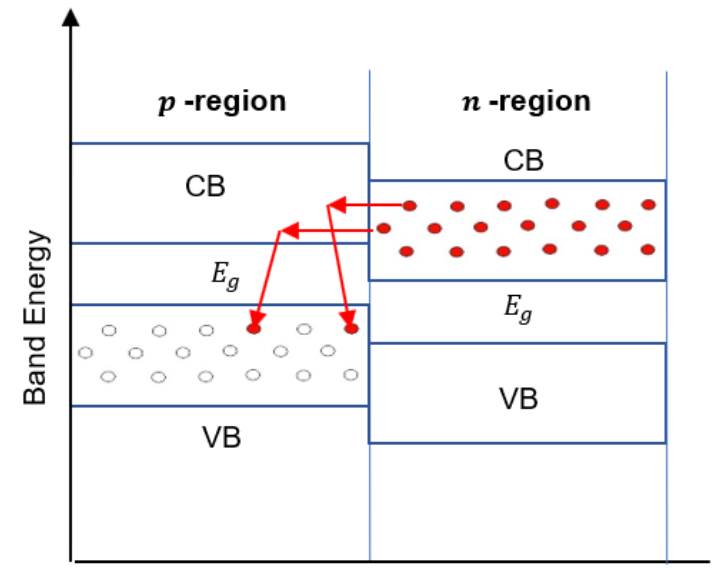

(a)

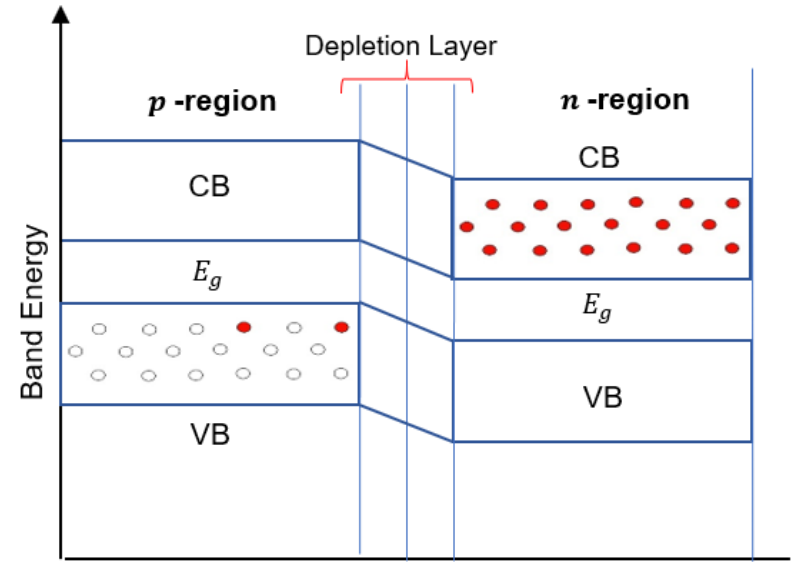

(b)

Figure 2.10: Energy band diagram of $p n$ junction.

\subsubsection{Fermi energy and holes}

In semiconductors, the existence of Fermi energy $\left(E_{f}\right)$ and holes have a certain interest. At room temperature, energy bands such as conduction band and valence band are partially filled. The higher of the conduction band is almost empty and the number of electrons exists in the bottom of the band. The band is termed as conduction band because of net electron flux or flow may be obtained in this band. Valence band is almost full of empty states near its top and exhibits conduction. Electrons occupy in this band are known as valence electrons and forms a covalent bond in a semiconductor.

Figure 2.11 represents the semiconductor in equilibrium at room temperature. Figure 2.11 shows the partially filled conduction band and empty valence band. Holes in the valence band are formed due to the shifting of electrons towards conduction band across the energy gap. Imaginary horizontal line lies between the bands at energy $E_{f}$ across the energy gap is termed as Fermi energy. $E_{f}$ represents energy above which the probability of electron states being filled is under $50 \%$, and below which the probability of electron states being filled is over $50 \%$. Valence band holes and conduction band electrons contribute in conductivity [18]. 


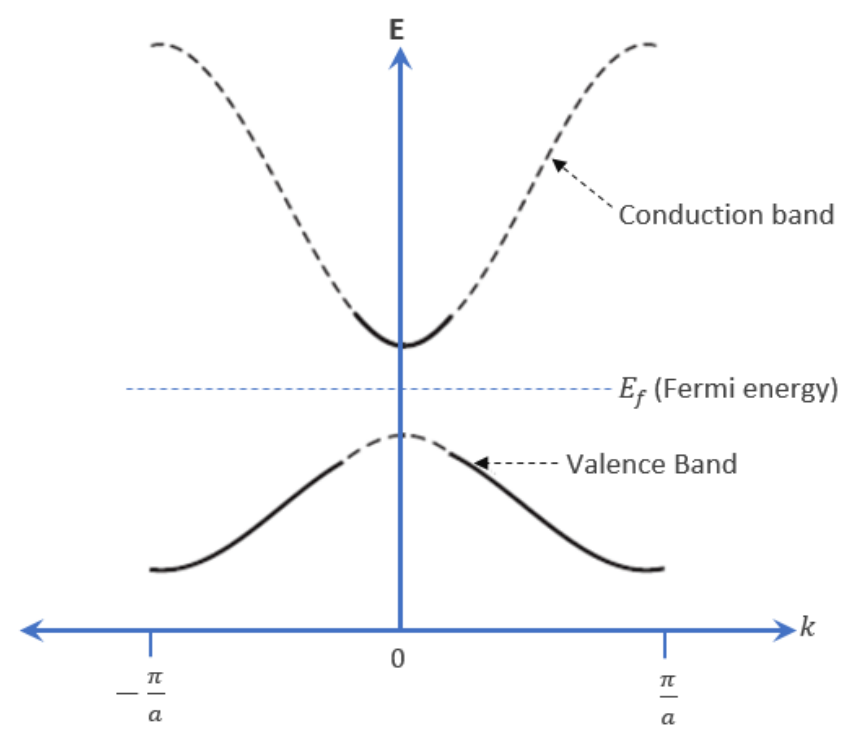

Figure 2.11: Semiconductor at room temperature showing fermi energy level.

In semiconductors like silicon atoms are bonded covalently. Covalent bond has two electrons. Valence electrons are optically or thermally excited and leave a bond to form an electron-hole pair (EHP) and creating free charge carriers in both bands. The energy required for the excitation of electrons must be equal to the bandgap energy. A hole is created when an electron leaves the covalent bond. An excited electron enters in the conduction band is able to move through the crystal whereas holes in the valence band are able to move through the crystal. To calculate the conductivity arising from certain band energy, we must know about the number of electrons $\mathrm{n}$ and number of holes p per unit volume of a semiconductor due to electron excitation across the energy gap $E_{g}$. So, carrier concentration for intrinsic semiconductor is $n_{i}=p_{i}$

\subsubsection{Biasing of $p n$ junction}

pn junction semiconductor diode has two terminals named as anode and cathode. The diode has very low resistance to flow the current in a forward direction, while the resistance in the other direction is very high. Thus, a diode is a unidirectional device. Which only allows the current in one direction while blocks the reverse current. Biasing of pn junction diode means that to connect it with a dc voltage source. To attain extreme current in the forward direction or in low resistance, diode must be connected in forward bias [19]. By connecting the positive battery terminal with an anode and negative battery terminal with a cathode, pn junction diode is said to be biased in the forward direction as given in Figure 2.12. In this condition, pn junction allows the flow of current across the junction. Negative battery terminal repels the electrons and positive terminal repels the holes. Holes and electrons are driven towards the junction, where recombination takes 
place. This movement of electrons and holes are the main cause of the flow of a large amount of current through the semiconductor diode. Forward biasing of pn junction diode reduces the depletion layer thickness.
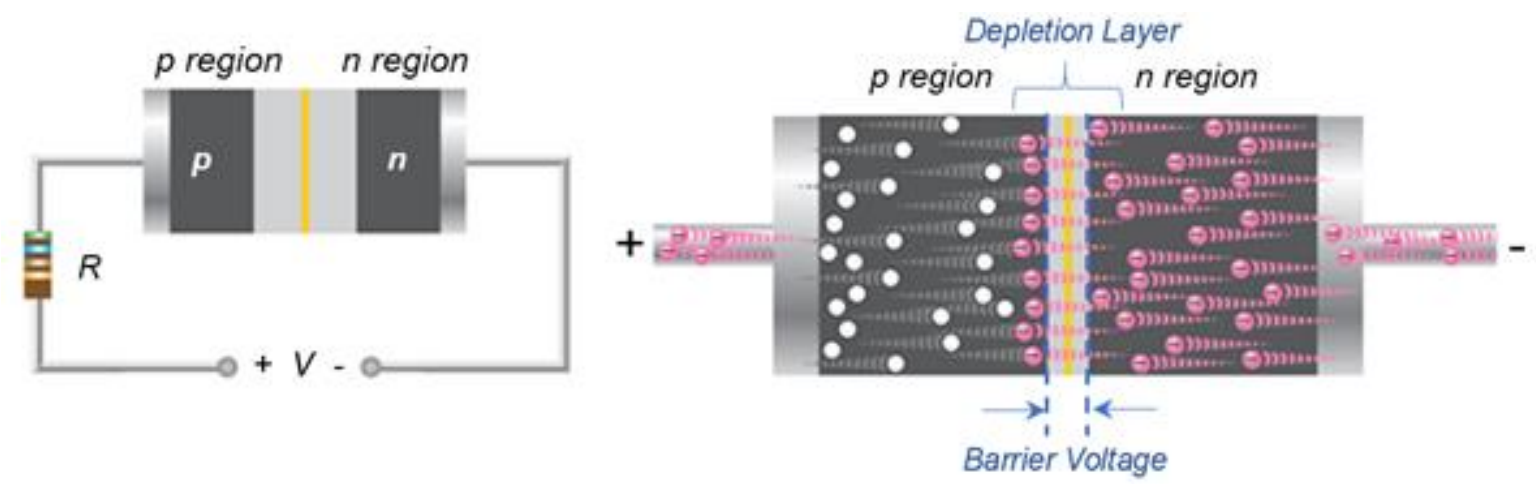

Figure 2.12: Forward biased $p n$ junction diode.

In reverse biasing of $p n$ junction diode, the negative terminal of a battery is connected with an anode and positive terminal with the cathode as shown in Figure 2.13. In this case, holes are attracted towards the negative terminal and electrons towards the positive battery terminal. So that both holes and electrons move away from the junction. Since at the junction there is no combination takes place and no current flows and junction offers high resistance. The width of the depletion layer rises with the increase of barrier potential.
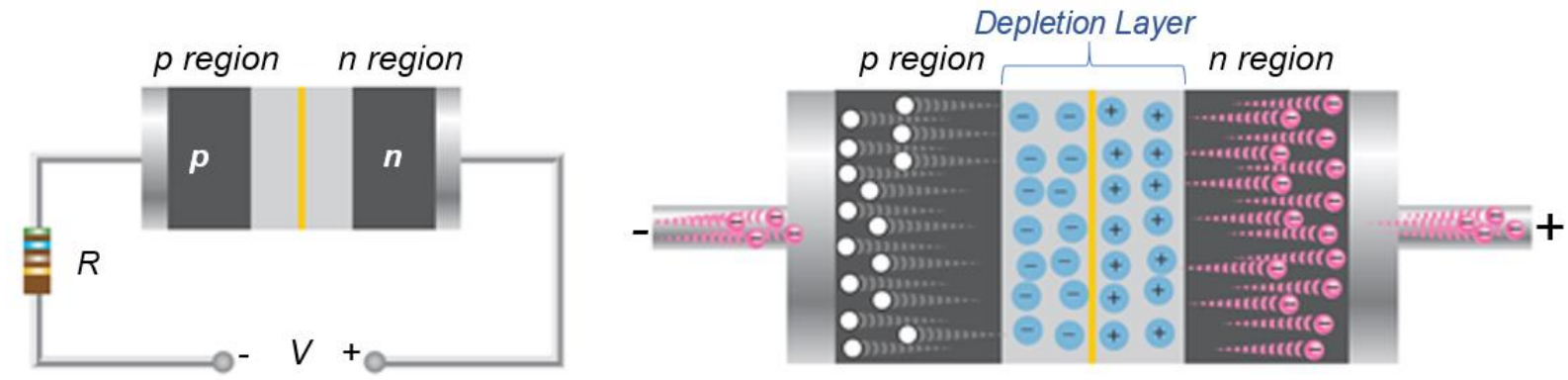

Figure 2.13: Reverse biased $p n$ junction diode.

\subsubsection{VI Characteristic curve}

VI characteristics curve of pn junction diode is shown in Figure 2.14. From Figure 2.14 it is illustrated that the forward current rises exponentially with applied forward voltage. The germanium diode has a potential barrier of $0.3 \mathrm{~V}$ and a silicon diode of $0.7 \mathrm{~V}$. It means that at room temperature, the potential difference of about $0.7 \mathrm{~V}$ for silicon and $0.3 \mathrm{~V}$ for germanium is required for the flow of forward current. This potential barrier is termed as threshold voltage $V_{t h}$, cut-in voltage or knee voltage. Practically it is the same as barrier voltage $V_{B}$. Before cut-in voltage or knee voltage, current flow is negligible and when an applied voltage is increased beyond a certain safe value then due to overheating, an extremely large current may destroy the junction. 
Reverse biasing of diode gives the reverse characteristics. Notice that the reverse biasing of the diode allows very little reverse saturation current to flow up to the point of breakdown and after that reverse current increases rapidly. The reverse saturation current is also referred to as leakage current of the pn junction. From Figure, it is illustrated that as reverse voltage is increased from zero, the reverse current quickly rises to its maximum or saturation value [20].

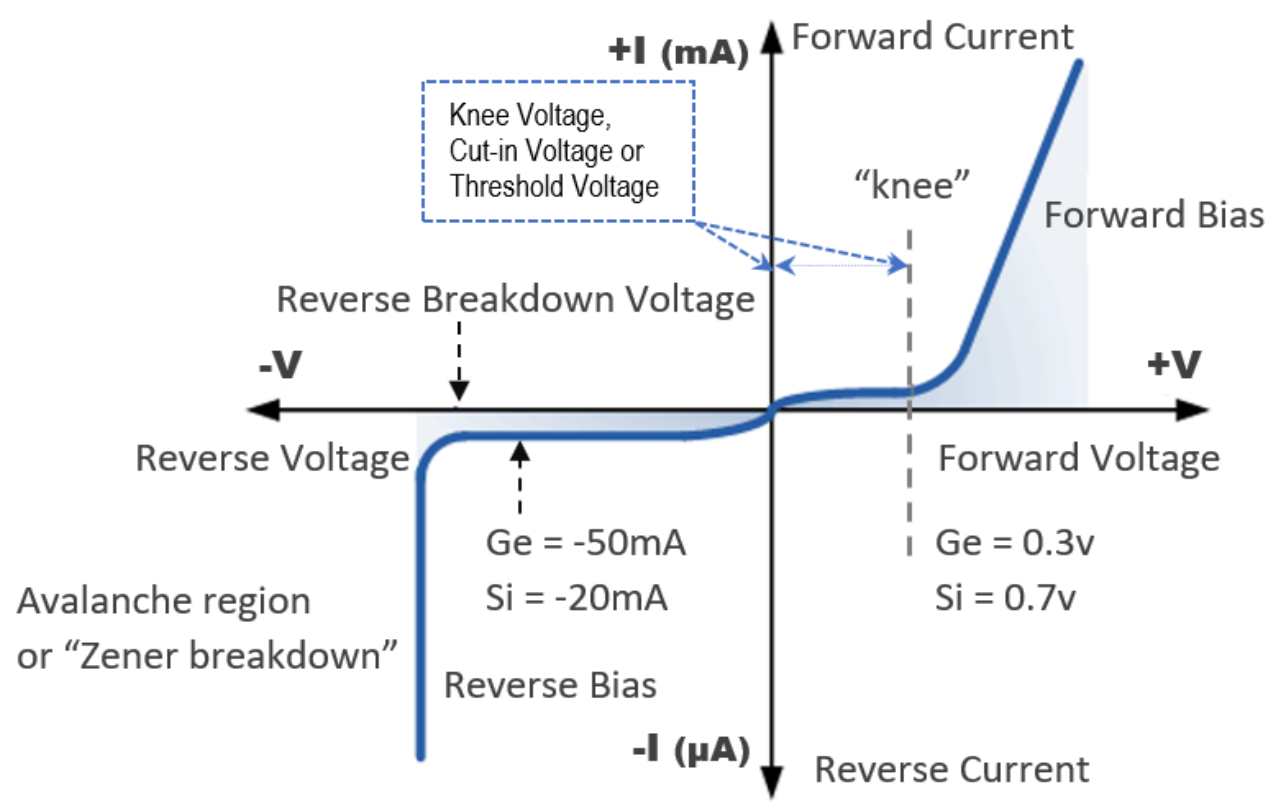

Figure 2.14: $p n$ junction semiconductor diode $V I$ characteristics.

\subsection{Diode current equation}

Shockley's equation explains the general characteristics of forward and reverse biasing regions of diode [21]. The diode current equation is given in equation in 2.6.

$$
I=I_{0}\left[\exp \left(\frac{V_{D}}{\eta V_{T}}\right)-1\right]
$$

Where $\mathrm{I}$ is diode current, $\mathrm{I}_{0}$ is reverse saturation current, $V_{D}$ is diode voltage, $\eta$ is semiconductor constant, depends on the construction and operating conditions ( 1 to 2 , usually taken as 1$)$ and $V_{T}$ is thermal voltage $\left(V_{T}=\frac{k T}{q}\right)$

Where $k$ is Boltzmann's constant $=1.38 \times 10^{-23} \mathrm{~J} / K, T$ is absolute temperature in kelvin and $q$ is magnitude of electronic charge $=1.6 \times 10^{-19} \mathrm{C}$

So, diode current equation becomes

$$
I=I_{0}\left[\exp \left(\frac{q V_{D}}{\eta k T}\right)-1\right]
$$




\subsection{Introduction to photovoltaics}

The period after World War II efforts were put into the reconstruction of the society. The emphasis was focused on the development and efficiency of mass production. New materials and new technologies were applied in the production. During this time energy demand was tremendously growing. In the second half of the $20^{\text {th }}$-century energy sources like gasoline and oil plays an important role. Gasoline, oil, and coal are known as fossil fuels and they are the traditional energy sources. Nuclear energy was also introduced in this period as a new source of energy. Currently one of the most substantial challenges is to full fill the energy demand for the world growth. Total demand of energy is increased with improvement in living standards and with the growing world population. The $21^{\text {st }}$ century epic challenge is filling the gap between energy demand and supply with inexpensive and clean energy. The main share of the energy production by mankind is from the fossil fuels, but unfortunately, due to limited fossil fuel reserves, they are not able to full fill all the energy requirements. These energy sources are also not environmentfriendly because it is the main cause of the hazardous environment and also contributes to global warming. So, there is a crucial necessity to rely on newer technologies that are environment-friendly and economical. Renewable energy resources contribute a significant role in the production of energy. The solid-state semiconductor photovoltaic devices have emerged as a newer and a relatively sustainable energy source. Which is ecofriendly and cost-effective if the production is on large scale.

\subsubsection{Advantages of using photovoltaic cells}

Following are the advantages that make the photovoltaic cells an efficient renewable energy source:

i. Conversion of electricity from sunlight or the sun's radiation is direct. So, there is no need to install a bulky generator.

ii. Solar electrical energy generation is environment-friendly. A photovoltaic panel provides clean and green energy. There is no emission of gases during electricity generation.

iii. Free from the use of fuels and water.

iv. Solar energy is generated by nature, it is free and simple.

v. Where sunlight is available solar energy can be generated easily.

vi. Photovoltaic energy is suitable for smart energy networks with distributed power generation. 
vii. Photovoltaic cells have no mechanically moving part as in wind turbines, so they have less breakage and also required little maintenance than other renewable energy sources.

viii. Photovoltaic panels are completely soundless and not providing noises.

ix. They can be used in distant zones, where the installation of an electric power grid is too expensive.

x. Photovoltaic panels are easily installable on grounds or on rooftops at residents without the interference of the residential lifestyle. [22]

xi. They have a long lifetime, up to 30 years

\subsection{Physics of solar cell}

\subsubsection{Photovoltaic effect}

The term "photovoltaic" is composed up from the Greek words "phos" meaning light and "voltaic" meaning electricity, associated with Italian physicist name, Alessandro Volta. Electricity can be produced from the "photovoltaic effect". A proper definition of the photovoltaic effect is the direct conversion of electromagnetic light radiation into electrical energy. The device used for the conversion of sunlight into usable electrical energy is known as a solar cell. Sunlight is an input source. The solar cells are also known as photovoltaic cells. It transforms sunlight into electricity. When sunlight falls on the photovoltaic cell then electrons freely move in a semiconductor material. If wires are connected to the positive and negative points of a photovoltaic cell, electron started to flow that is electricity and can be used to power an electric load.[23]

\subsubsection{Working principle of photovoltaic cell}

Photovoltaic cell working principle is based on the photovoltaic effect. Which is the formation of a potential difference due to electromagnetic at the junction of two different materials. This effect is closely related to the photoelectric effect, where the emission of electrons from a material is due to light absorption with a frequency above a materialdependent threshold frequency. This effect was explained by the scientist Albert Einstein in 1905 by assuming that the light comprises of well-defined energy quanta, called photons. The energy of such a photon is

$$
E=h v
$$

Where $v=c / \lambda$ and $c$ is the speed of light in a vacuum $\left(c=3 \times 10^{8} \mathrm{~m} / \mathrm{s}\right), h$ is the Planck's constant $\left(h=6.626 \times 10^{-34} \mathrm{Js}\right)$ and $v$ is the frequency of the light. For the 
explanation of this effect, Einstein received the Nobel Prize in Physics in 1921. The photovoltaic effect can be divided into the following three basic processes [24].

\subsubsection{Generation of charge carriers due to photon absorption}

Photon absorption in photovoltaic material excites the electrons and they move from initial energy state $E_{i}$ to higher energy state $E_{f}$ as given in Figure 2.15. Figure 2.15 (a) shows that photon energy $E_{p h}=h v$ excites electrons present in the valence band $\left(E_{\mathrm{i}}\right.$, initial energy state) shifted to the conduction band ( $E_{f}$, final energy state) after absorption of photon energy. Figure 2.15 (b) shows that if $E_{p h}>E_{g}$, a part of the energy is thermalized.

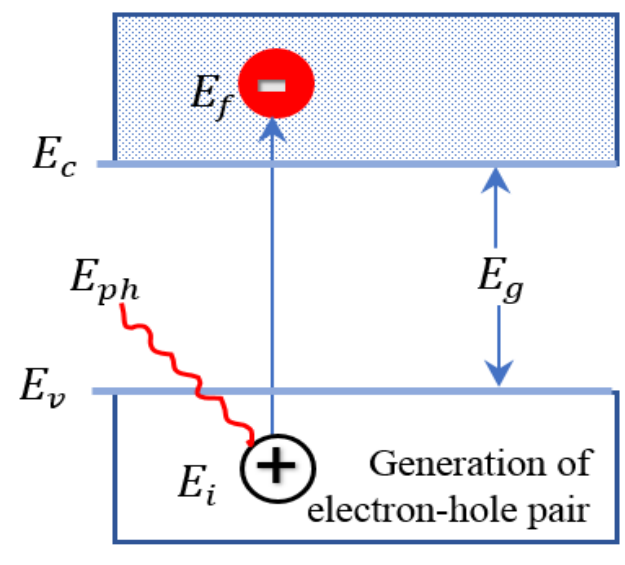

(a)

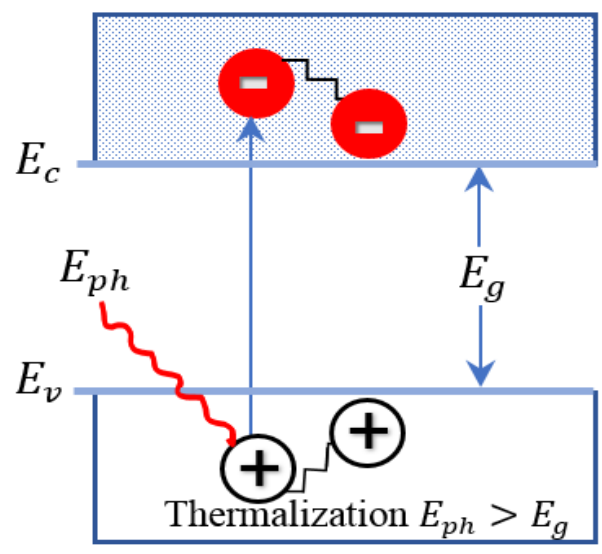

(b)

Figure 2.15: Generation of charge carrier by photon absorption.

Photon energy can be absorbed in the presence of $E_{f}$ and $E_{i}$ electron energy levels. Photon energy is equal to the difference of $E_{f}$ and $E_{i}$ as given in equation 2.9.

$$
h v=E_{f}-E_{i}
$$

In ideal case electron populates below then valence band edge $E_{v}$ and above the edge of conduction band $E_{c}$ in semiconductor. There is no other energy level for the electron population in amongst these two states. Hence the energy difference between $E_{c}$ and $E_{v}$ is called the band gap energy as given in equation 2.10. Therefore, the photon energy smaller than this band gap energy will not be absorbed.

$$
E_{g}=E_{c}-E_{v}
$$

\subsubsection{Separation of photogenerated charge carriers}

Recombination takes place in electron-hole pair. The electron will fall back to its initial energy state and energy releases in a form radiative recombination (photon emission) or non- radiative recombination (transfer of energy to other holes and electrons). Presence of semi membrane on both sides of the absorber allows the use of energy stored in these electron-hole pairs in an external circuit. Electron flows out from one membrane whereas 
holes from other as shown in Figure 2.16 [25]. From the figure, it is illustrated that electrons and holes are separated due to semipermeable membranes. p-type and n-type materials are used for the formation of the membranes. The solar cell is designed in such a way that before recombination of electron-hole pair, they must be reached to the membrane. It means that the time required to reach these charge carriers to their respected membrane must be shorter than their lifetime, due to this absorber thickness is limited.

\subsubsection{Extraction of photogenerated charge carriers}

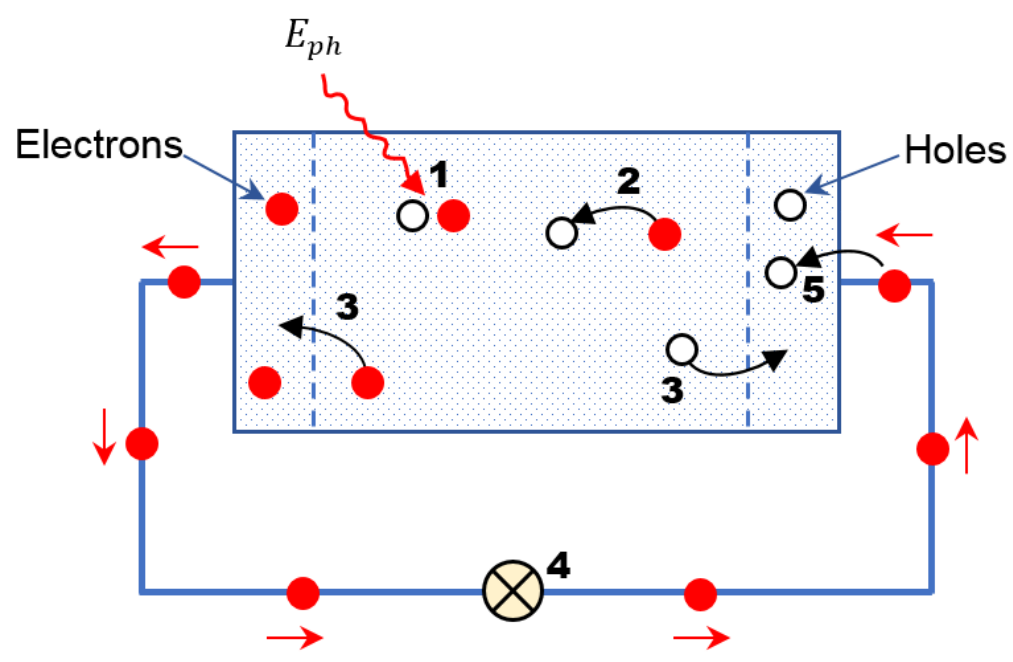

1. Generation of the electron-hole pair due to photon absorption.

2. Electron and hole recombination.

3. Separation of electrons and holes in semipermeable membranes.

4. External circuit driven from separated electrons.

5. Electron-hole recombination after passing of electrons through the external circuit.

Figure 2.16: Simple solar cell model.

Photo-generated charge carrier due to light absorption is extracted by using externally connected electrical contacts and allows the energy use in the external circuit. This phenomenon is well illustrated in Figure 2.16. In this stage, light energy is converted into electrical energy. At the back contact and absorber layer, electrons recombine with holes after passing from the external circuit.

\subsubsection{Solar radiation}

A solar cell having a pn junction or Schottky barrier structure can convert sunlight directly into electricity. Precise incident solar irradiance power under different conditions are used for the calculation of power conversion efficiency of a solar cell [26]. The radiant energy particularly electromagnetic energy emitted by the sun is solar radiation [19]. Figure 2.17 illustrates the solar irradiance spectra for two air-mass $(A M)$ conditions. The upper curve 
is the $A M 0$ solar irradiance spectrum and is measured above the earth's atmosphere. Under $A M 0$ conduction the irradiant power of the sun is $136.61 \mathrm{~mW} / \mathrm{cm}^{2}$. The lower curve is the $A M 1$ solar irradiance spectrum characterizes the sunlight on the earth's surface when the sun is at its zenith angle. Under $A M 1$ condition total incident power of sunlight $92.5 \mathrm{~mW} / \mathrm{cm}^{2}$. AM1.5G (global) is the standard spectrum at the earth's surface. AM1.5G spectrum $\left(\theta=48.2^{\circ}\right)$ has been normalized to give $100 \mathrm{~mW} / \mathrm{cm}^{2}$. For the calculation of solar cell power conversion efficiency in the terrestrial environment, $A M 1.5 G$ spectrum is the most suitable incident solar irradiance. To calculate the power conversion efficiency of the solar cell, specifying the exact $A M$ condition is very important [26].

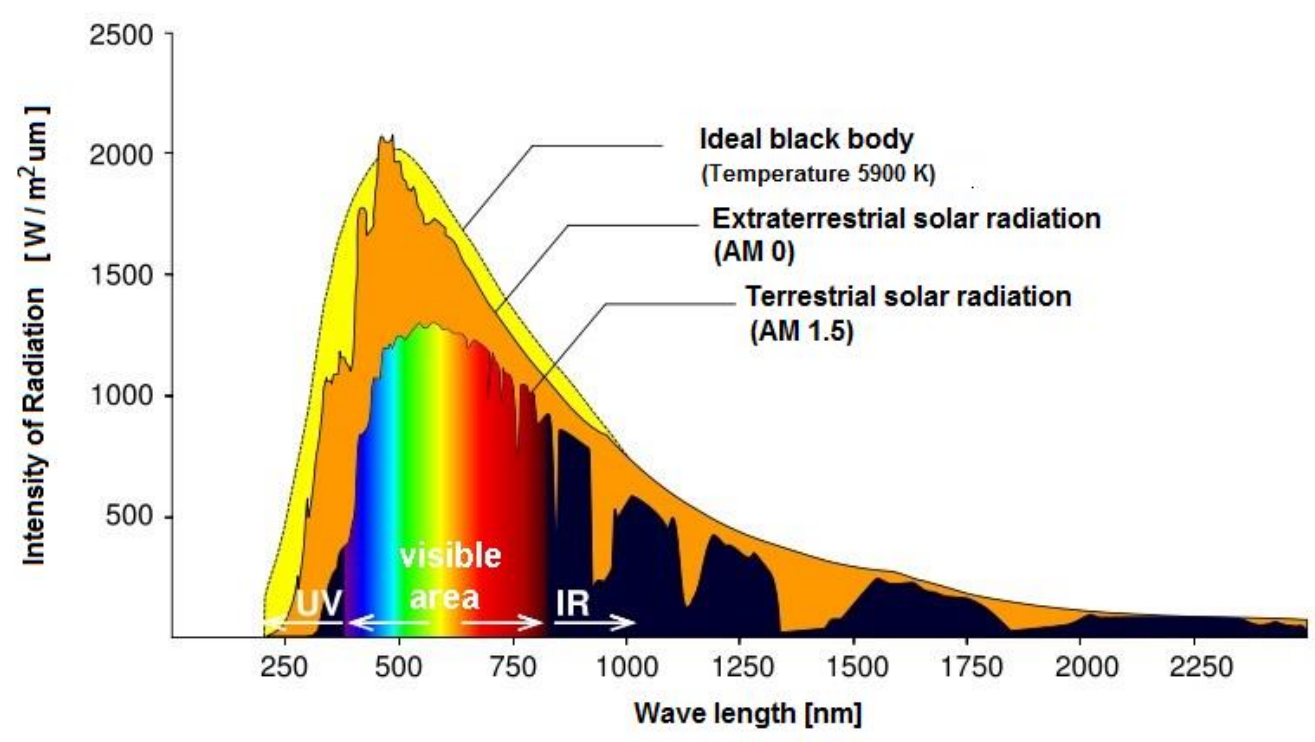

Figure 2.17: Solar irradiance spectrums versus wavelength. [26]

\subsubsection{Equivalent circuit of solar cell}

To understand the working principle of a solar cell, it is appropriate to make a model which is electrically equivalent. The ideal solar cell simplest model is given in Figure 2.18 and consists of a constant current source and parallel connected diode. Constant current source works like a generator to push the electrons to the external circuit. Photocurrent $I_{L}$ is generated due to the photovoltaic effect. Photocurrent depends on the intensity of the available sunlight, $I_{L}$ of a current source is directly proportional to solar radiation. It means that with an increase of intensity of available sunlight, $I_{L}$ must be increased. $I_{D}$ is the reverse saturation current of a solar cell [27]. 


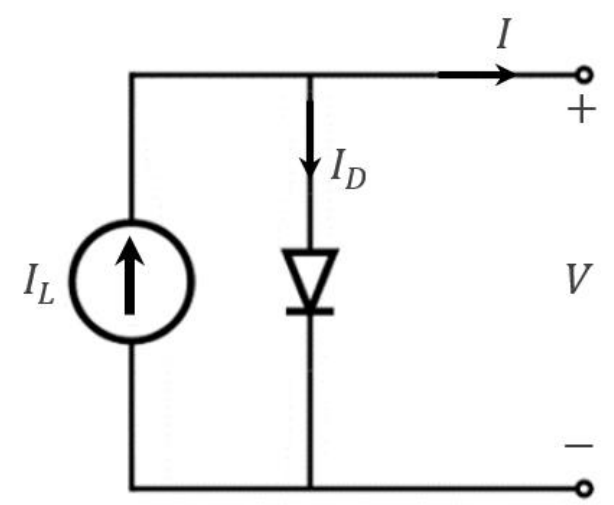

Figure 2.18: Ideal solar cell

Practically photovoltaic cells are not ideal. So, shunt and series resistance components are added to the equivalent circuit. The subsequent equivalent circuit is given in Figure 2.19.

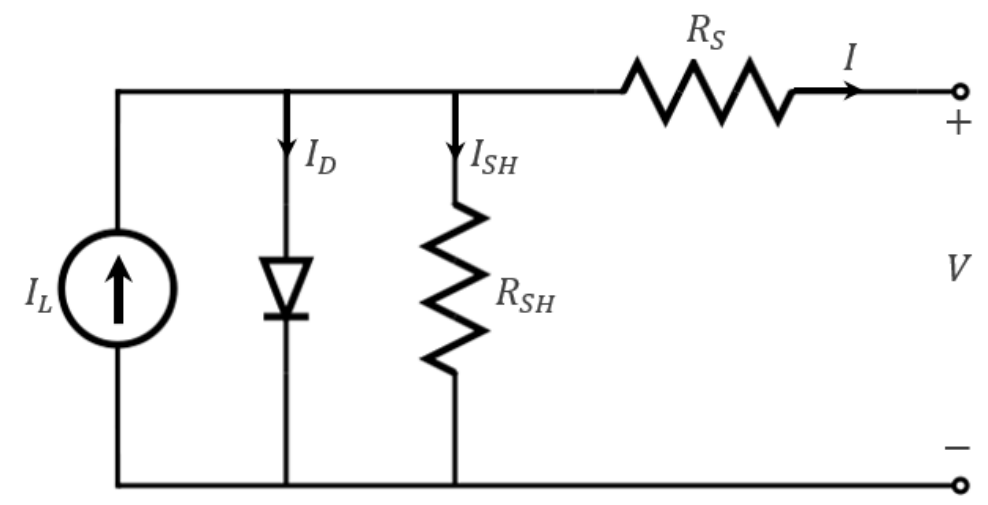

Figure 2.19: Photovoltaic cell equivalent circuit

From the schematic of a solar cell equivalent circuit, it is exemplified that the output current of a photovoltaic cell is the difference of photogenerated current, diode current, and shunt resistance current given in equation 2.11 .

$$
I=I_{L}-I_{D}-I_{S H}
$$

The voltage across these components governed the flow of currents

$$
V_{D}=V+I R_{S}
$$

Where $V_{D}$ is the voltage across shunt resistance and diode, $V$ is the output terminal voltage and a voltage across the series resistance is $I_{S}$.

Diode current from Shockley diode equation is:

$$
I_{D}=I_{0}\left[\exp \left(\frac{q V_{D}}{\eta k T}\right)-1\right]
$$

Current flows through shunt resistance can be calculated from ohms law

$$
I_{S H}=\frac{V_{D}}{R_{S H}}
$$

By substituting these values in equation 2.11 


$$
I=I_{L}-I_{0}\left[\exp \left(\frac{q\left(V+I R_{S}\right)}{\eta k T}\right)-1\right]-\frac{V+I R_{S}}{R_{S H}}
$$

\subsubsection{VI characteristic of a photovoltaic device}

VI characteristics curve is the graphical representation of the operation of a photovoltaic cell. It can be well understood by considering the equivalent circuit of a solar cell. VI characteristic of a photovoltaic cell is the superposition of the VI curve of a device in dark (absence of light) and illuminating (under light) conditions [28,29]. In dark conditions photovoltaic cell has similar electrical characteristics as of large diode. When light falls on the photovoltaic cell, electrical power can be extracted and VI curve down into the fourth quadrant. Amount of shift is directly proportional to the incident light intensity on a solar cell as shown in Figure 2.20. Where maximum power is indicated by the shaded area. Illuminated cell added with diode dark currents, diode law becomes:

$$
I=I_{0}\left[\exp \left(\frac{q V}{n k T}\right)-1\right]-I_{L}
$$

where $I_{0}=$ diode leakage current under dark or dark saturation current, $I_{L}=$ light generated current, $V=$ applied terminal voltage across diode, $q=$ electronic charge, $\mathrm{k}=$ Boltzmann's constant $n=$ ideality factor and $T=$ temperature

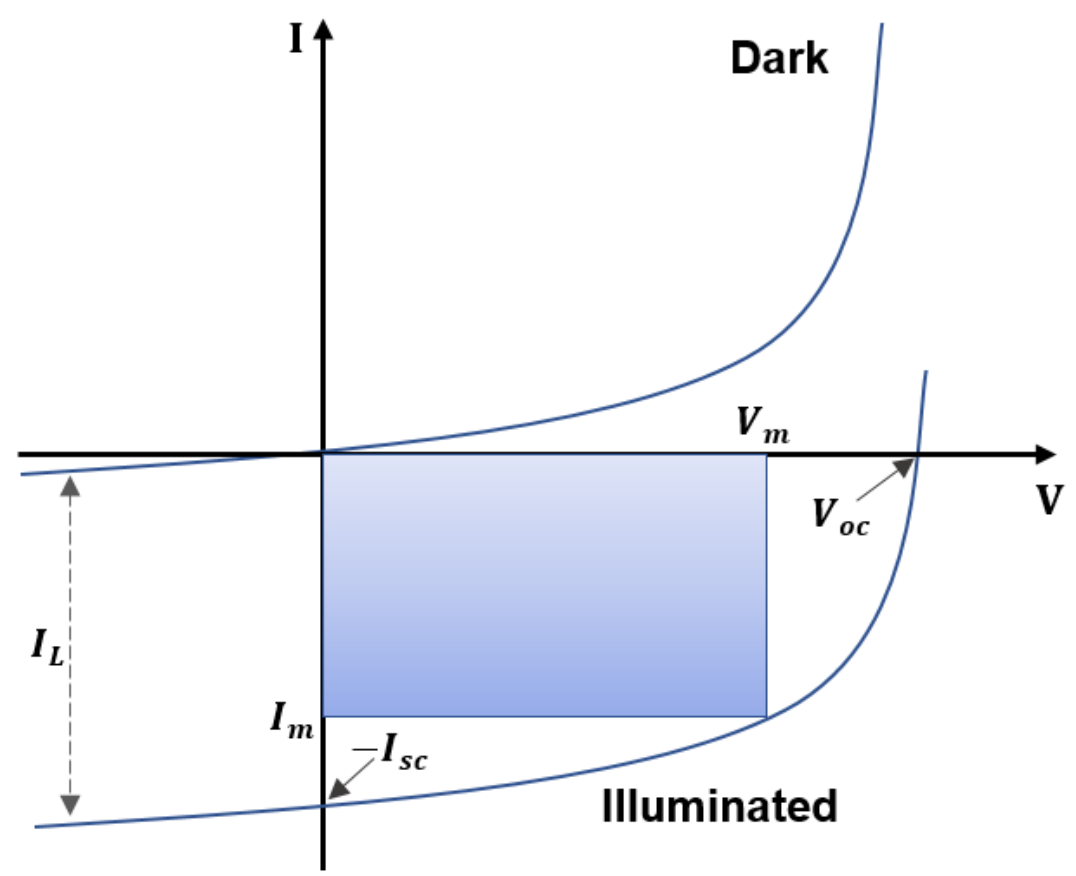

Figure 2.20: VI characteristic of photovoltaic cell under illuminated and dark. 


\subsection{Basic parameters and electrical characterization methods}

\subsubsection{Short circuit current}

The maximum current flow through the solar cell at zero load condition (at $R_{L}=0$ ) or short-circuited is known as short-circuit current $\left(I_{s c}\right)$. At the largest value of $I_{s c}$, the voltage of a solar cell will be zero [26]. The flow of $I_{s c}$ is due to the collection and generation of light generated carriers. It mainly depends on the number of incident photons as well as the spectrum, area of solar cell, optical properties and the collection probability of light generated carriers. The graphical representation of $I_{s c}$ is given in Figure 2.21.

\subsubsection{Open circuit voltage}

The maximum voltage is taken from the solar cell (at $\left.R_{L}=\infty\right)$ is known as open circuit voltage $\left(V_{o c}\right)$. When a solar cell is an open circuited, and no load is connected across the solar cell then current will be at its minimum (zero) value whereas the voltage will be at maximum value [12]. From solar cell equation, $V_{O C}$ can be derived by setting net current to zero and is given in equation 2.17.

$$
V_{o c}=\frac{n k T}{q} \ln \left(\frac{I_{L}}{I_{0}}+1\right) \text { at } I=0
$$

From the above equation, it is clear that open circuit voltage depends on $I_{0}$ (saturation current) and $I_{L}$ (light generated current). $I_{0}$ depends on recombination in the solar cell. So, $V_{o c}$ is a measure of the amount of recombination in a solar cell. The graphical representation of open circuit voltage is given in Figure 2.21.

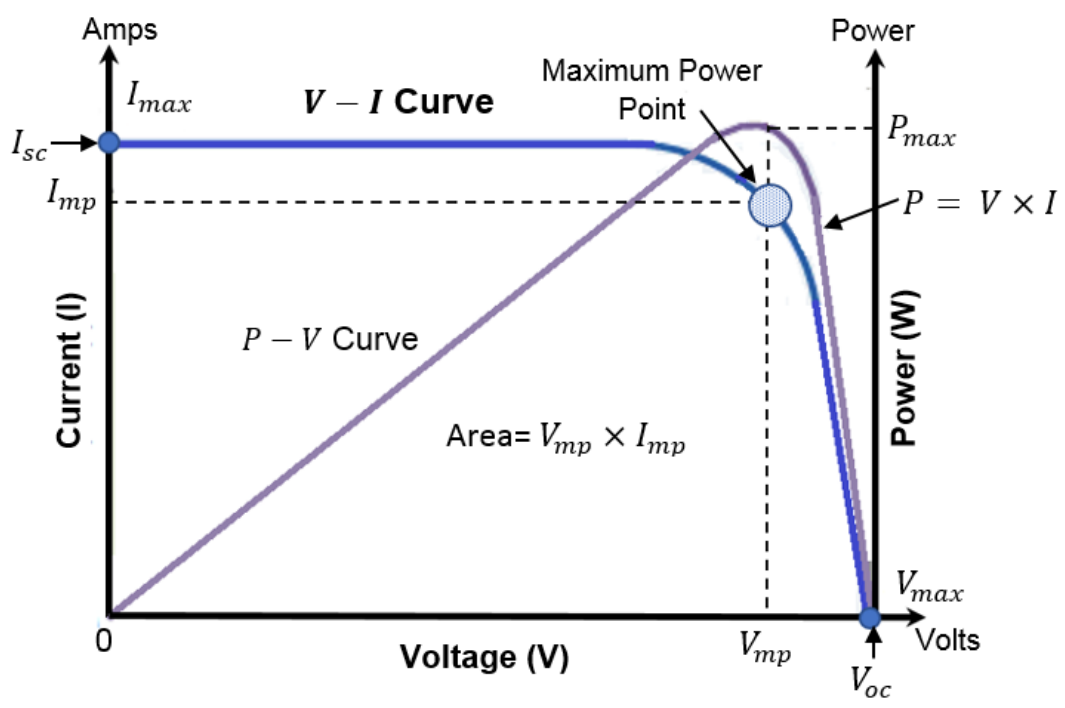

Figure 2.21: $I_{S C}$ and $V_{o c}$ representation in $V I$ cure

\subsubsection{Fill factor}

The measure of a photovoltaic cell quality is fill factor $(F F)$, which is derived by equating the maximum power $\left(P_{\max }\right)$ to the theoretical power $\left(P_{t}\right)$. Where power $\left(P_{t}\right)$ would be 
output at both the open circuit voltage $\left(V_{o c}\right)$ and short-circuit current $\left(U_{s c}\right)$ as given in equations 2.18 and 2.19 [30]. Fill factor can be interpreted graphically as the ratio of the rectangular areas depicted in Figure 2.22.

$$
\begin{aligned}
& F F=\frac{P_{\text {max }}}{P_{t}} \\
& F F=\frac{V_{\text {max }} I_{\text {max }}}{V_{o c} I_{s c}}
\end{aligned}
$$

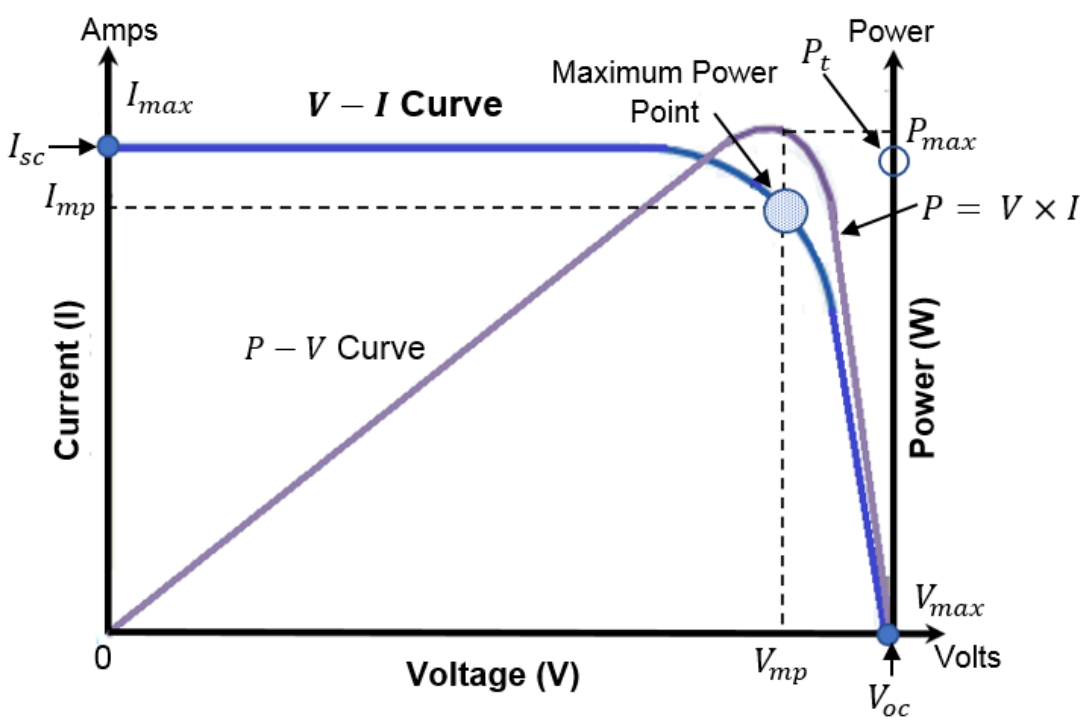

Figure 2.22: Attaining fill factor from VI characteristics cure

\subsubsection{Maximum power}

The output power of a solar cell is given in watts and is equal to the product of voltage times the current and is defined as

$$
P_{\text {out }}=V_{\text {out }} I_{\text {out }}
$$

Under short and open circuit conditions, no power is generated. The power output will be zero if both or anyone will be zero. The device will provide maximum power for maximum values of voltage and current.

$$
P_{\max }=V_{\max } I_{\max }
$$

In terms of fill factor maximum power is

by putting equation 2.19 in 2.21 we get

$$
P_{\max }=V_{o c} I_{S C} F F
$$

\subsubsection{Power conversion efficiency}

Power conversion efficiency is the most frequently used parameter to relate the performance of two solar cells and is termed as PCE. It is defined as the ratio of output power from a solar cell to the input power from the sun [12]. 


$$
P C E=\frac{P_{\text {max }}}{P_{\text {in }}}
$$

Where

$$
\begin{aligned}
P_{\text {max }} & =V_{o c} I_{s c} F F \\
P_{t} & =V_{o c} I_{s c}
\end{aligned}
$$

Therefore, from equation 2.23 and 2.24 the product of theoretical power $\left(P_{t}\right)$ and fill factor $(F F)$, divided by power the energy input from the sun is the power conversion efficiency [31]. Mathematically expressed in equation 2.26.

$$
P C E=\frac{V_{o c} I_{s c} F F}{P_{i n}}
$$

PCE depends on the parameters like incident sunlight intensity, solar cell working temperature and spectrum type. So, to compare two or more solar cells, it is important to carefully control the conditions under which $P C E$ is measured. Typical measurement setup for terrestrial solar cells is with an $A M 1.5 G$ spectrum at a temperature of $25^{\circ} \mathrm{C}$.

\subsubsection{Quantum efficiency}

The quantum efficiency $(Q E)$ is the ratio of the extracted free charge carriers by the solar cell to the number of incident photons. In other words, $Q E$ relates to the response of a solar cell to different wavelengths. It may be given either as a function of energy or wavelength. The $Q E$ will be unity at the precise wavelength if all certain wavelength photons are absorbed and the resulting minority carriers are collected.

\subsection{Recombination losses in solar cell in perspective of SCAPS}

Electron-hole pairs generated due to incident photons are termed as carriers. Theses generated carriers needs to be separated before recombination and emission of energy. This recombination is the major cause of the loss of photo-generated carriers and due to this overall efficiency of a solar cell is affected. In a solar cell, recombination takes place at different regions as like generation of carriers in different regions. The generated carriers near the depletion region are separated by the electric field of depletion region whereas generated carriers in a solar cell at bulk, front and far end has a less probability to get separated. So, generated carriers in these regions will again recombine with the emission of absorbed energy and they will not contribute in the photovoltaic process. Hence, to improve the efficiency of solar cell recombination of those carriers must be governed. In photovoltaic solar cell following recombination losses affected the device performance.

i. Bulk recombination loss 
ii. Interface recombination loss

iii. Recombination at metal-semiconductor contacts

\subsubsection{Bulk recombination loss}

If impurities are present in the semiconductor material, then these impurities create energy states, which acts as a trap for photon generated carriers. A model for trap assisted bulk recombination loss is given by Shockley read hall recombination which is illustrated with the help of Figure 2.23 [32].

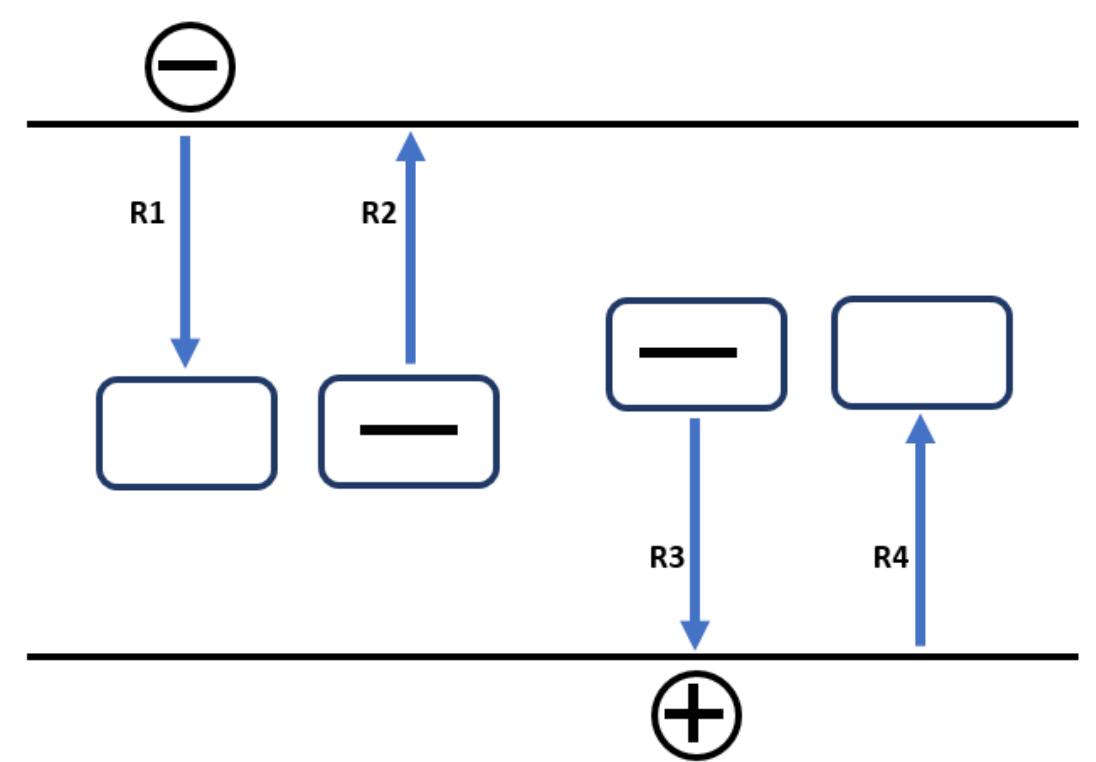

Figure 2.23: Trap assisted recombination

Figure 2.23 shows the possible ways in which holes and electrons may recombine and these processes are denoted by:

i. $R 1$ a possible way with which electron will be capture at energy state $E_{t}$.

ii. $R 2$ emission of an electron from trap state.

iii. $R 3$ capture of a hole.

iv. $R 4$ emission of holes.

To find out the dependency of these processes on trap state, we will analyze these four processes individually.

For R1 process: From Figure 2.23, trapping of an electron is depended upon the concentration of electron, defect density of state and probability of the empty state of these traps. Mathematically this is expressed in equation 2.27.

$$
R_{1}=v_{t h} \sigma_{n} n N_{t}\left(1-f_{t}\right)
$$

Where $v_{t h} \sigma_{n}$ are proportionality constants, $\mathrm{n}$ is the concentration of electrons, $N_{t}$ is density in trap states, and $f_{t}$ is the probability of occupation of trap state for the electron. The expression for $f_{t}$ is given in equation 2.28. 


$$
f_{t}=\frac{1}{1+\exp \left(\frac{E_{t}-E_{f}}{k T}\right)}
$$

$E_{t}$ is energy of trap state and $E_{f}$ is fermi energy level.

For process R2: Electron is emitted into the conduction band and is expressed as the emission of an electron with the probability of occupation of trap state. The relation is given in equation 2.29 .

$$
R_{2}=e_{n} N_{t} f_{t}
$$

Where $e_{n}$ is emission of electron.

\section{For process R3 an R4:}

For hole capture and hole emission expression is given in equation 2.30 and 2.31.

$$
\begin{aligned}
& R_{3}=v_{t h} \sigma_{n} p N_{t} f_{t} \\
& R_{4}=e_{p} N_{t}\left(1-f_{t}\right)
\end{aligned}
$$

To find the emission rate for the electron, we assume that the capture of electron and emission of an electron from trap state are equal. So, relating $R 1$ and $R 2$ with each other, we can find the emission rate for an electron.

$$
R_{1}=R_{2}
$$

By putting value of $R 1$ and $R 2$ in equation 2.32 it will become

$$
v_{t h} \sigma_{n} n N_{t}\left(1-f_{t}\right)=e_{n} N_{t} f_{t}
$$

Further solving, rearranging for $e_{n}$ and putting value for $f_{t}$ in equation 2.33 it will become as

$$
\begin{array}{r}
v_{t h} \sigma_{n} n\left(1-f_{t}\right)=e_{n} f_{t} \\
e_{n}=\frac{v_{t h} \sigma_{n} n\left(1-f_{t}\right)}{f_{t}} \\
e_{n}=v_{t h} \sigma_{n} n\left(\frac{1}{f_{t}}-1\right) \\
e_{n}=v_{t h} \sigma_{n} n \exp \left(\frac{E_{t}-E_{f}}{k T}\right)
\end{array}
$$

Where $n=n_{i} \exp ^{\left(\frac{E f-E i}{k T}\right)}$ and by putting the value of $\mathrm{n}$ we get

$$
e_{n}=v_{t h} \sigma_{n} n_{i} \exp ^{\left(\frac{E_{t}-E_{i}}{k T}\right)}
$$

for $e_{p}$ the expression will be as given in equation 2.37. 


$$
e_{p}=v_{t h} \sigma_{n} n_{i} \exp ^{\left(\frac{E_{i}-E_{t}}{k T}\right)}
$$

Now to derive the Shockley recombination model, we know that under equilibrium generation rate is equal to recombination rate.

$$
G=U=R_{1}-R_{2}=R_{3}-R_{4}
$$

So, solving it for equation 2.38 we will get equation 2.39 for total recombination.

$$
U=v_{t h} \sigma_{(n, p)} N_{t} \frac{n p-n_{i}^{2}}{n+p+2 \cosh \left(\frac{E_{t}-E_{i}}{k T}\right)}
$$

From equation 2.39 it is evident that recombination is highly depending upon the density of defect states $N_{t}$, capture cross section for (electrons, holes) $\sigma_{(n, p)}$ and concentration of (electrons, holes).

\subsubsection{Interface Recombination loss}

The incomplete bonds at the interface of solar cell work as a trap for photon generated carriers. So, loss due to irregular crystal shape at the interface is called interface recombination loss. Defects at the interface arise because of lattice mismatch, different size in grain boundaries and injection of impurity during junction formation between absorber and buffer interface. These trap state at the interface cause interface recombination and result in loss of open circuit voltage $\left(V_{o c}\right)$ of a solar cell. This is illustrated with the aid of Figure 2.24. From Figure 2.24 there are two possible interfaces that can be formed between absorber and buffer interfaces [33].

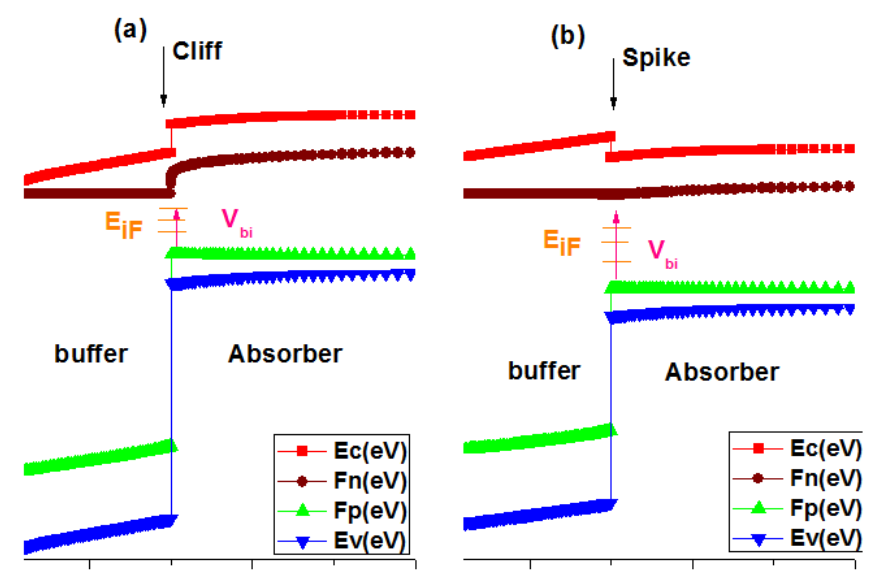

Figure 2.24: Interface between absorber/buffer layer

With electron affinity of the absorber is smaller than a buffer, a cliff like an interface will be formed with positive conduction band offset $(+C B O)$ as shown in Figure 2.24 (a). with an electron affinity of the absorber is larger than buffer a spike like an interface will be formed with a negative conduction band offset $(-C B O)$ as shown in Figure $2.24(\mathrm{~b})$. 
The difference between these two interfaces is the built-in potential at the junction interface. For cliff like interface the built-in potential is smaller than that of spike interface. Thus, creating a weak charge separation in the depletion layer and leading to high interface recombination.

Interface recombination of a solar cell is depended upon defect density and the relation for interface recombination. It can be derived from equation 2.38 and solving it for interface recombination. Now putting the value of $R_{1}$ and $R_{2}$ in equation 2.38 we will get equation 2.40 .

$$
R_{i F}=S_{n} n\left(1-f_{t}\right)-S_{n} f_{t} n_{i F}
$$

whereas $f_{t}=\frac{S_{n} n+S_{p} p_{i F}}{S_{p}\left(p+p_{i F}\right)+S_{n}\left(n+n_{i F}\right)}$ that can be found from equation 2.38 by solving it for $f_{t}, S_{p}=v_{t h} \sigma_{p} N_{t}, S_{n}=v_{t h} \sigma_{n} N_{t}$ and $n_{i F}=n_{i} \exp \left(\frac{E_{t}-E_{i}}{k T}\right)$. Now putting the value of $f_{t}$ in equation 2.40, we will get the result for interface recombination that is expressed in equation 2.41 .

$$
\begin{gathered}
R_{i F}=S_{n}\left(1-\frac{S_{n} n+S_{p} p_{i F}}{S_{p}\left(p+p_{i F}\right)+S_{n}\left(n+n_{i F}\right)}\right)-S_{n} \frac{S_{n} n+S_{p} p_{i F}}{S_{p}\left(p+p_{i F}\right)+S_{n}\left(n+n_{i F}\right)} n_{i F} \\
R_{i F}=\frac{S_{n} S_{p}\left(n p-n_{i}^{2}\right)}{S_{n}\left(n+n_{i F}\right)+S_{p}\left(p+p_{i F}\right)} \\
R_{i F}=\frac{n p-n_{i}^{2}}{S_{p}^{-1}\left(n+n_{i F}\right)+S_{n}^{-1}\left(p+p_{i F}\right)}
\end{gathered}
$$

Where $\mathrm{p}_{\mathrm{iF}}$ concentration of hole at interface, $\mathrm{n}_{\mathrm{iF}}$ concentration of electron at interface, $(p=$

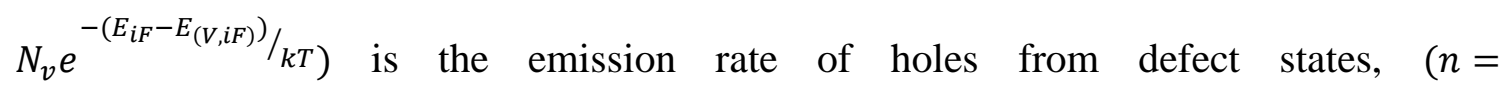
$\left.N_{c} e^{-\left(E_{(c, i F)}-E_{i F}\right)} / k T\right)$ emission rate of electrons from defect states, $\mathrm{S}_{\mathrm{p}}$ is hole interface recombination velocity, $S_{n}$ is electron interface recombination velocity and $R_{i F}$ is total interface recombination. Whereas $\left(S_{p}, S_{n}\right)$ are depended upon defect density at the interface $N_{t(i F)}$, capture cross section area for electron and hole at interface $\left(\partial_{n}, \partial_{p}\right)$ and thermal velocity of carries $v_{t h}$.

From equation 2.41 it is evident that surface/interface recombination loss is depending upon defect density and concentration of charges (electron, holes) at the interface. So, this loss can be reduced by introducing a passivation layer to avoid any lattice mismatch between absorber/buffer interface or by controlling band offset between the absorber/buffer interface. 


\subsubsection{Recombination at semiconductor and metal contacts}

When a metal makes a contact with the semiconductor, junction forms between the metal contact and semiconductor material at both ends such as front and back ends of the solar cell. Back contacts of a solar cell contribute more in the recombination process due to their wider contact area with the semiconductor material. Generated carriers are separated by an electric field of the depletion region needs to be collected at metal contacts to provide power to load. If generated carriers get recombines by defects in metal contact and semiconductor material, then power conversion efficiency of solar cell is affected [34]. Passivation of back contact or creating a strong electric field at back contact can reduce surface recombination velocity and recombination process. The strong electric field at rear contact can sweep those generated carriers very quickly. The electric field at the back contact can be created by heavily doping the semiconductor near the contact region. This high doping at rear contact will create a back-surface field (BSF) as shown in Figure 2.25. This field helps in the improvement or enhancing the efficiency of a solar cell $[35,36]$.

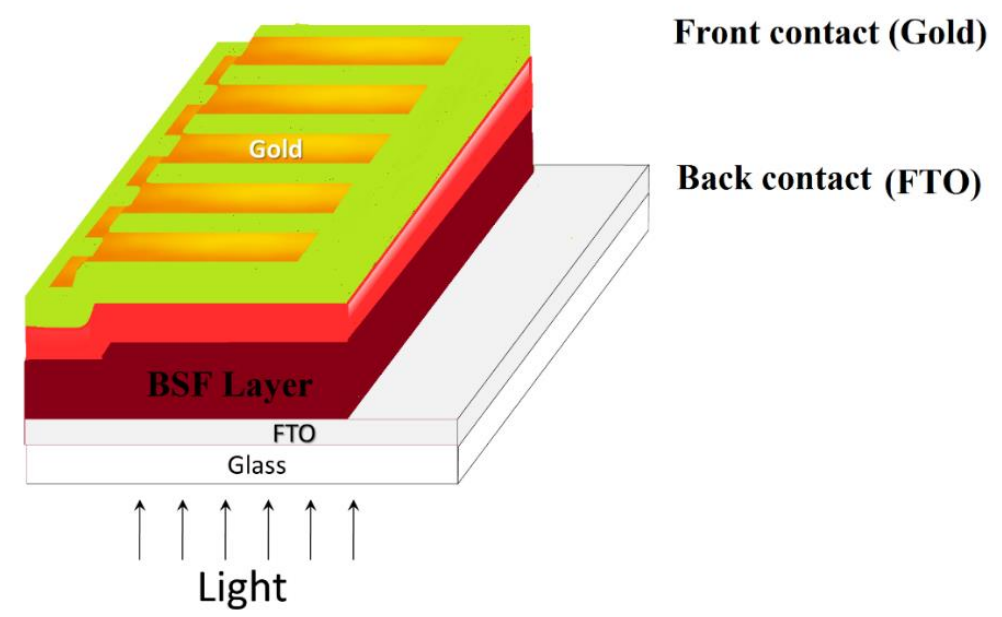

Figure 2.25: BSF layer at back contact

\subsection{Effect of minority charge carrier mobility on recombination}

The mobility of the charge carrier of bulk semiconductor material can seriously affect the performance of a solar cell [37]. It also plays a key role in defining the diffusion length of minority carriers $\left(L_{\text {diff }}\right)$. Diffusion length is average length scale over which it can travel in semiconductor material before recombining. Minority carrier diffusion length is defined in equation 2.42 .

$$
L_{\text {diff }}=\sqrt{D \tau}
$$


Where, $\mathrm{D}$ is the diffusion coefficient and $\tau$ is minority carrier lifetime. $\mathrm{D}$ is depended upon an elementary charge of the carrier (q), environment temperature (T), Boltzmann's constant k and mobility of carrier $\mu$. Relationship of $\mathrm{D}$ is given in equation 2.43 .

$$
D=\mu \frac{k T}{q}
$$

So, putting the value of equation 2.43 in equation 2.42 it will become as given in equation 2.44 .

$$
L_{\text {diff }}=\sqrt{\mu \frac{k T}{q} \tau}
$$

From equation 2.44 , the mobility of minority carriers will greatly affect the diffusion length. With an increase in mobility, the probability of collection of photogenerated charge carrier at the terminals will increase and thus contributing in enhanced photocurrent for a solar cell. whereas a reduction in mobility will cause degradation in solar cell performance. 
This page intentionally left blank 
CHAPTER 3

SOLAR CELL TECHNOLOGY 
This page intentionally left blank 


\subsection{Solar cell}

The photovoltaic cell or solar cell is an electronic device, which converts solar radiation into electrical energy. The solar cell has major two operations: generation of photogenerated charge carrier (holes and electrons) in absorption layer and separation and collection of these charge carrier at their respective metal contacts. The working principle is based on the photovoltaic effect. Practically for the photovoltaic energy conversion of solar radiation, semiconductor materials are used in a form of pn junction. Structure of a solar cell is can be well understood from Figure 3.1. As discuss in the previous chapter that, the basic steps in the operation of a solar cell are:

i. Generation of photogenerated carriers

ii. Generation of current via collection of photogenerated carriers.

iii. Generation of a large voltage across the solar cell.

iv. Power dissipation at the load.

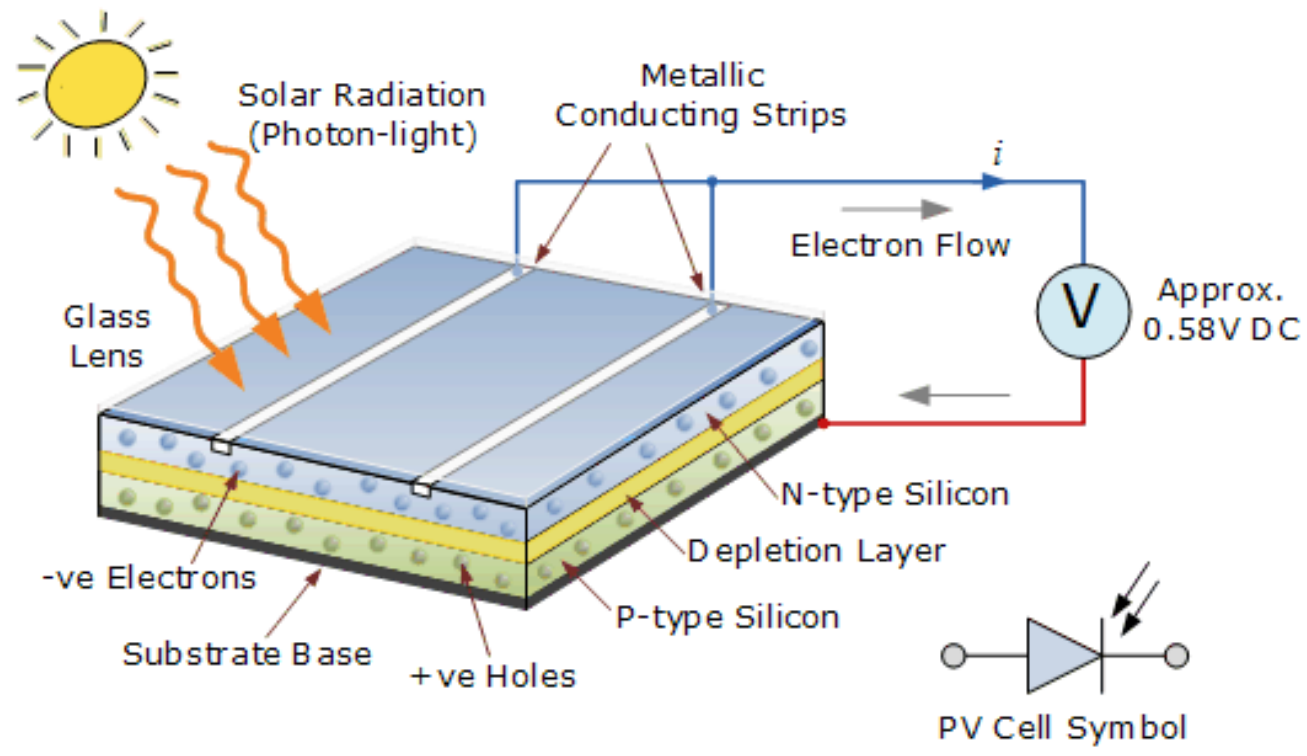

Figure 3.1: Cross section of solar cell [38]

In Figure 3.1 silicon-based solar cell is taken for a better understanding of the construction and working operation of a typical photovoltaic cell. $p$-type silicon works as an absorber layer and $\mathrm{n}$ type silicon as a window layer. $p$-type silicon has the positively charged majority carriers know as holes whereas n-type silicon has the negatively charged majority carriers know as electrons. Both sides of solar cells have conductive surface named as back metal contact and the front metal contact. Photogenerated current flows through the external circuit by using these front and back metal contacts. When solar radiation or photo 
light falls on the solar cell, carriers (holes and electrons) are generated. These generated carriers are also known as photogenerated carriers and moves towards their respected layers and metal contacts. Due to this, output voltage appears across the solar cell. If we connect the load or any measuring instrument, current flow is started [39].

\subsection{Solar cell historical facts}

Energy plays a crucial role in the socio-economic growth of humanity. To fulfill the energy demands, natural gas, coal, and oil are used. These fossil fuels are too expensive to generate and fulfill the energy demands. Another demerit of using these fossil fuels are the

emission of gases or fumes, which disrupts the greenhouse effect and the cause of global warming and also produce soil, air and water pollution. Globally energy demands increase continuously and with the rise in energy production, pollution also increases. The rising energy demands are the main cause of exploring and developing new energy sources. The energy crisis is managed easily by using renewable energy resources. Renewable energy resources are mainly consisting of hydrogen, geothermal, hydropower, solar, wind and biomass sources. These sources are not emitting pollution and help to reduce carbon emission. Solar energy is one of the best renewable energy sources to full fill the energy demands because it's a nature free gift for human mankind. Solar energy provides lowcost, abundant and clean electricity without emitting harmful waste and fumes. Photovoltaic cells are used for the generation of electricity from solar energy.

American Physical Society explains the history of a solar cell in its publication "APS News" volume 18, issue 4 in April 2009 [40]. According to APS news antiquity of solar cell is based on French physicist Alexandre-Edmond Becquerel observations of the photovoltaic effect in 1839. He was working with metal electrodes in an electrolyte solution. Where he perceived that when the metals were exposed to light then small electric currents were produced but he couldn't explain that effect. In 1873 English engineer named Willoughby Smith testing materials for underwater telegraph cable and discovered the photoconductivity of selenium. Charles Fritts was an American inventor and in 1883 he designed the first selenium based solar cells. He hoped that his solar cells will compete the coal-fired power plant designed by Edison's, but the efficiency of a cell was less than $1 \%$ to convert the sunlight energy to electrical energy. So, this design was not very practical.

The next major advancement in solar cell technology was made in 1940 by Russell Shoemaker Ohl, a semiconductor researcher at Bell Laboratories. He was working on 
silicon samples, one of the samples was crack at the center. He investigated that sample and observed that when light falls on it then current flow started. The cracked was expected to form at the boundaries between the regions containing different levels of impurities, so one side was positively doped and the other one was negatively doped. He made a $p-n$ junction unintentionally, the basics of a solar cell. Ohl patented his solar cell and the conversion efficiency was about $1 \%$. After thirteen years, the first silicon-based practical solar cell was made by scientist's team working at Bell Labs. Engineer Daryl Chapin was working on the telephone power source to use in remote locations in 1953 at Bell Labs. He tried different alternative energy sources and after investigating he got that solar power is one of the most promising power sources for this application.

At the same time, a physicist, Gerald Pearson, and a chemist, Calvin Fuller were working on silicon piece containing impurities of gallium. They dipped silicon piece in lithium, producing a p-n junction. An ammeter was hooked up to silicon by them and shined the light on it. The ammeter surprised them by jumping significantly. Pearson was already informed of Chapin's work, and he discussed with his friend not to waste time on solar cell of selenium, after that Chapin's, switched to work on silicon. Afterward, they all worked to improve their solar cell properties. They were facing two issues in their work first issue was producing good electrical contacts; the other problem was that over time lithium migrated through the silicon at room temperature and moves away from sunlight. To solve these problems they tried different impurities, finally arsenic and boron were selected these elements created p-n junction stayed close to surface, also they found that with boron-arsenic and silicon cells they can make good electrical contacts. After some other improvements, they linked some solar cells to create a solar battery. On April 25, 1954, Bell Labs announced the invention in Murray Hills, New Jersey. The solar panel was demonstrated by using it to power a solar power radio transmitter and Ferris wheel a small toy. It was a huge improvement of silicon solar cells over earlier solar cells that they were about 6 percent efficient at converting sunlight energy into electricity.

The first silicon solar cell was expensive to produce, and the initial efforts to commercialize were not an enormous success at the beginning. But within a few years, solar cells were used commonly to power satellites and other application. Chapin soon simplified silicon solar cell making process and developed experiment of solar cell science for high school students [40]. 


\subsection{Generations of solar cells}

Traditionally solar cells are separated into three generations.

\section{First Generation solar cells}

First generation $(1 G)$ of solar cells is mainly based on silicon wafers and typically the power conversion is about $15-20 \%$. Generally, in comparison of non-silicon based solar cells, this solar cell technology is more efficient and of longer life but at the higher temperature, they are more peril to lose some part of their efficiency. Currently, four types of silicon-based photovoltaic cells are commercially used for the manufacturing of solar panels. These types are monocrystalline, polycrystalline, amorphous and hybrid solar cells. These types are discussed in detail in the next section $[41,42]$.

\subsubsection{Second Generation solar cells}

Second generation $(2 G)$ of solar cells are based on amorphous silicon and non-silicon materials namely copper indium gallium selenide (CIGS) and cadmium telluride (CdTe), where typically the power conversion efficiency is about $10-15 \%$. Use of silicon wafers are avoided in second generation solar cell and consumption of lower material reduces the production cost of $2 G$ solar cells in comparison of the first-generation solar cell. This cell generation class is also known as thin film solar cells because of using only few micrometer thicknesses of different layer materials in comparison of crystalline siliconbased cells. This type of technology is commercially using because of lower manufacturing cost and using less material. The second-generation solar cells production is still limited due to the use of rare elements and high-temperature treatments. So, the production cost is less than the first generation solar cell but still higher than other technologies $[41,42]$.

\subsubsection{Third Generation solar cells}

In this new technology solar cells are made from the variety of new materials rather than using silicon such as solar inks using in printing technology, silicon wires, nanotubes, conductive plastics, and organic materials. The goal is to improve the commercially available solar cell by enhancing the efficiency and to reduce the cost to make them economical. So, more peoples will use this solar cell technology. Polymer solar cells are a subcategory of organic solar cells. Third generation solar cells are expensive highperformance multijunction experimental solar cells. Mostly the work is done in laboratories and not commercially available. Currently new class of thin film solar cells 
under investigations are perovskite solar cells and quaternary compounds material based solar cells such as kesterite solar cells. These types of devices show an enormous potential with record power conversion efficiency of about $20 \%$ on a very small area. Polymer solar cells are fabricated by roll to roll $(R 2 R)$ technology and can be compared to the newspaper printing. In the comparison of first and second-generation solar cells, third generation solar cells are limited but they have great potential. Recently research interest is significantly increases in polymer solar cells.[43]

\subsection{Different types of solar cells}

Solar cells are divided into two major groups. They are silicon semiconductor type and non-silicon type. The details are as follows.

\subsubsection{Silicon semiconductor type solar cells}

There are three major types of silicon semiconductor photovoltaic cells, which are used to create panels.

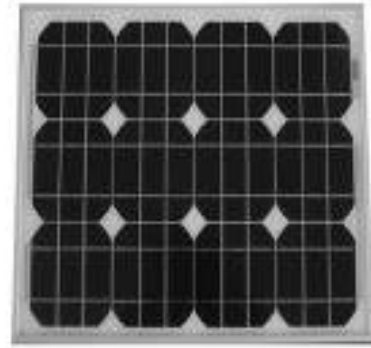

Mono Crystalline

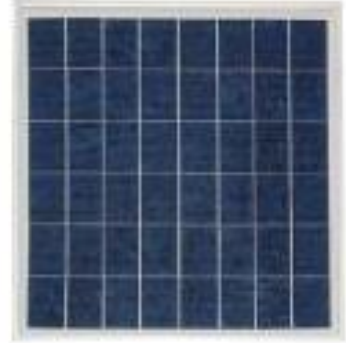

Poly Crystalline

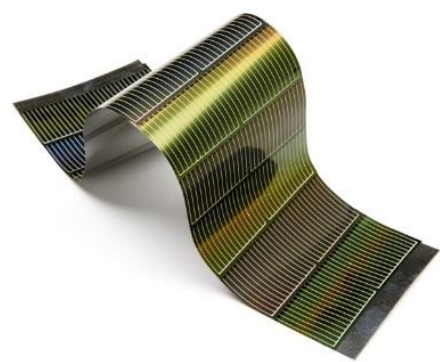

Thin film

Figure 3.2: Types of photovoltaic solar cells

\subsubsection{Monocrystalline solar cell}

These types of solar cells belong from first-generation solar cell technologies. The width of the wafer used in these types of solar cells is up to $200 \mu \mathrm{m}$. The cell slice is cut from a pure silicon bar, which allows them to more efficiently converting the sunlight radiation energy into electrical energy. Silicon used in monocrystalline is single-crystal silicon. The complete cell is aligned in the same direction, so when the light falls on the cells at the accurate direction, they are very efficient. In a sunny day, photovoltaic cells work best with the sunlight directly falls on accurate direction. They are absorbing most of the solar radiation, so they have a uniform blacker color. Cost of the production of these types of solar cells is more than in the comparison of a polycrystalline cell. In a comparison of polycrystalline, monocrystalline is the most efficient type of photovoltaic solar cells. 


\subsubsection{Polycrystalline solar cell}

These types of solar cells also belong from first-generation solar cell technologies. These cells are made up of several silicon cells joined together instead of using a single crystal of silicon. In general, the cost of production of a polycrystalline solar cell is not much higher than monocrystalline. Therefore, they are also more affordable. In comparison with a monocrystalline solar cell, the power conversion efficiency of polycrystalline solar cell is less. Their overall manufacturing design can often make up for the efficiency loss.

\subsubsection{Amorphous solar cell}

Amorphous silicon $(a-S i)$ solar cells belong from a thin-film solar cell. In these types of solar cells, one or more layers of photovoltaic materials are deposit on a substrate. In comparison with other technologies, they have low manufacturing cost. To make thin-film photovoltaic solar cells, manufacturers spray a layer of silicon on a substrate. They are produced by placing one or more thin layers of photovoltaic composite on a substrate. Thin film photovoltaic solar cells are different from other types; they are also more flexible than other types. It can be put onto different surfaces i.e. curved and straight.

\subsubsection{Other types of solar cell}

Above discussed, silicon-based solar cells are most commonly used solar cells. There are some other types such as (CIGS) and cadmium telluride (CdTe) based solar cells, kesterite and perovskite solar cells, which are also used due to their good conversion capabilities, earth-abundant materials, and enhanced power conversion efficiencies. These types of photovoltaic solar cells are deliberated in detailed in the next section.

\subsection{Thin film solar cells}

Thin film photovoltaic solar cells belong from second and third generation solar cell technology. These types of solar cells are manufactured by depositing one or more layers of photovoltaic materials on a metal, plastic or glass substrate. Commercially thin film photovoltaic solar cells are used in various technologies, such as copper indium gallium selenide (CIGS), cadmium telluride (CdTe), kesterite and perovskite solar cell technologies. The film thickness of these types of solar cells varies from few nm to tens of $\mu \mathrm{m}$ due to this, these types of solar cells are flexible and lower in weight. Thin film technology is cheaper than other technologies because of devices have relatively less material. 
Thin film photovoltaic technologies are based on various types of light absorbers semiconductor materials. The absorption coefficient of these types of materials is higher than crystalline materials. Therefore, a very thin layer of the absorber layer is sufficient for the effective absorption of sunlight. Historically in the thin film technology, amorphous silicon-based solar cells played a momentous role. Now a day's researchers move towards cadmium telluride (CdTe) and copper indium gallium selenide (CIGS) based thin film devices because of their high efficiency and good performance and reached in the commercial stage. In research and development scale these technologies have power conversion efficiency up to $18 \%$ [44] while commercially they have a conversion efficiency of 14-16\% [45,46]. For the fabrication and development of low cost and sustainable thin film photovoltaic cells kesterite based absorber materials are intensively studies such as copper zinc tin sulfide $\mathrm{Cu}_{2} \mathrm{ZnSnS}_{4}(\mathrm{CZTS})$, Copper zinc tin selenide $\mathrm{Cu}_{2} \mathrm{ZnSnSe}_{4}(\mathrm{CZTSe})$ and sulfur-selenium alloy $\mathrm{Cu}_{2} \mathrm{ZnSn}\left(\mathrm{S}_{x} \mathrm{Se}_{1-x}\right)_{4}$ (CZTSSe) [4753]. These materials drawing attention because of their good optical properties for photovoltaic applications [54]. These absorber materials are copper based nontoxic semiconductor materials [55]. They are the good replacement for the chalcopyrite absorbers by replacing indium (In) with comparatively inexpensive $\operatorname{zinc}(\mathrm{Zn})$ and gallium $(G a)$ with tin $(S n)$ in the CIGS absorbers [6-8]. The outstanding features and efficient performance of these kesterite based materials made them very fascinating in the thin film's community [56,57].

\subsection{Current research trends}

The power conversion efficiency of different types of solar cells is improved with the passage of time. Primarily semiconductor-based photovoltaic devices are of four types such as crystalline silicon $(C-S i)$ cells, multijunction cells, thin film technologies-based cells, and new emerging technologies-based cell. The worldwide research-based different types of PV technologies having the best power conversion efficiencies from 1976 to 2018 are shown in Figure 3.3. This information chart was published by National Renewable Energy Laboratory (NREL) of the United State Department of energy. In a given chart different color schemes shows different technologies, which are given in Table 3.1. Current trends in the research on thin film technology based photovoltaic devices are:
i. CIGS solar cells
ii. CdTe solar cells
iii. CFTS solar cells 
iv. Kesterite solar cells

v. Perovskite solar cells

Table 3.1: Device technologies

\begin{tabular}{|c|c|c|c|}
\hline No. & Color & Device Type & Description \\
\hline 1 & & Multi-junction cells & $\begin{aligned} \text { i. } & \text { Gallium Arsenide (GaAs) } \\
\text { ii. } & \text { Solar panels on spacecraft } \\
\text { iii. } & \text { Concentrator PV }\end{aligned}$ \\
\hline 2 & & Crystalline Si Cells & $\begin{array}{cl}\text { i. } & \text { Single crystal } \\
\text { ii. } & \text { Multi crystalline }\end{array}$ \\
\hline 3 & & Thin-Film Technologies & $\begin{aligned} \text { i. } & \text { Amorphous } S i \\
\text { ii. } & \text { CIGS } \\
\text { iii. } & \text { CdTe }\end{aligned}$ \\
\hline 4 & & Emerging PV & $\begin{aligned} \text { i. } & C Z T(S, S e) \text { based solar cells } \\
\text { ii. } & \text { Dye-sensitized solar cells } \\
\text { iii. } & \text { Quantum dot solar cells } \\
\text { iv. } & \text { Organic solar cells } \\
\text { v. } & \text { Perovskite solar cells }\end{aligned}$ \\
\hline
\end{tabular}




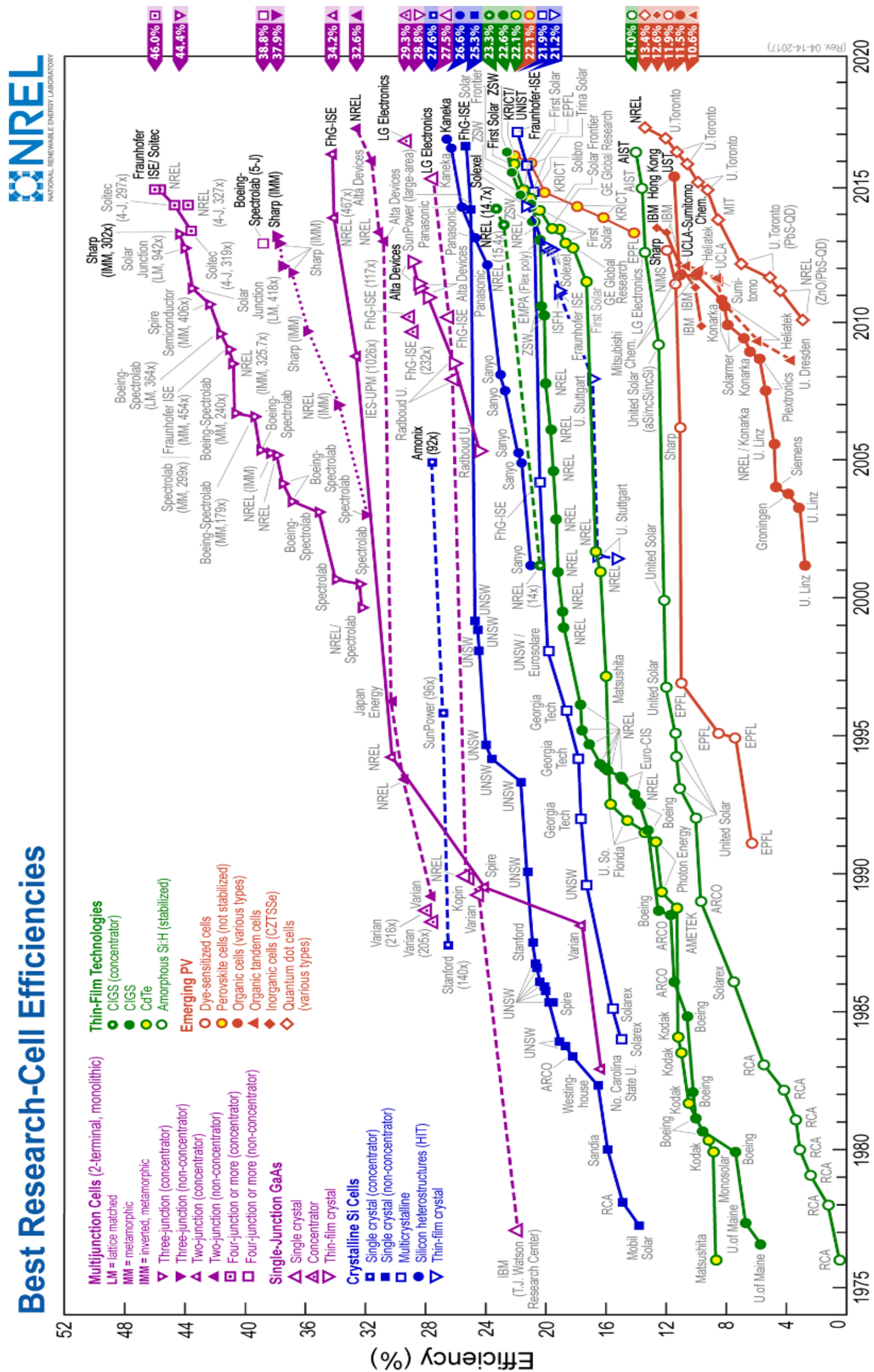

Figure 3.3: Conversion efficiencies of best research solar cells (NREL) [58] 
This page intentionally left blank 


\section{CHAPTER 4}

NUMERICAL MODELING 
This page intentionally left blank 


\subsection{Numerical modeling}

Numerical modeling or analysis is a computer simulation program which uses the mathematical model for the implementation of a physical system. Numerical modeling is the tool to study the system behavior having complex mathematical models and helps provide analytical solutions. It is an essential tool for better understanding of the working parameters of any device. Numerical analysis can play a significant role in the manufacturing and fabrication of efficiently working semiconductors based photovoltaic devices. For design engineers and researchers, the highest priority job of numerical modeling techniques implementation is the integration of real-life problem with virtual machine environment because of finding the optimum and efficient ways for solving a complex problem. The precious time is saved due to performing the real design problem in computer-based tests environments without physical or practical implementation, so research institutions and universities emphasize computer-based learnings techniques. The modeling techniques are used to compute the fundamental physical properties such as holes and electrons concentration and electrical potential. It also provides more information regarding the influence of material physical parameters on device functional parameters or characteristics. For the numerical modeling of solar cells, physical parameters of material are taken as input for the simulation software. To translate the practical or real device $J-V$ characteristics and functional parameters such as power conversion efficiency, fill factor, open circuit voltage and short circuit current in device modeling, it is mandatory to take experimental data. Numerical simulation provides a better and easier way to understand the device behavior. For the better understanding of the performance of a device, the simulation software that can be used for device modeling must be able to solve semiconductor basic equations like continuity equation for holes and electrons and the Poisson equation relating the charge to electrostatic potential. [59,60].

\subsection{Basic semiconductor equation}

To analyze the performance of the solar cell, device simulation software must be able to solve the basic semiconductor equations. In device performance, these equations play a crucial role. The Poisson equation relating the charge to electrostatic potential is the governing equation. Poisson's equation for electrostatic potential $(V)$ is given in equation $4.1[61]$.

$$
\frac{d^{2} V}{d x^{2}}=\frac{\rho}{\varepsilon}
$$


Where $\varepsilon$ is the product of permittivity of free space $\varepsilon_{0}$ and semiconductor dielectric constant $k_{s}$ i.e. $\left(\varepsilon=\varepsilon_{0} k_{S}\right)$ and $\rho$ is the density of charge $\left(C / \mathrm{cm}^{3}\right)$ and.

From charge neutrality equation $\rho$ can be expressed as given in equation 4.2 with an assumption that dopant is totally ionized.

$$
\rho=q\left(p-n+N_{D}^{+}-N_{A}^{-}\right)
$$

Where $\mathrm{q}$ is electronic charge, $\mathrm{p}$ is concentration of holes, $\mathrm{n}$ is concentration of electrons, $N_{A}^{-}$ionized acceptor dopant carrier concentration and $N_{D}^{-}$is ionized donor dopant carrier concentration. By putting equation 4.2 in equation 4.1 it will become as equation 4.3.

$$
\frac{d^{2} V}{d x^{2}}=\frac{q\left(p-n+N_{D}^{+}-N_{A}^{-}\right)}{\varepsilon}
$$

and to solve equation 4.3 for $\mathrm{V}$ as a function position value of $\mathrm{x}$ one must have to rearrange the expression for the concentration of carriers $(\mathrm{p}, \mathrm{n})$.

The second equation is a continuity equation, the reason that the continuity equation is called governing equation because drift, diffusion, generation, and recombination are analyzed simultaneously. Equation 4.4 and equation 4.5 represent continuity equation for concentration change in electron and hole.

$$
\begin{aligned}
& \frac{\partial n}{\partial t}=\frac{1}{q} \frac{\partial J_{n}}{\partial x}+\left(G_{n}-R_{n}\right) \\
& \frac{\partial p}{\partial t}=\frac{1}{q} \frac{\partial J_{p}}{\partial x}+\left(G_{p}-R_{p}\right)
\end{aligned}
$$

The output from equations 4.1, 4.4 and 4.5 have non-linear dependencies on charge carrier concentration $(\mathrm{p}, \mathrm{n})$. Therefore, these equations will be solved with numerical techniques with standard approaches like the discretization of an equation, discretization of device and set of boundary conditions.

To measure the current and characteristics of solar cell simulator must be able to solve drift-diffusion equation for current in a solar cell. The drift-diffusion equation of charge carriers is given in equation 4.6 and equation 4.7 [62].

$$
\begin{aligned}
& J_{n}=q \mu_{n} n \epsilon+q D_{n} \partial n \\
& J_{p}=q \mu_{p} p \epsilon-q D_{p} \partial p
\end{aligned}
$$

$J_{n}$ and $J_{p}$ are the current densities for electron and holes, $\mu_{n}$ and $\mu_{p}$ are mobility of carriers, $D_{n}$ and $D_{p}$ are diffusion coefficient of electrons and holes and from Einstein 
relationship, the diffusion coefficient is depended upon the mobility of carrier with the product of carrier lifetime. Relation of $D_{n}$ with the mobility of carrier is given in equation 4.8 .

$$
D_{(n, p)}=\sqrt{\mu_{(n, p)} \frac{k T}{q} \tau_{(n, p)}}
$$

To find the solution for equations $4.3,4.4$ and 4.5 other quantities needed like generation and recombination $(G, R)$ and this can also be expressed as net recombination in a device $(U)$. That is represented in equation 4.9 for $n$-type semiconductor.

$$
U=\frac{p-p_{0}}{\tau_{p}}
$$

\subsection{Photovoltaic device modeling tools}

Principally solar cell modeling tool can be capable to solve the basic semiconductor equations such as Poisson equation and continuity equation. To simulate the realistic cells, numerous additional requirements must be met by the device modeling software. They must be able to simulate multiple layers. Simulation tool should be able to give the response and correctly treats the recombination problem and, on an interface, and different layers defects. The modeling software must be able to calculate and simulate the electrooptical measurements under illumination and dark conditions, and this is not only JV characteristics but also the capacitance and spectral response.

To measure and analyze the different solar cell parameters, numerous tools are available and efficiently used for device modeling. Engineers and researchers are using different types of photovoltaic simulation software's in their research centers and in universities [63]. Most commonly used software's are enlisted below.

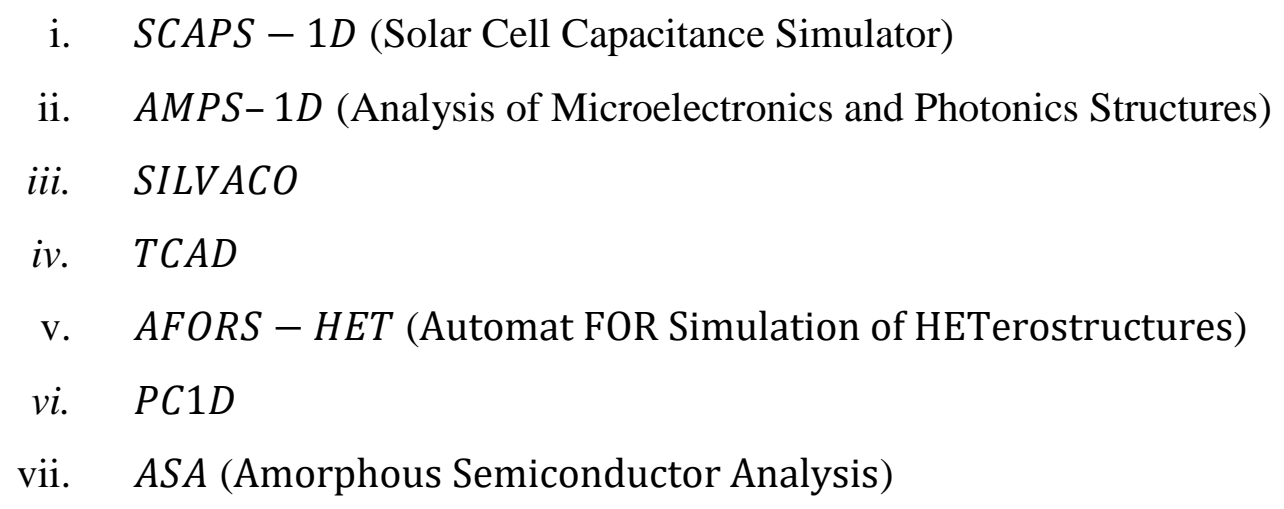

We use $S C A P-1 D$ software for my research work because of the extensively available literature on PV device modeling and analyzing the performance. 


\subsection{SCAPS-1D}

Solar Cell Capacitance Simulator (SCAPS) program developed at the University of Gent, Belgium is used to simulate the photovoltaic devices. Several researchers have contributed to its development such as Alex Niemegeers, Marc Burgelman, Koen Decock, Stefaan Degrave, Johan Verschraegen. SCAPS $-1 D$ is the one-dimensional simulation program for the modeling of PV devices. Seven different semiconductor layers exclusive of back and front contacts are possible to take as input in SCAPS $-1 D$ software. SCAPS $-1 D$ tool is freely available for the photovoltaic research community and can be freely downloaded from its web link. It runs on a window operating system environment. This software is designed to simulate and helps us to analyze the $J-V$ characteristics curve, ac characteristics $(C-V$ and $C-f)$, spectral response $(Q E)$ of a device, power conversion efficiency $(P C E)$, fill factor $(F F)$, short-circuit current $\left(J_{s c}\right)$, open circuit voltage $\left(V_{o c}\right)$, energy bands of materials used in solar cell and concentration of different material used by solving the semiconductor basic equations [60,64,65]

\subsubsection{Parameters}

For device modeling, input parameters or physical parameters are the fundamental requirements to solve the basic semiconductors equations. The physical parameters used in $S C A P S-1 D$ software for numerical analysis are layer thickness, electron-hole mobility, intrinsic carrier concentration, electron affinity, band gap and doping density of absorber, buffer and window layers, which are enlisted in Table 4.1. Where $N_{v}$ is the valence band effective density of state and $N_{c}$ is the conduction band effective density of states in $\mathrm{cm}^{-3}$. $\mathrm{p}$ is the hole concentration and $\mathrm{n}$ is electron concentration in $\mathrm{cm}^{-3}, \mathrm{~W}$ is the thickness in $\mu \mathrm{m} . \chi$ is the electron affinity in $e V, \mathrm{E}_{\mathrm{g}}$ is the bandgap in $\mathrm{eV}, \mu \mathrm{e}$ is the electron mobility in $\mathrm{cm}^{2} / V s, \mu_{\mathrm{p}}$ is the hole mobility in $\mathrm{cm}^{2} / \mathrm{Vs}$, All the simulations are conducted under $1.5 \mathrm{AM}$ solar radiation with the power density of $100 \mathrm{~mW} / \mathrm{cm}^{2}$ is used as the illuminating source. Functional parameters of solar cells are given in Table 4.2.

The device creation has two common objectives. First is the understanding and verification of real device behavior and the second one is the simulation of a device for given physical parameters and predicting the outcomes for those parameters. A good device modeling is defined by the behavior of the reference device (s) was how much well simulated. For the creation of device modeling, physical or input parameters are collected form referenced device experimental data. SCAPS offers a single simulation of $J-V$ characteristics curve, ac characteristics $(C-V$ and $C-f)$ and spectral response $(Q E)$ and advance batch 
simulations by varying the input parameters. Predefined physical parameters such as carrier concentration densities and layer thickness are monitor and analyze with the help of batch simulations. J - V characteristics curve, band alignment diagram, spectral response and other functional parameters such as $P C E, F F, J_{S C}$ and $V_{o c}$ are taken as output from SCAPS-1D software, which is very helpful for the fabrication of an efficient photovoltaic device. All measurements are calculated for illuminated or dark condition and as a function of temperature. Temperature-dependent parameters are the thermal velocity and effective density of states whereas band gap and mobility are temperature independent parameters. Shockley-Read-Hall ( $S R H)$ formalism is used for recombination at the interface states and in deep bulk level and their occupation.

Table 4.1: Physical parameters for numerical modeling.

\begin{tabular}{clcc}
\hline No. & Parameters & Abbreviation & Unit \\
\hline 1 & Layer Thickness & $\mathrm{W}$ & $\mu \mathrm{m}$ \\
2 & Bandgap energy & $\mathrm{E}_{\mathrm{g}}$ & $\mathrm{eV}$ \\
3 & Conduction band effective density of states & $\mathrm{N}_{\mathrm{c}}$ & $\mathrm{cm}^{-3}$ \\
4 & Valence band effective density of states & $\mathrm{N}_{\mathrm{v}}$ & $\mathrm{cm}^{-3}$ \\
5 & Dielectric permittivity & $\varepsilon_{\mathrm{r}}$ & - \\
6 & Electron affinity & $\mathrm{X}$ & $\mathrm{eV}$ \\
7 & Hole mobility & $\mu_{\mathrm{p}}$ & $\mathrm{cm}^{2} / \mathrm{Vs}$ \\
8 & Electron mobility & $\mu_{\mathrm{e}}$ & $\mathrm{cm}^{2} / \mathrm{Vs}$ \\
9 & Electron doping concentration & $\mathrm{N}$ & $\mathrm{cm}^{-3}$ \\
10 & Hole doping concentration & $\mathrm{P}$ & $\mathrm{cm}^{-3}$ \\
11 & Absorption coefficient & $\mathrm{A}$ & $\mathrm{cm}^{-1}$ \\
12 & Bulk defect concentration & $\mathrm{N}_{\mathrm{T}}$ & $\mathrm{cm}^{-3}$ \\
13 & Capture cross-section & $\Sigma$ & $\mathrm{cm}^{2}$ \\
14 & Defect energy level & $\mathrm{E}_{\mathrm{T}}$ & $\mathrm{eV}$ \\
15 & Metal work function & $\Phi_{\mathrm{M}}$ & $\mathrm{eV}$ \\
\hline
\end{tabular}

Table 4.2: Functional parameters.

\begin{tabular}{clcc}
\hline No. & Parameters & Abbreviation & Unit \\
\hline 1 & Power Conversion Efficiency & PCE, $\eta$ & $\%$ \\
2 & Short circuit current & $\mathrm{J}_{\mathrm{sc}}$ & $\mathrm{mA} / \mathrm{cm}^{2}$ \\
3 & Open circuit voltage & $\mathrm{V}_{\mathrm{oc}}$ & $\mathrm{v}$ \\
4 & Fill factor & $\mathrm{FF}$ & $\%$ \\
\hline
\end{tabular}




\subsubsection{SCAPS startup panel interface}

$S C A P S-1 D$ simulator, startup panel interface is shown in Figure 4.1. Several sections of the panel are number from 1 to 6 .

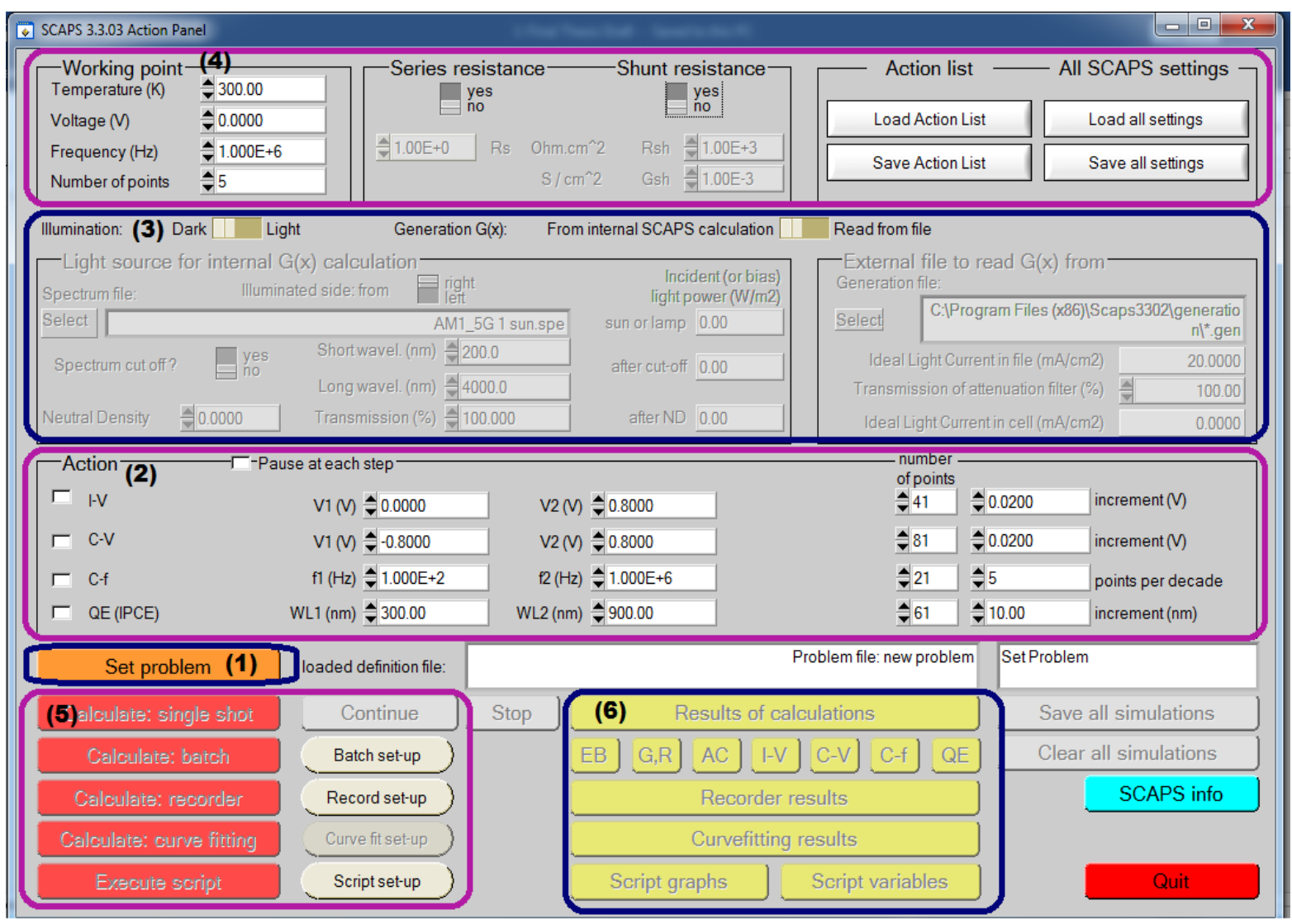

Figure 4.1: SCAPS - 1D simulator startup panel interface

Overview of these sections is as follows.

i. Section 1 is "Set problem" for the problem definition of the structure of a solar cell. Problem definition mainly having the details about the physical properties of different device layers. By clicking on the button "Set problem" another panel is open, where we define different layer physical properties.

ii. Section 2 is "Action" pane for different measurements of simulations and reading scale settings. This section includes $I-V$ characteristics scale settings and calibration, Quantum efficiency $(Q E)$ measurements, capacitance-voltage $(C-V)$ measurements and capacitance frequency $(C-f)$ measurements. Start and end values of argument and number of steps are adjusted if required.

iii. Section 3 is "Illumination" for the selection of light and dark condition for simulation and spectrum standards.

iv. Section 4 is "Working point" for settings of working temperature values and addition of series or shunt resistances if required. 
v. Section 5 is for single shot calculations, batch calculations and curve fitting for a simulated device. Batch values and their parameters are also selected here.

vi. Section 6 "Result of calculations" for the measurement and displaying of simulated device results such energy band $(E B), I-V, Q E, C-V$, and $C-f$ characteristics.

\subsubsection{Problem definition interface}

Problem definition mainly having the details about the physical properties of different device layers. By clicking on button "Set problem" another interface is open, where we define different layer physical properties. This interface is also named as "Device Definition Interface" and shown in Figure 4.2. This interface plays a significant role in device simulation because of defining or setting different layers of physical parameters and device structure visualization.

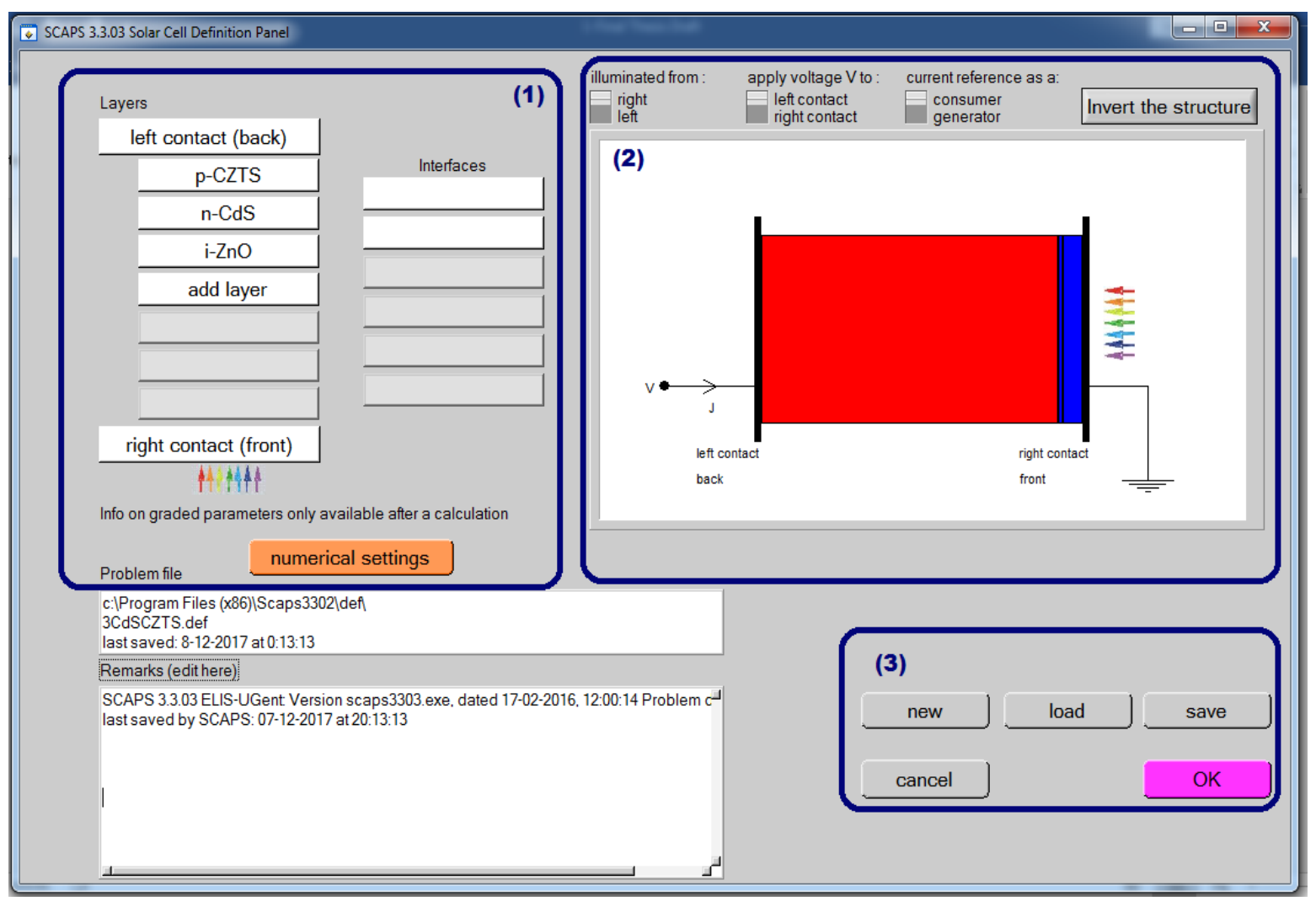

Figure 4.2: Device definition interface

There are three parts of device definition interface and details of these sections are as following.

i. Section 1 is for the definition of a different layer of device structure with front and back contact. We can simulate a maximum of 7-layers structured device in SCAPS software. 
ii. Section 2 is for display or visualization of defined photovoltaic device structure with back and front contact. Additional buttons are for the selection of illuminating the device either from back contact side or front contact side, the voltage applied to a device and current reference.

iii. Sections 3 having buttons for saving definition file in SCAPS library and loading of device structure definition files. Cancel and OK buttons are for leaving or entering device definition interface and return the user in startup interface.

\subsubsection{Adding device structure layers}

Adding or defining layers in $S C A P S-1 D$ software for modeling of $P V$ device is done by clicking on the button "add layer" given in section 1 of Figure 4.2. By clicking the button layer properties interface will be open. We set or add the layer physical parameter values in layer properties interface. The interface is shown in Figure 4.3.

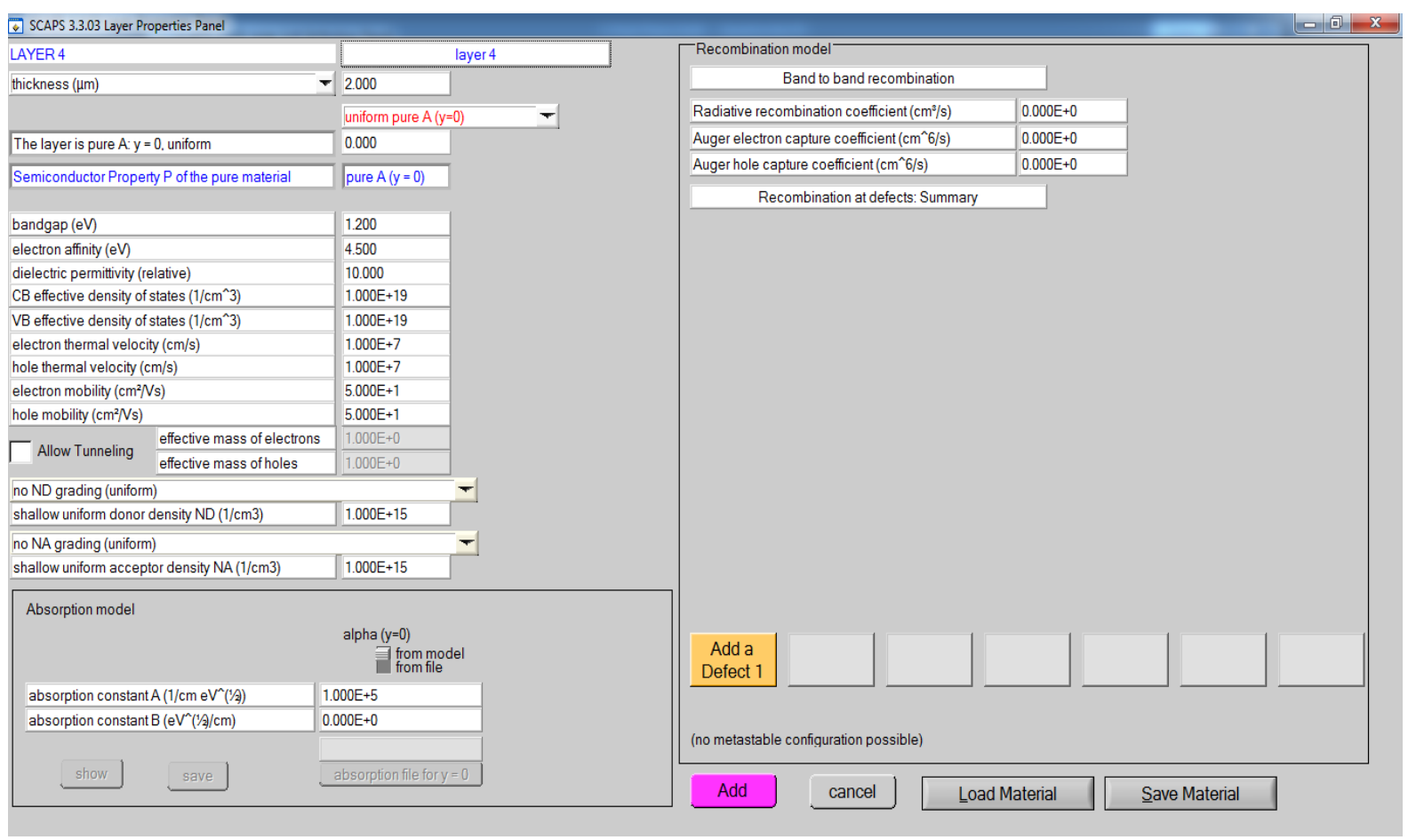

Figure 4.3: Layer properties panel

Numerical modeling or analysis of defined device structure is performed in $S C A P S-1 D$ software after defining physical parameters of all layers such as absorber layer, buffer layer, and the window layer. Effect of different layers physical parameters on the photovoltaic device performance are analyzed. These physical parameters are absorber and buffer layer thicknesses, their doping concentrations and operating temperature. 


\subsection{Numerical modeling of $\boldsymbol{C G S}$ solar cell [66]}

Electrical characteristics of a photovoltaic cell are analyzed by simulating the device in SCAPS software. Numerical modeling of $C G S / C d S / Z n O$ solar cell is explained in this section. Different parameters, which affects the device performance are also explained. Band gap energy of CGS absorber is smaller than CdS, so photon absorption in CGS layer is higher. Overall photovoltaic conversion efficiency and open circuit voltage $\left(V_{o c}\right)$ of thin film $P V$ cell are increases due to the photon absorption. Results taken from this analysis gives a valuable guideline for the fabrication of CGS based high-efficiency solar cell. An output of a PV device is highly depended on the parameters such as the concentration of charge carriers, temperature, device thickness and also on optical and electrical properties. The structure $C G S / C d S / Z n O$ photovoltaic cells is shown in Figure 4.4. The obligatory physical input parameters for the modeling of $C G S$ based $P V$ device use in the SCAPS $-1 D$ simulation environment is presented in Table 4.3 and 4.4.

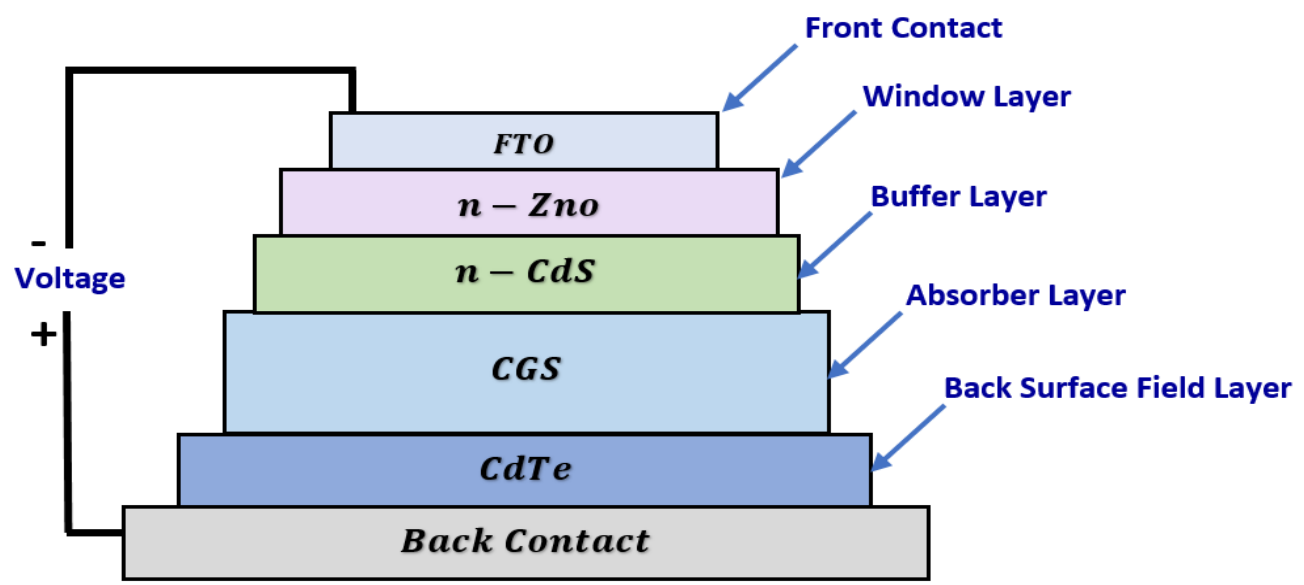

Figure 4.4: Block diagram of $C d T e / C G S / C d S / Z n O$ solar cell

Table 4.3: Simulation parameters.

\begin{tabular}{lcccc}
\hline \multicolumn{1}{c}{ Parameters } & $\begin{array}{c}\text { p+-CdTe } \\
\text { (BSF layer) }\end{array}$ & $\begin{array}{c}\text { p-CGS } \\
\text { (Absorber) }\end{array}$ & $\begin{array}{c}\text { n-CdS } \\
\text { (Buffer) }\end{array}$ & $\begin{array}{c}\text { n-ZnO } \\
\text { (Window) }\end{array}$ \\
\hline Thickness, $\mathrm{W}(\mu \mathrm{m})$ & 0.2 & 3 & 0.1 & 0.1 \\
Bandgap, Eg $(\mathrm{eV})$ & 1.45 & 2.2 & 2.42 & 3.35 \\
Electron affinity, $\chi(\mathrm{eV})$ & 4.28 & 4.5 & 4.4 & 4.5 \\
Dielectric permittivity, $\varepsilon_{r}$ & 9.4 & 13.6 & 10 & 9 \\
Effective Density of states, $\mathrm{NC}\left(\mathrm{cm}^{-3}\right)$ & $8 \times 10^{17}$ & $2.2 \times 10^{17}$ & $2.2 \times 10^{18}$ & $2.2 \times 10^{18}$ \\
Effective Density of states, $\mathrm{NV}\left(\mathrm{cm}^{-3}\right)$ & $1.8 \times 10^{19}$ & $1.8 \times 10^{18}$ & $1.7 \times 10^{19}$ & $1.8 \times 10^{19}$ \\
Electron mobility, $\mu_{\mathrm{e}}\left(\mathrm{cm}^{2} / \mathrm{Vs}\right)$ & 1050 & 100 & 340 & 100 \\
Hole mobility, $\mu_{\mathrm{p}}\left(\mathrm{cm}^{2} / \mathrm{Vs}\right)$ & 100 & 25 & 50 & 25 \\
Electron and hole concentration, $\mathrm{n}, \mathrm{p}\left(\mathrm{cm}^{-3}\right)$ & $1 \times 10^{18}$ & $1 \times 10^{16}$ & $1 \times 10^{17}$ & $1 \times 10^{18}$ \\
\hline
\end{tabular}


CHAPTER 4 Numerical Modeling

Table 4.4: Interface defects (Neutral)

\begin{tabular}{lcc}
\hline \multicolumn{1}{c}{ Defect layer properties } & p $^{+}$-CdTe/p-CGS & p-CGS/n-CdS \\
\hline Density of defect & $1.0 \times 10^{13} \mathrm{~cm}^{-2}$ & $1.0 \times 10^{13} \mathrm{~cm}^{-2}$ \\
Capture cross section area of electron/hole & $1.0 \times 10^{-15} \mathrm{~cm}^{2}$ & $1.0 \times 10^{-15} \mathrm{~cm}^{2}$ \\
Recombination Velocity for electron and hole (S) & $1.0 \times 10^{5} \mathrm{~cm} / \mathrm{s}$ & $1.0 \times 10^{5} \mathrm{~cm} / \mathrm{s}$ \\
\hline
\end{tabular}

\subsubsection{Energy band diagram}

Energy band diagram of $C d T e / C G S / C d S / Z n O$ structured photovoltaic cell is shown in Figure 4.5. This energy band diagram was obtained for analysis from the SCAPS software. Energy band diagrams help in explaining the properties of a photovoltaic cell.

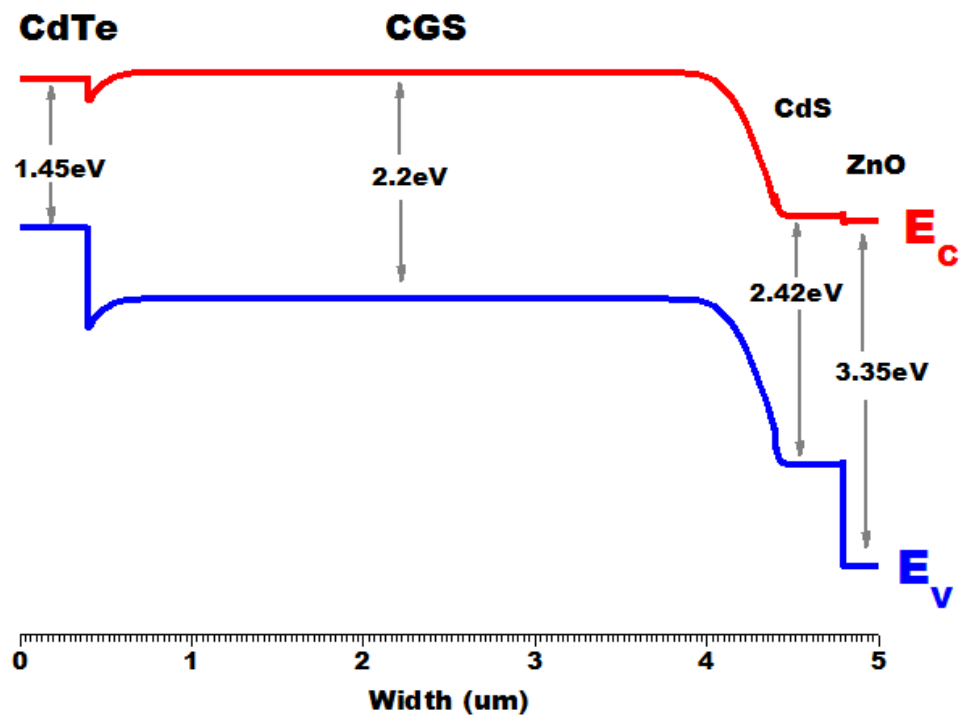

Figure 4.5: Energy Band diagram of $C G S$ solar cell

\subsection{2 $J-V$ characteristics of $C G S$ solar cell}

Figure 4.6 shows the $\mathrm{J}-\mathrm{V}$ characteristic of CGS/CdS/ZnO solar cells under illuminated.

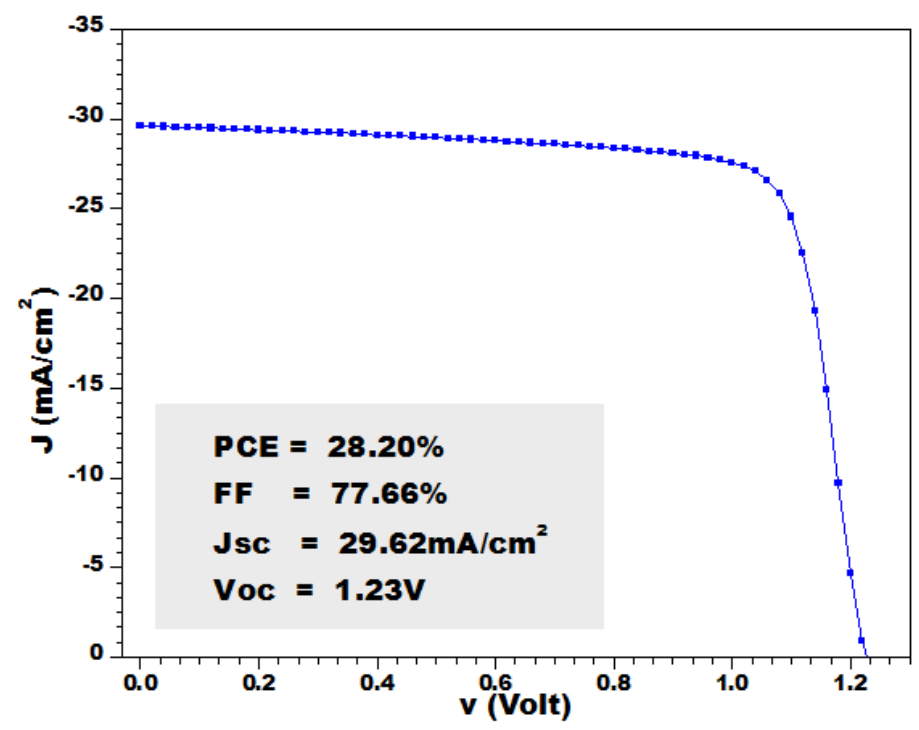

Figure 4.6: J - V characteristics 
Device characteristics were observed under dark and illumination condition. The function of the photovoltaic cell is to convert the light energy into electricity. In light illumination, the photovoltaic cell starts working and current flows due to charge carriers produced by incident photons. The thickness of CGS absorber layer taken was $4 \mu \mathrm{m}$ and band gap energy was $2.2 \mathrm{eV}$. Due to incident photons, the photovoltaic process starts, these photons will generate charge carriers, which are produced after exposing the cell to sunlight condition of 1 Sun (Air Mass 1.5).

\subsubsection{CGS absorber thickness effect on device performance}

CGS absorber thickness effect on device performance is explained with the help of Figure 4.7. The thickness of CGS was changed from $1 \mu \mathrm{m}$ to $10 \mu \mathrm{m}$. It is well understood from Figure 4.7 that with an increase in the thickness of CGS absorber layers, conversion efficiency increases with $\mathrm{FF}$ and $\mathrm{V}_{\mathrm{oc}}$. But after reaching an optimal thickness fill factor starts to decrease with increase in thickness whereas conversion efficiency, $\mathrm{J}_{\mathrm{sc}}$ and $\mathrm{V}_{\mathrm{oc}}$ are almost constant. To give an efficient output from a solar cell, the optimum thickness values for CGS taken was $3 \mu \mathrm{m}$.

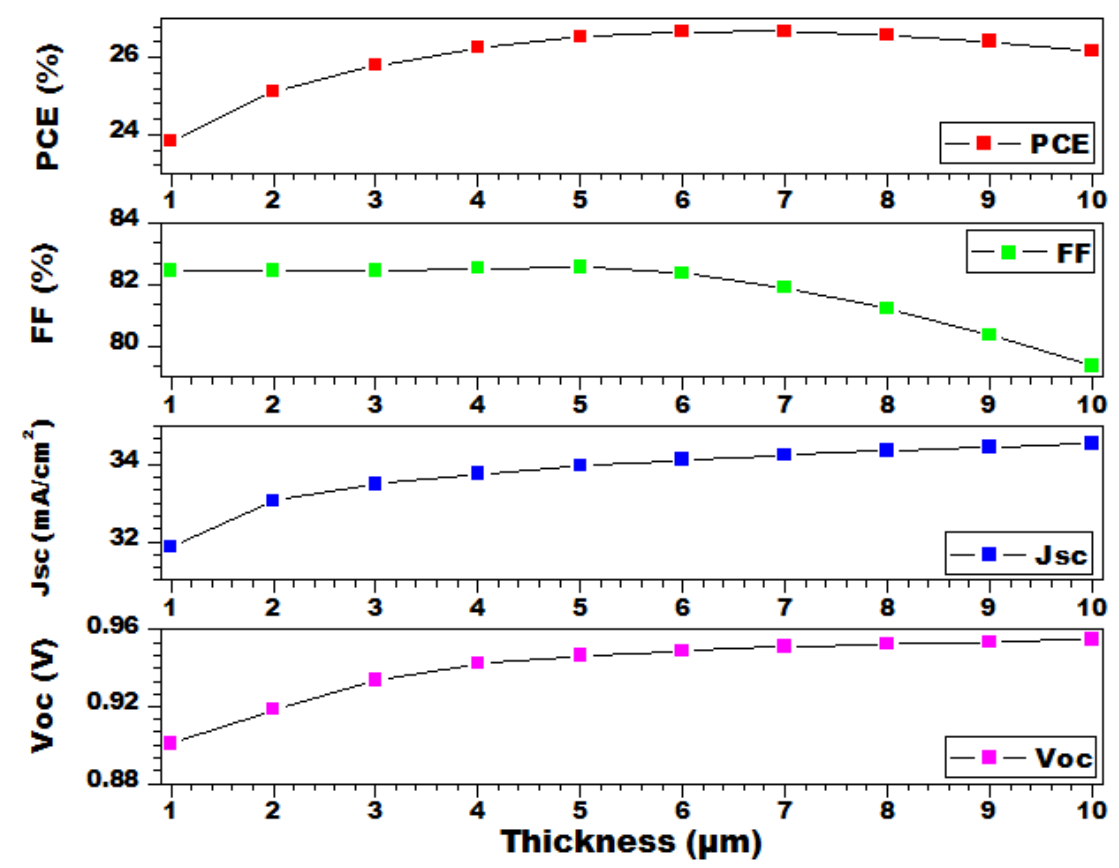

Figure 4.7: Thickness of CGS absorber layer

\subsubsection{Acceptor doping concentration effect on device performance}

The impact of carrier concentration on the functional parameters is given in Figure 4.8. The acceptor concentration of CGS absorber layer was varied from $1 \times 10^{13} \mathrm{~cm}^{-3}$ to $1 \times 10^{17} \mathrm{~cm}^{-3}$. With the increase of absorber doping concentration open circuit voltage $\left(\mathrm{V}_{\mathrm{oc}}\right)$, fill factor $(\mathrm{FF})$ and power conversion efficiency increases. Whereas $\mathrm{J}_{\mathrm{sc}}$ decreases 
with the increase of concentration in CGS. After reaching to the optimum value of acceptor carrier concentration, all functional parameters will be decreases. To give an efficient output from a solar cell, the optimum value of CGS absorber layer carrier concentration taken was $5 \times 10^{16} \mathrm{~cm}^{-3}$.

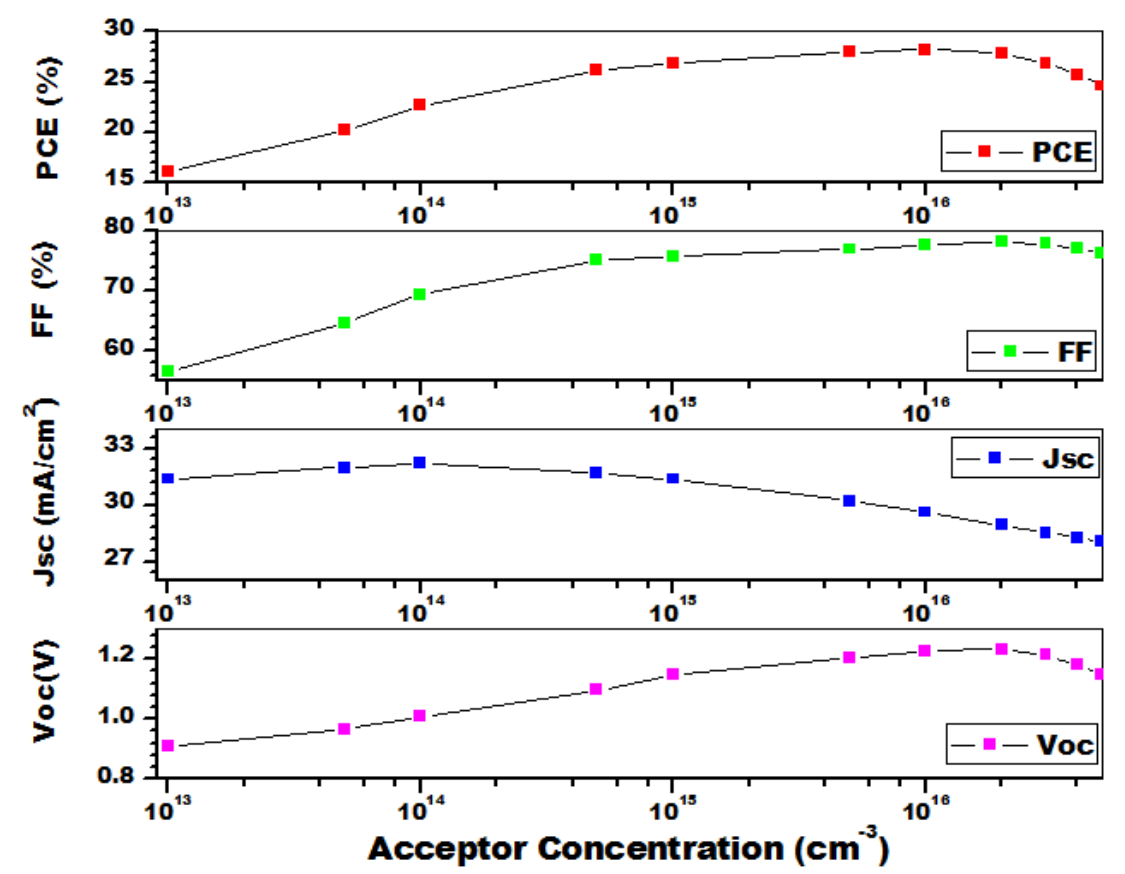

Figure 4.8: Acceptor concentration of CGS absorber layer

\subsubsection{Buffer thickness effect on device performance}

The influence of the thickness of CdS buffer layer on a performance of the photovoltaic solar cell is explored in this step. The thickness of CdS layer was changed from $0.01 \mu \mathrm{m}$ to $0.1 \mu \mathrm{m}$ and simulation results are shown in Figure 4.9.

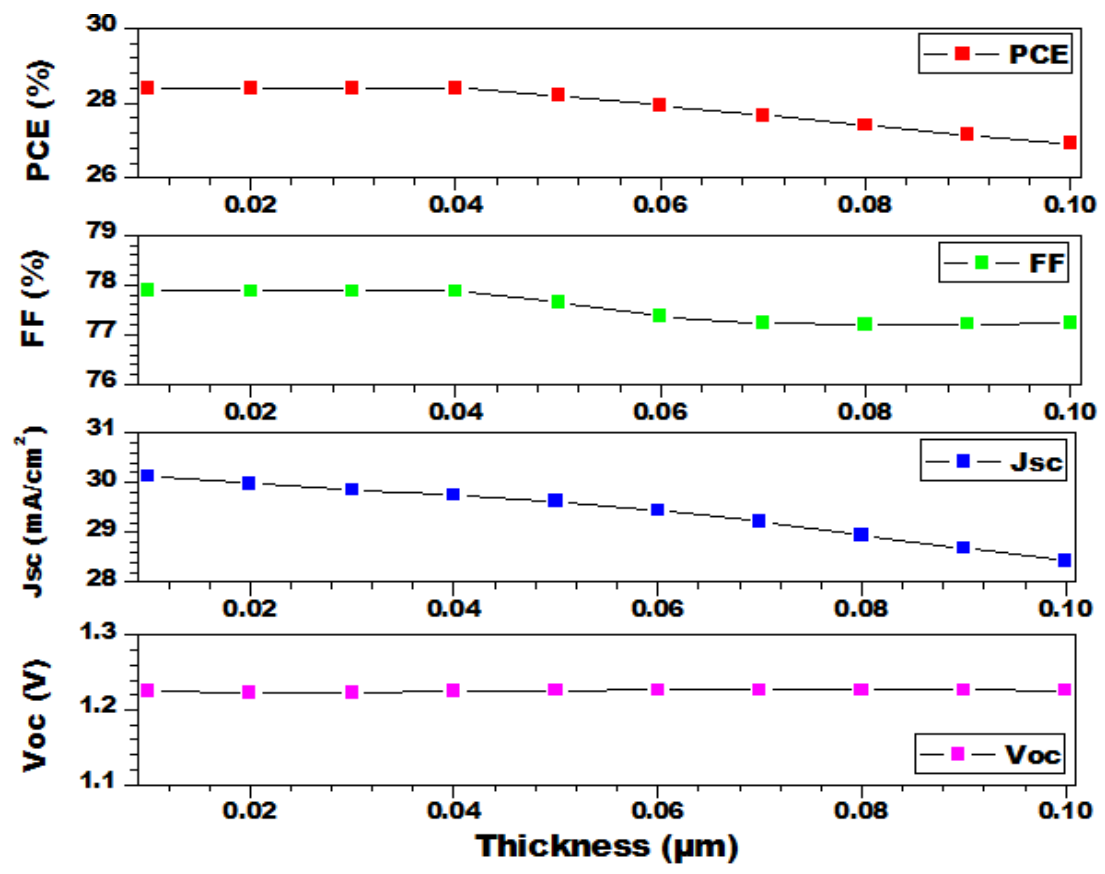

Figure 4.9: Thickness of CdS buffer layer 
From Figure 4.9, it is cleared that, although, in the increase of buffer layer thickness, there is no change in open circuit voltage $\left(\mathrm{V}_{\mathrm{oc}}\right)$. Whereas in short-circuit current $\left(\mathrm{J}_{\mathrm{sc}}\right)$, power conversion efficiency (PCE) and fill factor (FF) are constant up to the optimal value. After reaching the optimal thickness value PCE, FF, and $\mathrm{J}_{\mathrm{sc}}$ are decreased. The optimized and the preferred thickness of a buffer layer was $0.05 \mu \mathrm{m}$.

\subsubsection{Buffer layer donor concentration effect on device performance}

The buffer layer donor concentration simulation results are shown in Figure 4.10 and varied from $1 \times 10^{15} \mathrm{~cm}^{-3}$ to $1 \times 10^{18} \mathrm{~cm}^{-3}$. Figure 4.10 shows that with an increase in donor concentration, power conversion efficiency (PCE) of a proposed solar cell increases, this change is small but not negligible. Figure 4.10 illustrates that with an increase in the donor concentration of a buffer layer almost there is very small increase occurs in open circuit voltage $\left(\mathrm{V}_{\mathrm{oc}}\right)$, short-circuit current $\left(\mathrm{J}_{\mathrm{sc}}\right)$ and in fill factor $(\mathrm{FF})$. After reaching the optimal value of donor carrier concentration PCE and FF are constant and $\mathrm{J}_{\mathrm{sc}}$ decreases. If we further increase the concentration, PCE and FF will be decreased. To give an efficient output from a solar cell the optimum value of CdS buffer layer carrier concentration taken was $1 \times 10^{17} \mathrm{~cm}^{-3}$.

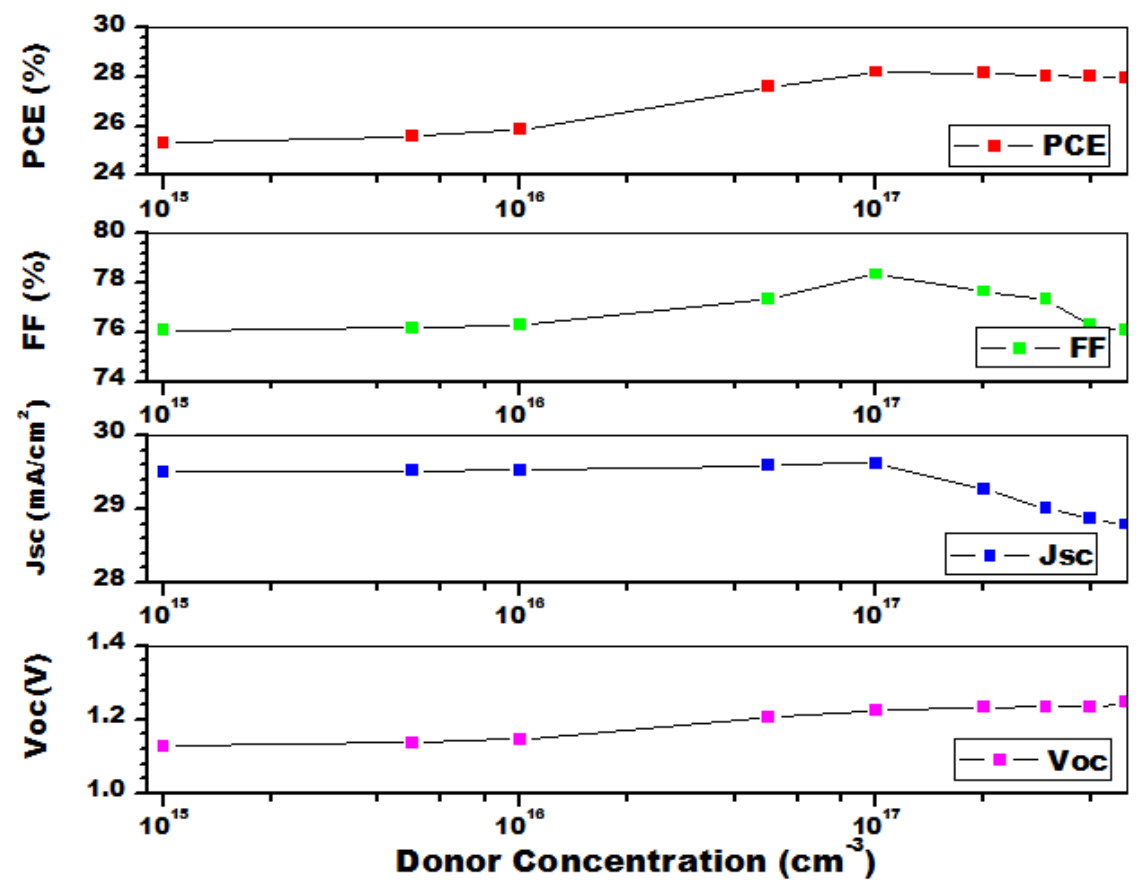

Figure 4.10: Donor concentration of CdS buffer layer

\subsubsection{Effect of $C d T e$ back surface field layer thickness}

Influence of CdTe as a BSF layer on the performance of the proposed device is explored and analyzed and shown in Figure 4.11. The thickness of a BSF layer was changed while remaining all other parameters of solar cell were kept constant. The thickness of CdTe BSF 
layer was varied from $0.1 \mu \mathrm{m}$ to $1 \mu \mathrm{m}$. Simulated fallouts show that with an increase in the thickness of BSF layer, there is a very small change observed in functional parameters i.e. in short-circuit current $\left(\mathrm{J}_{\mathrm{sc}}\right)$, open circuit voltage $\left(\mathrm{V}_{\mathrm{oc}}\right)$, power conversion efficiency (PCE) and the fill factor (FF). So, this result is comprehended that increase in BSF layer thickness does not affect the output of the proposed device. For the designing of CdTe/CGS/CdS solar cell, the optimum thickness of a BSF layer taken was $0.2 \mu \mathrm{m}$.

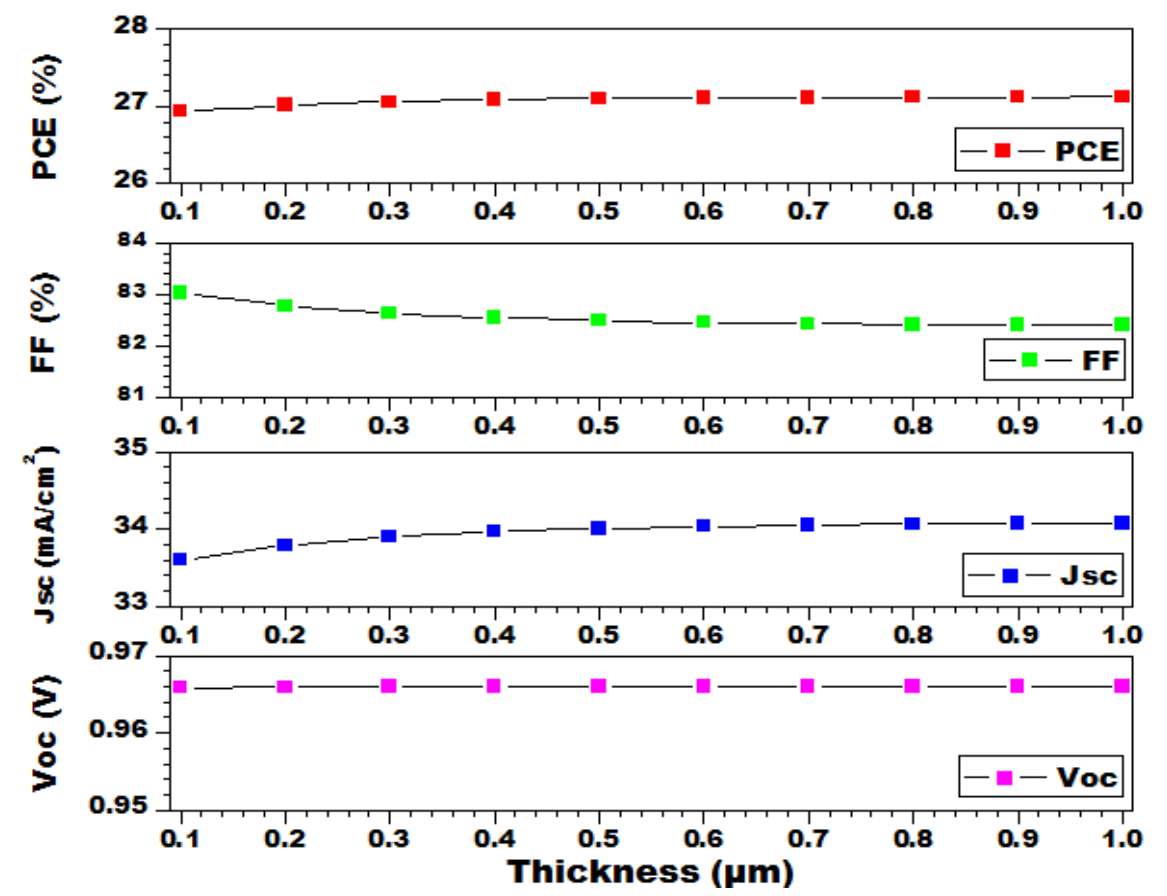

Figure 4.11: CdTe BSF layer thickness effect on functional parameters

\subsubsection{Working temperature effect on device performance}

Working temperature plays a significant role in device performance. The photovoltaic panels are installed in the open air. The impact of the working temperature on the proposed cell was also studied. For investigation of the performance of a cell, we took the temperature in a rage from $280 \mathrm{~K}$ to $400 \mathrm{~K}$. The simulation results are shown in Figure 4.12. With the increase in temperature, cell performance decreases. Due to the higher temperature the material carrier concentration, band gaps, electron, and hole mobilities are affected and lower conversion efficiency from a cell was achieved [33]. Reverse saturation current depends on the temperature and due to this $V_{\text {oc }}$ decreased with increase in temperature. Reverse saturation current increased with increase in temperature. This increase in current is the main cause of the $\mathrm{V}_{\mathrm{oc}}$ decrease. Electrons gain more energy from the increased operating temperature. These electrons are unstable due to the higher temperature and are more likely to recombines with the holes before reaching the depletion region. Figure 4.12 illustrates that with the increase of temperature, conversion efficiency 
decreases. $\mathrm{FF}, \mathrm{V}_{\mathrm{oc}}$ also decreases along with the increase in temperature whereas $\mathrm{J}_{\mathrm{sc}}$ increases.

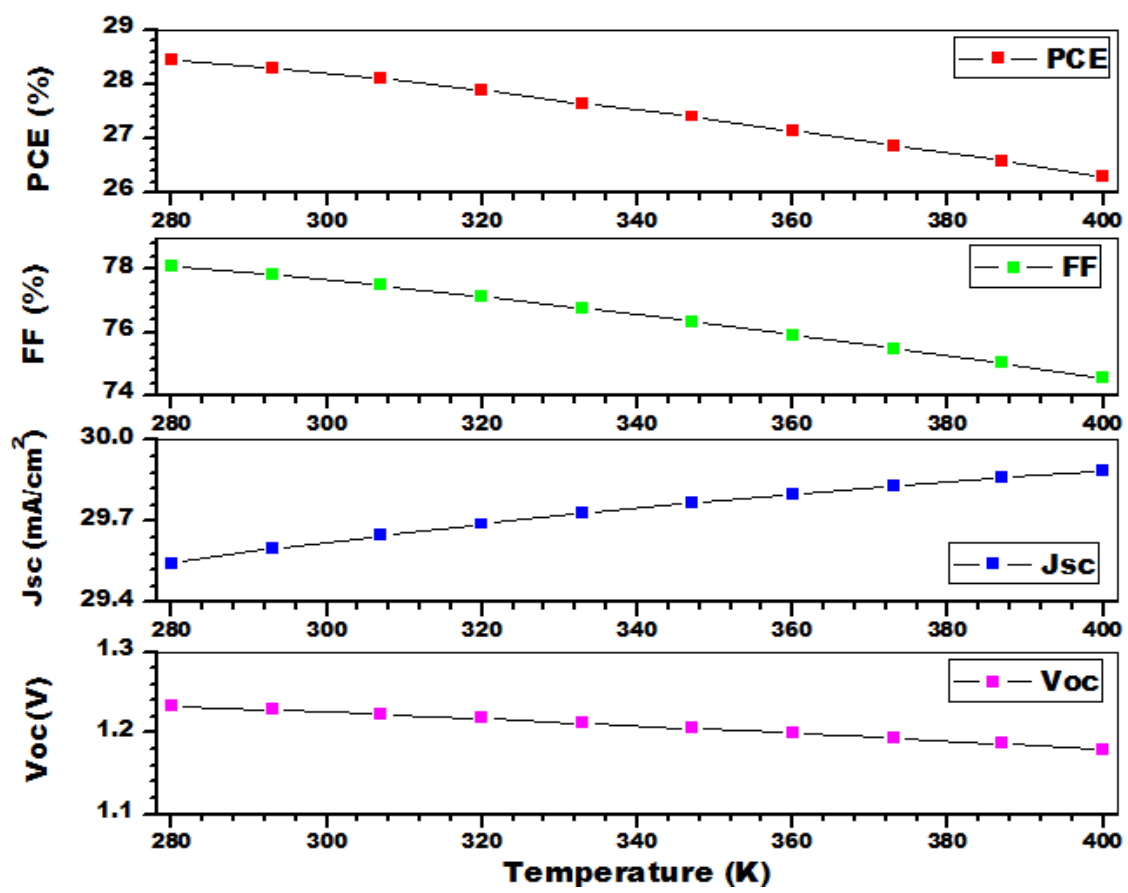

Figure 4.12: Temperature effect on cell performance

\subsubsection{Conclusion}

Thin film solar cell structure physical operating features are described by different software's. In this work, a detailed analysis of a solar cell was performed on SCAPS-1D software for better understanding of solar cell behavior. In-depth understanding of the solar cell, $\mathrm{J}-\mathrm{V}$ characteristic measures is not enough to fully describe its behavior, because the behavior or response of a solar cell also depends on its internal physical mechanism. In this work, the performance of a CGS/CdS/ZnO structured photovoltaic solar cell was simulated and analyzed on SCAPS simulator software. The values obtained from the proposed solar cell were the power conversion efficiency (PCE) of $28.20 \%$, fill factor (FF) $77.66 \%$, short circuit current $\left(\mathrm{J}_{\mathrm{sc}}\right) 29.62 \mathrm{~mA} / \mathrm{cm}^{2}$ and open circuit voltage $\left(\mathrm{V}_{\mathrm{oc}}\right) 1.22 \mathrm{~V}$. From the results, it is clear to attain improved performance from solar cell numerical modeling plays a significant role. 
This page intentionally left blank 


\section{CHAPTER 5}

MODELING OF CZTS KESTERITE SOLAR CELL 
This page intentionally left blank 
Semiconductor devices play a significant role in commercial applications and can be widely used in power generation in the form of photovoltaics. Photovoltaic cells absorb the radiation of sunlight and convert it into electrical energy [1]. Non-crystalline and crystalline photovoltaic cells are made from elemental and compound materials. Materials that exhibit higher conversion efficiencies are of a crystalline group, their cost of production is higher than polycrystalline and microcrystalline. Research gained more attention due to satisfactory performance, low-cost manufacturing, reliability and stability of a polycrystalline and microcrystalline family of materials [2]. For the manufacturing of photovoltaic cells, thin-film technology is one of the cost-effective and efficient subjects of intense research in photovoltaic industry. Thin-film photovoltaic cells are very suitable for low and large-scale photovoltaic cell applications. In the current scenario, the economic and high-power conversion efficiency photovoltaic devices without degradation of materials are fabricated for the generation of electricity [4]. Silicon-based photovoltaic cells dominated the market for many years and due to intensification in manufacturing capabilities, thin film photovoltaic cells are gaining significance [67]. For the manufacturing and production of silicon-based thin film solar cell, different major deposition techniques like sputtering, thermal evaporation, molecular beam epitaxy, ebeam evaporation, close space sublimation, and metal organic chemical vapor deposition techniques are attempted. Therefore the cost of a material, technology, and energy consumption used by these sophisticated fabrication techniques make the solar cell panel costly [5].

$\mathrm{Cu}(\mathrm{In}, \mathrm{Ga}) \mathrm{Se}_{2}$ (also known as CIGS) and related alloy based thin-film chalcopyrite photovoltaic cells have already presented in 2015, on laboratory scale they have a conversion efficiency of about $21.7 \%$ and these types of devices have high absorption coefficient [2,68]. The commercial production of CIGS photovoltaic cells is limited because of the higher cost of using gallium (Ga) and indium (In). Kesterite solar cells utilizing CZTS $\left(\mathrm{Cu}_{2} \mathrm{ZnSnS}_{4}\right), \quad$ CZTSe $\left(\mathrm{Cu}_{2} \mathrm{ZnSnSe}_{4}\right)$ and their alloys CZTSSe $\left(\mathrm{Cu}_{2} \mathrm{ZnSn}\left(\mathrm{S}_{\mathrm{x}} \mathrm{Se}_{1-\mathrm{x}}\right)_{4}\right)$ are emerging as the most auspicious replacement for the chalcopyrite absorbers by replacing indium (In) with comparatively inexpensive zinc (Zn) and gallium (Ga) with tin ( $\mathrm{Sn}$ ) in the CIGS absorbers [6-8]. The copper zinc tin sulfide $\left(\mathrm{Cu}_{2} \mathrm{ZnSnS}_{4}\right)$ solar cell fabrication is a very efficient and low price for electric power generation. The outstanding features of CZTS based solar cells made it very interesting in the thin film community. For the manufacturing of a thin film photovoltaic cell, CZTS is 
considered as an ideal light absorber material. CZTS is promising quaternary semiconductor compound of group I - II - IV - VI having kesterite symmetrical structure having direct optical band gap ranges among $1.4 \mathrm{eV}$ to $1.5 \mathrm{eV}$ [69-72] and large absorption coefficient $\alpha>10^{4} \mathrm{~cm}^{-1}$ [72-75]. In 1997 the first CZTS (vacuum deposited) solar cell is reported, having a power conversion efficiency of $0.66 \%[70]$. 6.7\% conversion efficiency of CZTS based photovoltaic solar cell was reported in 2009 [76]. In 2011 the record conversion efficiency was $8.4 \%$ [77]. 12.6\% conversion efficiency of CZTSSe was reported in 2013[78]. Shockley Queisser (SQ) limit is the standard for comparing new photovoltaic technologies. It defines the maximum possible solar energy conversion efficiency for a specific material [79]. According to the Shockley-Queisser limit, the optimum conversion efficiency of around $28 \%$ is theoretically possible from a CZTS based solar cell by tuning the band gap [80]. But still, it is not experimentally possible to achieve $28 \%$ conversion efficiency from a solar cell, because of the lack of understanding of material characteristics. Numerical analysis plays a significant role for the better understanding of the material characteristics and also for the cell performance. In 2010 the reported power conversion efficiency of the CZTS/CdS structured photovoltaic cell by numerical analysis is about 7.55\% [68]. 15\% conversion efficiency of CZTS/CdS structure photovoltaic solar cell was reported in 2016 [81]. The $18.05 \%$ conversion efficiency for CZTS/CdS structure solar cell is presented in 2017 [82].

\subsection{Numerical modeling of CZTS based kesterite solar cell [83]}

$\mathrm{Cu}_{2} \mathrm{ZnSnS}_{4}$ (CZTS) is non-toxic earth abundant material and a promising quaternary semiconductor compound of group I - II - IV - VI having kesterite symmetrical structure. Due to its optimum direct band gap, it has been considered as a suitable material for the absorber layer for photovoltaic cell applications. This work presents the numerical simulation and modeling of CZTS based thin film kesterite photovoltaic cell using SCAP1D software. The influence of device parameters such as carrier concentration, thickness, the density of absorber, buffer and window layers, the defect densities and temperature effect on the performance of $\mathrm{ZnO} / \mathrm{CdS} / \mathrm{CZTS} / \mathrm{Mo}$ photovoltaic cell structure was analyzed. Defect densities were added in the absorber layer and at the interface between the buffer layer and absorber layer. This type of solar cell does not comprise any toxic material and can lead to non-toxic thin film photovoltaic cells with outstanding optical properties. 


\subsubsection{Device modeling and material parameters}

Numerical analysis of the kesterite-based $\mathrm{ZnO} / \mathrm{CdS} / \mathrm{CZTS} / \mathrm{Mo}$ structured solar cell is presented in this work, SCAP-1D is used for the modeling of a solar cell. Different parameters which affected the performance of a photovoltaic cell is explained. In our simulation thickness of the absorber layer (CZTS) varied from $1 \mu \mathrm{m}$ to $5 \mu \mathrm{m}$ and the bandgap energy was $1.45 \mathrm{eV}$. The band gap of CdS buffer layer was more than the absorber layer; therefore, maximum photons are absorbed in CZTS. Due to this short-circuit current $\left(\mathrm{J}_{\mathrm{sc}}\right)$ and open circuit voltage $\left(\mathrm{V}_{\mathrm{oc}}\right)$ of solar cell increases, which also increases the overall conversion efficiency of the photovoltaic cell. Figure 5.1 visualizes the proposed $\mathrm{ZnO/CdS/CZTS/Mo} \mathrm{solar} \mathrm{cell} \mathrm{structure.} \mathrm{Here} \mathrm{CdS} \mathrm{and} \mathrm{CZTS} \mathrm{are} \mathrm{buffer} \mathrm{and} \mathrm{absorber}$ layers respectively. $\mathrm{ZnO}$ works as a window layer and molybdenum (Mo) as a back contact. These key elements of a device are used for determining the electrical as well as photoelectric characteristics of a solar cell. The analysis was performed on the parameters like the effect of temperature variations on the performance of the photovoltaic cell, absorber layer dopant concentration and thickness, buffer layer dopant concentration and thickness and the effect of sun illumination power. This analysis helps to achieve a conversion efficiency of $23.72 \%$. All simulations were conducted under AM 1.5 illumination. The input parameters used in SCAPS are listed in Table 5.1.

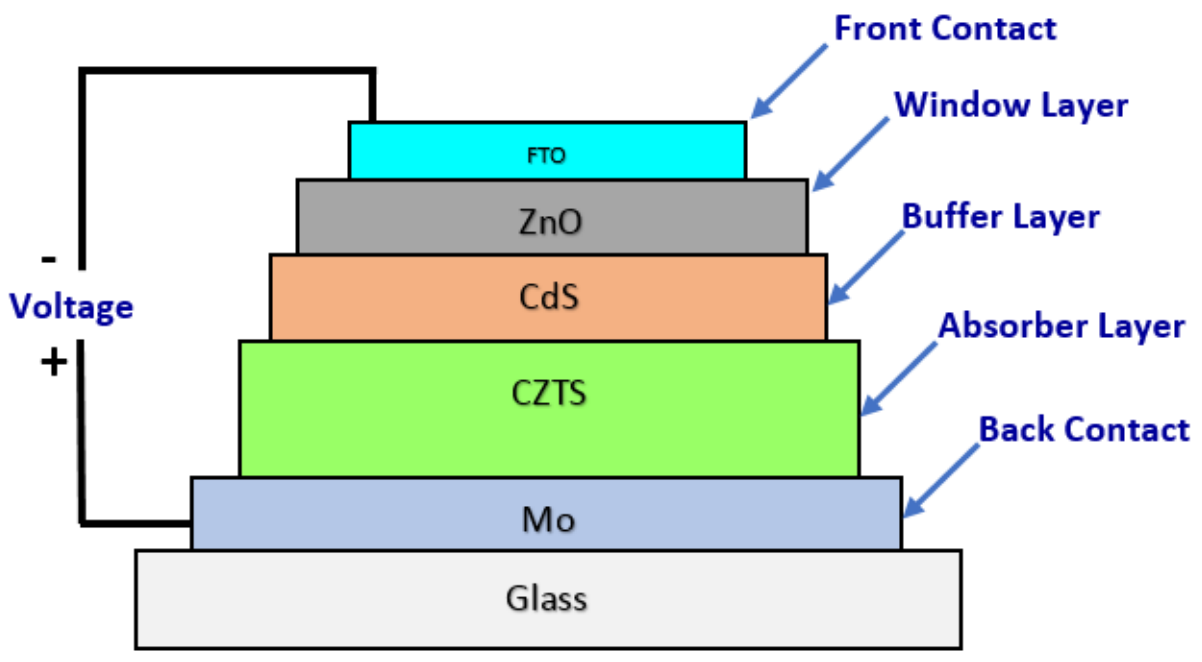

Figure 5.1: CZTS solar cell block diagram.

\subsubsection{Energy band diagram}

The energy band diagram of CdS/CZTS solar cells is shown in Figure 5.2. This energy band diagram was taken from the output of SCAPS for analysis purpose. Energy band diagram helps in explaining the properties of the solar cells. For incident light photons the 
band gap value that is optimal for most of light to be absorbed for effective conversion efficiency is greater or equal to the maximum band gap value of $1.45 \mathrm{eV}$.

Table 5.1: Simulation parameters for modeling of CZTS based kesterite solar cell $[77,81,84]$.

\begin{tabular}{lccc}
\hline \multicolumn{1}{c}{ Parameters } & $\begin{array}{c}\text { p-CZTS } \\
\text { (Absorber) }\end{array}$ & $\begin{array}{c}\text { n-CdS } \\
(\text { Buffer })\end{array}$ & $\begin{array}{c}\text { n-ZnO } \\
\text { (Window) }\end{array}$ \\
\hline Thickness, $\mathrm{W}(\mu \mathrm{m})$ & 4 & 0.05 & 0.2 \\
Bandgap, Eg $(\mathrm{eV})$ & 1.45 & 2.4 & 3.3 \\
Electron affinity, $\chi(\mathrm{eV})$ & 4.5 & 4.5 & 4.6 \\
Dielectric permittivity, $\varepsilon_{\mathrm{r}}$ & 9 & 9 & 9 \\
Effective Density of states, $\mathrm{NC}\left(\mathrm{cm}^{-3}\right)$ & $2.2 \times 10^{18}$ & $1.8 \times 10^{19}$ & $2.2 \times 10^{18}$ \\
Effective Density of states, $\mathrm{NV}\left(\mathrm{cm}^{-3}\right)$ & $1.8 \times 10^{19}$ & $2.4 \times 10^{18}$ & $1.8 \times 10^{19}$ \\
Electron mobility, $\mu_{\mathrm{e}}\left(\mathrm{cm}^{2} / \mathrm{Vs}\right)$ & 60 & 100 & 100 \\
Hole mobility, $\mu_{\mathrm{p}}\left(\mathrm{cm}^{2} / \mathrm{Vs}\right)$ & 20 & 25 & 25 \\
Electron and hole concentration, $\mathrm{n}, \mathrm{p}\left(\mathrm{cm}^{-3}\right)$ & $7 \times 10^{16}$ & $1 \times 10^{17}$ & $1 \times 10^{18}$ \\
\hline
\end{tabular}

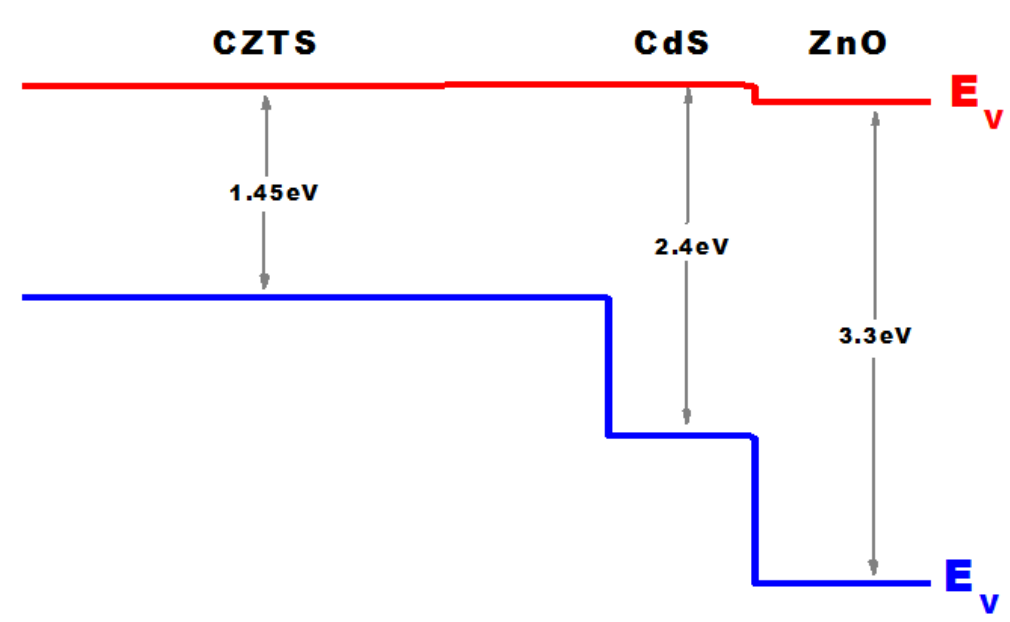

Figure 5.2: Energy band illustration of CZTS solar cell

\subsubsection{J $-V$ characteristics of $C d S / C Z T S$ solar cell}

Conversion of light energy into electrical energy is the main function of the photovoltaic cell. In the dark condition, when there is no light, the photovoltaic solar cell is a large flat diode and produces the exponential $\mathrm{J}-\mathrm{V}$ curve. The cell gives an extreme smallest value of current that is due to minority carriers in dark condition. Solar cell starts working under light illumination condition and current flows due to charge carriers generated by the incident photons. The $\mathrm{J}-\mathrm{V}$ characteristic curve of CdS/CZTS photovoltaic cell is illustrated in Figure 5.3. 


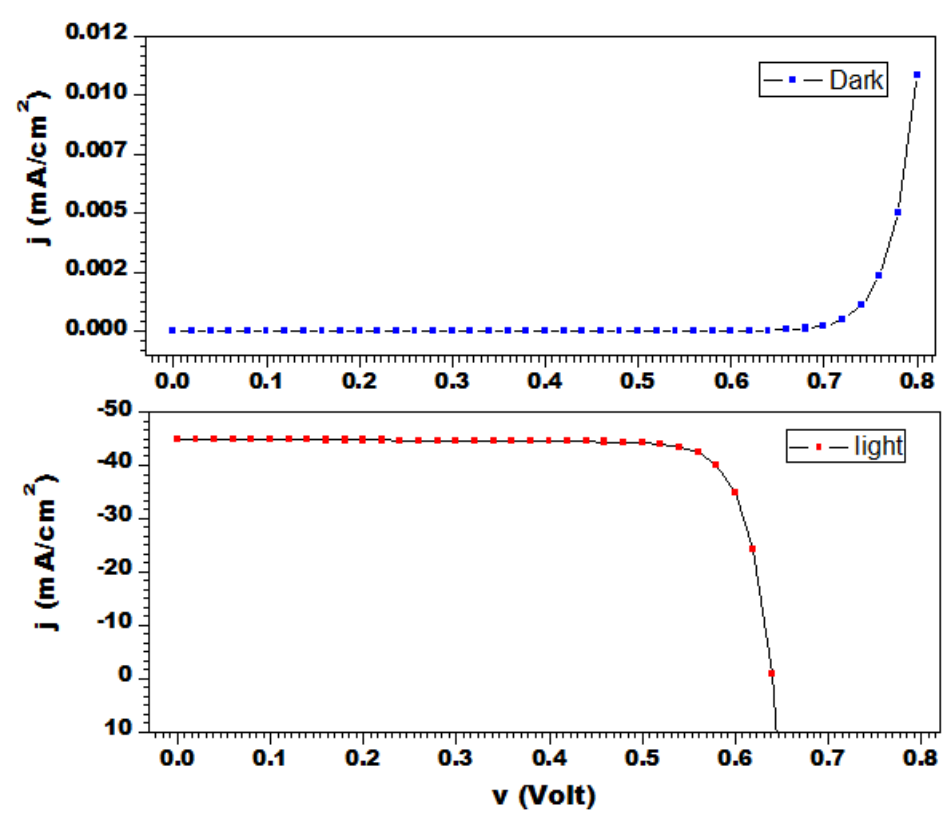

Figure 5.3: Dark vs light $J-V$ characteristics.

\subsubsection{Absorber layer thickness effect on device performance}

Power conversion efficiency (PCE) is directly affected by the absorber layer thickness of a device. The absorber layer (CZTS) thickness effect on photovoltaic cell performance is shown in Figure 5.4.
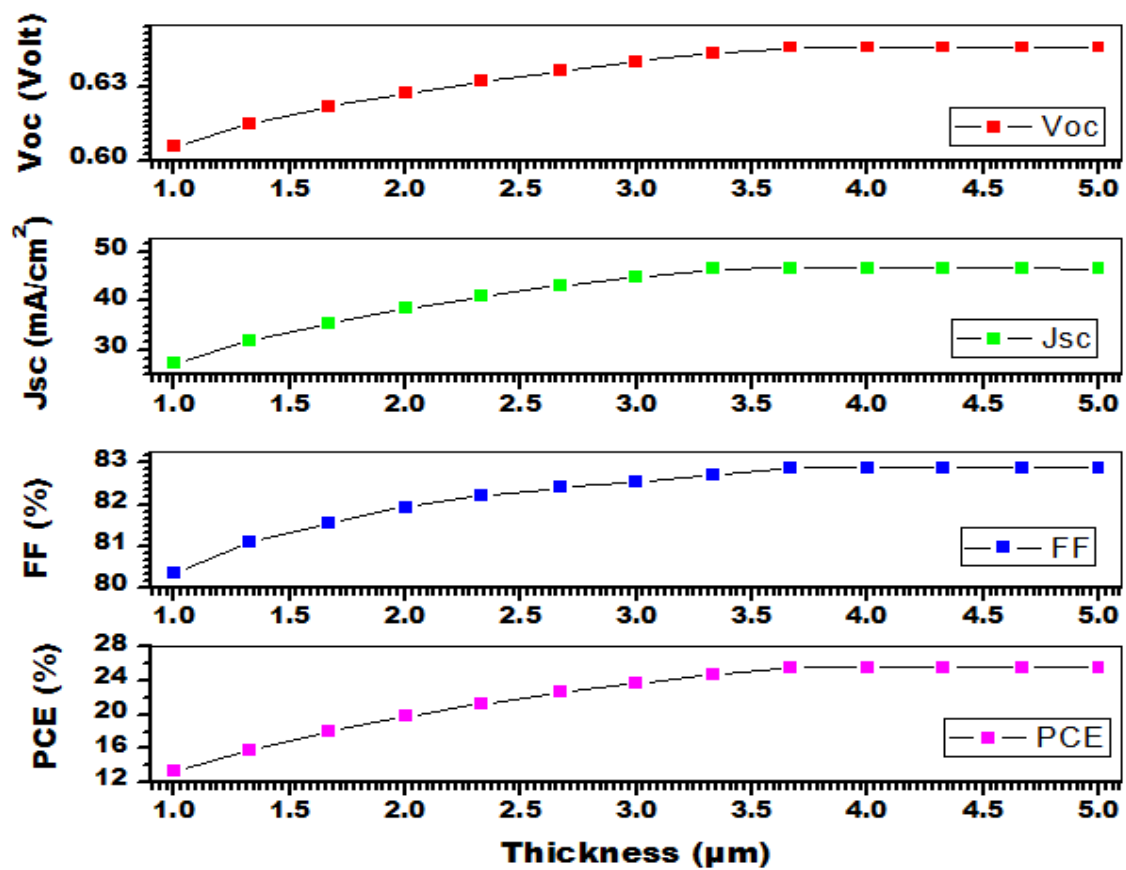

Figure 5.4: Effect of the absorber layer thickness on CZTS photovoltaic cells.

Effect of the thickness of absorber layer was analyzed by altering of CZTS absorber layer thickness from $1 \mu \mathrm{m}$ to $5 \mu \mathrm{m}$, while other material parameters of different layers were kept unchanged. With the increase in the thickness of an absorber layer, JSC increases with an increase of $\mathrm{V}_{\mathrm{OC}}$. PCE also increases with FF up to a point of optimal thickness. After 
reaching the optimal values conversion efficiency will be constant if we further increase the thickness PCE and FF will be decreased. The increase of JSC with an increase of $V_{O C}$ is primarily due to more absorption of photons of longer wavelength and this will, in turn, affect the ration of photo-generated carriers. The optimal value of thickness of absorber layer taken was $4 \mu \mathrm{m}$.

\subsubsection{Acceptor doping concentration effect on device performance}

The acceptor doping concentration simulation results are shown in Figure 5.5. Acceptor concentration was varied from $1 \times 10^{15} \mathrm{~cm}^{-3}$ to $1 \times 10^{18} \mathrm{~cm}^{-3}$. Figure 5.5 illustrates that $\mathrm{J}_{\mathrm{sc}}$ decreases with an increase in the doping concentration whereas $\mathrm{V}_{\mathrm{oc}}$ increases. The main reason behind is that with the increase of the acceptor carrier concentration, saturation current of a device also increases and then resultantly $V_{o c}$ increases. $J_{s c}$ decreases due to the fact that the higher carrier densities will boost the recombination process and reduce the probability of the collection of the photon-generated electrons. The photons of a longer wavelength having less energy are deeply absorbed in CZTS layer. Therefore, the collected conversion efficiency is more dependent on the influence of the concentration density. From Figure 5.5 it is very clear that FF and PCE also increase with an increase in the carrier concentration in absorber layer material. After reaching the optimal value of acceptor carrier concentration, PCE remains constant, whereas FF and $\mathrm{V}_{\mathrm{oc}}$ decrease gradually. The optimal value taken for acceptor carrier concentration was $7 \times 10^{17} \mathrm{~cm}^{-3}$.

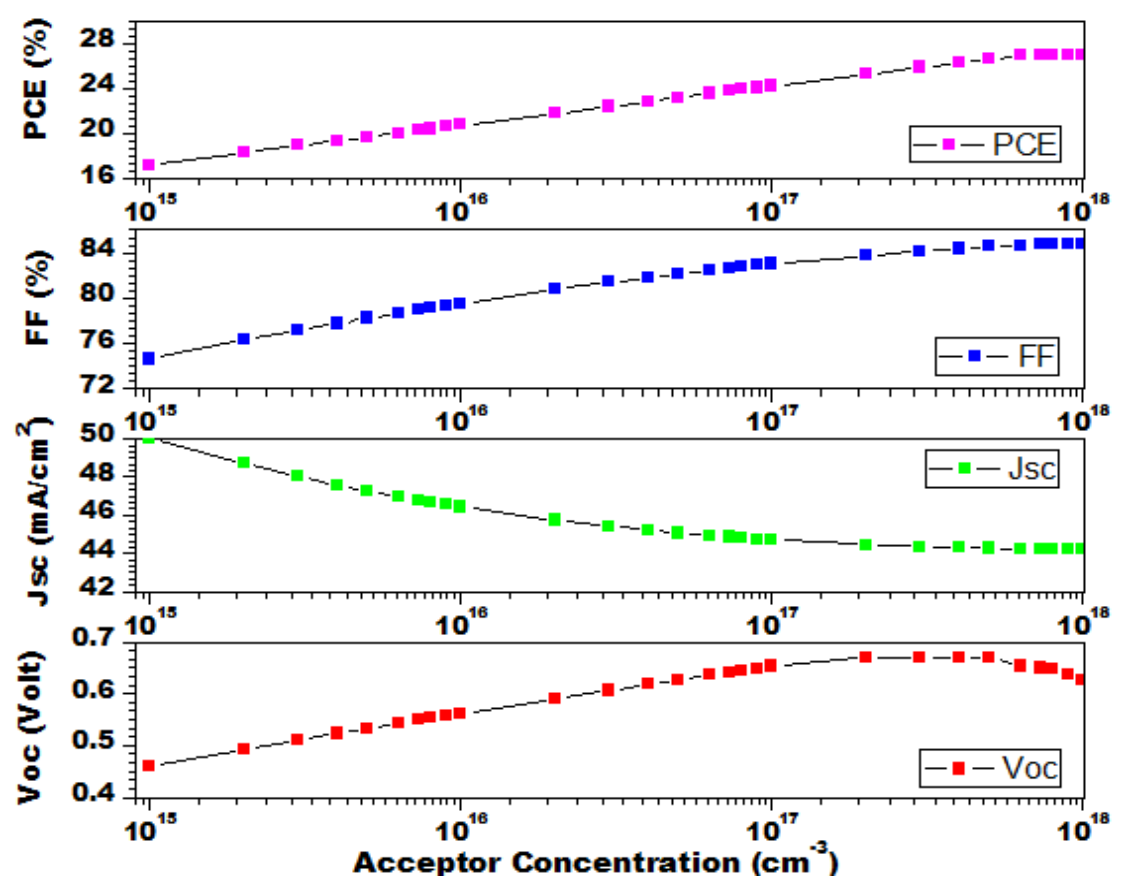

Figure 5.5: Acceptor concentration in the absorber layer. 


\subsubsection{Buffer layer thickness effect on device performance}

The buffer layer thickness influence on the performance of a photovoltaic cell is also explored. The buffer layer thickness was varied from $0.01 \mu \mathrm{m}$ to $0.1 \mu \mathrm{m}$. Simulated fallouts are shown in Figure 5.6. Figure 5.6 illustrates that with an increase in the buffer layer thickness there is no change in short-circuit current $\left(\mathrm{J}_{\mathrm{sc}}\right)$, open circuit voltage $\left(\mathrm{V}_{\mathrm{oc}}\right)$, power conversion efficiency (PCE) and the Fill Factor (FF). Therefore, this result was comprehended that change in thickness of buffer layer did not affect the output of a photovoltaic device. For designing of CZTS/CdS based kesterite device buffer, optimum thickness taken was $0.3 \mu \mathrm{m}$.

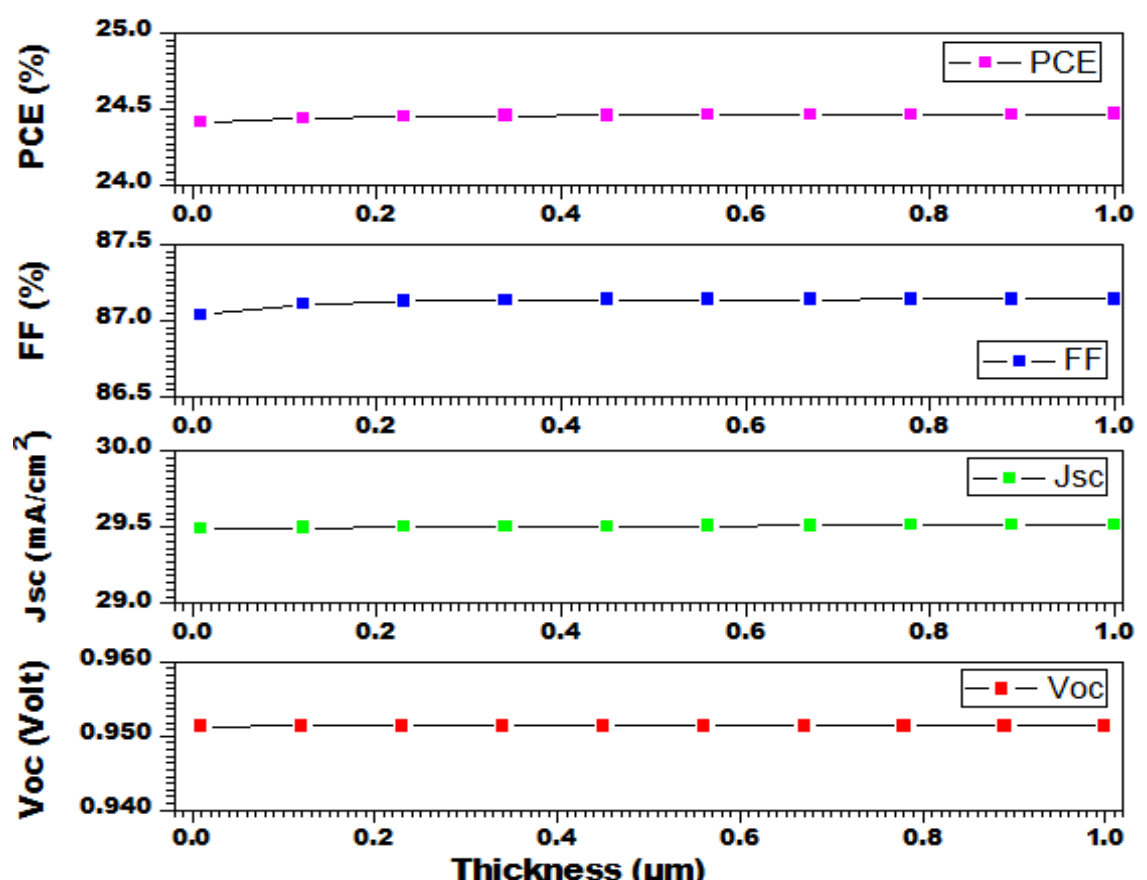

Figure 5.6: Effect of the buffer layer thickness on CZTS photovoltaic cells.

\subsubsection{Buffer layer doping concentration on device performance}

The donor concentration simulation results are shown in Figure 5.7. Donor concentration was varied from $1 \times 10^{15} \mathrm{~cm}^{-3}$ to $1 \times 10^{18} \mathrm{~cm}^{-3}$, The Figure illustrates that with increases in doping concentration, $\mathrm{J}_{\mathrm{sc}}$ and $\mathrm{V}_{\mathrm{oc}}$ are almost constant. Whereas conversion efficiency and fill factor of a device has slightly changed with an increase in doping concentration. After reaching to the optimum value conversion efficiency and fill factor of a device remains constant and start to decrease if we further increase the doping concentration in a buffer layer. Therefore, the clinched optimal concentration value of buffer layer was $1 \times 10^{17} \mathrm{~cm}^{-3}$. From Figure 5.7, with an increase in doping concentration in the buffer layer, there is no major change obtained that effects the working of a device. 
Therefore, this result was comprehended that the change in concentration in a buffer layer did not affect the overall output of a photovoltaic device.

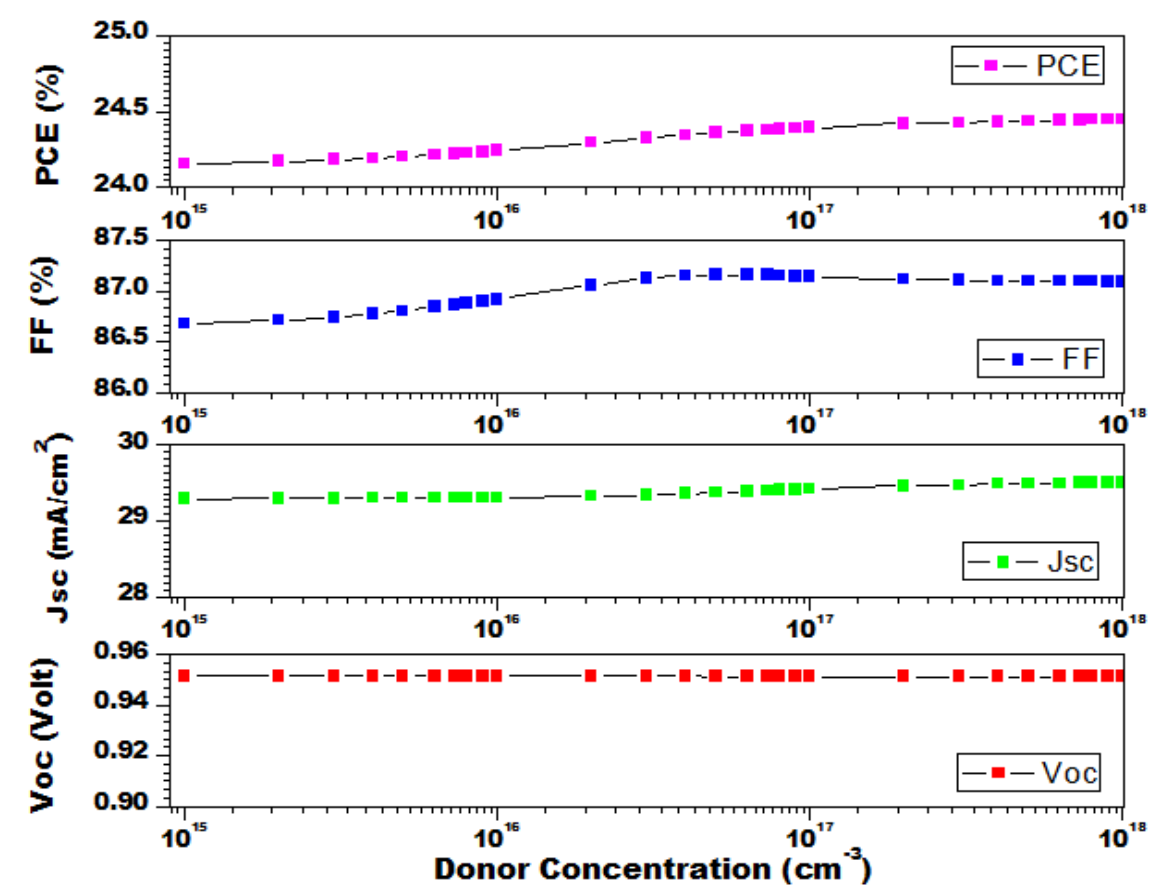

Figure 5.7: Donor concentration in the buffer layer.

\subsubsection{Working temperature effect on device performance}

In the performance of photovoltaic devices, working temperature plays a significant role. The photovoltaic panels are installed in the open atmosphere. Due to the incident light, heating on solar cell increases and this affects the performance of photovoltaic cells. The photovoltaic cell panels are operating at greater than $300 \mathrm{~K}$ temperature. The influence of the working temperature on the proposed cell is also investigated. For investigation purpose, we took the temperature in a rage from $250 \mathrm{~K}$ to $400 \mathrm{~K}$. The simulation results are shown in Figure 5.8. Open circuit voltage is directly affected by the temperature and due to this overall photovoltaic cell performance is also affected. With increases in temperature, photovoltaic cell performance decreases. Due to the higher temperature the material carrier concentration, band gaps, electron and hole mobility is affected and lower conversion efficiency from a cell is achieved [85]. Reverse saturation current $\mathrm{J}_{0}$ depends on the temperature due to this $V_{o c}$ decreases with increase in temperature. Reverse saturation current rises with temperature rise and this increase of current is the main cause of the $\mathrm{V}_{\mathrm{oc}}$ decrease as given in equation 5.1[86] where $J_{e}$ is the light generated photocurrent. Electrons gain more energy from the increased operating temperature. These electrons are unstable due to the higher temperature and are more likely to recombines with the holes before reaching the depletion region. Figure 5.8 illustrates that with 
increases in temperature, the conversion efficiency of the device decreases. $\mathrm{FF}$ and $\mathrm{V}_{\mathrm{Oc}}$ also decrease with increase in temperature whereas $\mathrm{J}_{\mathrm{sc}}$ increases.

$$
\mathrm{J}_{\mathrm{e}}(\mathrm{V})=\mathrm{J}_{0}\left[e^{\left(\frac{\mathrm{qV_{oc }}}{\mathrm{k}_{\mathrm{B}} \mathrm{T}}\right)}-1\right]
$$
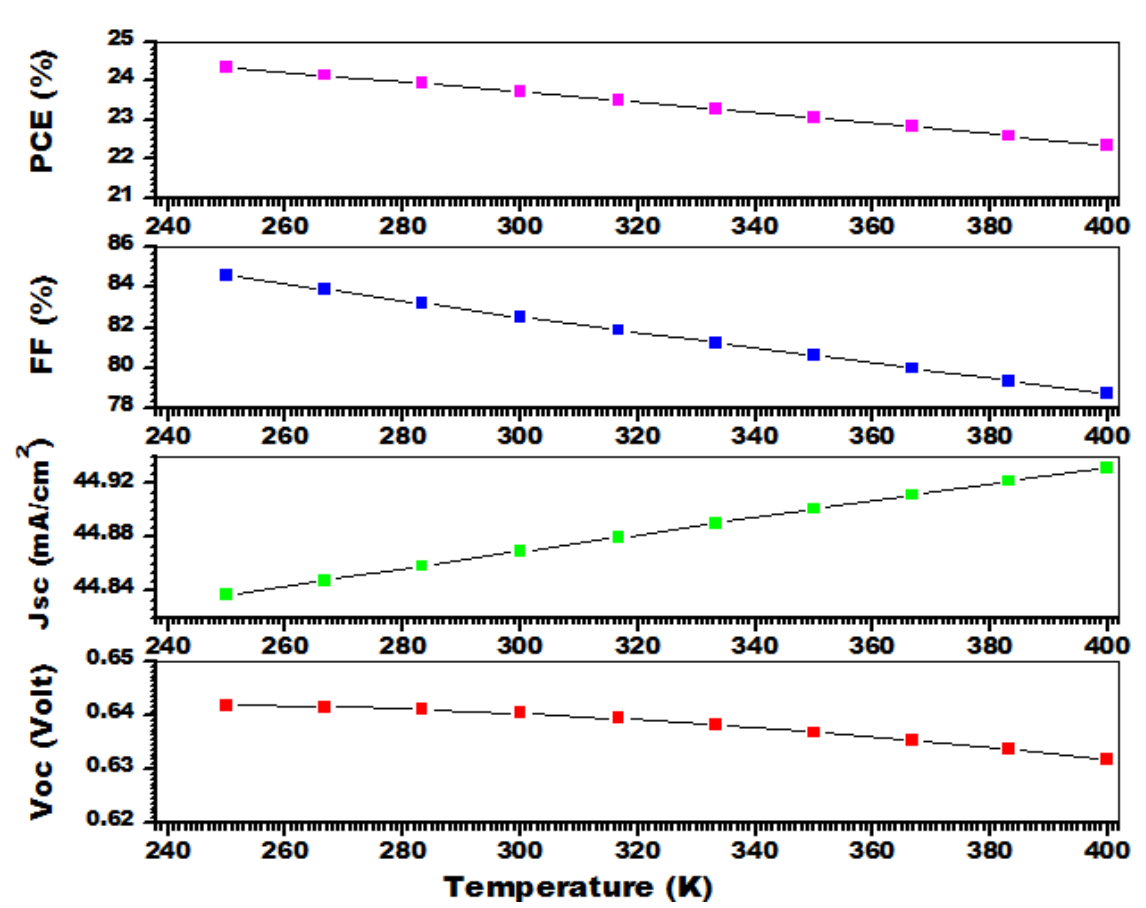

Figure 5.8: Effect of temperature on CZTS photovoltaic cell

\subsubsection{Effect of defects on device performance}

Effect of absorber layer defect on photovoltaic cell performance was analyzed in this step. The density of these defects has a direct effect on the photovoltaic cell performance because with an increase in density of defect the minority carrier lifetime reduces and with reduction of a lifetime the diffusion length of electron and hole also reduce. Thus, increasing the recombination loss in the absorber layer. Figure 5.9 shows the effect of absorber defect density on solar cell performance.

Effect of interface defect density between CdS/CZTS on solar cell performance was carried out in this step using SCAPS. The trap density at the interface will lead to surface recombination of light generated electron-hole pair and this will affect the performance of the solar cell. Figure 5.10 shows the result of interface defect density effect on $V_{\text {oc }}$ and $\mathrm{J}_{\mathrm{sc}}$. From Figure 5.10 increasing the density of defects will reduce the $\mathrm{V}_{\mathrm{oc}}$ but there will be a slight decrease in $\mathrm{J}_{\mathrm{sc}}$ this happens because when interface trap defect density increases the surface interface recombination also increases and Figure 5.10 shows the validation of the result of effect of interface recombination of solar cell performance. 


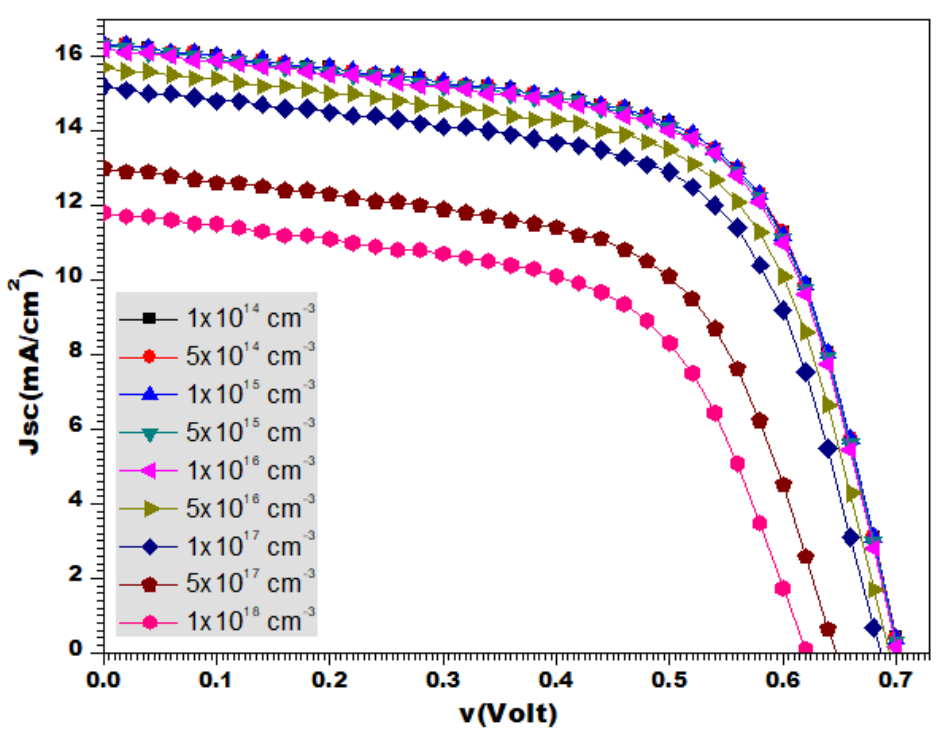

Figure 5.9: Absorber layer defect effect on device performance

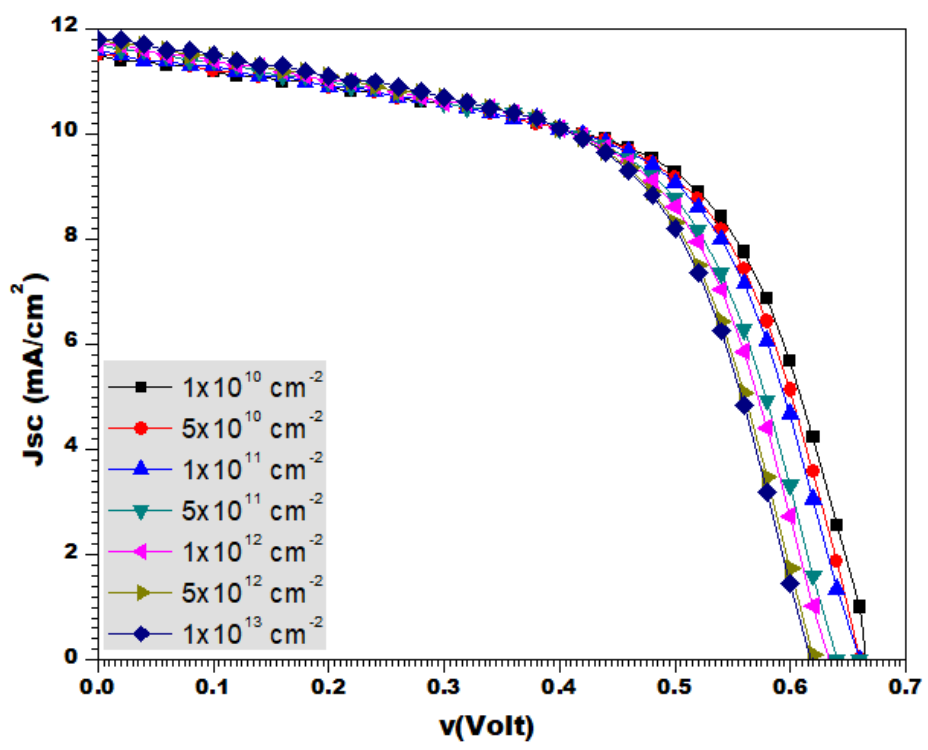

Figure 5.10: Effect of Interface defects on photovoltaic cell performance

\subsubsection{Comparison with experimental solar cell}

For the comparison of simulation results with an experimental result the values added between interface of CdS/CZTS was $\mathrm{N}_{\mathrm{t}}=5 \times 10^{12}\left(\mathrm{~cm}^{-2}\right)$. In Table 5.2 CZTS absorber layer defect is shown $[81,87]$.

Table 5.2: Defects in CZTS absorber layer

\begin{tabular}{lc}
\hline \multicolumn{1}{c}{ Defect properties } & Values \\
\hline Energy level with respect to Reference $(\mathrm{eV})$ & 0.6 \\
Total density $\left(1 / \mathrm{cm}^{3}\right) \mathrm{N}_{\mathrm{t}}$ & $1 \times 10^{15}$ \\
Capture cross section area of electrons $\left(\mathrm{cm}^{2}\right) \delta_{\mathrm{e}}$ & $4.4 \times 10^{-15}$ \\
Capture cross section area of holes $\left(\mathrm{cm}^{2}\right) \delta_{\mathrm{h}}$ & $4.4 \times 10^{-15}$ \\
\hline
\end{tabular}


Figure 5.11 illustrates the results of CdS/CZTS solar cell simulated in SCAPS with defects and compared it with the experimental result obtainable in [88]. After defect study, result from experimental work was simulated using SCAPS software to validate the proposed model. With more study of those defects, it is probable that we can enhance the efficiency of CdS/CZTS solar cell.

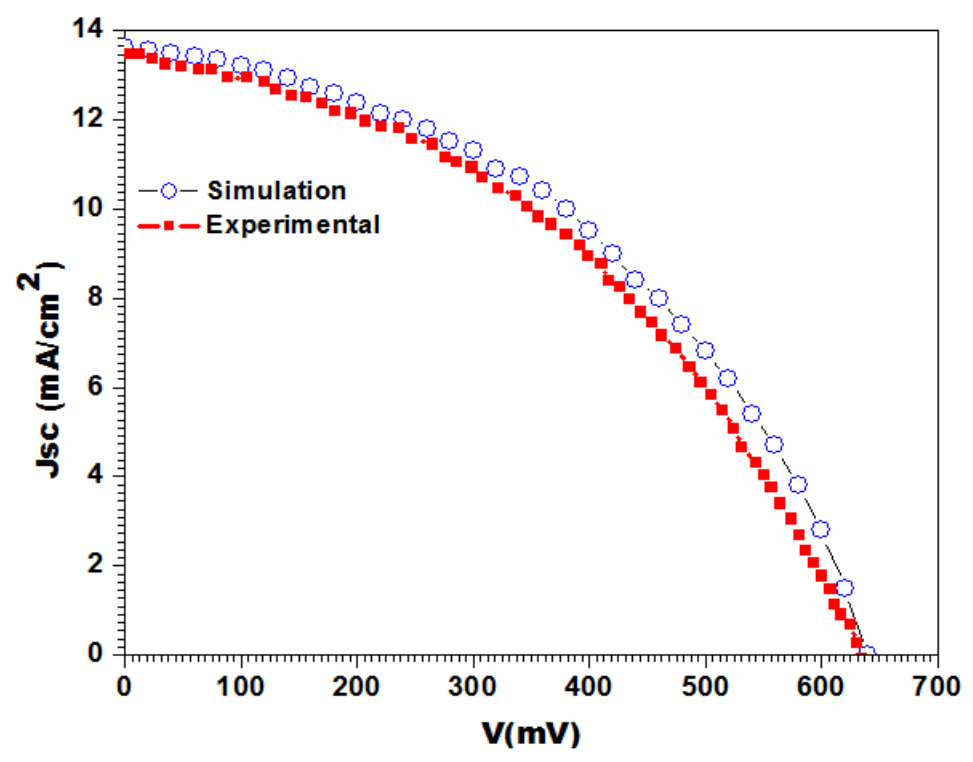

Figure 5.11: Comparison of SCAPS results with experimental data presented in [88].

The obtained results of CdS/CZTS solar cell along with defects and without defects is given in Table 5.5. These results were compared with the stated experimental and simulation data, which are given in Table 5.3 and Table 5.4.

Table 5.3: Functional parameters of experimentally stated kesterite solar cell from literature.

\begin{tabular}{lccccc}
\hline Structure & PCE (\%) & $\mathbf{J}_{\mathbf{S C}}\left(\mathbf{m A} / \mathbf{c m}^{\mathbf{2}}\right)$ & $\mathbf{V}_{\mathbf{O C}}(\mathbf{m V})$ & $\mathbf{F F}(\boldsymbol{\%})$ & Reference \\
\hline CZTS /CdS & 3.59 & 13.6 & 635 & 41.9 & {$[88]$} \\
$\mathbf{C Z T S} / \mathbf{C d S}$ & 6.77 & 17.9 & 610 & 62 & {$[76]$} \\
$\mathbf{C Z T S} / \mathbf{C d S}$ & 8.4 & 19.5 & 661 & 65.8 & {$[77]$} \\
$\mathbf{C Z T S} / \mathbf{C d S}$ & 6.25 & 15.7 & 623 & 63.9 & {$[87]$} \\
$\mathbf{C Z T S} / \mathbf{C d S}$ & 6.77 & 17.9 & 610 & 62 & {$[89]$} \\
$\mathbf{C Z T S} / \mathbf{C d S}$ & 6.81 & 17.8 & 587 & 65 & {$[90]$} \\
$\mathbf{C Z T S} / \mathbf{C d S}$ & 1.3 & 7.13 & 582.4 & 32 & {$[91]$} \\
$\mathbf{C Z T S} / \mathbf{C d S}$ & 7.1 & 21.8 & 614.3 & 55.5 & {$[92]$} \\
$\mathbf{C Z T S} / \mathbf{C d S}$ & 6.7 & 19.9 & 592.4 & 57.6 & {$[92]$} \\
$\mathbf{C Z T S} / \mathbf{C d S}$ & 4.4 & 14.6 & 572.6 & 52.2 & {$[92]$} \\
$\mathbf{C Z T S} / \mathbf{C d S}$ & 4.0 & 16.1 & 546.7 & 45.8 & {$[92]$} \\
CZTS /CdS & 9.4 & 21.3 & 700 & 63 & {$[93]$} \\
\hline
\end{tabular}




\begin{tabular}{lccccc}
\hline CZTS /CdS & 2.6 & 14.2 & 650 & 28 & {$[93]$} \\
CZTS /CdS & 2.35 & 12.8 & 399.2 & 45.8 & {$[94]$} \\
$\mathbf{C Z T S} /$ CdS & 1.68 & 4.6 & 723.3 & 51 & {$[95]$} \\
$\mathbf{C Z T S} / \mathbf{C d S}$ & 2.08 & 5.5 & 723.3 & 54 & {$[95]$} \\
$\mathbf{C Z T S} / \mathbf{C d S}$ & 6.44 & 17.59 & 584 & 62.89 & {$[96]$} \\
$\mathbf{C Z T S} / \mathbf{C d S}$ & 3.7 & 16.5 & 420 & 53 & {$[97],[96]$} \\
$\mathbf{C Z T S} / \mathbf{C d S}$ & 4.1 & 13 & 541 & 59.7 & {$[98],[96]$} \\
$\mathbf{C Z T S} / \mathbf{C d S}$ & 4.59 & 15.44 & 545 & 54.57 & {$[99]$} \\
$\mathbf{C Z T S} / \mathbf{C d S}$ & 4.31 & 16.34 & 518 & 50.93 & {$[99]$} \\
$\mathbf{C Z T S} / \mathbf{C d S}$ & 3.91 & 14.62 & 526 & 50.81 & {$[99]$} \\
$\mathbf{C Z T S} / \mathbf{C d S}$ & 6.77 & 17.9 & 610 & 62 & {$[99],[96]$} \\
$\mathbf{C Z T S} / \mathbf{C d S}$ & 7.3 & 22 & 567 & 58.1 & {$[100],[96]$} \\
\hline
\end{tabular}

Table 5.4: Functional parameters of simulation based kesterite solar cell from literature.

\begin{tabular}{cccccc}
\hline Structure & PCE $(\%)$ & $\mathbf{J}_{\mathbf{s c}}\left(\mathbf{m A} / \mathbf{c m}^{\mathbf{2}}\right)$ & $\mathbf{V}_{\mathbf{O C}}(\mathbf{m V})$ & $\mathbf{F F}(\%)$ & Reference \\
\hline $\mathbf{C Z T S} / \mathbf{C d S}$ & 8.4 & 19.5 & 749 & 57.48 & {$[81]$} \\
$\mathbf{C Z T S} / \mathbf{C d S}$ & 18.05 & 25.67 & 1020 & 69.26 & {$[82]$} \\
$\mathbf{C Z T S} / \mathbf{C d S}$ & 12.03 & 24.786 & 744.7 & 65.19 & {$[60]$} \\
$\mathbf{C Z T S} / \mathbf{C d S}$ & 13.41 & 19.31 & 1000.2 & 69.35 & {$[96]$} \\
$\mathbf{C Z T S} / \mathbf{C d S}$ & 10.4 & 20.3 & 772 & 66.5 & {$[101]$} \\
$\mathbf{C Z T S} / \mathbf{C d S}$ & 8.4 & 20.3 & 661 & 62.7 & {$[101]$} \\
$\mathbf{C Z T S} / \mathbf{C d S}$ & 22.63 & 51.925 & 780 & 55.83 & {$[102]$} \\
$\mathbf{C Z T S} / \mathbf{Z n S e}$ & 15.90 & 48.441 & 684 & 48.00 & {$[102]$} \\
$\mathbf{C Z T S} / \mathbf{C d S}$ & 10 & 23.96 & 640 & 65.2 & {$[103]$} \\
$\mathbf{C Z T S} / \mathbf{C d S}$ & 23.45 & 29.23 & 1118.8 & 71.70 & {$[104]$} \\
$\mathbf{C Z T S} / \mathbf{C d S}$ & 23.45 & 29.23 & 1118.8 & 71.70 & {$[104]$} \\
$\mathbf{C Z T S} / \mathbf{I n} \mathbf{I}_{\mathbf{2}}$ & 11.68 & 26.66 & 770 & 56.96 & {$[105]$} \\
\hline
\end{tabular}

The proposed results including the defects and excluding the defects of CZTS based kesterite solar cell are shown in Table 5.5.

Table 5.5: Proposed results (with and without defects) of CZTS based kesterite solar cell.

\begin{tabular}{lccccc}
\hline & Structure & PCE (\%) & $\mathbf{J}_{\mathbf{S C}}\left(\mathbf{m A} / \mathbf{c m}^{2}\right)$ & $\mathbf{V}_{\text {OC }}(\mathbf{V})$ & FF (\%) \\
\hline Without Defects & CZTS /CdS & 23.72 & 44.87 & 0.64 & 82.54 \\
With Defects & CZTS /CdS & 3.67 & 15.57 & 0.637 & 42.8 \\
Experimental Data[88] & CZTS /CdS & 3.59 & 13.6 & 0.635 & 41.9 \\
\hline
\end{tabular}

The result of our proposed simulation work with previous simulation work is given in Figure 5.12 below and in Table 5.6 and 5.7. 


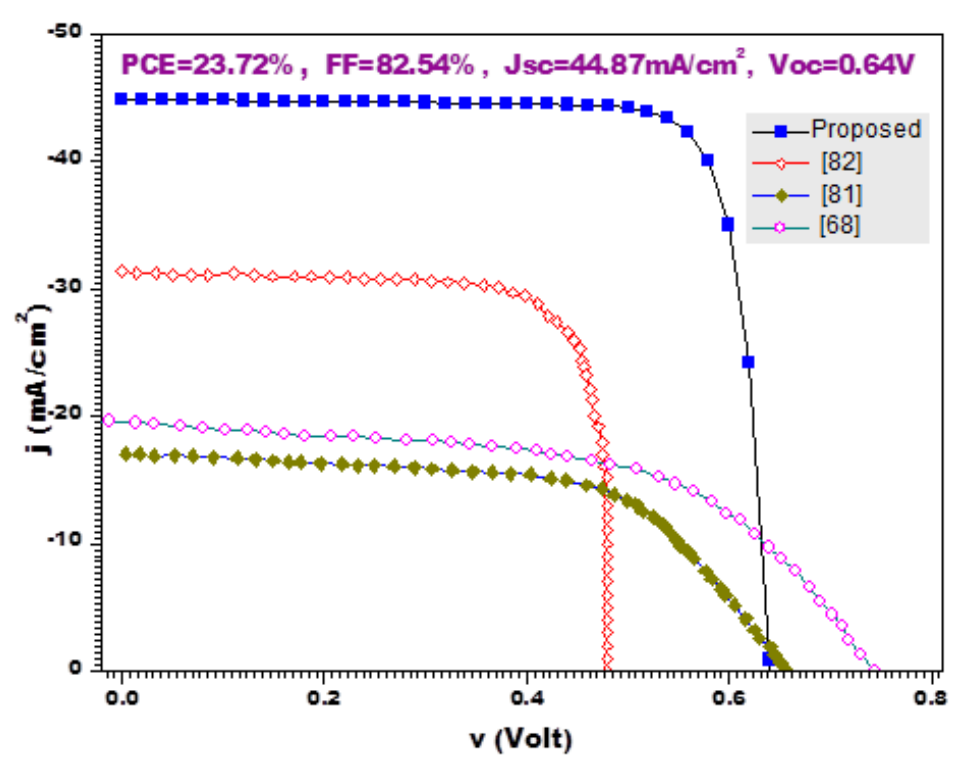

Figure 5.12: Comparison with simulated results $[68,81,82]$.

Table 5.6: Comparison of functional parameters with previous simulations.

\begin{tabular}{cccccc}
\hline Structure & PCE (\%) & JSC $_{\text {SC }}\left(\mathbf{m A} / \mathbf{c m}^{\mathbf{2}}\right)$ & $\mathbf{V}_{\mathbf{O C}}(\mathbf{V})$ & FF (\%) & Reference \\
\hline CZTS /CdS & 7.55 & 30.83 & 0.513 & 47.65 & {$[68]$} \\
CZTS /CdS & 8.4 & 19.5 & 0.749 & 57.48 & {$[81]$} \\
CZTS /CdS & 18.05 & 25.67 & 1.02 & 69.26 & {$[82]$} \\
CZTS /CdS & 23.72 & 44.87 & 0.64 & 82.54 & Proposed \\
\hline
\end{tabular}

Table 5.7: Comparison of physical optimized parameters with previous simulations.

\begin{tabular}{ccccc}
\hline CZTS & Ref. [68] & Ref. [81] & Ref. [82] & Proposed \\
\hline Thickness $(\boldsymbol{\mu m})$ & 2.2 & 0.6 & 3 & 4 \\
Acceptor Concentration $\left(\mathbf{c m}^{-3}\right)$ & $2 \times 10^{14}$ & $1 \times 10^{16}$ & $7 \times 10^{17}$ & $7 \times 10^{17}$ \\
\hline
\end{tabular}

\subsubsection{Conclusion}

In this work, we simulated the kesterite based $\mathrm{ZnO}$, CdS, CZTS, Mo solar cell on SCAPS software. This work is very helpful for the understanding of researchers, who are interested in the manufacturing of CZTS based kesterite solar cells. Different parameters which affected the performance of a photovoltaic cell and the conversion efficiency was explained. For the in-depth understanding of a solar cell, J - V characteristic measures are not enough to describe the behavior of a device because the response of the solar cell also depends on its internal physical mechanism. Forgetting the confidence in the modeling of a solar cell, different characteristics, as well as different possible conditions, are to be considered for simulation. In this work promising optimized results had been achieved 
with the conversion efficiency of $23.72 \%$, fill factor (FF) $82.54 \%$, short-circuit current $\left(\mathrm{J}_{\mathrm{sc}}\right) 44.87 \mathrm{~mA} / \mathrm{cm}^{2}$ and open circuit voltage $\left(\mathrm{V}_{\mathrm{oc}}\right) 0.64 \mathrm{~V}$. The results will give some important guidance for the feasible fabrication of higher efficiency CZTS based photovoltaic cells. From the accomplished results, it is clear to attain improved performance from solar cell numerical modeling plays a significant role.

\subsection{Efficiency enhancement of CZTS based experimental solar cell [106]}

This research work presents numerical modeling of experimentally designed CZTS solar cell by applying CZTSe as back surface field layer. In this work, we simulated the results for experimentally designed CZTS solar cell in SCAPS environment. The SCAPS results were compared with experimental results. After optimization of cell physical parameters, the power conversion efficiency of an optimized device was increased. With further optimization and by applying a BSF layer, the conversion efficiency was further increased. All the simulations were conducted under 1.5 AM solar radiation spectrum. The technique to boosts the photovoltaic cell conversion efficiency was the use of a back-surface field layer. In the comparison of the conventional device, the device with back surface filed layer gives much greater output voltage [56]. Rollover effect can be overcome by using proper BSF layer and also decreases the barrier height of the back contact and reduces the recombination loss of minority carrier at the back contact [107-109]. Our approach for the improvement of CZTS solar cell performance was by means of addressing the following facts:

i. Comparison and validation of simulated cell with an experimental cell.

ii. Further optimization of the validated simulation.

iii. By analyzing the minority carrier lifetime to improve the efficiency of a device.

iv. Proposing a back-surface field layer for further enhancing the conversion efficiency of a solar cell.

\subsubsection{Modeling parameters and solar cell structure}

Figure 5.13 shows our proposed photovoltaic cell structure Mo/CZTSe/CZTS/CdS/ZnO/ FTO, which comprises back contact layer Mo, absorber layer CZTS, back surface field layer CZTSe, buffer layer CdS, window layer ZnO and front contact FTO. These key elements of a device were used for determining the electrical as well as photoelectric characteristics of a solar cell. That is very helpful for the understanding of the performance of a device through numerical analysis. 


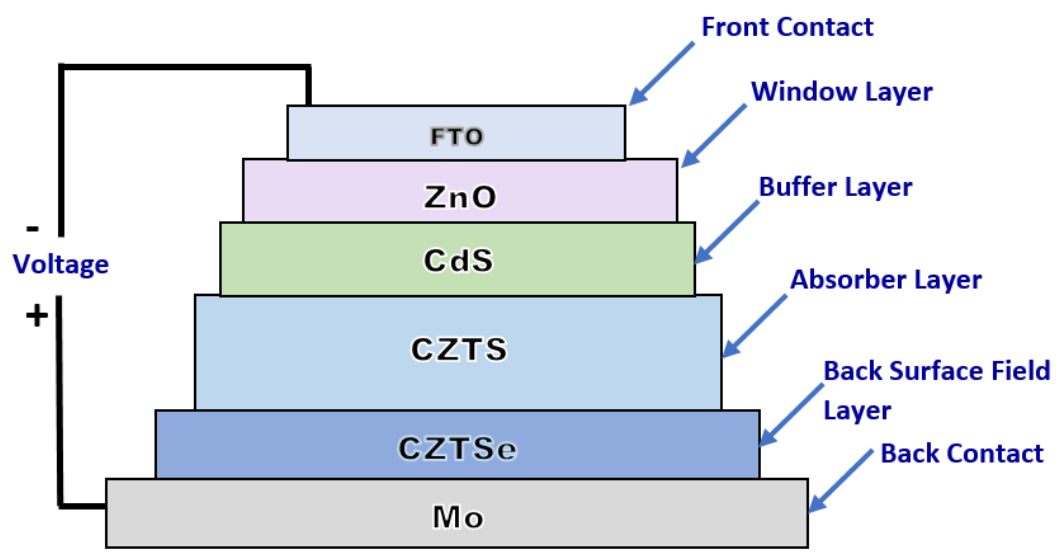

Figure 5.13: Block diagram of CZTS solar cell

All simulations were conducted under 1.5 AM solar radiation with the power density of $100 \mathrm{~mW} / \mathrm{cm}^{2}$ were used as an illuminating source. The simulation parameters used for numerical analysis of the device are listed in Table 5.8.

Table 5.8: Material parameters used in simulation for modeling CZTS based solar cells $[77,81,84]$.

\begin{tabular}{lccc}
\hline \multicolumn{1}{c}{ Parameters } & $\begin{array}{c}\text { n-ZnO } \\
\text { (Window) }\end{array}$ & $\begin{array}{c}\text { n-CdS } \\
\text { (Buffer) }\end{array}$ & $\begin{array}{c}\text { p-CZTS } \\
\text { (Absorber) }\end{array}$ \\
\hline Thickness, $\mathrm{W}(\mu \mathrm{m})$ & 0.1 & 0.1 & $1 \sim 4$ \\
Bandgap, $\mathrm{Eg}(\mathrm{eV})$ & 3.3 & 2.4 & 1.45 \\
Electron affinity, $\chi(\mathrm{eV})$ & 4.6 & 4.5 & 4.5 \\
Dielectric permittivity, $\varepsilon_{\mathrm{r}}$ & 9 & 9 & 9 \\
Effective Density of states, $\mathrm{NC}\left(\mathrm{cm}^{-3}\right)$ & $2.2 \times 10^{18}$ & $1.8 \times 10^{19}$ & $2.2 \times 10^{18}$ \\
Effective Density of states, $\mathrm{NV}\left(\mathrm{cm}^{-3}\right)$ & $1.8 \times 10^{19}$ & $2.4 \times 10^{18}$ & $1.8 \times 10^{19}$ \\
Electron mobility, $\mu_{\mathrm{e}}\left(\mathrm{cm}^{2} / \mathrm{Vs}\right)$ & 100 & 100 & 60 \\
Hole mobility, $\mu_{\mathrm{p}}\left(\mathrm{cm}^{2} / \mathrm{Vs}\right)$ & 25 & 25 & 20 \\
Electron and hole $c$ concentration, $\mathrm{n}, \mathrm{p}\left(\mathrm{cm}^{-3}\right)$ & $1 \times 10^{17}$ & $1 \times 10^{16}$ & $4 \times 10^{18}$ \\
\hline
\end{tabular}

\subsubsection{Validation of experimental results}

SCAPS-1D is a very helpful tool for the understanding of the researcher, to numerically analyze the device performance. By using this software, it is possible to simulate the experimental results in a soft environment that saves time. In this work for the validation of our work with experimental work, we first simulated the experimental results presented in [88]. There was good consistency between experimental presented and simulated results using the SCAPS software. The width of different layers was taken from the experimental work. The width of the absorber layer was $800 \mathrm{~nm}$, buffer layer width was $70 \mathrm{~nm}$ and window layer width of $60 \mathrm{~nm}$ [88]. The values added between interface of CZTS/CdS was $\mathrm{N}_{\mathrm{t}}=5 \times 10^{12}\left(\mathrm{~cm}^{-2}\right)$. In Table 5.9 Interface and absorber layer defect are given $[81,87]$. 
Table 5.9: Added value of interface and absorber material defects

\begin{tabular}{lcc}
\hline \multicolumn{1}{c}{ Defect properties } & $\begin{array}{c}(\mathbf{p}-\mathbf{C Z T S} / \mathbf{n}-\mathbf{C d S}) \\
\text { Interface defect }\end{array}$ & $\begin{array}{c}(\mathbf{p}-\mathbf{C Z T S}) \\
\text { Absorber layer defect }\end{array}$ \\
\hline Energy level with respect to Reference $(\mathrm{eV})$ & 0.6 & 0.6 \\
Total Density Nt & $5 \times 10^{12} \mathrm{~cm}^{-2}$ & $1 \times 10^{15} \mathrm{~cm}^{-3}$ \\
Capture Cross section area of electrons $\left(\mathrm{cm}^{2}\right) \delta_{\mathrm{e}}$ & $4 \times 10^{-18}$ & $4.4 \times 10^{-15}$ \\
Capture Cross section area of holes $\left(\mathrm{cm}^{2}\right) \delta_{\mathrm{h}}$ & $4 \times 10^{-18}$ & $4.4 \times 10^{-15}$ \\
\hline
\end{tabular}

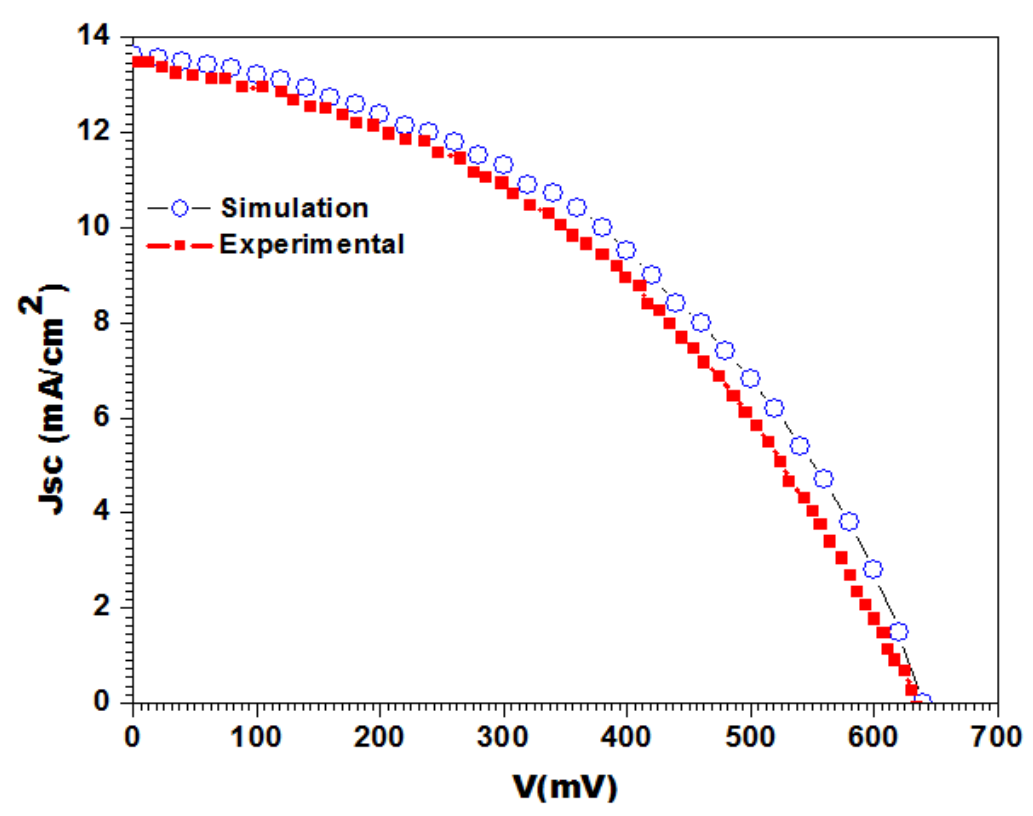

Figure 5.14: Comparison of SCAPS results with experimental data [88]

Figure 5.14 illustrates the simulated results of CZTS/CdS solar cell with defects and compared it with the experimental results obtained in [88]. The SCAPS results were very similar to experimental presented results. More detail study of those defects, it is probable that we can enhance the efficiency of $C Z T S / C d S$ solar cell.

\subsubsection{Device optimization}

\subsubsection{Energy band diagram}

The energy band diagram of CZTS/CdS simulated solar cells is shown in Figure 5.15. This energy band diagram was taken from the SCAPS for analysis purpose. Energy band diagram helps in explaining the properties of the solar cells. For incident light photons the band gap value that is optimal for most of light to be absorbed for effective conversion efficiency is greater or equal to the maximum band gap value of $1.45 \mathrm{eV}$. 


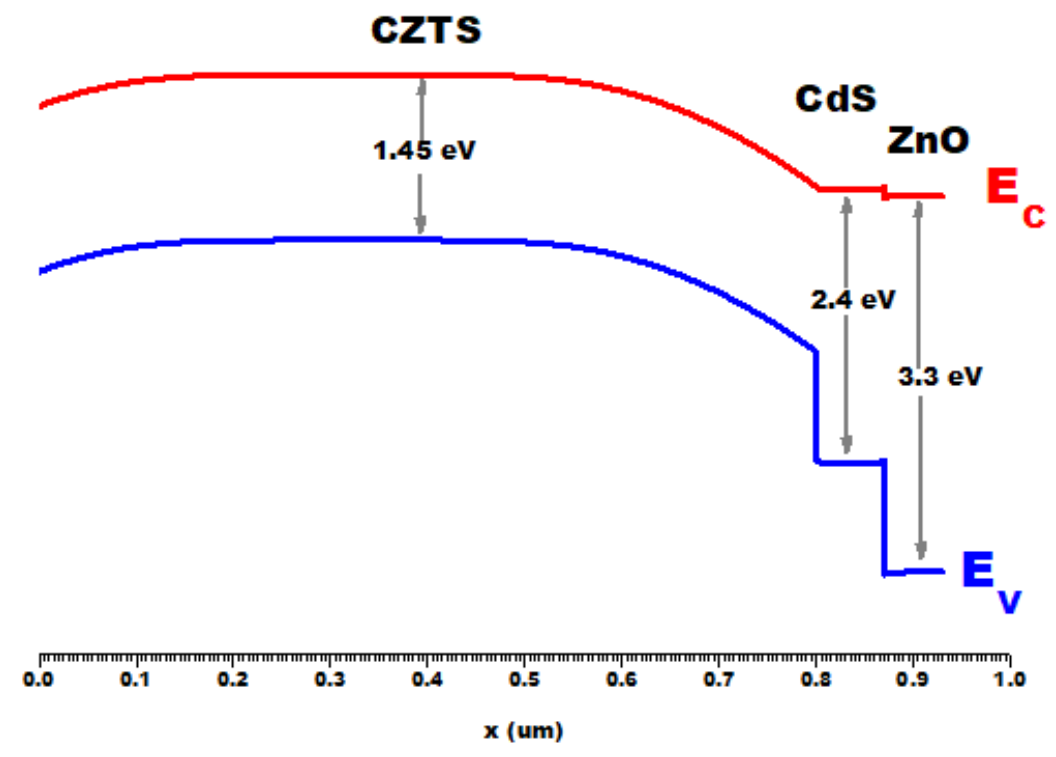

Figure 5.15: Energy band diagram.

\subsubsection{2 $J-V$ characteristics of $C d S / C Z T S$ solar cell}

Conversion of light energy into electrical energy is the main function of the photovoltaic cell. In the dark condition when there is no light, the photovoltaic solar cell is a large flat diode and produces the exponential J-V curve. The cell gives an extreme smallest value of current that is due to minority carriers in dark condition. In the light illumination condition solar cell starts working and current flows due to charge carriers generated by the incidence photons. The J-V characteristic curve of CZTS/CdS photovoltaic cell is given in Figure 5.16. The optimization of solar cell gives the conversion efficiency of $6.42 \%$ with a fill factor of $55.94 \%$, short circuit current of $20.43 \mathrm{~mA} / \mathrm{cm}^{2}$ and open circuit voltage of $562 \mathrm{mV}$.

\subsubsection{Acceptor doping concentration effect on device performance}

The acceptor concentration was varied from $1 \times 10^{15} \mathrm{~cm}^{-3}$ to $1 \times 10^{18} \mathrm{~cm}^{-3}$, simulation results are shown in Figure 5.17. Figure 5.17 demonstrates that $\mathrm{J}_{\mathrm{sc}}$ decreases with an increase in the doping concentration whereas $\mathrm{V}_{\mathrm{oc}}$ increases. The main reason behind is that with the increase of the carrier density, saturation current of a device also increases and then resultantly the $V_{\text {oc }}$ increases. $J_{\text {sc }}$ decrease since the higher carrier densities will boost the recombination process and reduce the probability of the collection of the photongenerated electrons. The photons of a longer wavelength having less energy are deeply absorbed in CZTS layer. Therefore, the collected conversion efficiency is more dependent on the influence of the concentration density. From Figure 5.17 it is very clear that FF and PCE also increase with an increase in the carrier concentration in absorber layer material. 
After reaching the optimal value of acceptor concentration, PCE decreases. The optimal value of the concentration of acceptor density of the absorber layer was $1 \times 10^{16} \mathrm{~cm}^{-3}$.

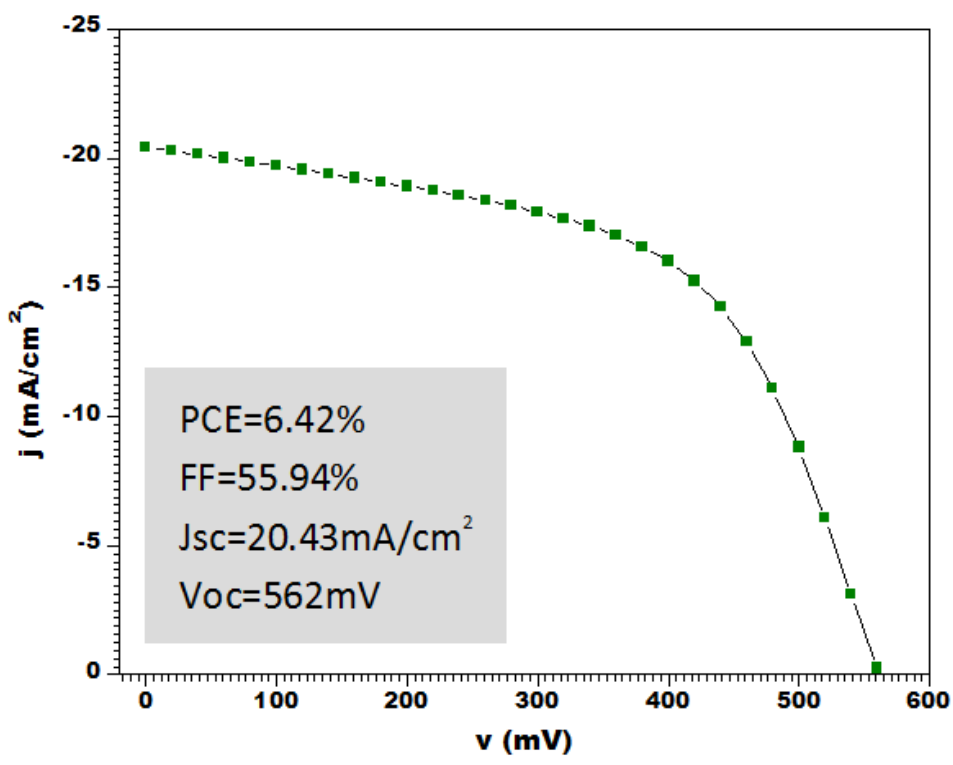

Figure 5.16: $J-V$ characteristics under light illumination.

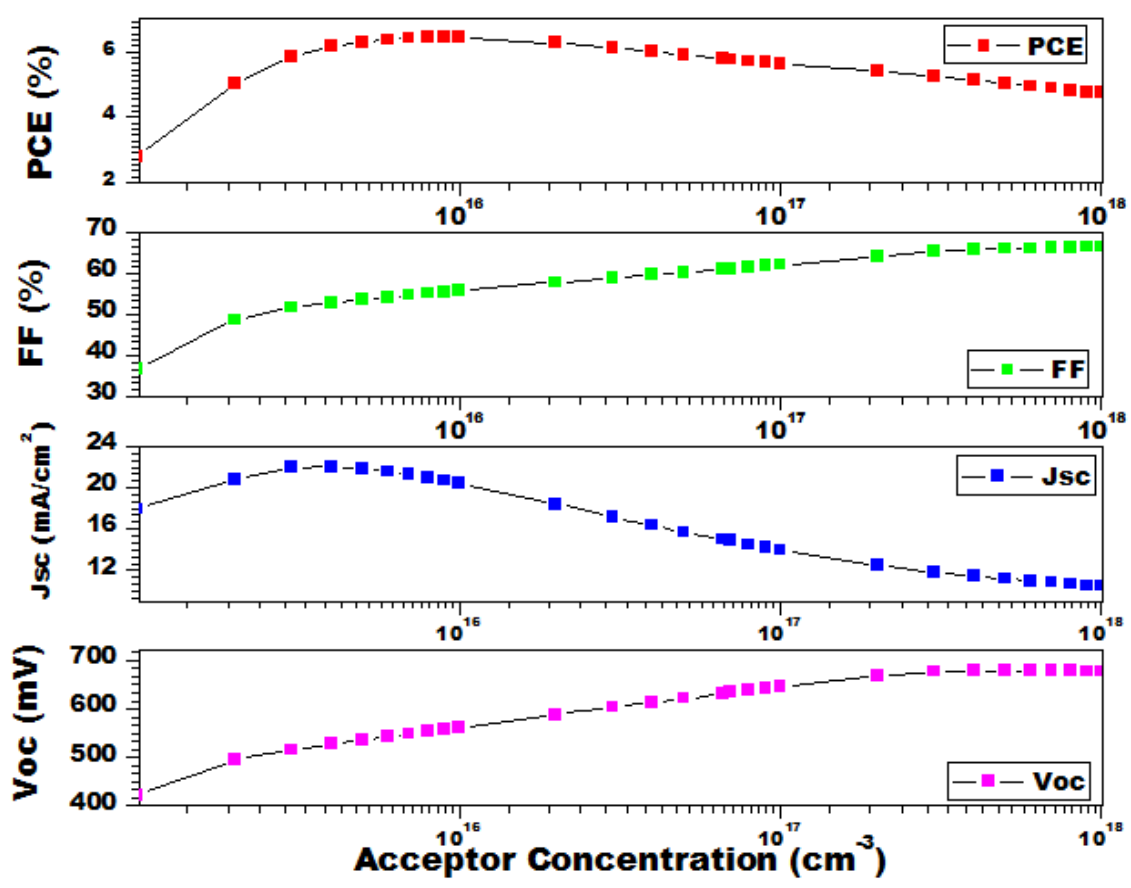

Figure 5.17: Acceptor concentration in the absorber layer.

\subsubsection{Buffer layer doping concentration on device performance}

The buffer layer donor concentration simulation results are shown in Figure 5.18. Donor concentration was varied from $1 \times 10^{15} \mathrm{~cm}^{-3}$ to $1 \times 10^{18} \mathrm{~cm}^{-3}$, The Figure illustrates that with increases in doping concentration, $\mathrm{J}_{\mathrm{sc}}$ and $\mathrm{V}_{\mathrm{oc}}$ increases. Conversion efficiency and fill factor of a device has slightly changed with an increase in doping concentration 
till reaching to the optimum value. The optimal value of the concentration of donor density of buffer layer was $1 \times 10^{18} \mathrm{~cm}^{-3}$.

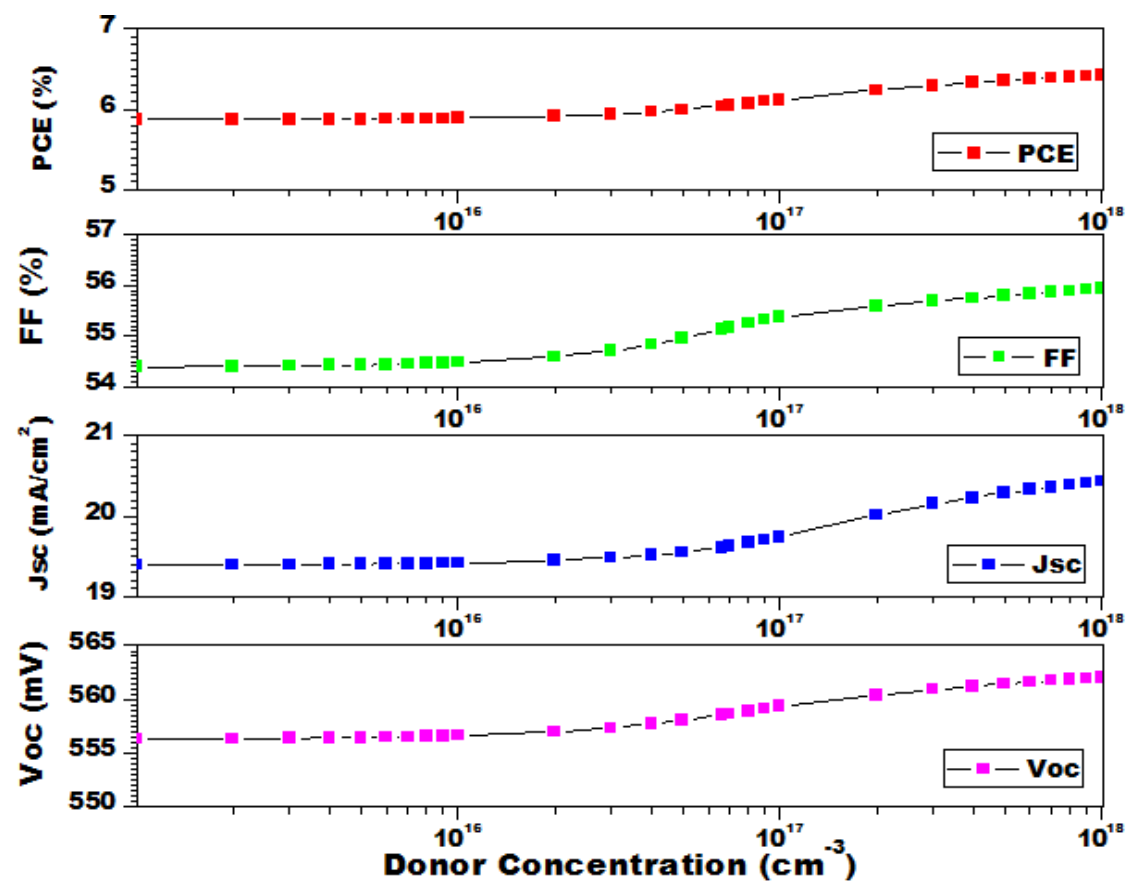

Figure 5.18: Donor concentration in the buffer layer.

\subsubsection{CZTS absorber thickness effect on device performance}

The absorber (CZTS) thickness effect on photovoltaic cell performance is shown in Figure 5.19 .

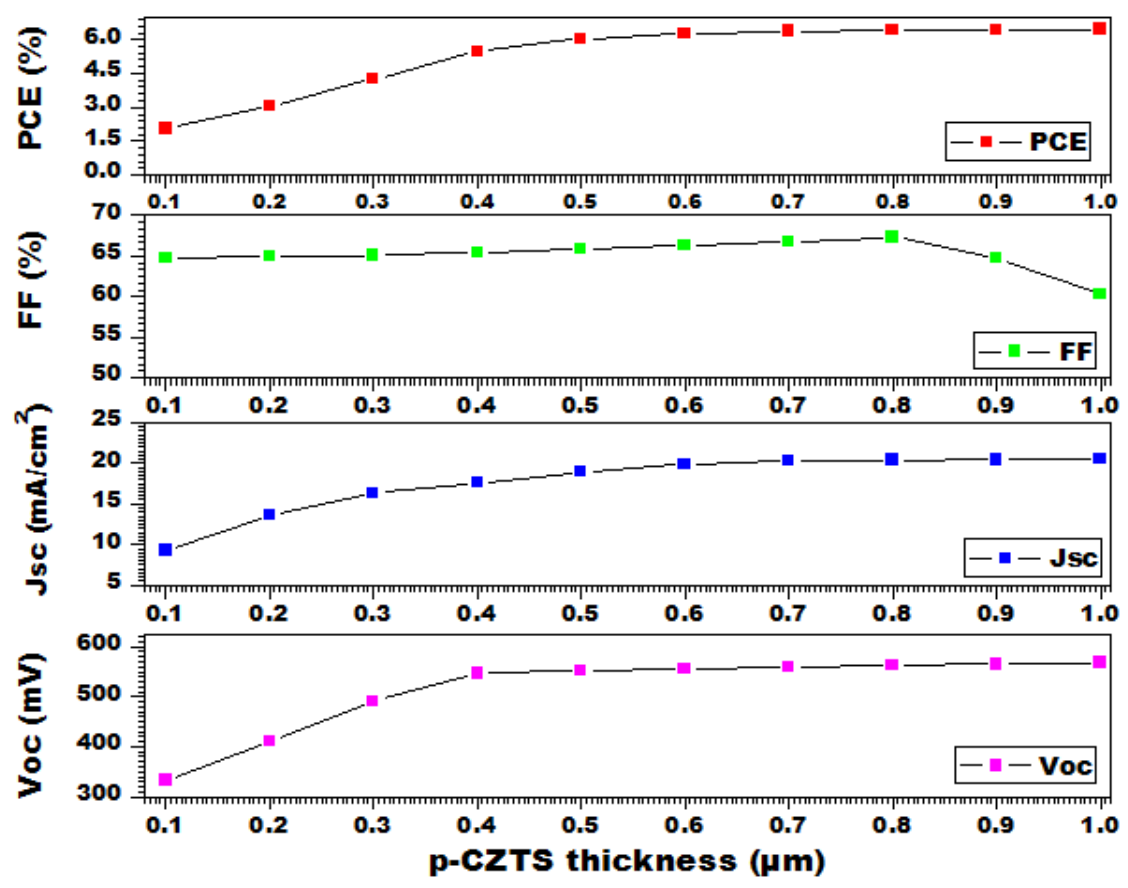

Figure 5.19: Effect of the absorber layer thickness on CZTS photovoltaic cells. 
Effect of the thickness of absorber layer was analyzed by altering of CZTS absorber layer thickness from $0.1 \mu \mathrm{m}$ to $1 \mu \mathrm{m}$, while other material parameters of different layers are kept unchanged. Power conversion efficiency (PCE) varied with a thickness of the absorber layer. With an increase in the thickness of an absorber layer, JSC increases with an increase of $\mathrm{V}_{\mathrm{OC}}$. PCE also increases with FF up to a point of optimal thickness. After reaching the optimal values conversion efficiency will remain constant but FF decreases. The decrease in FF happens because with an increase in thickness there will increase in series resistance. The increase of $\mathrm{J}_{\mathrm{SC}}$ with an increase of $\mathrm{V}_{\mathrm{OC}}$ is primarily due to more absorption of photons of longer wavelength and this will, in turn, affect the ratio of photo-generated carriers. The optimal value of the thickness of absorber layer was $0.8 \mu \mathrm{m}$.

\subsubsection{Buffer layer thickness effect on device performance}

The buffer layer thickness influence on the performance of a photovoltaic cell was also explored. The buffer layer thickness was varied from $0.01 \mu \mathrm{m}$ to $1 \mu \mathrm{m}$. Simulated results are shown in Figure 5.20. At the start there is an increase in solar cell parameters with an increase in buffer layer thickness, but after reaching to a thickness of $0.1 \mu \mathrm{m}, \mathrm{PCE}, \mathrm{FF}, \mathrm{J}_{\mathrm{SC}}$ and $\mathrm{V}_{\mathrm{OC}}$ starts to decrease. This happens because of a thicker buffer layer, where less photon will be absorbed. The thickness of buffer layer will increase the series resistance of a solar cell.

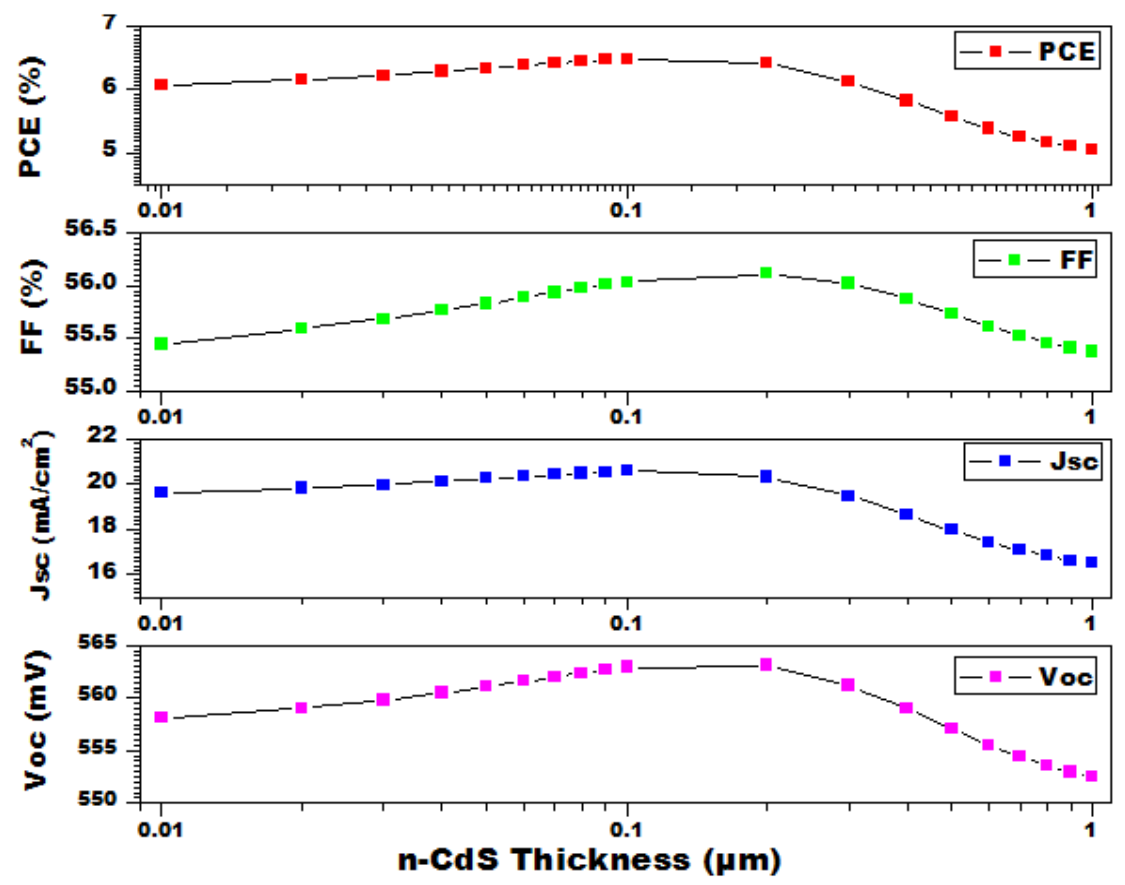

Figure 5.20: Effect of the buffer layer thickness on CZTS photovoltaic cells. 


\subsubsection{Effect of minority carrier lifetime}

Carrier lifetime $(\tau)$ is the average time required for a minority carrier to recombine. The minority carrier lifetime plays a most crucial role in the performance of a solar cell [110]. For the preparation of photovoltaic cell, minority carrier lifetime is one of the most imperative parameters for the characterization of semiconductor wafers. It is depending on the recombination rate as demonstrated in equation 5.2.

$$
\tau=\frac{\Delta \mathrm{n}}{\mathrm{R}}
$$

Where $\tau$ is minority carrier lifetime, $\mathrm{R}$ is the recombination rate and $\Delta \mathrm{n}$ is excess minority carrier concentration. The effect of minority carrier lifetime on the solar cell performance was also analyzed. The $J-V$ characteristics curve by changing the lifetime of minority carriers are shown in Figure 5.21. By improving minority carrier lifetime, enables the solar cell conversion efficiency from $6.4 \%$ to $9.61 \%$ [77]. Enhancement of the conversion efficiency by improving the carrier lifetime is well understood from Figure 5.21. The optimized results had been achieved with the conversion efficiency of $9.61 \%$, fill factor (FF) $57.23 \%$, short-circuit current $\left(\mathrm{J}_{\mathrm{sc}}\right) 26.45 \mathrm{~mA} / \mathrm{cm}^{2}$ and open circuit voltage $\left(\mathrm{V}_{\mathrm{oc}}\right)$ $634.85 \mathrm{mV}$.

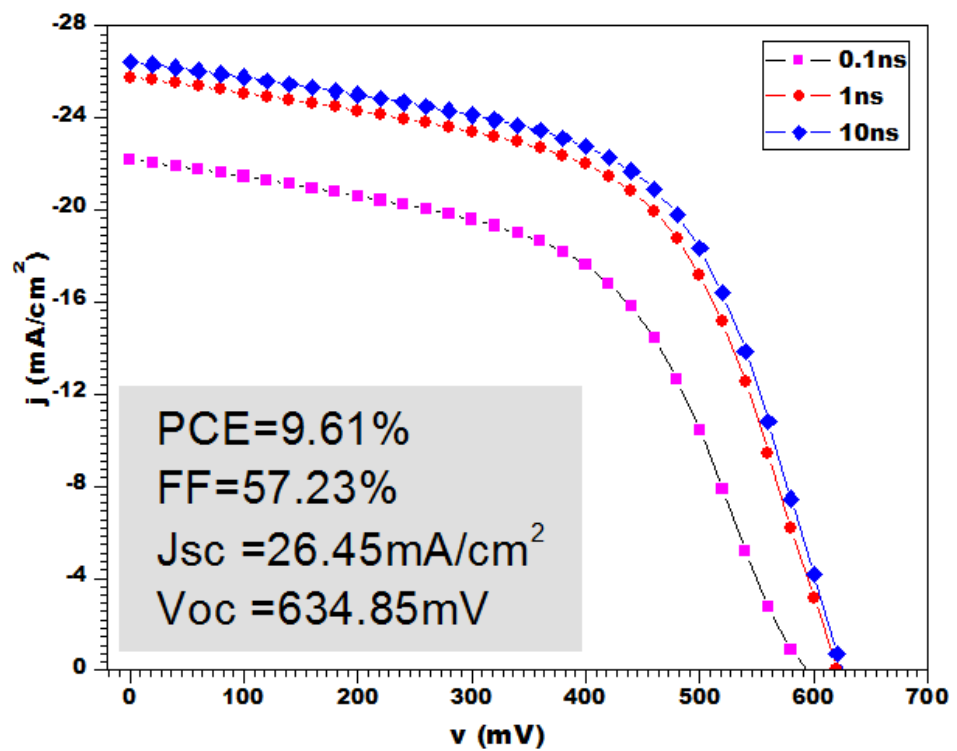

Figure 5.21: $J-V$ characteristics of a proposed solar cell with different carrier lifetime.

\subsubsection{Effect of CZTSe BSF layer}

The effect of a BSF layer on the solar cell performance was also analyzed. Energy band diagram of the proposed cell with a BSF layer is shown in Figure 5.22, which helps in explaining the properties of the solar cells. 


\section{CZTSe CZTS}

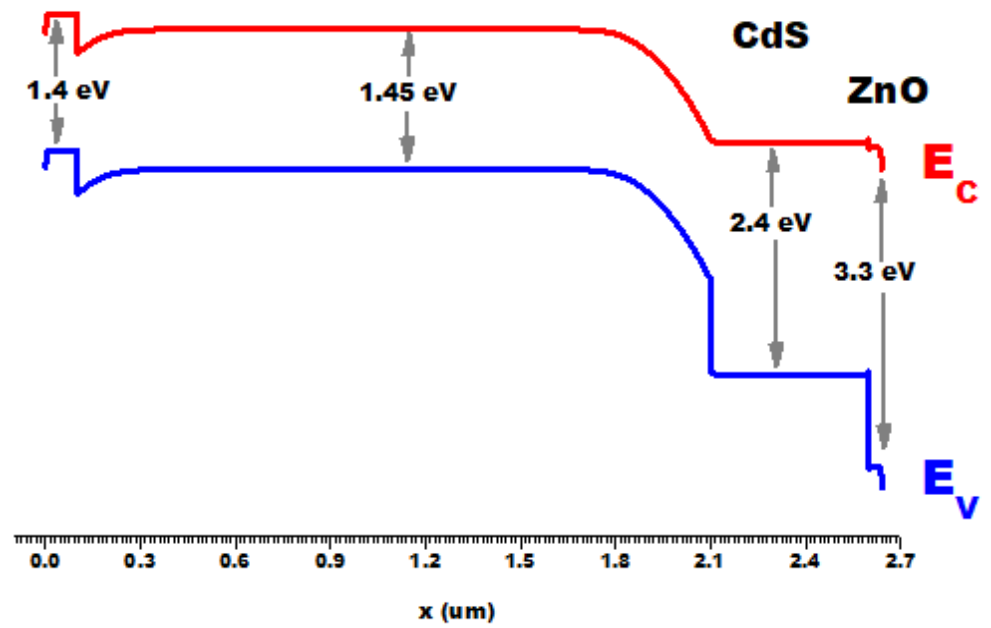

Figure 5.22: Energy band diagram of the proposed solar cell with BSF layer.

The high carrier concentration of a back-surface field layer can decrease the recombination of photogenerated carriers at back contact and makes the contact more ohmic, which increases the photocurrent by collecting more photoelectrons. CZTSe thin layer of about $0.1 \mu \mathrm{m}$ was considered as BSF layer because with an increase in thickness, there was a minor effect of BSF layer thickness on the performance of solar cell and the effect of BSF layer thickness is shown in Figure 5.23. The optimum thickness of $0.1 \mu \mathrm{m}$ was chosen because with an increase in BSF layer thickness there is a decrease in FF.

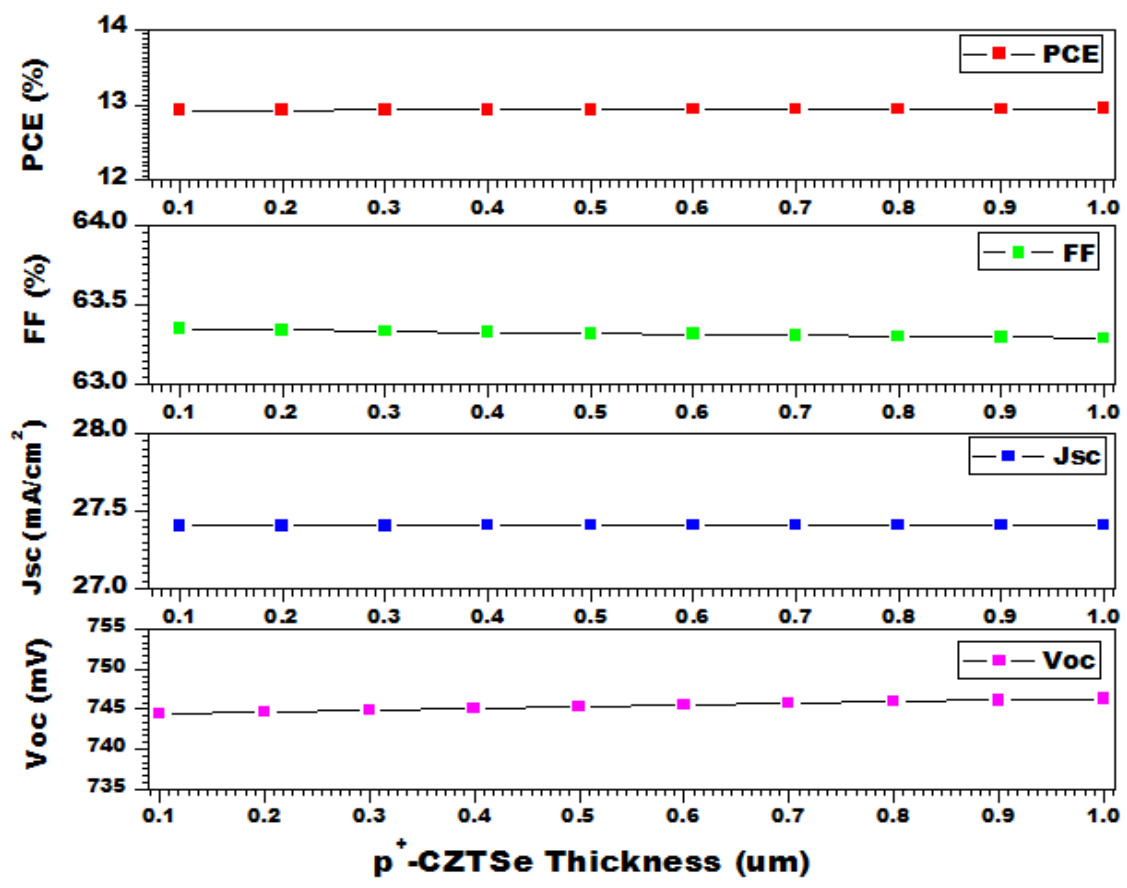

Figure 5.23: Effect of the BSF thickness on CZTS photovoltaic cells performance.

CZTSe has a low band gap which reduces the barrier height, decreases the possible recombination loss at the back contact of CZTS solar cell. The effect of the parameters like 
carrier concentration and thickness of CZTSe on the functional parameters of the solar cell was analyzed. The optimized acceptor carrier concentration for our proposed device was $1 \times 10^{19} \mathrm{~cm}^{-3}$ and the optimized thickness was $100 \mathrm{~nm}$. J $-\mathrm{V}$ characteristics curve of the proposed solar cell with a BSF layer is shown in Figure 5.24. The proposed device structure with BSF layer gives higher open circuit voltage as well as short circuit current than without BSF layer device. The BSF layer enables the solar cell conversion efficiency from $9.61 \%$ to $12.92 \%$ and fill factor from $57.23 \%$ to $63.35 \%$.

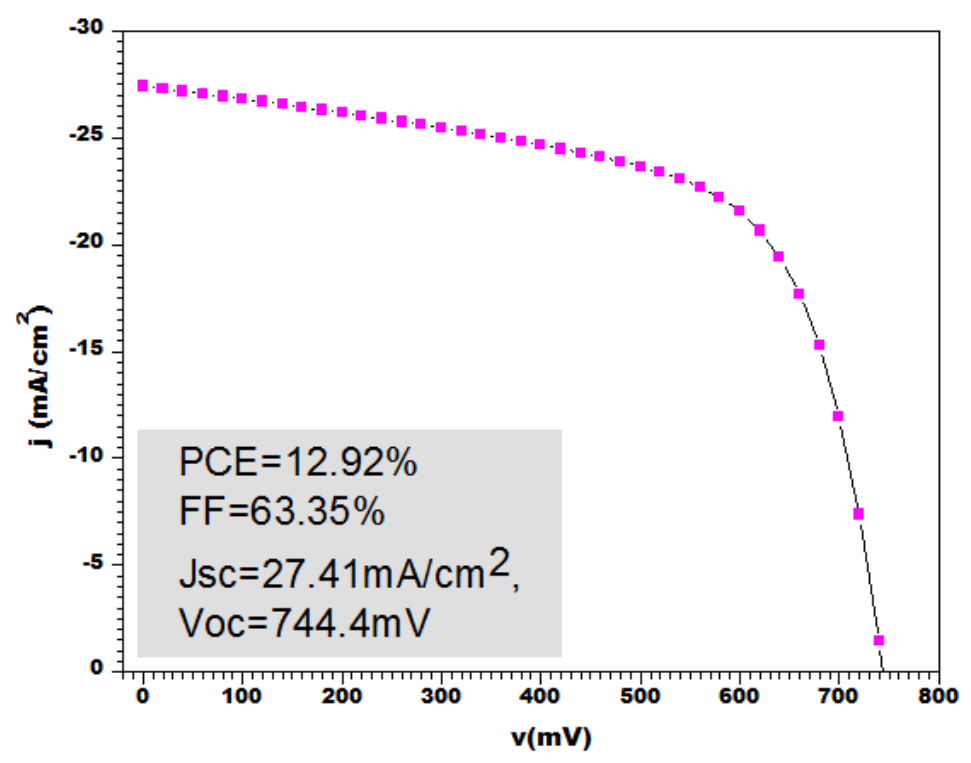

Figure 5.24: $J-V$ characteristics curve of the proposed solar cell with BSF layer.

The material properties of CZTSe as back surface field layer for simulation is given in Table 5.10.

Table 5.10: Simulation parameters of CZTSe as BSF layer[111].

\begin{tabular}{lc}
\hline \multicolumn{1}{c}{ Parameters } & p-CZTSe \\
\hline Thickness, $\mathrm{W}(\mu \mathrm{m})$ & 0.1 \\
Bandgap, $\mathrm{Eg}(\mathrm{eV})$ & 1.4 \\
Electron affinity, $\chi(\mathrm{eV})$ & 4.1 \\
Dielectric permittivity, $\varepsilon_{r}$ & 9 \\
Effective Density of states, $\mathrm{NC}\left(\mathrm{cm}^{-3}\right)$ & $2.2 \times 10^{18}$ \\
Effective Density of states, $\mathrm{NV}\left(\mathrm{cm}^{-3}\right)$ & $1.8 \times 10^{19}$ \\
Electron mobility, $\mu_{\mathrm{e}}\left(\mathrm{cm}^{2} / \mathrm{Vs}\right)$ & 100 \\
Hole mobility, $\mu_{\mathrm{p}}\left(\mathrm{cm}^{2} / \mathrm{Vs}\right)$ & 12.5 \\
Electron and hole concentration, $\mathrm{n}, \mathrm{p}\left(\mathrm{cm}^{-3}\right)$ & $1 \times 10^{19}$ \\
\hline
\end{tabular}

\subsubsection{Results comparison}

The comparison of JV characteristics curves of an experimental cell with the optimized solar cell, with an improved minority carrier lifetime and with applying BSF layer is shown 
in Figure 5.25. It illustrates a clear improvement for $\mathrm{J}_{\mathrm{SC}}$ and $\mathrm{V}_{\mathrm{OC}}$ in comparison to the reference cell. The experimental cell [88] was our reference solar cell, which was first reproduced in SCAPS. The defect densities were considered for the reproduction of the experimental results. The experimental device had a conversion efficiency of $3.59 \%$, FF $(41.9 \%), \mathrm{J}_{\mathrm{sc}}\left(13.6 \mathrm{~mA} / \mathrm{cm}^{2}\right)$ and $\mathrm{V}_{\mathrm{oc}}(635 \mathrm{mV})$.

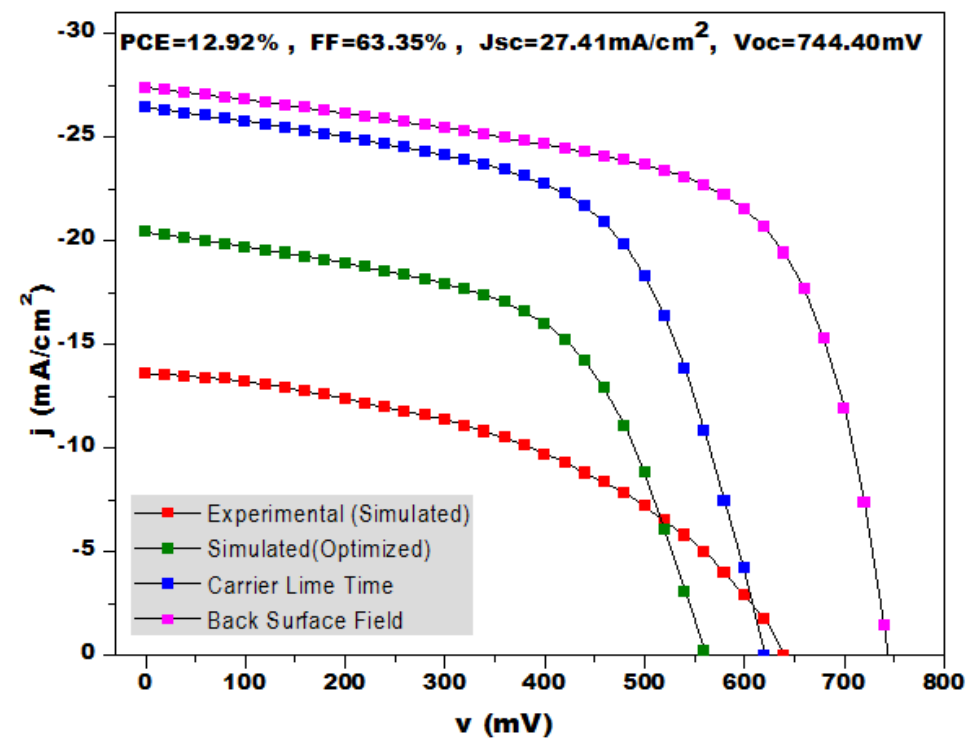

Figure 5.25: $J-V$ characteristics curve of the proposed solar cell with BSF layer.

Figure 5.25 shows that the functional parameters like power conversion efficiency (PCE), fill factor $(\mathrm{FF})$, short circuit current $\left(\mathrm{J}_{\mathrm{sc}}\right)$ and open circuit voltage $\left(\mathrm{V}_{\mathrm{oc}}\right)$, increases by optimizing the simulated reference cell. By improving minority carrier lifetime further increase in functional parameters are observed. Applying the CZTSe back surface field layer, more increase in functional parameters are achieved. All the improved parameters are given in Table 5.11. Which improves the overall performance of a solar cell. In this work, the promising results had been achieved with the conversion efficiency of $12.92 \%$, $\mathrm{FF}(63.35 \%), \mathrm{J}_{\mathrm{sc}}\left(27.41 \mathrm{~mA} / \mathrm{cm}^{2}\right)$ and $\mathrm{V}_{\text {oc }}(744.4 \mathrm{mV})$.

Table 5.11: Comparison of functional parameters.

\begin{tabular}{lcccc}
\hline & PCE (\%) & $\mathbf{J}_{\mathbf{S C}}\left(\mathbf{m A} / \mathbf{c m}^{2}\right)$ & $\mathbf{V}_{\mathbf{O C}}(\mathbf{m V})$ & FF (\%) \\
\hline Experimental (Simulated) & 3.67 & 13.8 & 637 & 42.8 \\
Simulated (Optimized) & 6.42 & 20.43 & 562 & 55.94 \\
Improved minority carrier life time & 9.61 & 26.45 & 634.85 & 57.23 \\
BSF layer & 12.92 & 27.41 & 744.4 & 63.35 \\
\hline
\end{tabular}

\subsubsection{Conclusion}

We simulate the kesterite based Mo/CZTSe/CZTS/CdS/ZnO/FTO structured solar cell using SCAPS software. Different parameters which affect the performance of a 
photovoltaic cell and the conversion efficiency is explained. At starting the experimental results were reproduced in the SCAPS program and then validate with experimental data. The influence of the minority carrier lifetime on the performance of solar cell was also analyzed. CZTSe as a back-surface field layer was also proposed, which further enhances the efficiency of a device. The promising results had been achieved with the conversion efficiency of $12.92 \%, \mathrm{FF}(63.35 \%), \mathrm{J}_{\mathrm{sc}}\left(27.41 \mathrm{~mA} / \mathrm{cm}^{2}\right)$ and $\mathrm{V}_{\mathrm{oc}}(744.4 \mathrm{mV})$. The results will give imperative guidance for the feasible fabrication of higher efficiency CZTS based photovoltaic cells. From the accomplished results, it is clear to achieve improved cell performance from solar cell numerical modeling plays a significant role. 
This page intentionally left blank 
CHAPTER 6

MODELING OF CFTS SOLAR CELL 
This page intentionally left blank 
Cadmium telluride (CdTe), copper indium gallium selenide (CIGS) and related alloy based thin-film chalcopyrite photovoltaic cells materials are commercially used for the fabrication of thin film photovoltaic devices because of high conversion efficiency, excellent electrical as well as optical properties [112] and also these types of devices have a high absorption coefficient $[2,68]$. The toxic materials restrict the further development of these types of cells and rare materials like indium and gallium used for the fabrication of solar cell also increase the fabrication cost [112]. Therefore, the commercial production of CIGS based photovoltaic cell is limited. Non-toxic earth abundant materials having kesterite symmetrical structure like CZTS $\left(\mathrm{Cu}_{2} \mathrm{ZnSnS}_{4}\right)$, CZTSe $\left(\mathrm{Cu}_{2} \mathrm{ZnSnSe}_{4}\right)[82,113-$ 116] and stannite structure CFTS $\left(\mathrm{Cu}_{2} \mathrm{FeSnS}_{4}\right)$, CFTSe $\left(\mathrm{Cu}_{2} \mathrm{FeSnSe}_{4}\right)$ and their alloys are emerging as the most auspicious replacement for the chalcopyrite absorbers (CIGS, CIGSe) by replacing indium ( $\mathrm{In}$ ) and gallium (Ga) materials with iron (Fe), zinc( $\mathrm{Zn}$ ) and tin (Sn) in the CIGS absorbers [6-8]. The growing attention towards these quaternary compounds for photovoltaic cells production is due to their potential [117-120]. Among these quaternary compounds, CFTS is one of the most promising compounds for an effective light absorber material due to its suitable optical band gap of $1.2-1.5 \mathrm{eV}$ [121-125] and large absorption coefficient $\alpha>10^{4} \mathrm{~cm}^{-1}[119,126-130]$. The power conversion efficiency of about $0.29 \%$ for CFTS based solar cell is presented in [131]. In [26], the reported conversion efficiency is $2.73 \%$.

\subsection{Baseline study for the modeling of CFTS based solar cell [30]}

$\mathrm{Cu}_{2} \mathrm{FeSnS}_{4}$ (CFTS) is auspicious nontoxic and earth-abundant semiconductor compound. It is an attractive and suitable material for the fabrication of low cost, high efficiency, and sustainable thin film photovoltaic cell. CFTS based photovoltaic cell device modeling was performed in this work. The influence of device parameters such as the thickness, acceptor and donor doping concentration densities of absorber and electron transport layer (ETL), the effect of back contact metal work function and the temperature effect on the performance of CFTS based photovoltaic cell was analyzed by using one-dimensional solar cell capacitance simulator (SCAPS-1D) software. In this work, promising optimized results had been achieved with the conversion efficiency of $19.97 \%$.

\subsubsection{Solar cell design and material parameters}

Baseline study of $M o / C F T S / \mathrm{TiO}_{2} /$ FTO structured photovoltaic cell was proposed in this work. In our simulations, the thickness of absorber layer (CFTS) varied from $1 \mu \mathrm{m}$ to $4 \mu \mathrm{m}$ 
and the bandgap energy was $1.3 \mathrm{eV}$. The band gap of electron transport layer was larger than that of absorber layer; hence, maximum photons were absorbed in CFTS, which will increase the overall conversion efficiency of a photovoltaic cell. Figure 6.1 shows the photovoltaic cell structure FTO/ $\mathrm{TiO}_{2} / \mathrm{CFTS} / \mathrm{Mo}$, which comprises back contact layer Mo, absorber layer CFTS, electron transport layer $\mathrm{TiO}_{2}$ and window layer FTO. We have investigated the influence of parameters like temperature variations, absorber layer dopant concentration and thickness, electron transport layer dopant concentration and thickness and illumination power of the sun, on the performance of our photovoltaic cell model. For optimum values of parameters (absorber layer thickness $4 \mu \mathrm{m}$ and acceptor carrier concentration $3 \times 10^{18} \mathrm{~cm}^{-3}$ ), we found a conversion efficiency of $19.97 \%$.

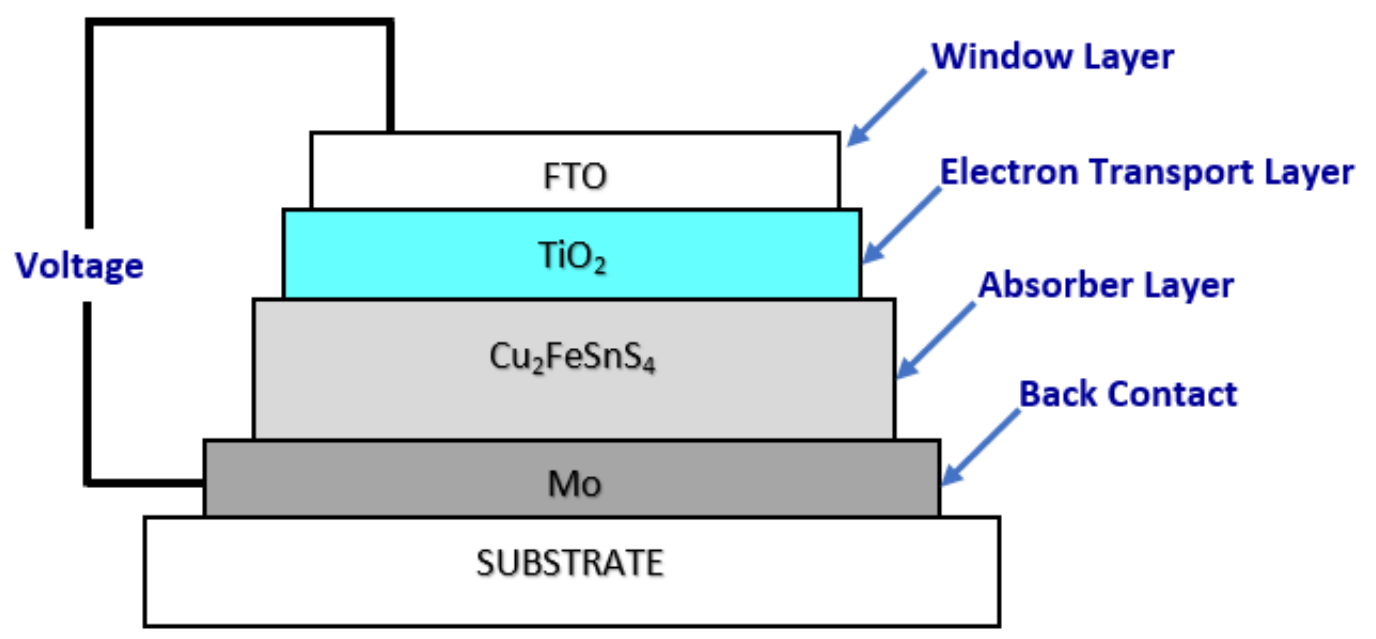

Figure 6.1: Block diagram of CFTS solar cell

The physical material parameters used in SCAPS-1D software for device modeling are given in Table 6.1. All the simulations are performed under AM 1.5 illumination.

Table 6.1: Baseline parameters for modeling CFTS based solar cells[132-134]

\begin{tabular}{lccc}
\hline \multicolumn{1}{c}{ Parameters } & p-CFTS & n-TiO & n-FTO \\
\hline Thickness, $\mathrm{W}(\mu \mathrm{m})$ & 4 & 0.4 & 0.5 \\
Band gap, Eg $(\mathrm{eV})$ & 1.3 & 3.2 & 3.5 \\
Electron affinity, $\chi(\mathrm{eV})$ & 3.3 & 3.86 & 4 \\
Dielectric permittivity, $\varepsilon_{\mathrm{r}}$ & 9 & 9 & 9 \\
Effective Density of states, $\mathrm{NC}\left(\mathrm{cm}^{-3}\right)$ & $2.2 \times 10^{18}$ & $1.8 \times 10^{19}$ & $1 \times 10^{19}$ \\
Effective Density of states, $\mathrm{NV}\left(\mathrm{cm}^{-3}\right)$ & $1.8 \times 10^{19}$ & $2.4 \times 10^{18}$ & $1 \times 10^{18}$ \\
Electron mobility, $\mu_{\mathrm{e}}\left(\mathrm{cm}^{2} / \mathrm{Vs}\right)$ & 21.98 & 100 & 20 \\
Hole mobility, $\mu_{\mathrm{p}}\left(\mathrm{cm}^{2} / \mathrm{Vs}\right)$ & 21.98 & 25 & 10 \\
Electron and hole $\mathrm{concentration} \mathrm{n}, \mathrm{p}\left(\mathrm{cm}^{-3}\right)$ & $3 \times 10^{18}$ & $1 \times 10^{15}$ & $1 \times 10^{18}$ \\
\hline
\end{tabular}




\subsubsection{Energy band diagram}

Energy band diagram of a proposed $\mathrm{CFTS} / \mathrm{TiO}_{2}$ device is shown in Figure 6.2 and was taken from SCAPS software. Energy band diagram helps in explaining the properties of a solar cell. For incident light photons the band gap value that is optimal for most of light to be absorbed for effective power conversion efficiency is greater or equal to the maximum band gap value of $1.3 \mathrm{eV}$.

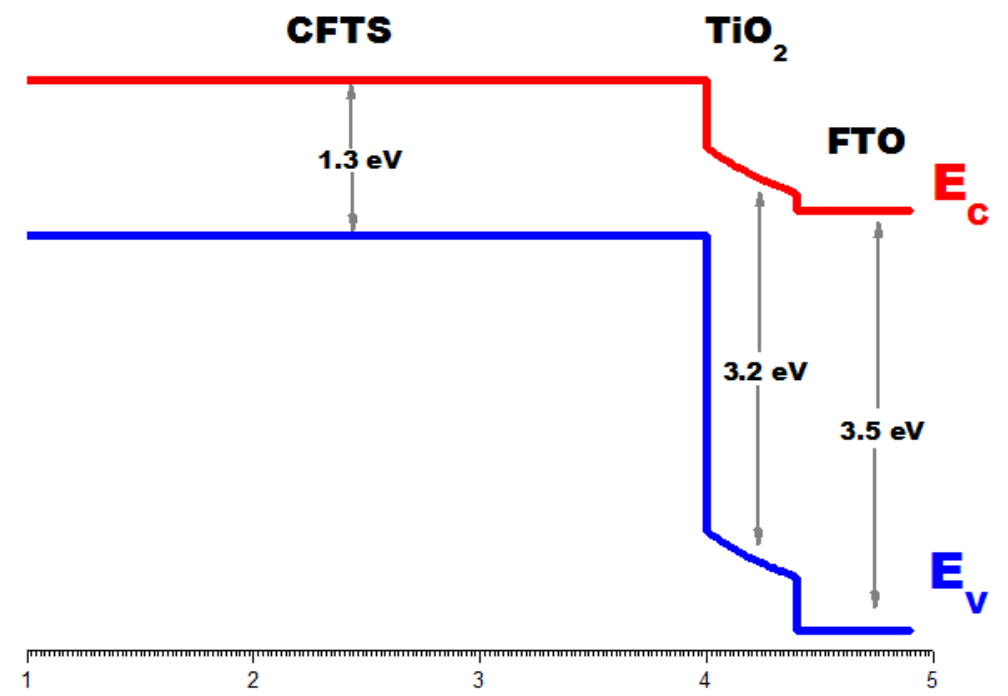

Figure 6.2: Energy band illustration of CFTS solar cell

\subsubsection{J - V characteristics of $\mathrm{CFTS}^{\mathrm{T}} \mathrm{TiO}_{2}$ photovoltaic cell}

The $\mathrm{J}-\mathrm{V}$ characteristic curve of $\mathrm{CFTS} / \mathrm{TiO}_{2}$ photovoltaic cell is given in Figure 6.3.

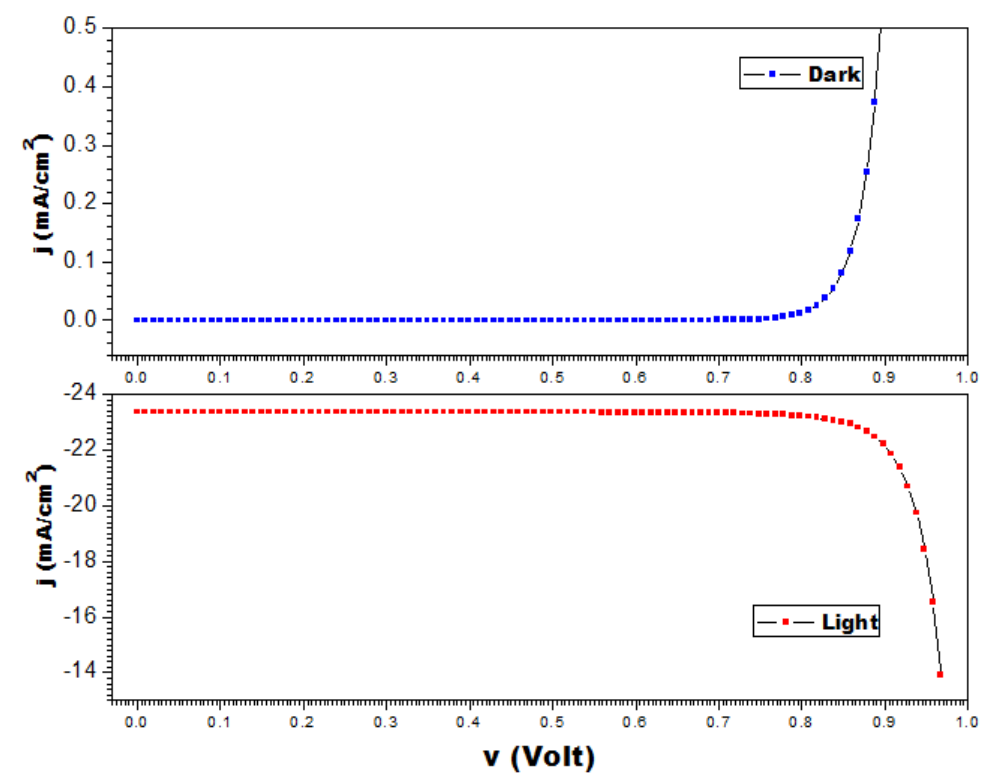

Figure 6.3: Dark vs light $J-V$ characteristics.

The main working of a photovoltaic cell is to convert sunlight energy into electricity. When there is an absence of light, the photovoltaic cell is a large flat diode and gives the 
exponential curve in $\mathrm{J}-\mathrm{V}$ measurements. The cell gives an extreme smallest value of current that is due to minority carriers in dark condition, as illustrated in Figure 6.3. Photovoltaic cell starts working under light illumination condition. Generation of charge carriers due to absorption of incident photons from sunlight in this state is the main reason for the flow of a current.

\subsubsection{CFTS absorber thickness effect on device performance}

The absorber layer (CFTS) thickness effect on photovoltaic cell performance is shown in Figure 6.4. Effect of the thickness of CFTS absorber layer was analyzed by varying the thickness value from $1 \mu \mathrm{m}-10 \mu \mathrm{m}$, while all other material parameters of different layers were constant. With increasing the absorber thickness, short circuit current $\left(\mathrm{J}_{\mathrm{SC}}\right)$ increases with an increase of open circuit voltage $\left(\mathrm{V}_{\mathrm{OC}}\right)$. Fill factor $(\mathrm{FF})$ and power conversion efficiency (PCE) are also increases up to a point of optimal thickness. After reaching the optimal absorber thickness values, fill factor starts to decrease. The increase in $\mathrm{J}_{\mathrm{SC}}$ with an increase of $\mathrm{V}_{\mathrm{OC}}$ and PCE up to optimal absorber thickness, is principally due to more absorption of photons of longer wavelength and this will in turn, affect the ratio of photogenerated carriers. The optimal value for absorber thickness layer was $4 \mu \mathrm{m}$.

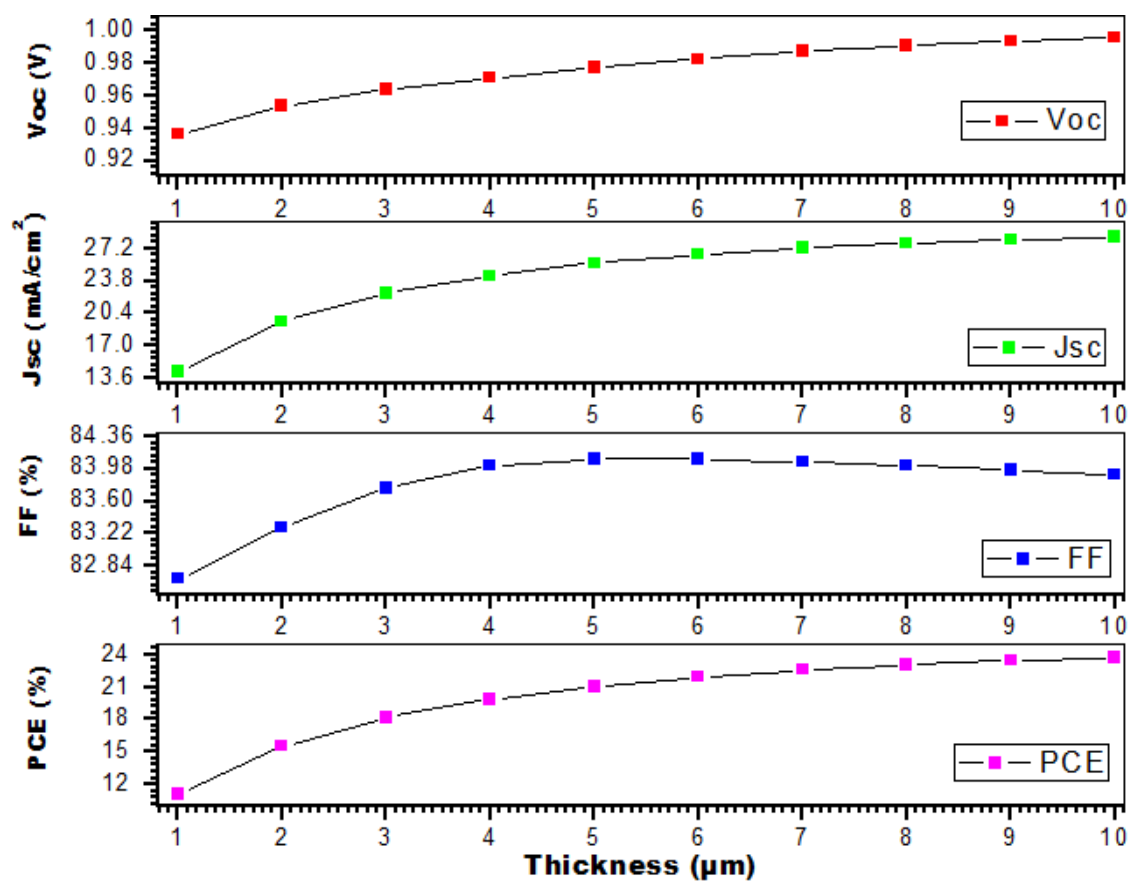

Figure 6.4: Effect of the absorber layer thickness on CFTS photovoltaic cells

\subsubsection{Acceptor doping concentration effect on device performance}

Acceptor concentration densities in absorber layer was varied from $1 \times 10^{18} \mathrm{~cm}^{-3}$ to $1 \times 10^{19} \mathrm{~cm}^{-3}$ as shown in Figure 6.5. The Figure illustrates that $\mathrm{V}_{\mathrm{oc}}$ rises with an 
increase in the acceptor doping concentration, whereas $J_{s c}$ decreases with an increase in the doping concentration. The main reason is that the saturation current of a device increases with the increase of the carrier concentration density and resultantly the $V_{\text {oc }}$ increases with increasing doping concentration. However, the short-circuit current will decrease with the increasing of carrier densities. This decrease in $\mathrm{J}_{\mathrm{sc}}$ with increasing doping concentration is because of the higher carrier densities will increase the recombination process and lessen the probability of the collection of the photon-generated electrons. So, the collected conversion efficiency is more dependent on the influence of the concentration density. From Figure 6.5, it is clear that power conversion efficiency and fill factor increase with an increase in the carrier concentration in absorber layer material. The optimal value of the concentration of acceptor density of the absorber layer was $3 \times 10^{18} \mathrm{~cm}^{-3}$.
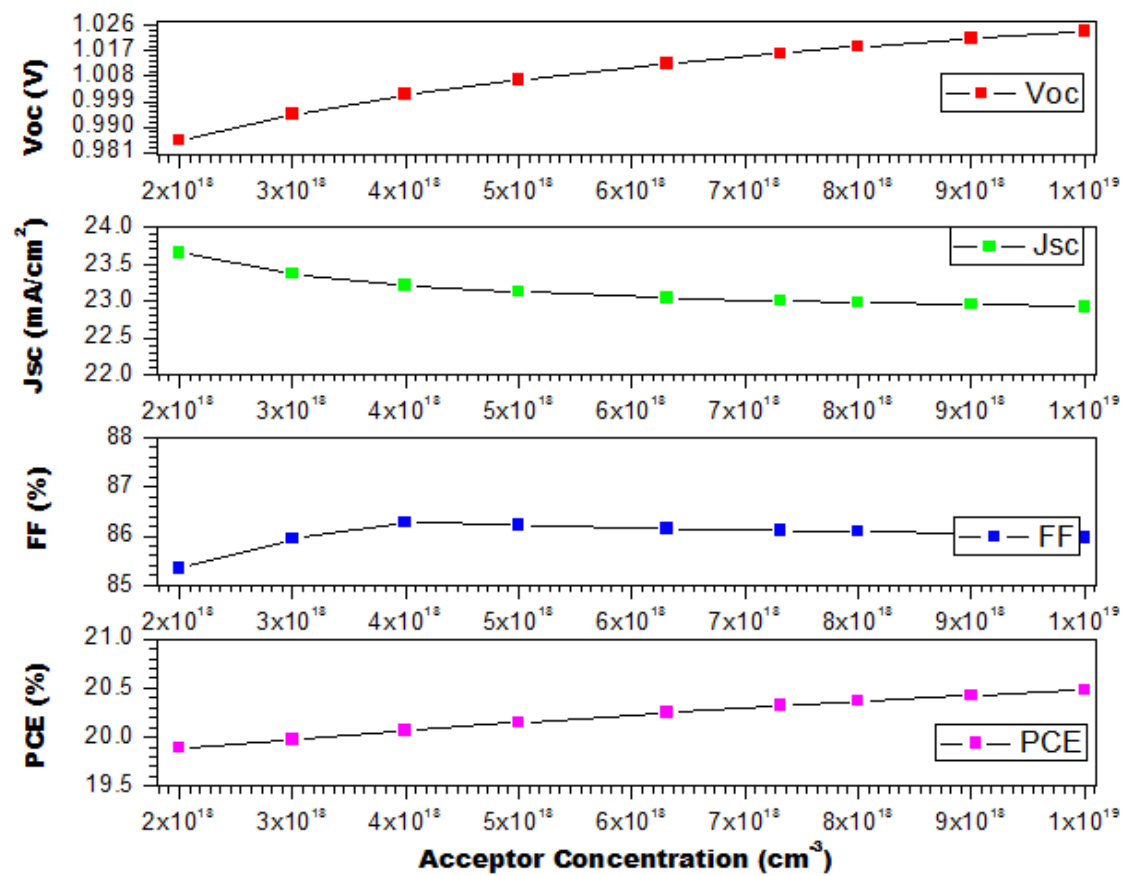

Figure 6.5: Acceptor concentration in the absorber layer.

\subsubsection{Electron transport layer effect on device performance}

$\mathrm{TiO}_{2}$ electron transport layer (ETL) influence on the performance of a photovoltaic cell was also explored and given in Figure 6.6. The ETL thickness was varied from $0.1 \mu \mathrm{m}$ to $1 \mu \mathrm{m}$. Simulated fallouts illustrate that with an increase in the ETL thickness, there was no change in short-circuit current $\left(\mathrm{J}_{\mathrm{sc}}\right)$, open circuit voltage $\left(\mathrm{V}_{\mathrm{oc}}\right)$, power conversion efficiency (PCE) and the Fill Factor (FF). Therefore, this result was comprehended that change in thickness of ETL layer did not affect the output of CFTS/TiO 2 photovoltaic device. For the designing of $\mathrm{CFTS} / \mathrm{TiO}_{2}$ based device, optimum thickness taken is $0.4 \mu \mathrm{m}$. 


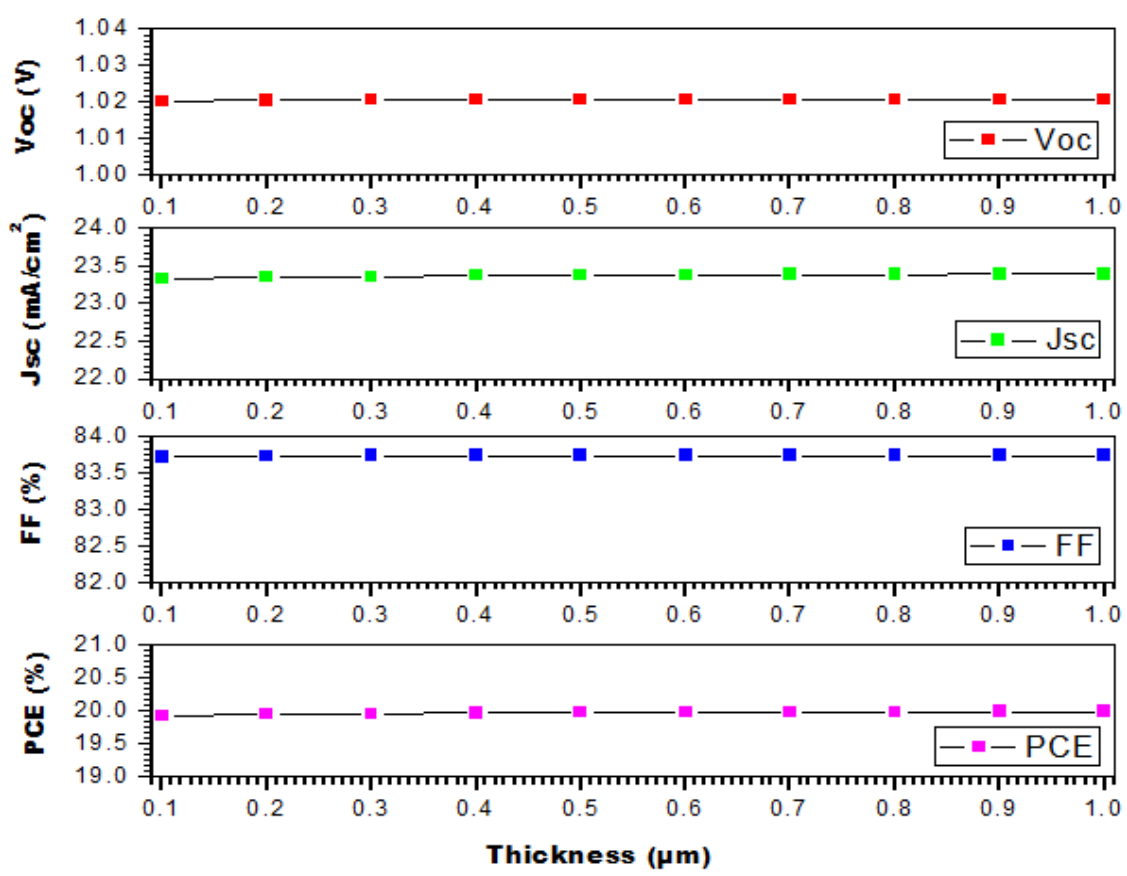

Figure 6.6: Effect of the Electron Transport Layer thickness on CFTS photovoltaic cells.
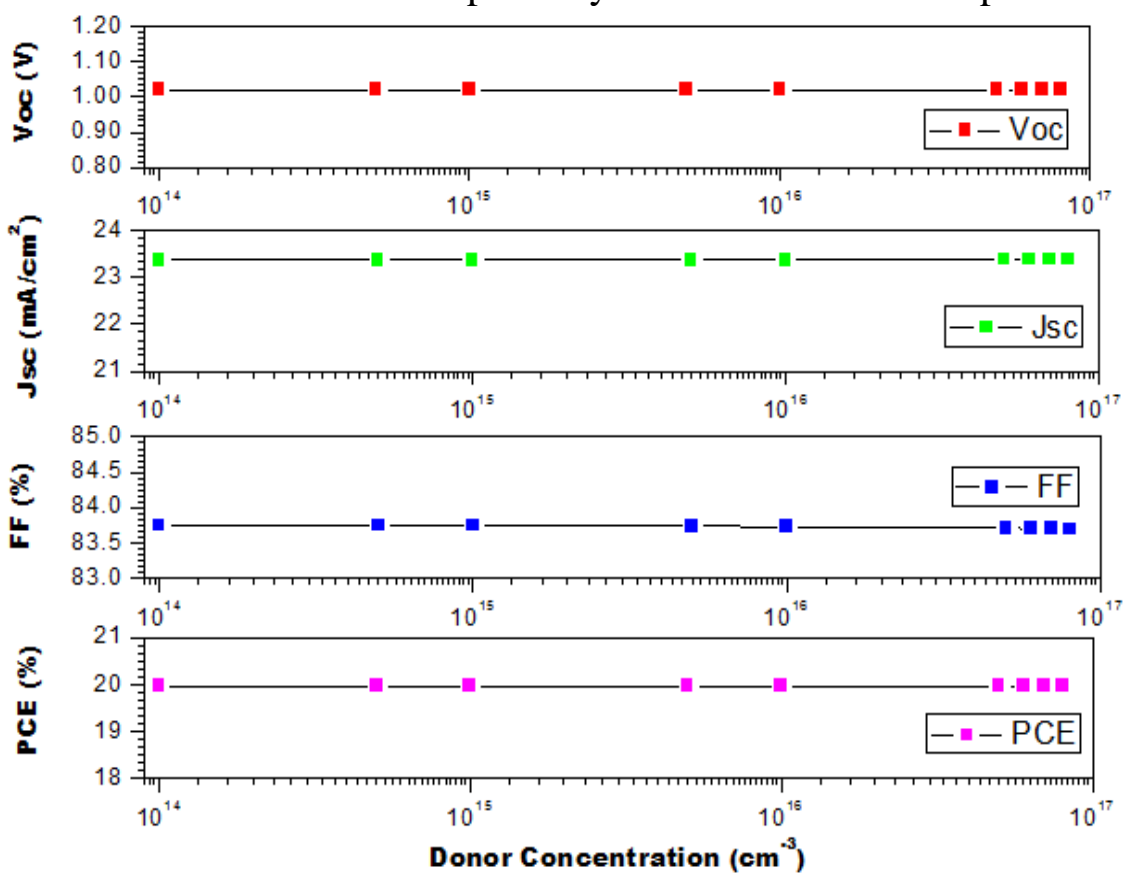

Figure 6.7: Donor concentration in the Electron Transport Layer.

The effect of ETL donor concentration on the device performance was analyzed by changing the concentration density value varied from $1 \times 10^{15} \mathrm{~cm}^{-3}$ to $1 \times 10^{17} \mathrm{~cm}^{-3}$. With an increase in doping concentration in ETL, there is no major change obtained that affects the performance of a device as illustrated in Figure 6.7. Therefore, this result was comprehended that by changing the ETL donor concentration, functional parameters of the photovoltaic device was not affected. For the designing of $\mathrm{CFTS} / \mathrm{TiO}_{2}$ based device, optimum donor doping concentration taken was $1 \times 10^{15} \mathrm{~cm}^{-3}$ 


\subsubsection{Back contact metal work function effect on JV characteristic curve}

Metal work function of back contact affected the performance of a solar cell. The metal work function is well illustrated in Figure 6.8. With an increase in the contact metal work function, open circuit voltage increases. Along with open circuit voltage, short circuit current also increases. This can be explained with the aid of energy band diagram shown in Figure 6.9 for the metal work function of $4.9 \mathrm{eV}$. From Figure 6.8, it can be seen that there is a conduction band offset which stops the flow of electrons to the back contact, thus helps in improving the open circuit voltage of a solar cell.

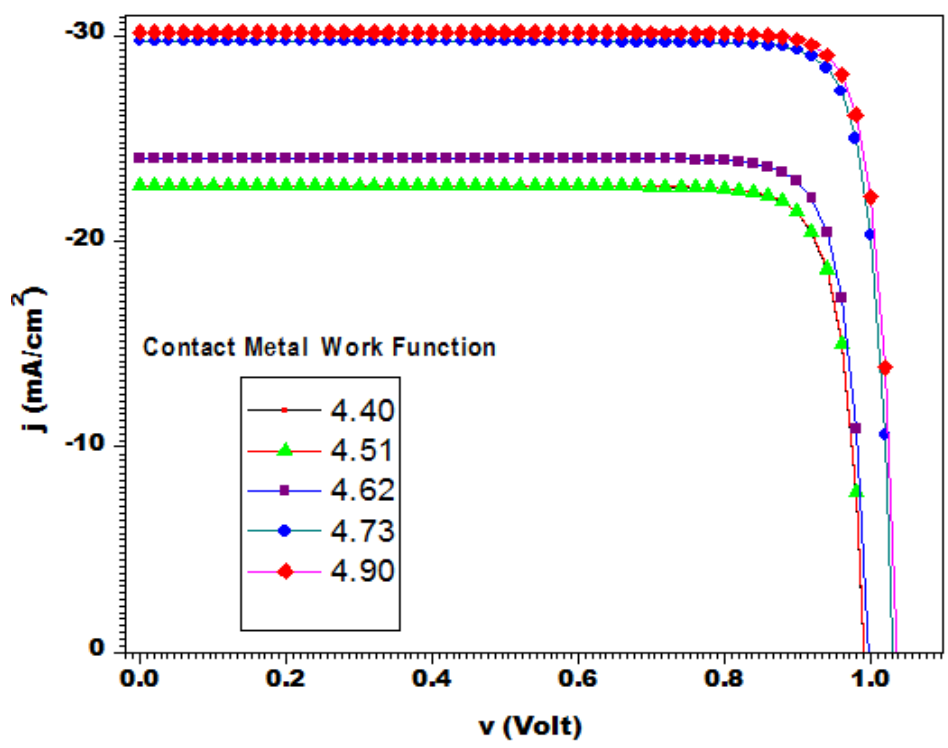

Figure 6.8: Back contact metal work function affecting JV characteristic curve.

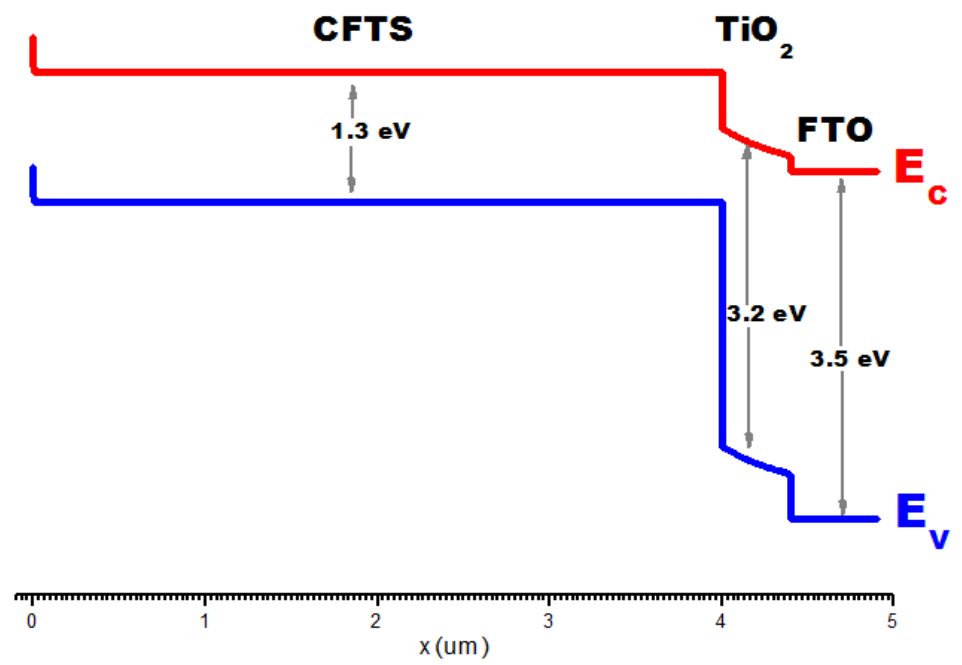

Figure 6.9: Energy band diagram illustration of back contact metal work function effect

\subsubsection{Effect of working temperature on photovoltaic cell performance}

Analysis of the device by means of its working temperature was explored to check the performance of a photovoltaic cell. The photovoltaic panels are installed in the open sky. 
Therefore, heating on photovoltaic cell increases due to the sunlight, which directly affects the performance of photovoltaic cells. The panels are operated at temperatures greater than $300 \mathrm{~K}$. The influence of the working temperature on the proposed device was also investigated. For inquiring the temperature effect, we took the temperature in a rage from $300 \mathrm{~K}$ to $500 \mathrm{~K}$. The simulation results are shown in Figure 6.10.

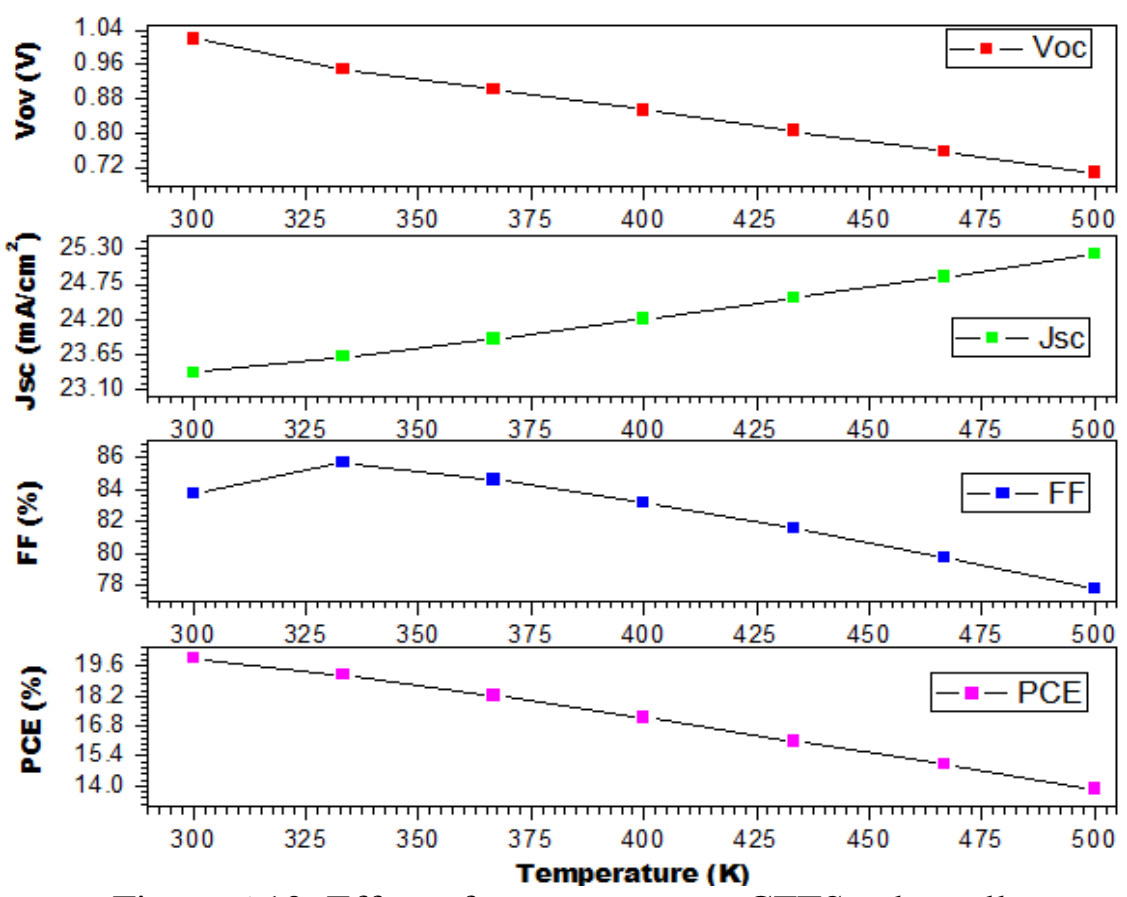

Figure 6.10: Effect of temperature on CFTS solar cell.

\subsubsection{Conclusion}

The baseline parameters of $\mathrm{FTO} / \mathrm{TiO}_{2}$ / CFTS/ Mo photovoltaic device was analyzed. This will be very helpful for designers, researchers, and engineers for analyzing and manufacturing CFTS based devices. The different parameters which affect the cell performance were described. For the in-depth understanding and getting the confidence in the modeling of a photovoltaic cell, different characteristics, as well as different possible conditions, were to be considered for simulation. In this work, promising optimized results had been achieved with the conversion efficiency of 19.97\%, fill factor (FF) $85.94 \%$, short-circuit current $\left(\mathrm{J}_{\mathrm{sc}}\right) 23.37 \mathrm{~mA} / \mathrm{cm}^{2}$ and open circuit voltage $\left(\mathrm{V}_{\mathrm{oc}}\right) 0.995 \mathrm{~V}$. The results will give imperative guidance for the feasible fabrication of higher efficiency CFTS based photovoltaic cells.

\subsection{Proposing novel structure for CFTS based solar cell [135]}

CFTS is earth abundant semiconductor compound having stannite symmetrical structure. It is an attractive and suitable class of material for the fabrication of low cost, high efficiency, and sustainable thin film photovoltaic cell. CFTS based photovoltaic 
cell device modeling was performed on SCAPS software. In this work, we analyzed the performance of CFTS/ZnS/Zn(O, S)/FTO thin film stannite solar cell. $\operatorname{Zn}(0, S)$ as buffer layer up till now had not been proposed for CFTS based solar cells. In this work impact of device parameters such as acceptor and donor doping concentration densities of absorber and buffer layers, and different layers thicknesses on the functional parameters were analyzed. Promising optimized functional parameters had been achieved.

$\mathrm{Zn}(\mathrm{O}, \mathrm{S})\left(\mathrm{ZnO}_{1-\mathrm{x}} \mathrm{S}_{\mathrm{x}}\right.$ with $\left.0<\mathrm{x} \leq 1\right)$ can be used as the buffer material for CFTS solar cell. Up till now, there was no model proposed with $\mathrm{Zn}(0, \mathrm{~S})$ as a buffer layer. It is the most promising material due to higher optical band gap and its non-toxic nature, which allows the collection of greater blue photons. By changing the $\mathrm{O}$ and $\mathrm{S}$ contents in $\mathrm{Zn}(\mathrm{O}, \mathrm{S})$ buffer layer, the conduction band offset $(\mathrm{CBO})$ value at the interface of the junction can be tuned [136-138]. In this work thickness of absorber layer (CFTS) varied from $1 \mu \mathrm{m}$ to $10 \mu \mathrm{m}$ and the bandgap energy was $1.3 \mathrm{eV}$. The band gaps of $\mathrm{ZnS}$ and $\operatorname{Zn}(0, S)$ buffer layers were larger than the absorber layer, therefore maximum photons were absorbed in CFTS. Due to this open circuit voltage $\left(\mathrm{V}_{\mathrm{oc}}\right)$ of solar cell increased, which also increased the overall conversion efficiency of the photovoltaic cell. The proposed results will give a valuable guideline for the designing of the higher performance of CFTS based stannite solar cells.

\subsubsection{Numerical modeling and material parameters}

Numerical analysis of the stannite based CFTS/ZnS/Zn(O,S)/FTOphotovoltaic cell structure is shown in Figure 6.11. CFTS works as absorber layer, $\mathrm{ZnS}$ and $\mathrm{Zn}(0, \mathrm{~S})$ as stacked buffer layers and FTO as a window layer. These layers were the key elements for determining the electrical as well as photoelectric characteristics of a solar cell.

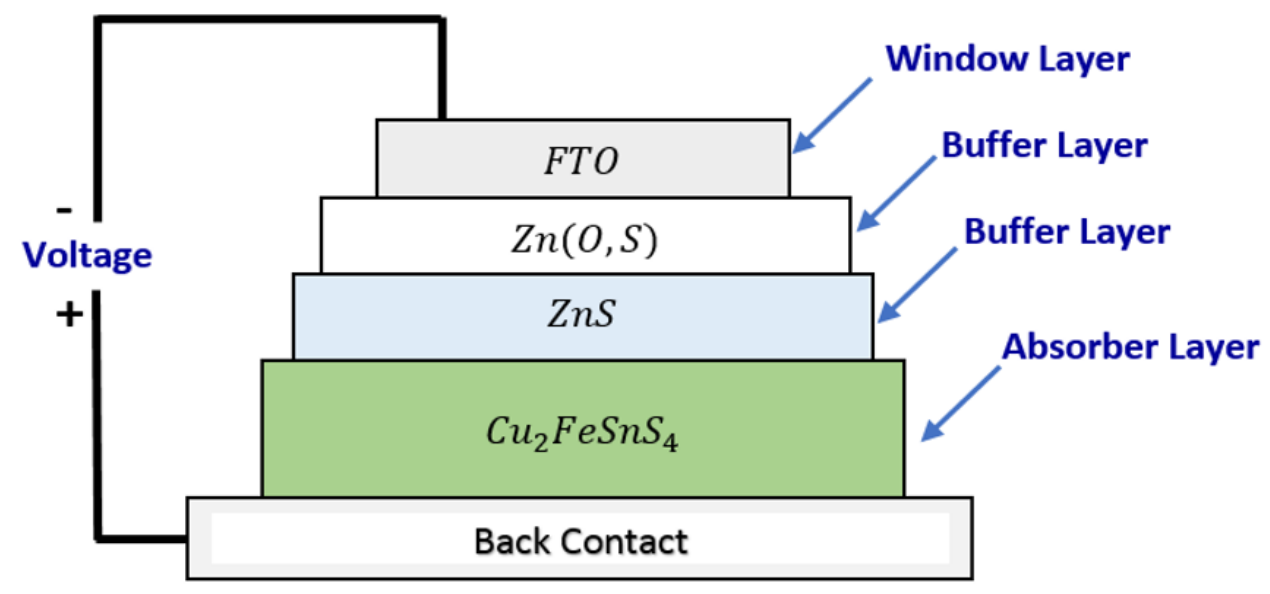

Figure 6.11: Block diagram of CFTS solar cell 
The analysis was performed on the parameters like the absorber layer dopant concentration and thickness, buffer and window layers dopant concentration and thickness and the effect of the illumination power of the sun had been investigated. All the simulations were conducted under AM 1.5 illumination spectrum. The input parameters used in our numerical analysis performed are listed in Table 6.2.

Table 6.2: Simulation parameters for modeling CFTS based solar cells

\begin{tabular}{lcccc}
\hline \multicolumn{1}{c}{ Parameters } & p-CFTS & n-ZnS & n-Zn $(\mathbf{O}, \mathbf{S})$ & n-FTO \\
\hline Thickness, $\mathrm{W}(\mu \mathrm{m})$ & 4 & 0.2 & 0.2 & 0.5 \\
Bandgap, Eg $(\mathrm{eV})$ & 1.3 & 3.6 & 3.2 & 3.5 \\
Electron affinity, $\chi(\mathrm{eV})$ & 3.3 & 3.44 & 3.86 & 4 \\
Dielectric permittivity, $\varepsilon_{\mathrm{r}}$ & 9 & 9 & 9 & 9 \\
Effective Density of states, $\mathrm{NC}\left(\mathrm{cm}^{-3}\right)$ & $2.2 \times 10^{18}$ & $1.8 \times 10^{19}$ & $1.8 \times 10^{19}$ & $1 \times 10^{19}$ \\
Effective Density of states, $\mathrm{NV}\left(\mathrm{cm}^{-3}\right)$ & $1.8 \times 10^{19}$ & $2.4 \times 10^{18}$ & $2.4 \times 10^{18}$ & $1 \times 10^{18}$ \\
Electron mobility, $\mu_{\mathrm{e}}\left(\mathrm{cm}^{2} / \mathrm{Vs}\right)$ & 21.98 & 100 & 100 & 20 \\
Hole mobility, $\mu_{\mathrm{p}}\left(\mathrm{cm}^{2} / \mathrm{Vs}\right)$ & 21.98 & 25 & 25 & 10 \\
Electron and hole concentration, $\mathrm{n}, \mathrm{p}\left(\mathrm{cm}^{-3}\right)$ & $3 \times 10^{18}$ & $5 \times 10^{16}$ & $1 \times 10^{18}$ & $1 \times 10^{18}$ \\
\hline
\end{tabular}

\subsubsection{Energy band diagram}

The proposed CFTS/ZnS $/ \mathrm{Zn}(0, \mathrm{~S})$ solar cell energy band diagram is shown in Figure 6.12. For the analysis of solar cell, energy band diagram was taken from the SCAPS and it helps in explaining the properties of the solar cells. For incident light photons the band gap value that is optimal for most of light to be absorbed for effective power conversion efficiency is greater or equal to the maximum band gap value of $1.3 \mathrm{eV}$.

\section{CFTS ZnS}

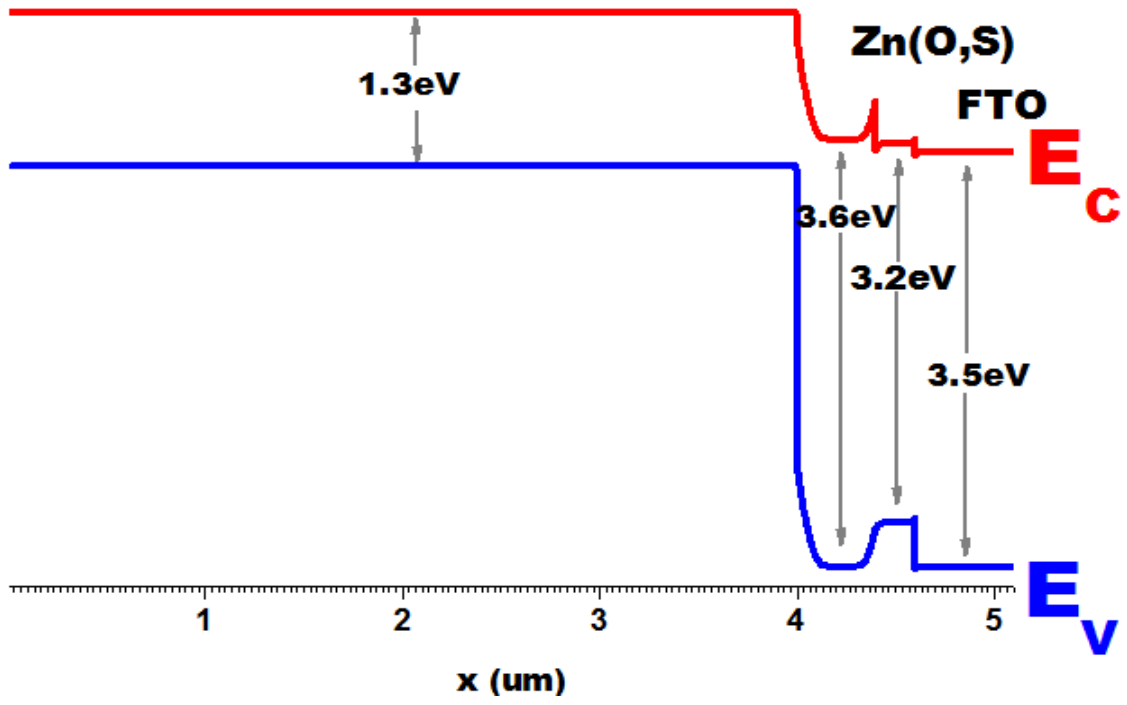

Figure 6.12: Energy band illustration of CFTS solar cell 


\subsubsection{J - V characteristics of CFTS/ZnS/Zn(O,S) photovoltaic cell}

The main working of a photovoltaic cell is to convert sunlight energy into electricity. When there is an absence of light, the photovoltaic cell is a large flat diode and gives the exponential curve in $\mathrm{J}-\mathrm{V}$ measurement. The cell gives an extreme smallest value of current that is due to minority carriers in dark condition as illustrated in Figure 6.13. Photovoltaic cell starts working under light illumination condition. Generation of charge carriers due to absorption of incident photons from sunlight in this state is the main reason for the flow of a current. The $J-V$ characteristic curve of CFTS/ZnS/Zn $(0, S)$ photovoltaic cell is given in Figure 6.13.

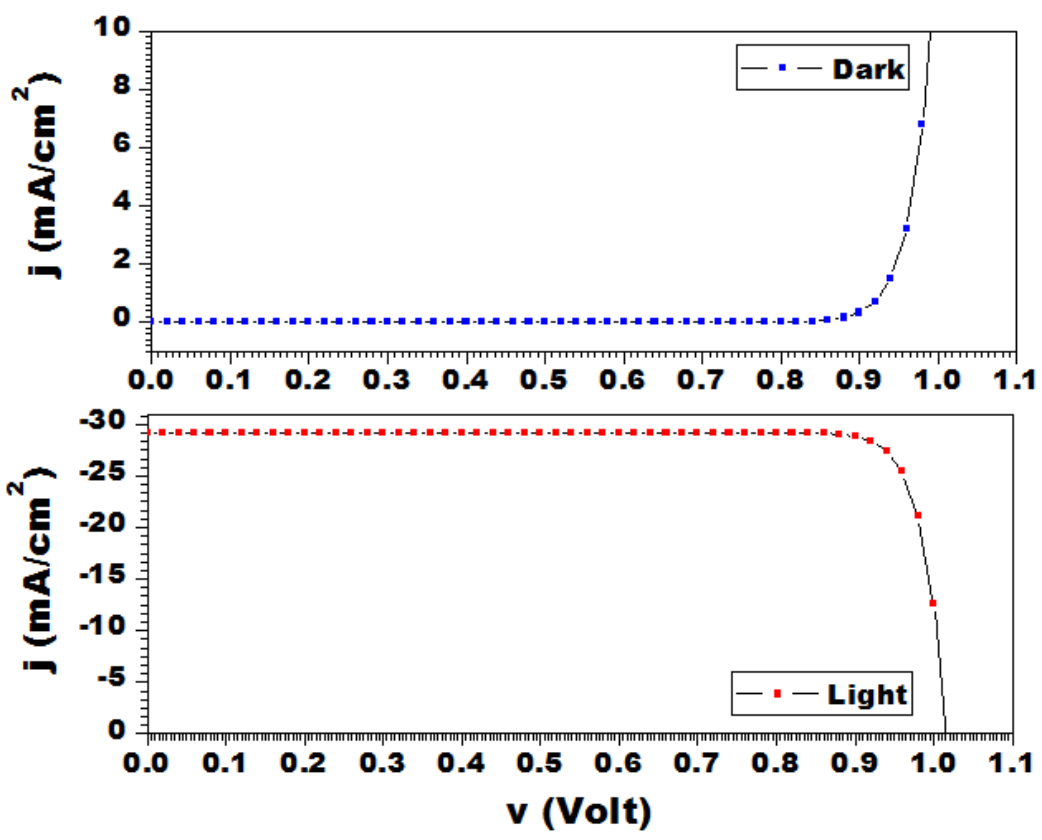

Figure 6.13: Dark vs light J - V characteristics.

\subsubsection{CFTS absorber thickness effect on device performance}

Increase in the thickness of the absorber layer gives a direct effect on the power conversion efficiency (PCE). With an increase in absorber layer thickness PCE increases and after meeting the optimum thickness value conversion efficiency remains constant as shown in Figure 6.14. After optimal thickness, if there is further increase in width, conversion efficiency starts to decrease. The absorber layer (CFTS) thickness effect on photovoltaic cell performance is shown in Figure 6.14. Effect of the thickness of CFTS absorber layer was analyzed by varying the thickness value from $1 \mu \mathrm{m}$ to $10 \mu \mathrm{m}$, while all other material parameters of different layers kept constant. With increasing the absorber thickness, short circuit current ( $\left.\mathrm{J}_{\mathrm{SC}}\right)$ increases, while after the optimal value there was a very small decrease in open circuit voltage $\left(\mathrm{V}_{\mathrm{OC}}\right)$ was 
observed. Fill factor (FF) also increased up to a point of optimal thickness. After reaching the optimal absorber thickness values, fill factor starts to decrease. The increase in $\mathrm{J}_{\mathrm{SC}}$ with an increase of PCE is principally due to more absorption of photons of longer wavelength and this will, in turn, affect the ratio of photo-generated carriers. The optimal value for absorber thickness layer was $4 \mu \mathrm{m}$.

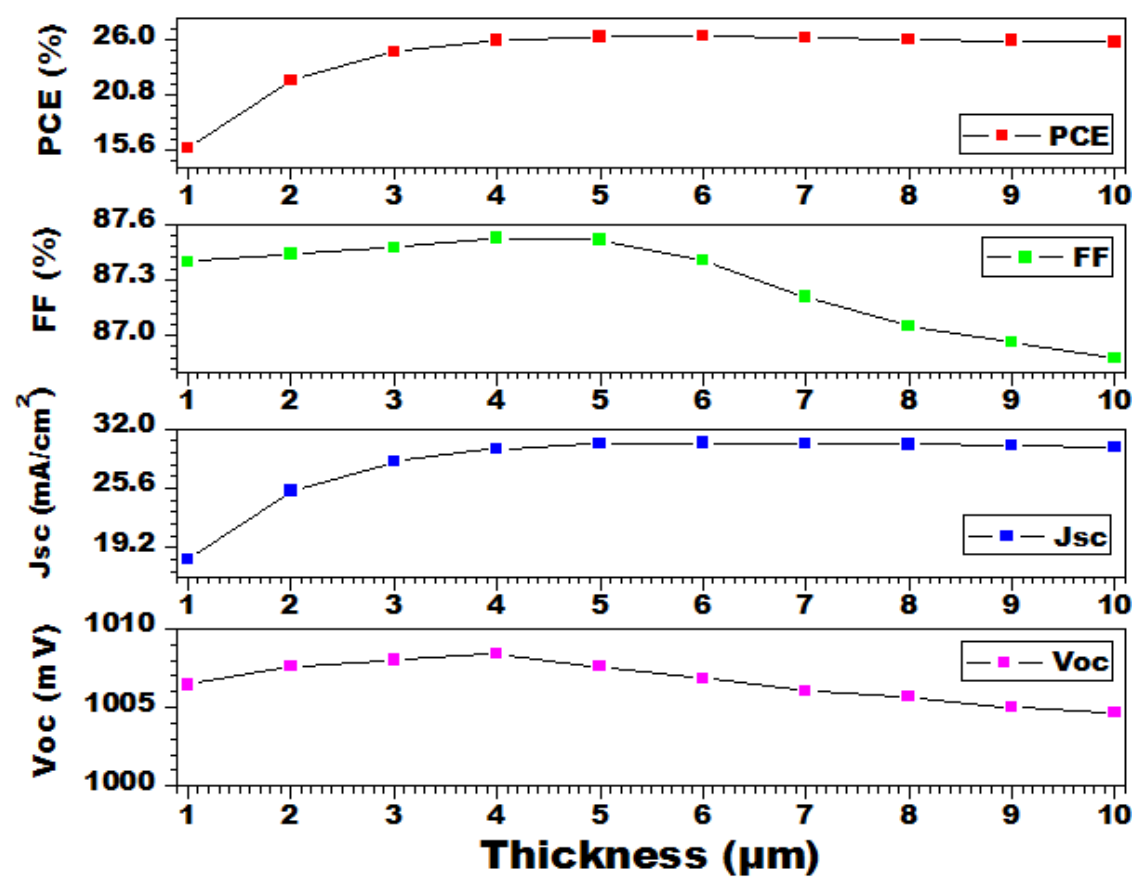

Figure 6.14: Effect of the absorber layer thickness on CFTS solar cell.

\subsubsection{Acceptor doping concentration on device performance}

Acceptor doping concentration in absorber layer was varied from $5 \times 10^{17} \mathrm{~cm}^{-3}$ to $1 \times 10^{19} \mathrm{~cm}^{-3}$ as shown in Figure 6.15. The Figure illustrates that $V_{o c}$ increases with an increase in the doping concentration, whereas $\mathrm{J}_{\mathrm{sc}}$ decreases. The main reason is that the saturation current of a device increases with the increase of the carrier concentration density and resultantly the $V_{o c}$ increases. However, the short-circuit current will decrease with the increasing of carrier densities. This decrease in $\mathrm{J}_{\mathrm{sc}}$ is since the higher carrier densities will increase the recombination process and lessen the probability of the collection of the photon-generated electrons. Therefore, the collected conversion efficiency is more dependent on the influence of the concentration density. From Figure 6.15, power conversion efficiency and fill factor increase with an increase in the optimal value of carrier doping concentration in absorber layer material. The optimal value of the concentration of acceptor density of the absorber layer was $2 \times 10^{18} \mathrm{~cm}^{-3}$. 


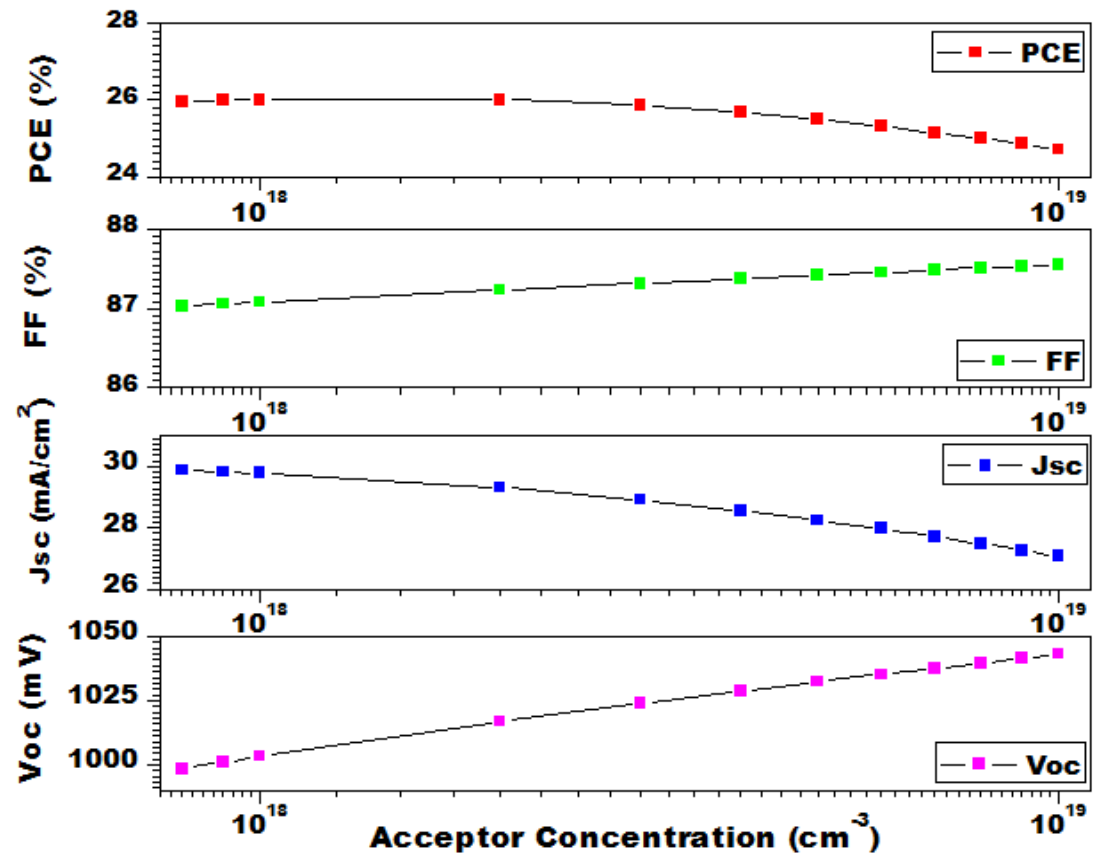

Figure 6.15: Acceptor concentration in the absorber layer.

\subsection{6 $\mathrm{ZnS}$ and $\mathrm{Zn}(\mathrm{O}, \mathrm{S})$ buffer layers parameters effect on device performance}

$\mathrm{ZnS}$ and $\mathrm{Zn}(\mathrm{O}, \mathrm{S})$ buffer layers influence on the performance of a solar cell were also explored and given in Figure 6.16 and Figure 6.17. The buffer layer thicknesses were varied from $0.1 \mu \mathrm{m}$ to $1 \mu \mathrm{m}$ for both materials. Simulated fallouts illustrate that with an increase in the buffer thickness, there was no major change found in $\mathrm{J}_{\mathrm{sc}}, \mathrm{V}_{\mathrm{oc}}, \mathrm{PCE}$, and FF. Therefore, this result was comprehended that change in thicknesses of buffer layers did not affect the output of the solar cell. For the designing of CFTS/ZnS/Zn $(0, S)$ based stannite device, optimum thickness for $\mathrm{ZnS}$ and $\mathrm{Zn}(0, \mathrm{~S})$ taken were $0.2 \mu \mathrm{m}$.

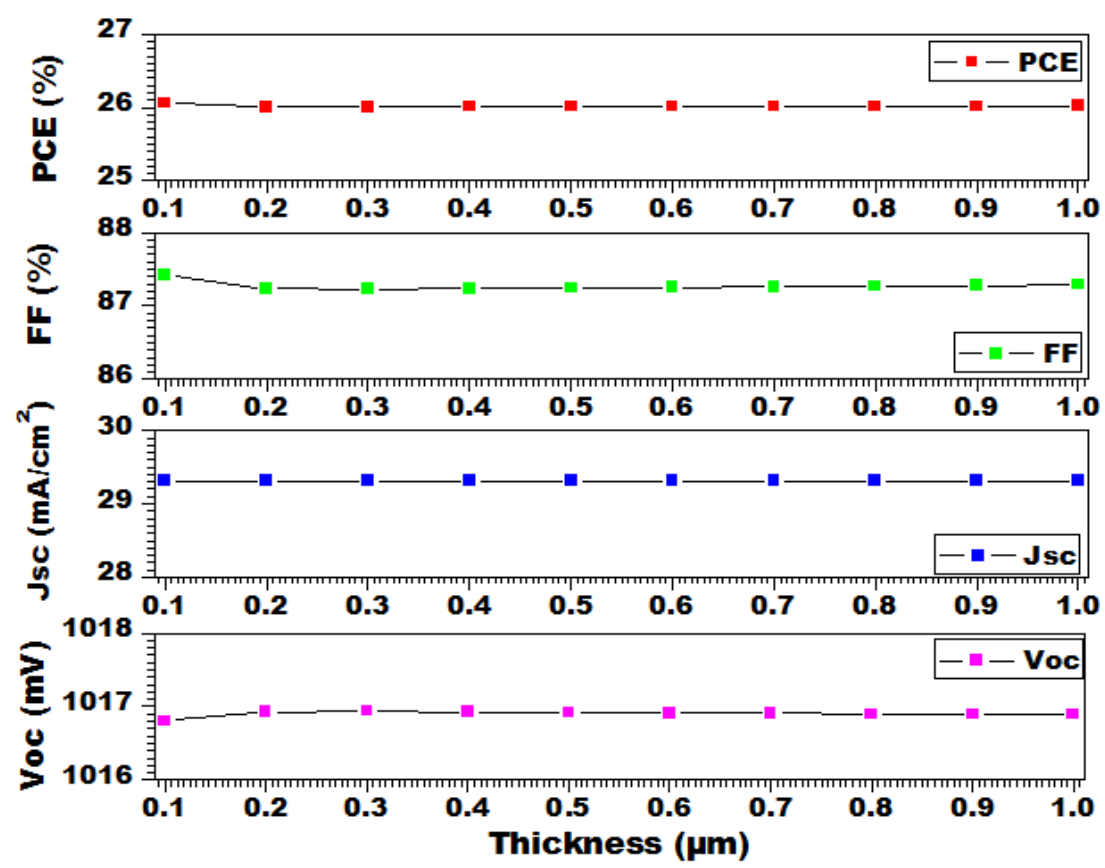

Figure 6.16: Effect of the ZnS buffer layer thickness. 


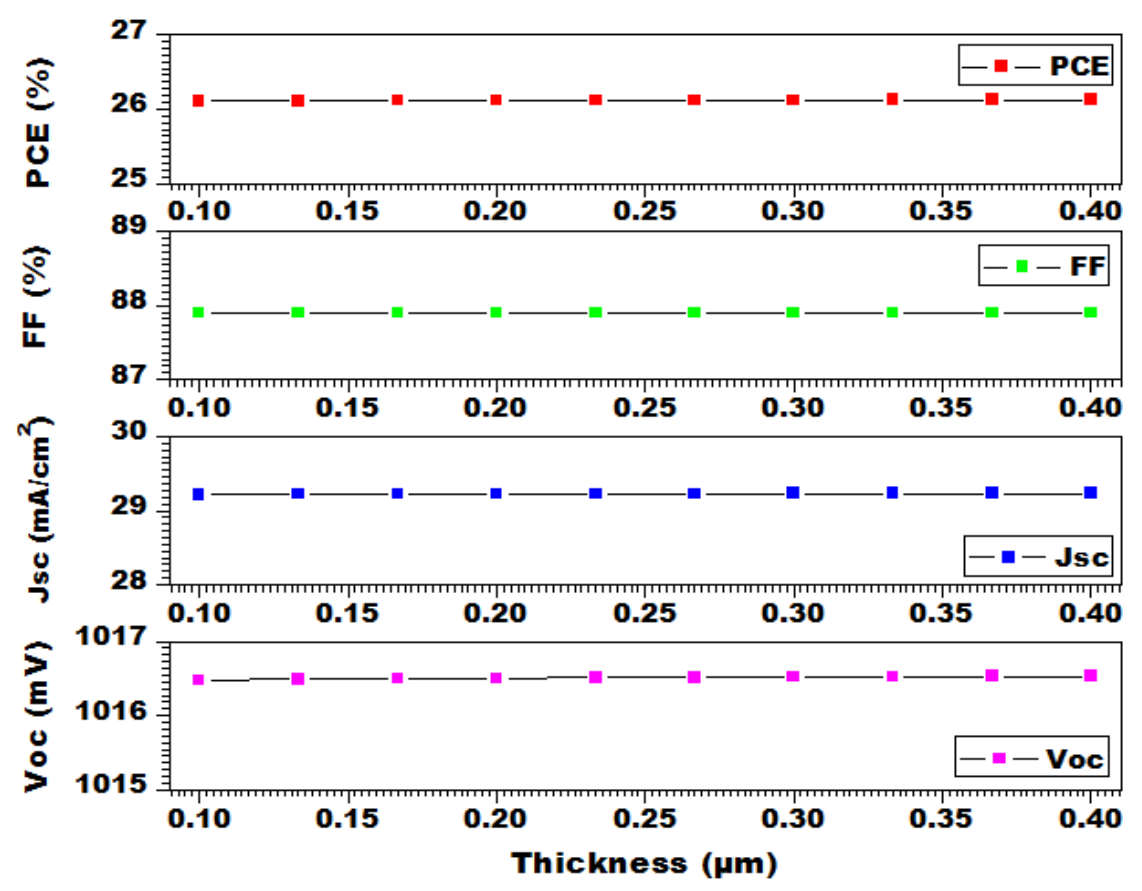

Figure 6.17: Effect of the $\mathrm{Zn}(0, \mathrm{~S})$ buffer layer thickness.

The effect of $\mathrm{ZnS}$ and $\mathrm{Zn}(\mathrm{O}, \mathrm{S})$ buffer layers donor concentration on the device performance were analyzed by changing the concentration densities. With an increase in doping concentration in buffer layers, there was a minor change in PCE and $\mathrm{J}_{\mathrm{sc}}$, whereas $\mathrm{FF}$ and $\mathrm{V}_{\mathrm{oc}}$ were affected by increasing donor doping concentration of stacked buffer layers, effects of the performance of the device are illustrated in Figure 6.18 and Figure 6.19.

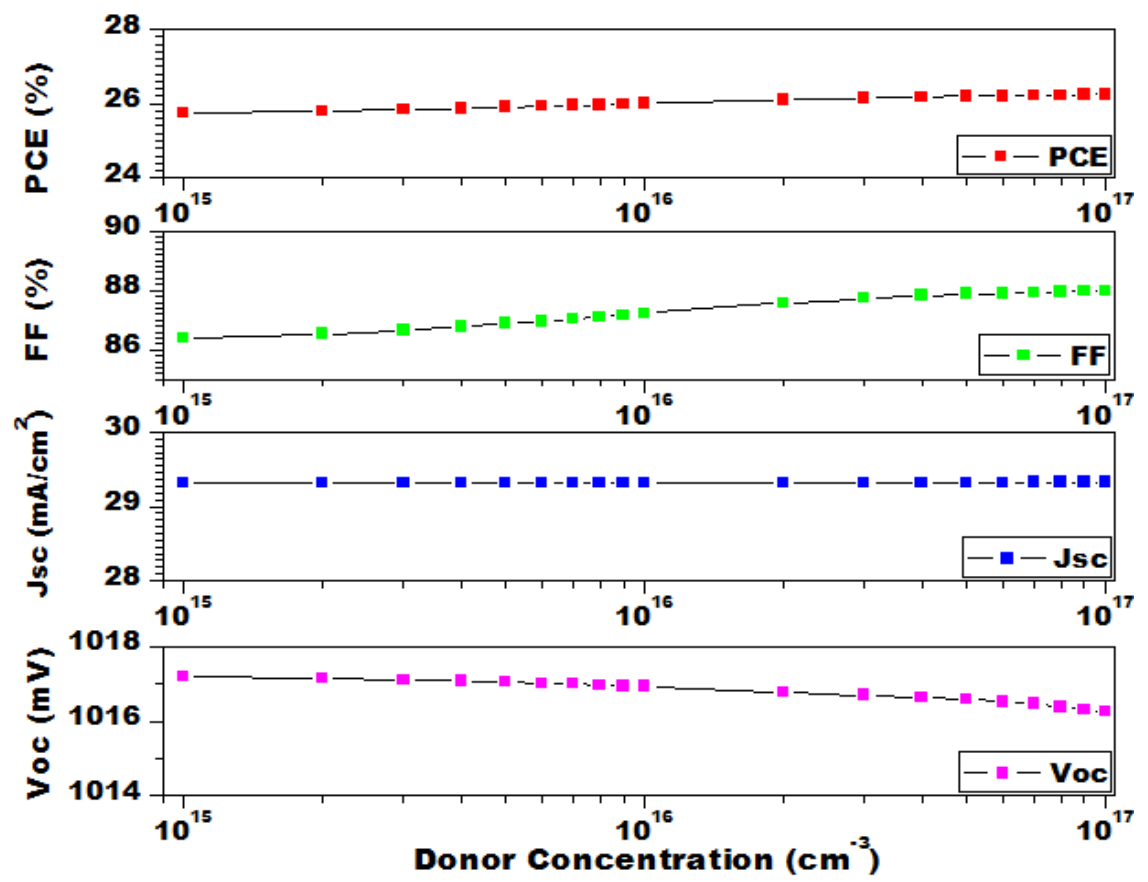

Figure 6.18: Donor concentration in the $\mathrm{ZnS}$ buffer layer. 


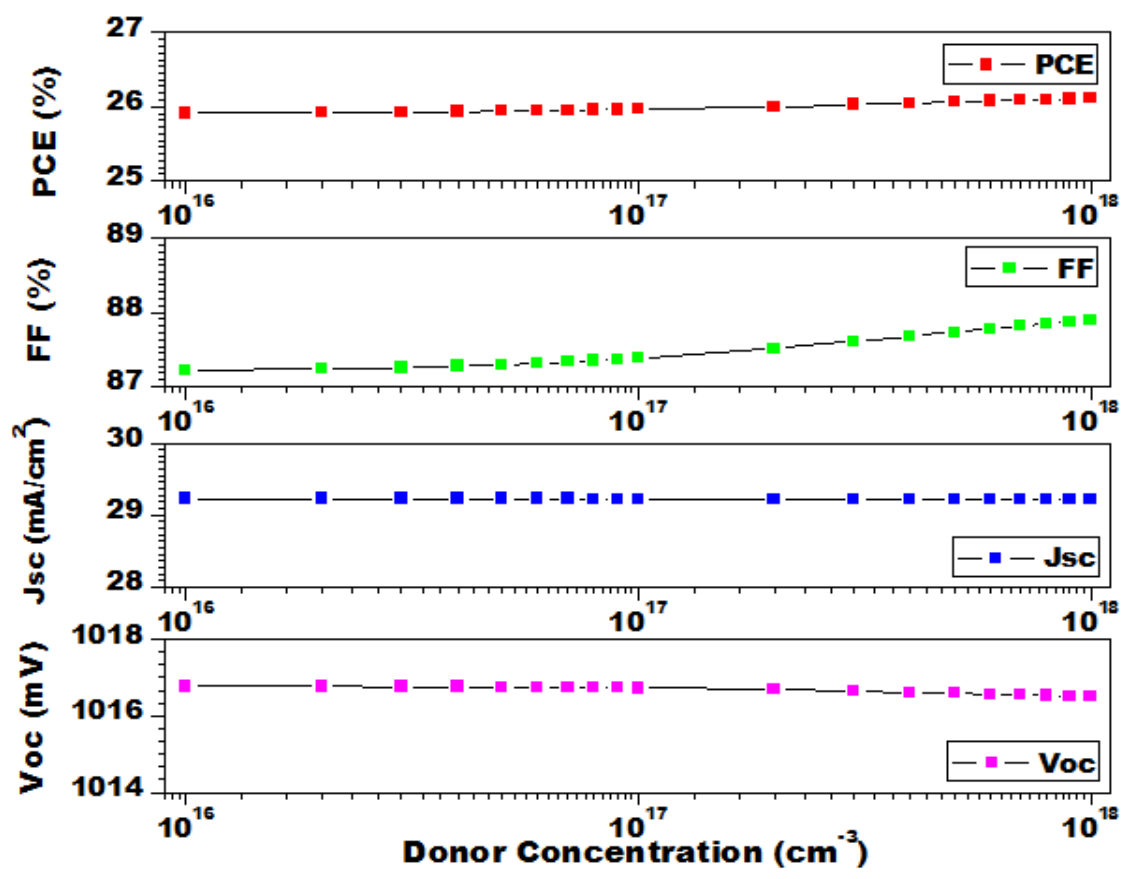

Figure 6.19: Donor concentration in the $\mathrm{Zn}(0, \mathrm{~S})$ buffer layer.

\subsubsection{Conclusion}

Mo/CFTS/ZnS / Zn(O, S)/ FTO photovoltaic device was proposed in this work. This work will provide the necessary guidelines for analyzing and manufacturing of CFTS based solar cell. For the in-depth understanding and getting the confidence in the modeling of a photovoltaic cell, different characteristics, as well as different possible conditions, were to be considered for simulation. In this work promising optimized results had been achieved with the conversion efficiency of $26.11 \%$, fill factor (FF) $87.90 \%$, short-circuit current $\left(\mathrm{J}_{\mathrm{sc}}\right) 29.22 \mathrm{~mA} / \mathrm{cm}^{2}$ and open circuit voltage $\left(\mathrm{V}_{\text {oc }}\right)$ $1016.5 \mathrm{mV}$. The results will give imperative guidance for the feasible fabrication of higher efficiency CFTS based photovoltaic cells. 
This page intentionally left blank 


\section{CHAPTER 7}

CONCLUSION AND FUTURE WORK 
This page intentionally left blank 


\subsection{Conclusion}

In this thesis, numerical modeling was carried out to estimate and analyze the parameters of different photovoltaic thin-film solar cells. Device modeling was performed on the dedicated simulation software "Solar Cell Capacitance Simulator" (SCAPS). To analyze the performance of a photovoltaic device, the analysis was performed on different physical parameters such as thickness and doping concentration of absorber, buffer and window layers, temperature effect and effect of illumination power of the sun on a solar cell. This analysis can help to achieve the high conversion efficiency from thin film solar cells.

Numerical modeling of CZTS based kesterite solar cell is explained. We simulate kesterite based ZnO, CdS, CZTS, Mo structured solar cell on SCAPS software. Different parameters which affected the performance of a photovoltaic cell and the conversion efficiency were explained. For the In-depth understanding of a solar cell, J - V characteristic measures are not enough to describe the behavior of a device because the response of the solar cell also depends on its internal physical mechanism. Forgetting confidence in the modeling of a solar cell, different characteristics, as well as different possible conditions were to be considered for simulation. Promising optimized results had been achieved with the power conversion efficiency of $23.72 \%$, fill factor of $82.54 \%$, short-circuit current 44.87 $\mathrm{mA} / \mathrm{cm}^{2}$ and open circuit voltage $0.64 \mathrm{~V}$.

Efficiency enhancement of CZTS based experimental solar cell is also presented. The work presents numerical modeling of experimentally designed CZTS solar cell by applying CZTSe as back surface field layer. Experimentally designed CZTS solar cell results were first simulated in SCAPS environment. The SCAPS simulated results were then compared with experimental results. After optimization of cell parameters, the conversion efficiency of an optimized device was increased. With further optimization and by applying a backsurface layer, conversion efficiency further increased. All the simulations were conducted under 1.5 AM solar radiation spectrum. The technique to boosts the photovoltaic cell conversion efficiency was the use of a back-surface field layer. In the comparison of a conventional device, the device with a back surface filed layer gives much greater output voltage. Our approach for the improvement of CZTS solar cell performance was by means of comparing and validating SCAPS simulations with an experimental cell, optimization of the validated simulation, analyzing the minority carrier lifetime and proposing a backsurface field layer for further enhancing the conversion efficiency of a solar cell. 
Baseline study for the modeling of CFTS solar cell is also deliberated. $\mathrm{Mo} / \mathrm{CFTS}_{\mathrm{TiO}} / \mathrm{T}$ FTO structured photovoltaic device modeling was performed and analyzed. $\mathrm{Cu}_{2} \mathrm{FeSnS}_{4}$ is (CFTS) auspicious nontoxic and earth-abundant semiconductor compound. It is an attractive and suitable material for the fabrication of low cost, high efficiency, and sustainable thin film solar cell. The influence of device parameters such as the thickness, acceptor and donor carrier doping concentration densities of absorber and electron transport layers, the effect of back contact metal work function and the temperature effect on the performance of CFTS based solar cell were analyzed by using one-dimensional SCAPS software. Promising optimized results had been achieved with the conversion efficiency of $19.97 \%$, fill factor of $85.94 \%$, short-circuit current of $23.37 \mathrm{~mA} / \mathrm{cm}^{2}$ and open circuit voltage of $0.995 \mathrm{~V}$.

Novel structure for CFTS $\left(\mathrm{Cu}_{2} \mathrm{FeSnS}_{4}\right)$ quaternary semiconductor compound based thin film solar cell device is proposed and having the structure CFTS $\operatorname{ZnS} / \operatorname{Zn}(O, S) / F T O$. Performance of a proposed device was analyzed by means of numerical modeling. $\operatorname{Zn}(O, S)$ as buffer layer up till now had not been used for CFTS based solar cells. The significance of this work increased because we propose for the first time $\operatorname{Zn}(0, S)$ as a buffer layer for high-efficiency CFTS solar cell. In this work auspicious optimized results had been achieved with the conversion efficiency of $26.11 \%$, fill factor of $87.90 \%$, shortcircuit current of $29.22 \mathrm{~mA} / \mathrm{cm}^{2}$ and open circuit voltage of $1016.5 \mathrm{mV}$. The proposed results will greatly help the engineers and researches to find an optimum way to optimize the solar cell performance and will also help in the design of efficient CFTS based solar cell.

Based on different device structure modeling, it was found that solar cell with structure CFTS/ZnS/Zn $(O, S) / F T O$ can exhibit an efficiency of $26.11 \%$ with optimized physical parameters like absorber thickness layer of $4 \mu \mathrm{m}$ and acceptor concentration density of $2 \times 10^{18} \mathrm{~cm}^{-3}$. The proposed results will give a valuable guideline for the feasible fabrication and designing of high-power conversion efficiency solar cells.

\subsection{Future Work}

In this work, numerical modeling of quaternary compound based solar cells are performed in order to estimate and analyze the physical parameters directly influencing the fabrication regimes of the solar cell. A one-dimensional Solar Cell Capacitance Simulator software was used to run the desirable device modeling routines based on fundamental transport theory with a detailed examination of the device-physical parameters. The key 
finding of our work is the modeling of a new structure (CFTS/ZnS/Zn(O, S)/FTO) with reduced interface recombination. The predicted power conversion efficiency requires testing of the experimental device with all sources of losses duly addressed in the original device design.

In terms of device modeling in general, SCAPS $-1 D$ is restricted to one dimension. Further extension of device modeling design is possible by using two dimensions or three dimensions program. Electrical effects such as grain boundaries state over the bulk, bandgap fluctuations and a laterally varying space-charge region, and an optical effect of interference and surface roughness; may affect device behavior interpretation. These two dimensions and three dimensions effects will possibly not overturn our current understanding, but they will, however, be of interest for future research. 
This page intentionally left blank 


\section{Bibliography}

[1] A.R. I. Rimmaudo, A. Salavei, Effects of activation treatment on the electrical properties of low temperature grown CdTe devices, Thin Solid Films, 535 (2013) $253-256$.

[2] M.A. Green, K. Emery, Y. Hishikawa, W. Warta, E.D. Dunlop, Solar cell efficiency tables (Version 45), Prog. Photovoltaics Res. Appl. 23 (2015) 1-9. doi:10.1002/pip.2573.

[3] Y.H. Khattak, T. Mahmood, K. Alam, T. Sarwar, U.H. Ullah, Inayat, Smart energy management system for utility source and photovoltaic power system using FPGA and ZigBee, Am. J. Electr. Power Energy Syst. 3 (2014) 86-94. doi:10.11648/j.epes.20140305.11.

[4] K. Jimbo, R. Kimura, T. Kamimura, S. Yamada, W.S. Maw, H. Araki, K. Oishi, H. Katagiri, Cu2ZnSnS4-type thin film solar cells using abundant materials, Thin Solid Films. 515 (2007) 5997-5999. doi:10.1016/j.tsf.2006.12.103.

[5] A. Mutalikdesai, S.K. Ramasesha, Solution process for fabrication of thin film CdS/CdTe photovoltaic cell for building integration, Thin Solid Films. 632 (2017) 73-78. doi:10.1016/j.tsf.2017.04.036.

[6] I.L. Repins, M.J. Romero, J. V. Li, S.-H. Wei, D. Kuciauskas, C.-S. Jiang, C. Beall, C. DeHart, J. Mann, W.-C. Hsu, G. Teeter, A. Goodrich, R. Noufi, Kesterite Successes, Ongoing Work, and Challenges: A Perspective From Vacuum Deposition, IEEE J. Photovoltaics. 3 (2013) 439-445. doi:10.1109/JPHOTOV.2012.2215842.

[7] H. Wang, Y. Liu, M. Li, H. Huang, H.M. Xu, R.J. Hong, H. Shen, Multifunctional TiO2nanowires-modified nanoparticles bilayer film for 3D dye-sensitized solar cells, Optoelectron. Adv. Mater. Rapid Commun. 4 (2010) 1166-1169. doi:10.1039/b000000x.

[8] H. Zhou, W.-C. Hsu, H.-S. Duan, B. Bob, W. Yang, T.-B. Song, C.-J. Hsu, Y. Yang, CZTS nanocrystals: a promising approach for next generation thin film photovoltaics, Energy Environ. Sci. 6 (2013) 2822. doi:10.1039/c3ee41627e.

[9] Semiconductor technology, (n.d.).

https://www.halbleiter.org/en/fundamentals/conductors-insulatorssemiconductors/.

[10] R. Lewis, Electronics Servicing, Macmillan Education UK, London, 1983. 
doi:10.1007/978-1-349-05771-9.

[11] B. V Van Zeghbroeck, Principles of semiconductor devices and heterojunctions, 1st ed., Prentice Hall, 2010.

[12] H. Ullah, B. Marí, H.N. Cui, Investigation on the Effect of Gallium on the Efficiency of CIGS Solar Cells through Dedicated Software, Appl. Mech. Mater. 448-453 (2013) 1497-1501. doi:10.4028/www.scientific.net/AMM.448-453.1497.

[13] Physics and radio electronics, (n.d.). http://www.physics-and-radioelectronics.com/electronic-devices-and-circuits/semiconductor-diodes/p-njunction-introduction.html.

[14] Jesse Zheng, Optical Frequency-Modulated Continuous-Wave (FMCW) Interferometry, Springer-Verlag, New York, 2005. doi:10.1007/b100384.

[15] B L Theraja \& A K Theraja, A Textbook of Electrical Technology: Basic Electrical Engineering in S.I. System of Units, 23rd ed., S. Chand India, 2002.

[16] R. Lewis, Semiconductor diodes and applications, in: Electron. Serv., Macmillan Education UK, London, 1983: pp. 42-56. doi:10.1007/978-1-349-05771-9_3.

[17] S.M. Naidu, Engineering physics, Pearson Education, 2009.

[18] A. Kitai, Principles of Solar Cells, LEDs and Diodes: The role of the PN junction, John Wiley \& Sons, Ltd, Chichester, UK, 2011. doi:10.1002/9781119974543.

[19] W. Tress, Organic Solar Cells, Springer International Publishing, Cham, 2014. doi:10.1007/978-3-319-10097-5.

[20] PN junction diode theory and VI characteristics, (n.d.). https://www.elprocus.com/vi-characteristics-of-pn-junction-diode/.

[21] M. Naidu, Engineering Physics, Pearson Education India, 2009.

[22] T.N.S. news Page, National Aeronautics and Space Administration, Http://Science.Nasa.Gov/Science-News/Science-at-Nasa/2002/Solarcells/. (n.d.).

[23] P.J. Sturman, Photovoltaic and Photo-refractive Effects in Noncentrosymmetric Materials, CRC Press Taylor \& Francis Group, 1992.

[24] M.Z. Klaus Jager, Olindo Isabella, Arno H. M. Smets, Rene A. C. M. M. van Swaaij, Solar Energy Fundamentals, Technology and Systems, 2014. doi:10.1007/SpringerReference_29746.

[25] P. Wurfel, Physics of Solar Cells from Principles to nNew Concepts, 2009. doi:10.1002/9783527618545.

[26] S.S. Li, Semiconductor Physical Electronics, Springer US, Boston, MA, 1993. doi:10.1007/978-1-4613-0489-0. 
[27] A. Ortiz-Conde, F. García-Sánchez, J. Muci, A. Sucre-González, A review of diode and solar cell equivalent circuit model lumped parameter extraction procedures, Facta Univ. - Ser. Electron. Energ. 27 (2014) 57-102. doi:10.2298/FUEE1401057O.

[28] F.A. Lindholm, J.G. Fossum, E.L. Burgess, Application of the superposition principle to solar-cell analysis, IEEE Trans. Electron Devices. 26 (1979) 165-171. doi:10.1109/T-ED.1979.19400.

[29] S.M. Sze, K.K. Ng, Physics of Semiconductor Devices, John Wiley \& Sons, Inc., Hoboken, NJ, USA, 2006. doi:10.1002/0470068329.

[30] Y.H. Khattak, F. Baig, S. Ullah, B. Marí, S. Beg, H. Ullah, Numerical modeling baseline for high efficiency ( $\mathrm{Cu} 2 \mathrm{FeSnS} 4$ ) CFTS based thin film kesterite solar cell, Optik (Stuttg). 164 (2018) 547-555. doi:10.1016/j.ijleo.2018.03.055.

[31] B. Qi, J. Wang, Fill factor in organic solar cells, Phys. Chem. Chem. Phys. 15 (2013) 8972. doi:10.1039/c3cp51383a.

[32] W. Shockley, W.T. Read, Statistics of the Recombinations of Holes and Electrons, Phys. Rev. 87 (1952) 835-842. doi:10.1103/PhysRev.87.835.

[33] F. Baig, Y.H. Khattak, B. Marí, S. Beg, S.R. Gillani, A. Ahmed, Mitigation of interface recombination by careful selection of ETL for efficiency enhancement of MASnI 3 solar cell, Optik (Stuttg). $170 \quad$ (2018) 463-474. doi:10.1016/j.ijleo.2018.05.135.

[34] N.J. Woods, S. Hall, On the contribution of recombination currents in Schottky barrier diodes, Semicond. Sci. Technol. 9 (1994) 2295-2297. doi:10.1088/0268$1242 / 9 / 12 / 023$.

[35] B. Chen, J. Chen, Y. Shen, K. Ge, J. Guo, F. Li, H. Liu, Y. Xu, Y. Mai, Magnesium thin film as a doping-free back surface field layer for hybrid solar cells, Appl. Phys. Lett. 110 (2017) 133504. doi:10.1063/1.4979345.

[36] H. Wen, H. Cai, Y. Du, X. Dai, Y. Sun, J. Ni, J. Li, D. Zhang, J. Zhang, Improving the organic/Si heterojunction hybrid solar cell property by optimizing PEDOT:PSS film and with amorphous silicon as back surface field, Appl. Phys. A. 123 (2017) 14. doi:10.1007/s00339-016-0612-8.

[37] A. Spies, J. Reinhardt, M. List, B. Zimmermann, U. Würfel, Impact of Charge Carrier Mobility and Electrode Selectivity on the Performance of Organic Solar Cells, in: 2017: pp. 401-418. doi:10.1007/978-3-319-28338-8_17.

[38] Solar cell 2018-Solar panel construction, (n.d.). http://fen-nu.com/solar-panel- 
construction/solar-cell-2018-solar-panel-construction-2/.

[39] Using photovoltaic solar cells to produce solar electricity, (n.d.). http://www.alternative-energy-tutorials.com/solar-power/photovoltaics.html.

[40] R. Blandford, M. Watkins, This Month in Physics History, Am. Phys. Soc. News. 18 (2009) 2. https://www.aps.org/publications/apsnews/200904/upload/April2009-Volume-18-Number-4-Entire-Issue.pdf.

[41] Solar cells - the three generations, (n.d.). http://plasticphotovoltaics.org/lc/lcsolarcells/lc-introduction.html.

[42] Solar facts and advice, (n.d.). www.solar-facts-and-advice.com/solar-cells.html.

[43] F.C. Krebs, M. Hösel, M. Corazza, B. Roth, M. V. Madsen, S.A. Gevorgyan, R.R. Søndergaard, D. Karg, M. Jørgensen, Freely available OPV-The fast way to progress, Energy Technol. 1 (2013) 378-381. doi:10.1002/ente.201300057.

[44] M.A. Green, Y. Hishikawa, W. Warta, E.D. Dunlop, D.H. Levi, J. Hohl-Ebinger, A.W.H. Ho-Baillie, Solar cell efficiency tables (version 50), Prog. Photovoltaics Res. Appl. 25 (2017) 668-676. doi:10.1002/pip.2909.

[45] First Solar website, (n.d.). http://www.firstsolar.com.

[46] White paper for CIGS thinfilm solar cell technology, (n.d.). http://cigs-pv.net/cigswhite-paper-initiative/.

[47] E.S. Jüri Krustok, Taavi Raadik, Maarja Grossberg, Sergio Giraldo, Markus Neuschitzer, Simon López-Marino, Temperature dependent electroreflectance study of Cu2ZnSnSe4 solar cells, Mater. Sci. Semicond. Process. 39 (2015) 251254. doi:10.1016/j.mssp.2015.04.055.

[48] G. Brammertz, M. Buffie, M. Meuris, J. Poortmans, K. Ben Messaoud, S. Sahayaraj, C. K, Characterization of defects in $9.7 \%$ efficient Cu2ZnSnSe 4 -CdSZnO solar cells, Appl. Phys. Lett. 103 (2013) 2-5.

[49] Susanne Siebentritt and Susan Schorr, Solar Cells Utilizing Small Molecular Weight Organic Semiconductors, Prog. Photovoltaics Res. Appl. 20 (2012) 512519. doi:10.1002/pip.2156.

[50] S. Delbos, Kësterite thin films for photovoltaics : a review, EPJ Photovoltaics. 3 (2012) 1-13. doi:10.1051/epjpv/2012008.

[51] K.I. and T. Nakazawa, Electrical and Optical Properties of Stannite-Type Quarternary Semiconductor Thin Films, Jpn. J. Appl. Phys. 27 (1988) 2094-2097. doi:10.1143/JJAP.27.2094.

[52] M.E. Platzer-Bjorkmann, J. Scragg, H. Flammersberger, T. Kubart, Influence of 
precursor sulfur content on film formation and compositional changes in Cu2ZnSnS4 films and solar cells, Sol. Energy Mater. Sol. Cells. 98 (2012) 110117. doi:10.1016/j.solmat.2011.10.019.

[53] C. Persson, Electronic and optical properties of $\mathrm{Cu} 2 \mathrm{ZnSnS} 4$ and $\mathrm{Cu} 2 \mathrm{ZnSnSe} 4, \mathrm{~J}$. Appl. Phys. 107 (2010) 1-8. doi:10.1063/1.3318468.

[54] M. Dimitrievska, A. Fairbrother, E. Saucedo, A. Pérez-Rodríguez, V. IzquierdoRoca, Influence of compositionally induced defects on the vibrational properties of device grade Cu\$2\$ZnSnSe\$_4 absorbers for kesterite based solar cells, Appl. Phys. Lett. 106 (2015) 1-5. doi:10.1063/1.4913262.

[55] J.K. E. Kask, M. Grossberg, R. Josepson, P. Salu, K. Timmo, Defect studies in $\mathrm{Cu} 2 \mathrm{ZnSnSe} 4$ and $\mathrm{Cu} 2 \mathrm{ZnSn}(\mathrm{Se} 0.75 \mathrm{~S} 0.25) 4$ by admittance and photoluminescence spectroscopy, Mater. Sci. Semicond. Process. $16 \quad$ (2013) 992-996. doi:10.1016/j.mssp.2013.02.009.

[56] J.-K.K. and D.-H.K. Kee-Jeong Yang, Dae-Ho Son, Shi-Joon Sung, Jun-Hyoung Sim, Young-Ill Kim, Si-Nae Park, Dong-Hwan Jeon, JungSik Kim, Dae-Kue Hwang, Chan-Wook Jeon, Dahyun Nam, Hyeonsik Cheong, A band-gap-graded CZTSSe solar cell with $12.3 \%$ efficiency, J. Mater. Chem. A. 4 (2016) 1015110158. doi:10.1039/C6TA01558A.

[57] L.X.J. and F.Y.L. Fang Qin Zeng, Yan Qing Lai, Zi Li Han, Boon K. Ng, Zhi An Zhang, Hong Liang Zhang, Fabrication of earth-abundant Cu2ZnSn(S,Se)4 light absorbers by a sol-gel and selenization route for thin film solar cells, RCS Adv. 6 (2016) 6562-6570. doi:10.1039/C5RA18975F.

[58] National Renewable Energy Laboratory (NREL), Best Research-Cell Efficiencies, (n.d.). https://www.nrel.gov/pv/.

[59] H. Movla, Optimization of the CIGS based thin film solar cells: Numerical simulation and analysis, Optik (Stuttg). $125 \quad$ (2014) 67-70. doi:10.1016/j.ijleo.2013.06.034.

[60] O.K. Simya, A. Mahaboobbatcha, K. Balachander, A comparative study on the performance of Kesterite based thin film solar cells using SCAPS simulation program, Superlattices $\quad$ Microstruct. $82 \quad$ (2015) 248-261. doi:10.1016/j.spmi.2015.02.020.

[61] R.A. Jabr, M. Hamad, Y.M. Mohanna, Newton-Raphson Solution of Poisson's Equation in a Pn Diode, Int. J. Electr. Eng. Educ. 44 (2007) 23-33. doi:10.7227/IJEEE.44.1.3. 
[62] Chenming C. Hu, Modern Semiconductor Devices for Integrated Circuits, in: 2010.

[63] M. Burgelman, P. Nollet, S. Degrave, Modelling polycrystalline semiconductor solar cells, Thin Solid Films. 361-362 (2000) 527-532. doi:10.1016/S00406090(99)00825-1.

[64] A. Niemegeers, M. Burgelman, Numerical modelling of AC-characteristics of CdTe and CIS solar cells, in: Conf. Rec. Twenty Fifth IEEE Photovolt. Spec. Conf. - 1996, IEEE, 1996: pp. 901-904. doi:10.1109/PVSC.1996.564274.

[65] K. Decock, P. Zabierowski, M. Burgelman, Modeling metastabilities in chalcopyrite-based thin film solar cells, J. Appl. Phys. 111 (2012). doi:10.1063/1.3686651.

[66] Y.H. Khattak, F. Baig, B. Marí, S. Beg, S.R. Gillani, T. Ahmed, Effect of CdTe Back Surface Field on the Efficiency Enhancement of a CGS Based Thin Film Solar Cell, J. Electron. Mater. (2018). doi:10.1007/s11664-018-6405-4.

[67] S. Hegedus, Thin film solar modules: the low cost, high throughput and versatile alternative to Si wafers, Prog. Photovoltaics Res. Appl. 14 (2006) 393-411. doi:10.1002/pip.704.

[68] N. Amin, M.I. Hossain, P. Chelvanathan, A.S.M. Mukter Uzzaman, K. Sopian, Prospects of $\mathrm{Cu} 2 \mathrm{ZnSnS4}(\mathrm{CZTS})$ solar cells from numerical analysis, in: Int. Conf. Electr. Comput. Eng. (ICECE 2010), IEEE, 2010: pp. 730-733. doi:10.1109/ICELCE.2010.5700796.

[69] J. SEOL, S. LEE, J. LEE, H. NAM, K. KIM, Electrical and optical properties of $\mathrm{CuZnSnS} \mathrm{thin} \mathrm{films} \mathrm{prepared} \mathrm{by} \mathrm{rf} \mathrm{magnetron} \mathrm{sputtering} \mathrm{process,} \mathrm{Sol.} \mathrm{Energy}$ Mater. Sol. Cells. 75 (2003) 155-162. doi:10.1016/S0927-0248(02)00127-7.

[70] H. Katagiri, N. Sasaguchi, S. Hando, S. Hoshino, J. Ohashi, T. Yokota, Preparation and evaluation of $\mathrm{Cu} 2 \mathrm{ZnSnS} 4$ thin films by sulfurization of E-B evaporated precursors, Sol. Energy Mater. Sol. Cells. 49 (1997) 407-414. doi:10.1016/S09270248(97)00119-0.

[71] K. Tanaka, N. Moritake, H. Uchiki, Preparation of $\mathrm{Cu} 2 \mathrm{ZnSnS4}$ thin films by sulfurizing sol-gel deposited precursors, Sol. Energy Mater. Sol. Cells. 91 (2007) 1199-1201. doi:10.1016/j.solmat.2007.04.012.

[72] H. Wei, W. Guo, Y. Sun, Z. Yang, Y. Zhang, Hot-injection synthesis and characterization of quaternary Cu2ZnSnSe4 nanocrystals, Mater. Lett. 64 (2010) 1424-1426. doi:10.1016/j.matlet.2010.03.034.

[73] D.B. Mitzi, O. Gunawan, T.K. Todorov, K. Wang, S. Guha, The path towards a 
high-performance solution-processed kesterite solar cell, Sol. Energy Mater. Sol. Cells. 95 (2011) 1421-1436. doi:10.1016/j.solmat.2010.11.028.

[74] C.P. Chan, H. Lam, C. Surya, Preparation of Cu2ZnSnS4 films by electrodeposition using ionic liquids, Sol. Energy Mater. Sol. Cells. 94 (2010) 207-211. doi:10.1016/j.solmat.2009.09.003.

[75] X. Wu, W. Liu, S. Cheng, Y. Lai, H. Jia, Photoelectric properties of Cu $2 \mathrm{ZnSnS} 4$ thin films deposited by thermal evaporation, J. Semicond. 33 (2012) 022002. doi:10.1088/1674-4926/33/2/022002.

[76] H. Katagiri, K. Jimbo, W.S. Maw, K. Oishi, M. Yamazaki, H. Araki, A. Takeuchi, Development of CZTS-based thin film solar cells, Thin Solid Films. 517 (2009) 2455-2460. doi:10.1016/j.tsf.2008.11.002.

[77] B. Shin, O. Gunawan, Y. Zhu, N.A. Bojarczuk, S.J. Chey, S. Guha, Thin film solar cell with $8.4 \%$ power conversion efficiency using an earth-abundant $\mathrm{Cu} 2 \mathrm{ZnSnS} 4$ absorber, Prog. Photovoltaics Res. Appl. 21 (2013) 72-76. doi:10.1002/pip.1174.

[78] W. Wang, M.T. Winkler, O. Gunawan, T. Gokmen, T.K. Todorov, Y. Zhu, D.B. Mitzi, Device Characteristics of CZTSSe Thin-Film Solar Cells with $12.6 \%$ Efficiency, Adv. Energy Mater. 4 (2014) 1301465. doi:10.1002/aenm.201301465.

[79] Y. Xu, T. Gong, J.N. Munday, The generalized Shockley-Queisser limit for nanostructured solar cells, Sci. Rep. 5 (2015) 13536. doi:10.1038/srep13536.

[80] W. Shockley, H.J. Queisser, Detailed Balance Limit of Efficiency of p-n Junction Solar Cells, J. Appl. Phys. 32 (1961) 510-519. doi:10.1063/1.1736034.

[81] M. Djinkwi Wanda, S. Ouédraogo, F. Tchoffo, F. Zougmoré, J.M.B. Ndjaka, Numerical Investigations and Analysis of $\mathrm{Cu} 2 \mathrm{ZnSnS} 4$ Based Solar Cells by SCAPS-1D, Int. J. Photoenergy. 2016 (2016) 1-9. doi:10.1155/2016/2152018.

[82] A.D. Adewoyin, M.A. Olopade, M. Chendo, Enhancement of the conversion efficiency of $\mathrm{Cu} 2 \mathrm{ZnSnS} 4$ thin film solar cell through the optimization of some device parameters, Opt. - Int. J. Light Electron Opt. 133 (2017) 122-131. doi:10.1016/j.ijleo.2017.01.008.

[83] Y.H. Khattak, F. Baig, S. Ullah, B. Marí, S. Beg, H. Ullah, Enhancement of the conversion efficiency of thin film kesterite solar cell, J. Renew. Sustain. Energy. 10 (2018) 033501. doi:10.1063/1.5023478.

[84] A.D. Adewoyin, M.A. Olopade, M. Chendo, Enhancement of the conversion efficiency of $\mathrm{Cu} 2 \mathrm{ZnSnS} 4$ thin film solar cell through the optimization of some device parameters, Optik (Stuttg). $133 \quad$ (2017) 122-131. 
doi:10.1016/j.ijleo.2017.01.008.

[85] K.S. M. S. Hossain, N. Amin, M. A. Matin, M.M. Aliyu, T. Razykov, A numerical study on the prospects of high efficiency ultra thin ZnxCd1-xS/CdTe solar cell, Chalcogenide Lett. 8 (2011) 263-272.

[86] W.E.I. Sha, X. Ren, L. Chen, W.C.H. Choy, The efficiency limit of CH 3 NH 3 PbI 3 perovskite solar cells, Appl. Phys. Lett. $106 \quad$ (2015) 221104. doi:10.1063/1.4922150.

[87] L. Yin, G. Cheng, Y. Feng, Z. Li, C. Yang, X. Xiao, Limitation factors for the performance of kesterite $\mathrm{Cu} 2 \mathrm{ZnSnS} 4$ thin film solar cells studied by defect characterization, RSC Adv. 5 (2015) 40369-40374. doi:10.1039/C5RA00069F.

[88] Z. Li, S. Wang, X. Ma, M. Yang, Z. Jiang, T. Liu, Y. Lu, S. Liu, A simple structure of $\mathrm{Cu} 2 \mathrm{ZnSnS} 4$ /CdS solar cells prepared by sputtering, Phys. B Condens. Matter. 526 (2017) 80-83. doi:10.1016/j.physb.2017.09.009.

[89] S. Chen, A. Walsh, X. Gong, S. Wei, Classification of Lattice Defects in the Kesterite $\mathrm{Cu} 2 \mathrm{ZnSnS} 4$ and $\mathrm{Cu} 2 \mathrm{ZnSnSe} 4$ Earth-Abundant Solar Cell Absorbers, Adv. Mater. 25 (2013) 1522-1539. doi:10.1002/adma.201203146.

[90] K. Wang, O. Gunawan, T. Todorov, B. Shin, S.J. Chey, N.A. Bojarczuk, D. Mitzi, S. Guha, Thermally evaporated Cu2ZnSnS4 solar cells, Appl. Phys. Lett. 97 (2010) 143508. doi:10.1063/1.3499284.

[91] E. Kask, T. Raadik, M. Grossberg, R. Josepson, J. Krustok, Deep defects in $\mathrm{Cu} 2 \mathrm{ZnSnS} 4$ monograin solar cells, Energy Procedia. 10 (2011) 261-265. doi:10.1016/j.egypro.2011.10.188.

[92] J. Tao, J. Liu, L. Chen, H. Cao, X. Meng, Y. Zhang, C. Zhang, L. Sun, P. Yang, J. Chu, 7.1\% efficient co-electroplated $\mathrm{Cu} 2 \mathrm{ZnSnS} 4$ thin film solar cells with sputtered CdS buffer layers, Green Chem. 18 (2016) 550-557. doi:10.1039/C5GC02057C.

[93] S. Tajima, M. Umehara, M. Hasegawa, T. Mise, T. Itoh, Cu 2 ZnSnS 4 photovoltaic cell with improved efficiency fabricated by high-temperature annealing after $\mathrm{CdS}$ buffer-layer deposition, Prog. Photovoltaics Res. Appl. 25 (2017) 14-22. doi:10.1002/pip. 2837.

[94] M.G. Sousa, A.F. da Cunha, J.P. Teixeira, J.P. Leitão, G. Otero-Irurueta, M.K. Singh, Optimization of post-deposition annealing in $\mathrm{Cu} 2 \mathrm{ZnSnS} 4$ thin film solar cells and its impact on device performance, Sol. Energy Mater. Sol. Cells. 170 (2017) 287-294. doi:10.1016/j.solmat.2017.05.065. 
[95] S. Mahajan, E. Stathatos, N. Huse, R. Birajdar, A. Kalarakis, R. Sharma, Low cost nanostructure kesterite CZTS thin films for solar cells application, Mater. Lett. 210 (2018) 92-96. doi:10.1016/j.matlet.2017.09.001.

[96] M. Patel, A. Ray, Enhancement of output performance of $\mathrm{Cu} 2 \mathrm{ZnSnS4}$ thin film solar cells-A numerical simulation approach and comparison to experiments, Phys. B Condens. Matter. $407 \quad$ (2012) 4391-4397. doi:10.1016/j.physb.2012.07.042.

[97] N. Momose, M.T. Htay, T. Yudasaka, S. Igarashi, T. Seki, S. Iwano, Y. Hashimoto, K. Ito, Cu 2 ZnSnS 4 Thin Film Solar Cells Utilizing Sulfurization of Metallic Precursor Prepared by Simultaneous Sputtering of Metal Targets, Jpn. J. Appl. Phys. 50 (2011) 01BG09. doi:10.1143/JJAP.50.01BG09.

[98] B.-A. Schubert, B. Marsen, S. Cinque, T. Unold, R. Klenk, S. Schorr, H.-W. Schock, Cu2ZnSnS4 thin film solar cells by fast coevaporation, Prog. Photovoltaics Res. Appl. 19 (2011) 93-96. doi:10.1002/pip.976.

[99] H. Katagiri, K. Jimbo, S. Yamada, T. Kamimura, W.S. Maw, T. Fukano, T. Ito, T. Motohiro, Enhanced Conversion Efficiencies of $\mathrm{Cu} 2 \mathrm{ZnSnS} 4$-Based Thin Film Solar Cells by Using Preferential Etching Technique, Appl. Phys. Express. 1 (2008) 041201. doi:10.1143/APEX.1.041201.

[100] S. Ahmed, K.B. Reuter, O. Gunawan, L. Guo, L.T. Romankiw, H. Deligianni, A High Efficiency Electrodeposited Cu2ZnSnS4 Solar Cell, Adv. Energy Mater. 2 (2012) 253-259. doi:10.1002/aenm.201100526.

[101] M. Courel, J.A. Andrade-Arvizu, O. Vigil-Galán, Towards a CdS/Cu 2 ZnSnS 4 solar cell efficiency improvement: A theoretical approach, Appl. Phys. Lett. 105 (2014) 233501. doi:10.1063/1.4903826.

[102] S.M.U. Rafee Mahbub, Md. Saidul Islam, Farhana Anwar, Sakin Sarwar Satter, Simulation of CZTS thin film solar cell for different buffer layers for high efficiency performance, South Asian J. Eng. Technol. 2 (2016) 1-10.

[103] A. Cherouana, R. Labbani, Study of CZTS and CZTSSe solar cells for buffer layers selection, Appl. Surf. Sci. 424 (2017) 251-255. doi:10.1016/j.apsusc.2017.05.027.

[104] Q.N.U.I. and M.A.H. Mohammad Wahidur Rahman, Saad Mohammad Abdullah, Mohammed Akhyar Bakth, Numerical Analysis of Stacked Layered CZTS and CZTSe-Based Thin Film Solar Cell, Int. Conf. Electr. Comput. Commun. Eng. (2017) 115-118.

[105] A. Shama, M. Miraz, M. Faruk, M.A. Rahman, Numerical Analysis of Deep Level 
Defects in Cu2ZnSnS4 (CZTS ) Thin Film Solar Cells, IEEE. 4 (2015) 0-5.

[106] Y.H. Khattak, F. Baig, H. Toura, S. Ullah, B. Marí, S. Beg, H. Ullah, Effect of CZTSe BSF and minority carrier life time on the efficiency enhancement of CZTS kesterite solar cell, Curr. Appl. Phys. 18 (2018) 633-641. doi:10.1016/j.cap.2018.03.013.

[107] D.-H.K. Mir Kazem Omrani, Mehran Minbashi, Nafiseh Memarian, Improve the performance of CZTSSe solar cells by applying a SnS BSF layer, Solid. State. Electron. (2017) 1-8. doi:10.1016/j.sse.2017.12.004.

[108] T.R. Md. Sharafat Hossain, Nowshad Amin, Prospects of back contacts with back surface fields in high efficiency ZnxCd1-xS/CdTe solar cells from numerical modeling, Chalcogenide Lett. 8 (2011) 187-198.

[109] S.K. and S.H. Keshmiri, Design of a high efficiency ultrathin CdS/CdTe solar cell using back surface field and backside distributed Bragg reflector, Opt. Express. 22 (2014) 1-9. doi:10.1364/OE.22.00A921.

[110] R. Jayakrishnan, S. Gandhi, P. Suratkar, Correlation between solar cell efficiency and minority carrier lifetime for batch processed multicrystalline Si wafers, Mater. Sci. Semicond. Process. 14 (2011) 223-228. doi:10.1016/j.mssp.2011.02.020.

[111] M. Chadel, A. Chadel, M.M. Bouzaki, M. Aillerie, B. Benyoucef, J. Charles, Optimization by simulation of the nature of the buffer, the gap profile of the absorber and the thickness of the various layers in CZTSSe solar cells, (n.d.). doi:https://doi.org/10.1088/2053-1591/aa95df.

[112] J. Zhou, Z. Ye, Y. Wang, Q. Yi, J. Wen, Solar cell material Cu2FeSnS4 nanoparticles synthesized via a facile liquid re fl ux method, Mater. Lett. 140 (2015) 119-122. doi:10.1016/j.matlet.2014.11.004.

[113] F.Z. Boutebakh, M.L. Zeggar, N. Attaf, M.S. Aida, Electrical properties and back contact study of CZTS/ZnS heterojunction, Opt. - Int. J. Light Electron Opt. 144 (2017) 180-190. doi:10.1016/j.ijleo.2017.06.080.

[114] S. Ananthakumar, J. Ram Kumar, S. Moorthy Babu, Synthesis of Cu 2 ZnSnSe 4 hierarchical nanostructures by colloidal method, Opt. - Int. J. Light Electron Opt. 127 (2016) 10360-10365. doi:10.1016/j.ijleo.2016.08.058.

[115] M. Benchikhi, R. El Ouatib, L. Er-Rakho, S. Guillemet-Fritsch, J.J. Demai, B. Durand, Low-temperature molten salt synthesis and characterization of $\mathrm{Cu} 2 \mathrm{ZnSnS}$ 4 ultrafine powders, Opt. - Int. J. Light Electron Opt. 138 (2017) 568-572. doi:10.1016/j.ijleo.2017.02.076. 
[116] X. Zhou, W. Meng, C. Dong, C. Liu, Z. Qiu, J. Qi, J. Chen, M. Wang, Cu2ZnSnS4 quantum dots as effective electron acceptors for hybrid solar cells with a broad spectral response, RSC Adv. 5 (2015) 90217-90225. doi:10.1039/C5RA16898H.

[117] M.Y.V. X. Fontané, V. Izquierdo-Roca, E. Saucedo, S. Schorr, V.O. Yukhymchuk, J.R.M. A. Pérez-Rodríguez, Vibrational properties of stannite and kesterite type compounds : Raman scattering analysis of $\mathrm{Cu} 2(\mathrm{Fe}, \mathrm{Zn}) \mathrm{SnS} 4$, J. Alloy. Compd. J. 539 (2012) 190-194. doi:10.1016/j.jallcom.2012.06.042.

[118] C. Yan, C. Huang, J. Yang, F. Liu, J. Liu, Y. Lai, Synthesis and characterizations of quaternary Cu2FeSnS4 nanocrystals, Chem. Commun. (2012) 2603-2605. doi:10.1039/c2cc16972j.

[119] B.L. and A.G. Xiaoyan Zhang, Ningzhong Bao, Karthik Ramasamy, Yu-Hsiang A. Wang, Yifeng Wang, Crystal phase-controlled synthesis of Cu2FeSnS4 nanocrystals with a band gap of around 1.5 eV, Chem. Commun. 48 (2012) 49564958. doi:10.1039/c2cc31648j.

[120] S.U. Schorr, H.A.-J.O. Hoebler, M.I. Tovar, A neutron diffraction study of the stannite-kesterite solid solution series, Eur. J. Mineral. 19 (2007) 65-73. doi:10.1127/0935-1221/2007/0019-0065.

[121] C. Dong, G.Y. Ashebir, J. Qi, J. Chen, Z. Wan, W. Chen, M. Wang, Solutionprocessed $\mathrm{Cu} 2 \mathrm{FeSnS} 4$ thin films for photovoltaic application, Mater. Lett. 214 (2018) 287-289. doi:10.1016/j.matlet.2017.12.032.

[122] Y. Liu, M. Hao, J. Yang, L. Jiang, C. Yan, C. Huang, D. Tang, F. Liu, Y. Liu, Colloidal synthesis of $\mathrm{Cu} 2 \mathrm{FeSnSe} 4$ nanocrystals for solar energy conversion, Mater. Lett. 136 (2014) 306-309. doi:10.1016/j.matlet.2014.08.072.

[123] X. Meng, H. Deng, J. He, L. Sun, P. Yang, J. Chu, Synthesis, structure, optics and electrical properties of $\mathrm{Cu} 2 \mathrm{FeSnS} 4$ thin film by sputtering metallic precursor combined with rapid thermal annealing sulfurization process, Mater. Lett. 151 (2015) 61-63. doi:10.1016/j.matlet.2015.03.046.

[124] X. Meng, H. Deng, J. Tao, H. Cao, X. Li, L. Sun, P. Yang, J. Chu, Heating rate tuning in structure, morphology and electricity properties of $\mathrm{Cu} 2 \mathrm{FeSnS} 4$ thin films prepared by sulfurization of metallic precursors, J. Alloys Compd. 680 (2016) 446451. doi:10.1016/j.jallcom.2016.04.166.

[125] R.R. Prabhakar, N. Huu Loc, M.H. Kumar, P.P. Boix, S. Juan, R.A. John, S.K. Batabyal, L.H. Wong, Facile water-based spray pyrolysis of earth-abundant $\mathrm{Cu} 2 \mathrm{FeSnS} 4$ thin films as an efficient counter electrode in dye-sensitized solar cells, 
ACS Appl. Mater. Interfaces. 6 (2014) 17661-17667. doi:10.1021/am503888v.

[126] P. Nazari, A. Yazdani, Z. Shadrokh, B.A. Nejand, N. Farahani, R. Sei, Journal of Physics and Chemistry of Solids Band gap engineering of Cu3 FexS (1-x)S4 : A potential absorber material for solar energy, J. Phys. Chem. Solids. 111 (2017) 110114. doi:10.1016/j.jpcs.2017.07.005.

[127] D.B. Khadka, J. Kim, Structural Transition and Band Gap Tuning of $\mathrm{Cu} 2$ (Zn,Fe)SnS 4 Chalcogenide for Photovoltaic Application, J. Phys. Chem. C. 118 (2014) 14227-14237. doi:10.1021/jp503678h.

[128] H. Guan, H. Shen, B. Jiao, X. Wang, Structural and optical properties of $\mathrm{Cu} 2 \mathrm{FeSnS} 4$ thin film synthesized via a simple chemical method, Mater. Sci. Semicond. Process. 25 (2014) 159-162. doi:10.1016/j.mssp.2013.10.021.

[129] M. Adelifard, Preparation and characterization of $\mathrm{Cu} 2 \mathrm{FeSnS} 4$ quaternary semiconductor thin films via the spray pyrolysis technique for photovoltaic applications, J. Anal. Appl. Pyrolysis. $122 \quad$ (2016) 209-215. doi:10.1016/j.jaap.2016.09.022.

[130] X. Jiang, W. Xu, R. Tan, W. Song, J. Chen, Solvothermal synthesis of highly crystallized quaternary chalcogenide $\mathrm{Cu} 2 \mathrm{FeSnS} 4$ particles, Mater. Lett. 102-103 (2013) 39-42. doi:10.1016/j.matlet.2013.03.102.

[131] C. Dong, W. Meng, J. Qi, M. Wang, Cu2FeSnS4 nanocrystals as effective electron acceptors for hybrid solar cells, Mater. Lett. 189 (2017) 104-106. doi:10.1016/j.matlet.2016.11.090.

[132] H.W. Shuo Wang, Ruixin Ma, Chengyan Wangb, Shina Li, Fabrication and photoelectric properties of $\mathrm{Cu} 2 \mathrm{FeSnS} 4(\mathrm{CFTS})$ and $\mathrm{Cu} 2 \mathrm{FeSn}(\mathrm{S}, \mathrm{Se}) 4(\mathrm{CFTSSe})$ thin film, Appl. Surf. Sci. 422 (2017) 39-45. doi:10.1016/j.apsusc.2017.05.244.

[133] R.T. and G.U. Anima Ghosh, Dhirendra K. Chaudhary, Amrita Biswas, Solutionprocessed $\mathrm{Cu} 2 \mathrm{XSnS} 4(\mathrm{X}=\mathrm{Fe}, \mathrm{Co} \mathrm{Ni})$ photo-electrochemical and thin film solar cells on vertically grown ZnO nanorod arrays, RSC Adv. 6 (2016) 115204-115212. doi:10.1039/C6RA24149B.

[134] H. Hou, H. Guan, L. Li, Synthesis of Cu2FeSnS4 thin films with stannite and wurtzite structure directly on glass substrates via the solvothermal method, J. Mater. Sci. Mater. Electron. 28 (2017) 7745-7748. doi:10.1007/s10854-017-6469-6.

[135] Y.H. Khattak, F. Baig, S. Ullah, B. Marí, S. Beg, H. Ullah, Efficiency Enhancement of Cu2FeSnS4 Based Thin Film Solar Cell: A Numerical Analysis, J. Nanoelectron. Optoelectron. 13 (2018) 1096-1101. doi:10.1166/jno.2018.2337. 
[136] L.-Y. Lin, Y. Qiu, Y. Zhang, H. Zhang, Analysis of Effect of Zn(O,S) Buffer Layer Properties on CZTS Solar Cell Performance Using AMPS, Chinese Phys. Lett. 33 (2016) 107801. doi:10.1088/0256-307X/33/10/107801.

[137] C. Platzer-Björkman, T. Törndahl, D. Abou-Ras, J. Malmström, J. Kessler, L. Stolt, $\mathrm{Zn}(\mathrm{O}, \mathrm{S})$ buffer layers by atomic layer deposition in $\mathrm{Cu}(\mathrm{In}, \mathrm{Ga}) \mathrm{Se} 2$ based thin film solar cells: Band alignment and sulfur gradient, J. Appl. Phys. 100 (2006) 044506. doi:10.1063/1.2222067.

[138] C. Persson, C. Platzer-Björkman, J. Malmström, T. Törndahl, M. Edoff, Strong Valence-Band Offset Bowing of ZnO1-xSx Enhances p-Type Nitrogen Doping of ZnO-like Alloys, Phys. Rev. Lett. $97 \quad$ (2006) 146403. doi:10.1103/PhysRevLett.97.146403. 
This page intentionally left blank 


\section{LIST OF PUBLICATIONS}

[1] Y.H. Khattak, F. Baig, S. Ullah, B.M. Soucase, S. Beg, H. Ullah, Enhancement of the conversion efficiency of thin film kesterite solar cell, J. Renew. Sustain. Energy. 10 (2018) 033501. doi:10.1063/1.5023478.

[2] Y.H. Khattak, F. Baig, H. Toura, S. Ullah, B.M. Soucase, S. Beg, H. Ullah, Effect of CZTSe BSF and minority carrier life time on the efficiency enhancement of CZTS kesterite solar cell, Curr. Appl. Phys. 18 (2018) 633-641. doi:10.1016/j.cap.2018.03.013.

[3] Y.H. Khattak, F. Baig, S. Ullah, B.M. Soucase, S. Beg, H. Ullah, Numerical modeling baseline for high efficiency $\left(\mathrm{Cu}_{2} \mathrm{FeSnS}_{4}\right)$ CFTS based thin film kesterite solar cell, Optik (Stuttg). 164 (2018) 547-555. doi:10.1016/j.ijleo.2018.03.055.

[4] Y.H. Khattak, F. Baig, S. Ullah, B.M. Soucase, S. Beg, H. Ullah, Efficiency Enhancement of $\mathrm{Cu}_{2} \mathrm{FeSnS}_{4}$ Based Thin Film Solar Cell: A Numerical Analysis, J. Nanoelectron. Optoelectron. 13 (2018) 1096-1101. doi:10.1166/jno.2018.2337.

[5] Y.H. Khattak, F. Baig, B.M. Soucase, S. Beg, S.R. Gillani,T. Ahmed, Effect of CdTe Back Surface Field on the Efficiency Enhancement of a CGS Based Thin Film Solar Cell, J. Electron. Mater. 47 (2018) 5183-5190. doi:10.1007/s11664018-6405-4.

[6] F. Baig, Y.H. Khattak, S. Ullah, B.M. Soucase, S. Beg, H. Ullah, Numerical analysis a guide to improve the efficiency of experimentally designed solar cell, Appl. Phys. A. 124 (2018) 471. doi:10.1007/s00339-018-1877-X.

[7] F. Baig, Y.H. Khattak, B.M. Soucase, S. Beg, S.Ullah, Effect of anionic bath temperature on morphology and photo electrochemical properties of $\mathrm{Cu}_{2} \mathrm{O}$ deposited by SILAR, Mater. Sci. Semicond. Process. 88 (2018) 35-39. doi:10.1016/j.mssp.2018.07.031.

[8] Y.H. Khattak, F. Baig, B.M. Soucase, S. Beg, S.R. Gillani, S. Ahmed, Efficiency enhancement of novel CNTS/ZnS/Zn(O,S) thin film solar cell, Optik (Stuttg). 171 (2018) 453-462. doi:10.1016/j.ijleo.2018.06.001.

[9] Y.H. Khattak, F. Baig, S. Ullah, B.M. Soucase, S. Beg, K. Khan, Effect of Cu2O hole transport layer and improved minority carrier life time on the efficiency enhancement of $\mathrm{Cu}_{2} \mathrm{NiSnS}_{4}$ based experimental solar cell, J. Renew. Sustain. Energy. 10 (2018) 043502. doi:10.1063/1.5037471. 
[10] F. Baig, Y.H. Khattak, B.M. Soucase, S. Beg, S.R. Gillani, S. Ahmed, A Baseline for the Numerical Study of $\mathrm{Sb}_{2} \mathrm{Se}_{3}$ Absorber Material Based Solar Cell, J. Nanoelectron. Optoelectron. 14 (2019) 72-79. doi:10.1166/jno.2019.2451.

[11] F. Baig, Y.H. Khattak, B.M. Soucase, S. Beg, S.R. Gillani, A. Ahmed, Mitigation of interface recombination by careful selection of ETL for efficiency enhancement of MASnI3 solar cell, Optik (Stuttg). $170 \quad$ (2018) 463-474. doi:10.1016/j.ijleo.2018.05.135.

[12] Y.H. Khattak, F. Baig, B.M. Soucase, S. Beg, S.R. Gillani, S. Ahmed, Effect of $\mathrm{Cu}_{2} \mathrm{O}$ Back Surface Field on the Efficiency Enhancement of CZTSe Kesterite Photovoltaic Cell, Mater. Focus. 7 (2018) 604-609. doi:10.1166/mat.2018.1563.

[13] Y.H. Khattak, F. Baig, B.M. Soucase, S. Beg, S. Ahmed, Baseline for the Numerical Analysis of High Efficiency Copper Manganese Tin Sulfide $\mathrm{Cu}_{2} \mathrm{MnSnS}_{4}$ Based Thin Film Solar Cell, J. Nanoelectron. Optoelectron. 13 (2018) 1678-1684. doi:10.1166/jno.2018.2421.

[14] F. Baig, Y.H. Khattak, B.M. Soucase, S. Beg, A. Ahmed, K. Khan, Efficiency Enhancement of $\mathrm{CH}_{3} \mathrm{NH}_{3} \mathrm{SnI}_{3}$ Solar Cells by Device Modeling, J. Electron. Mater. 47 (2018) 5275-5282. doi:10.1007/s11664-018-6406-3.

[15] F. Baig, Y.H. Khattak, S. Ullah, B.M. Soucase, S. Beg, H. Ullah, Numerical Analysis of a Novel FTO/n-MAPbI $3 /$ p-MAPbI $3 / \mathrm{p}-\mathrm{MAPbBr}_{3}$ Organic-Inorganic Lead Halide Perovskite Solar Cell, J. Nanoelectron. Optoelectron. 13 (2018) 1320 1327. doi:10.1166/jno.2018.2363.

[16] H. Bayad, A. El Manouni, B.M. Soucase, Y.H. Khattak, S. Ullah, F. Baig, Influence of $\mathrm{P}^{+}-\mathrm{ZnTe}$ back surface contact on photovoltaic performance of $\mathrm{ZnTe}$ based solar cells, Opt. Quantum Electron. 50 (2018) 259. doi:10.1007/s11082-018$\underline{1530-0 .}$.

[17] F. Baig, Y.H. Khattak, S. Ullah, B.M. Soucase, S. Beg, K. Khan, Effect of $\mathrm{MAPbBr}_{3} \mathrm{HTL}$ and CBD Deposited $\mathrm{Cd}_{1-\mathrm{x}} \mathrm{Zn}_{\mathrm{x}} \mathrm{S}$ ETL Band Offset on Lead Halide Perovskite Solar Cell, Mater. Focus. 7 (2018) 610-616. doi:10.1166/mat.2018.1555.

[18] Y.H. Khattak, F. Baig, B.M. Soucase, S. Beg, Efficiency Enhancement of $\mathrm{Cu}_{2} \mathrm{BaSnS}_{4}$ Thin Film Solar Cell, Mater. Focus. 7 (2018) doi: $\underline{10.1166 / m a t .2018 .1575}$

[19] F. Baig, Y.H. Khattak, B.M. Soucase, A. Shehzad, S. Beg, S. Ullah, Successive Ionic Layer Absorption and Reaction Deposited SnS and CdZnS for Efficiency 
Enhancement of $\mathrm{MAPbI}_{3}$ Solar Cell by Numerical Analysis, Mater. Focus. 7 (2018) doi: 10.1166/mat.2018.1582

[20] F. Baig, Y.H. Khattak, B.M. Soucase, S. Beg, N.A.K.Khani, Efficiency Limits of SnS Thin Film Solar Cells, Mater. Focus. 7 (2018) doi: 10.1166/mat.2018.1589.

[21] Y.H. Khattak, F. Baig, B.M. Soucase, H. Ullah, T. Ahmed, Numerical Modeling of $\mathrm{Cd}_{1-\mathrm{x}} \mathrm{Zn}_{\mathrm{x}} \mathrm{S} / \mathrm{Cd}_{1-\mathrm{x}} \mathrm{Zn}_{\mathrm{x}} \mathrm{Te}$ Photovoltaic Solar Cells, in: 2017 Int. Renew. Sustain. Energy Conf., IEEE, 2017: pp. 1-4. doi:10.1109/IRSEC.2017.8477588.

[22] F. Baig, Y.H. Khattak, B.M. Soucase, S. Ullah, H. Ullah, S. Ahmed, Efficiency enhancement of SnS solar cell using back surface field, in: 2018 1st Int. Conf. Power, Energy Smart Grid, IEEE, 2018: pp. 1-5. doi:10.1109/ICPESG.2018.8384496.

[23] F. Baig, H. Ullah, Y.H. Khattak, B. Mari Soucase, Numerical analysis of SnS Photovoltaic cells, in: 2016 Int. Renew. Sustain. Energy Conf., IEEE, 2016: pp. 596-600. doi:10.1109/IRSEC.2016.7983899.

[24] A. Rehman, F. Baig, Y.H. Khattak, B.M. Soucase, A. Mahmood, Centralized Intelligent Home Energy Management System, in: 2017 Int. Renew. Sustain. Energy Conf., IEEE, 2017: pp. 1-4. doi:10.1109/IRSEC.2017.8477352. 
This page intentionally left blank 



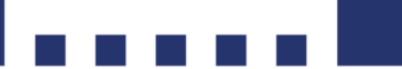

Escuela Técnica Superior de Inneniería del Diseño School of Design Engineering
INSTITUTO
DE DISENEO Y
FABRICACIÓN

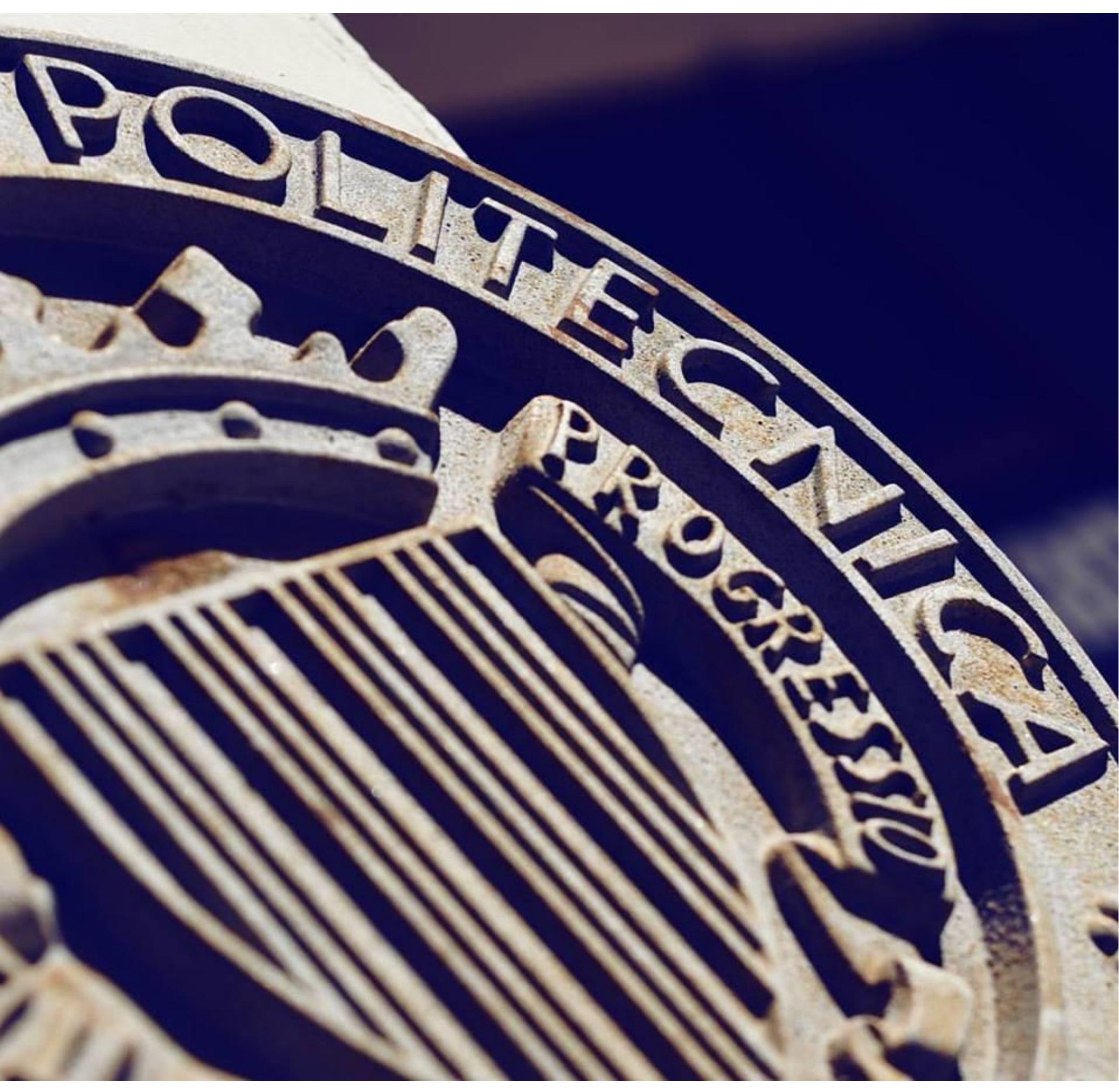

VLC

CAMPUS

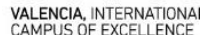

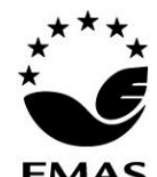

EMAS 